\title{
Health and life skills curriculum for the Adolescent Girls Empowerment Program (AGEP)
}

Population Council

Follow this and additional works at: https://knowledgecommons.popcouncil.org/departments_sbsr-pgy

Part of the Family, Life Course, and Society Commons, and the Gender Equity in Education Commons How does access to this work benefit you? Let us know!

\section{Recommended Citation}

Population Council. 2013. "Health and life skills curriculum for the Adolescent Girls Empowerment Program (AGEP)." Lusaka: Population Council. 

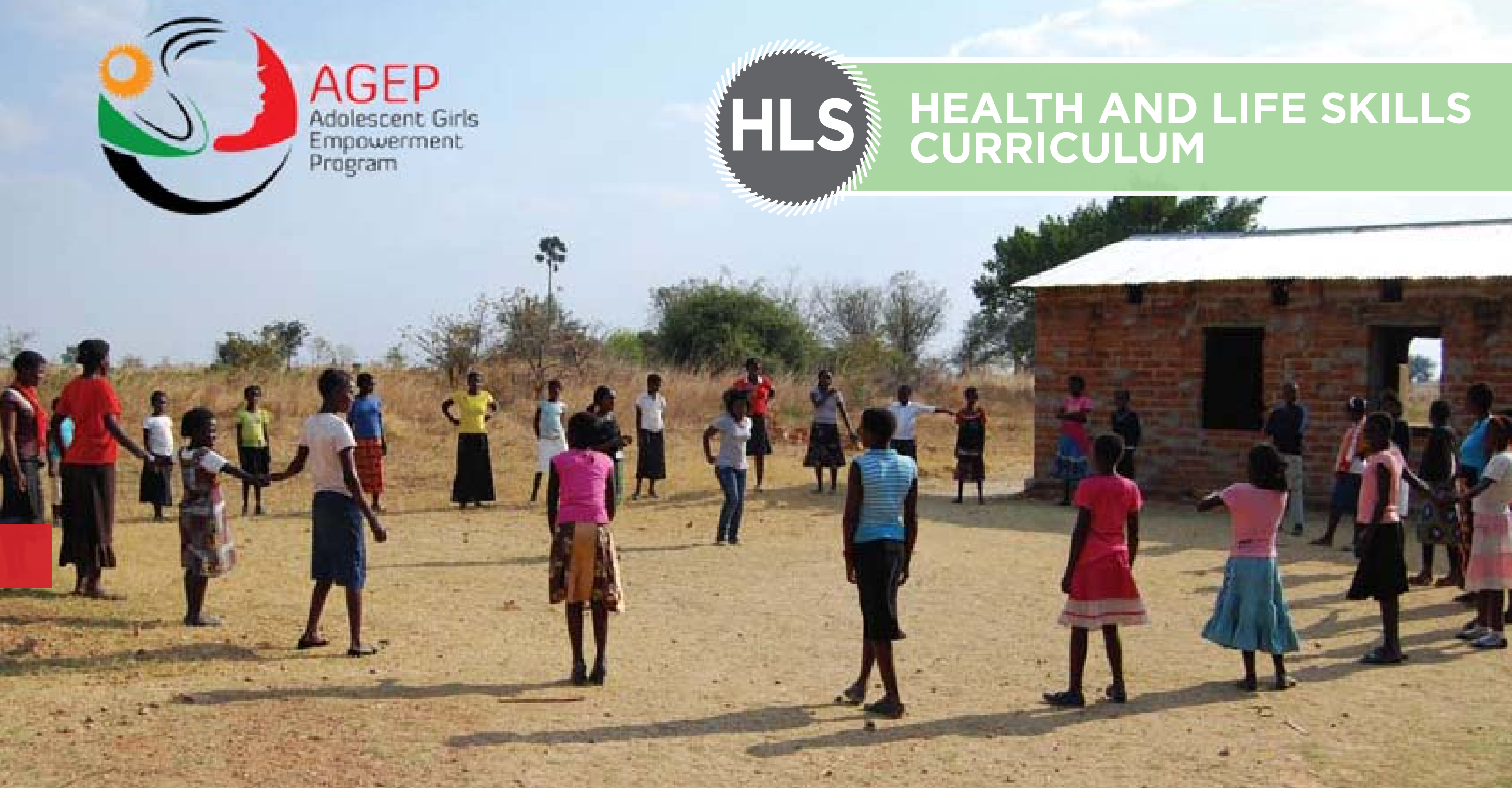


\section{(P) Population Council}

The Population Council confronts critical health and development issues-from stopping the spread of HIV to improving reproductive health and ensuring that young people lead full and productive lives. Through biomedical, social science, and public health research in 50 countries, we work with our partners to deliver solutions that lead to more effective policies, programs, and technologies that improve lives around the world. Established in 1952 and headquartered in New York, the Council is a nongovernmental, nonprofit organization governed by an international board of trustees.

Population Council

One Dag Hammarskjold Plaza

New York, NY 10017

Tel: 212-339-0500

Fax: 212-775-6092

www.popcouncil.org

Email: publications@popcouncil.org

Email: agep@popcouncil.org

Population Council - Zambia

Plot 3670 No. 4 Mwaleshi Road

Olympia Park, Lusaka

P/Bag RW 319X, Lusaka 10101, Zambia

Lusaka, Zambia 10101

Tel: +260 211295925

(c) 2013 The Population Council, Inc.

Written permission from the Population Council is required for any reproduction or distribution of more than fifty (50) copies per year, any electronic reproduction or any major change in content.

For inquiries regarding rights and permission, please contact publications@popcouncil.org.

Sections of this book may be reproduced, translated or adapted with minor changes to meet local needs, provided they are distributed free or at cost and not for profit and provided that any changes maintain the integrity of the book. Please inform the Population Council of plans to translate these materials into another language and provide one (1) copy of the publication.

This curriculum has been adapted from several sources, which are listed in the references section.

Please include the following statements on all section reproductions:

Reprinted from Population Council: Life Skills and Health Curriculum for the Adolescent Girls Empowerment

Program (AGEP). 
Introduction $\ldots \ldots \ldots \ldots \ldots \ldots \ldots \ldots \ldots \ldots \ldots \ldots$ Overview of AGEP. . . . . . . . . . . . . . . . . Beneficiaries . . . . . . . . . . . . . . . . . Curriculum Structure $\ldots \ldots \ldots \ldots \ldots \ldots \ldots \ldots 2$ Before the Program Begins . . . . . . . . . . . . 4 General Facilitation Tips. . . . . . . . . . . . . 4 Talking about Sensitive Issues. . . . . . . . . . . 5 Working with Parents . . . . . . . . . . . . . 6 Participatory Teaching Methods............. 7 Session Structure. . . . . . . . . . . . . . . 8

\section{Introductory Sessions}

Session 1: What to Expect - Part 1 . . . . . . . . 11 Session 2: What to Expect - Part 2 . . . . . . . . 17 Session 3: Teamwork. ....................21 Session 4: His and Hers (Gender Roles) . ........ 26 Session 5: Communication. ............... 32 Session 6: Self-Esteem . . . . . . . . . . . . . . 38 Session 7: Goal Identification - The Road of Life . . . 42 Session 8: Goal Setting and Achieving .........446 Session 9: My Relationships. . . . . . . . . . . . . . 51

\section{Reproductive Health}

Session 1: Life Cycle..................... 56

Session 2: My Body Is Changing - Am I Normal?. . . .60 Session 3: How Does Pregnancy Happen, Anyway? . . 66 Session 4: Preventing Unintended Pregnancy (Contraceptives)................ 75 Session 5: Reproductive Myths............. 83 Session 6: Sexual Desire................... 89

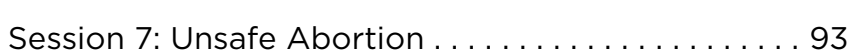
Session 8: Abortion and Stigma.............. 100 Session 9: Maternal Mortality ............... 106

\section{Life Skills}

112

Session 1: I Have Healthy Relationships. . . . . . . . . . 113

Session 2: Reasons to Delay Sex ............ 120

Session 3: Strategies for Delaying Sex . . . . . . . . 124

Session 4: Passive, Assertive, Aggressive. . . . . . . 130

Session 5: Drugs, Alcohol and Other MindAltering Substances. . . . . . . . . . . 136

Session 6: Peer Pressure ... . . . . . . . . . . . . . . 141

Session 7: Making Good Decisions. . . . . . . . . . . 146

Session 8: How to Communicate with Adults . . . . . 152

Session 9: How to Communicate with a Partner. . 156

Session 10: Managing Stress, Anger, and Conflict . . . . . . . . . . . . . 161

Session 11: Conflict Resolution and Problem Solving Skills ................. 168

\section{HIV, AIDS, and STIs}

174

Session 1: HIV and AIDS . . . . . . . . . . . . . . . . . 175

Session 2: Myth or Fact? ................ 185

Session 3: HIV Testing and Counseling .......... 193

Session 4: Risky Behavior .................. 198

Session 5: The Relationship of STIs and HIV and AIDS ...................203

Session 6: Stigma and Discrimination in HIV-Positive People............. 210

\section{Gender and Gender-Based Violence}

215

Session 1: Sexual Exploitation.............. 216

Session 2: How to Report and Avoid Cases of Sexual Violence . . . . . . . . . . . . 223

Session 3: Rape and Gender Violence. . . . . . . . . . 228

Session 4: Preventing Unwanted Advances.... . . . 235

\section{Leadership}

239

Session 1: Leadership ....................240

Session 2: Community Service-Putting Leadership into Action . . . . . . . . . . 244

\section{Human Rights}

Session 1: Human Rights and Children's Rights . . . 250

Session 2: Sexual and Reproductive Health Rights .................... . 256

Session 3: HIV and AIDS and Human Rights ..... . 263

\section{Appendixes}

\section{Glossary of Terms}

269

Appendix A: Additional Topical Information 274

The Menstrual Cycle . . . . . . . . . . . . . . . . . . . . . . 274

Reproduction and Pregnancy ............... 276

Emergency Contraception. . . . . . . . . . . . . . . 278

Zambia's Abortion Act and Regulations. . . . . . . . 279

Childbirth and Breastfeeding .............. 281

Tips for Teaching about HIV and AIDS . . . . . . . 282

Background Information on HIV and AIDS. . . . . . 283

Frequently Asked Questions About HIV and AIDS . . 284

HIV and AIDS and Human Rights. . . . . . . . . . . . 286

\section{Appendix B: Participatory Facilitation}

\section{Resources}

Trust-Building Activities. . . . . . . . . . . . . . 288

Group Formation Activities. . . . . . . . . . . . . . . 295

Icebreaker Activities (from The International HIV/AIDs Alliance) 


\section{ACKNOWLEDGMENTS}

This manual was adapted by Averie Baird, Bwalya Mushiki, Cassandra Burke, Deogratias Chileshe, Diana Bulanda, Karen Austrian, Natalie Jackson Hachonda, and Pamela Nyirenda.

Technical input was provided by Abigail Tuchili, Alice L. Bwalya, Andrew Saka, Andrew Tandeo, Benjamin Mwape, Chanda Katongo, Chikonde Ngwira, Chinyama Augustine, Diana B. Shalala, Diana Macauley, Eugenia Temba, Febby Imbula, Francis Kapapa, Gershom B.M. Banda, Hamaundu Hachonda, Izek Jere, Josephine T. Mukandawire, Kamanda Mwelwa, Mara Hildebrand, Martin Chidwayi, Michelle Hunsberger, Misheck Mwanza, Mwenda Mweetwa, Mwenya C. Mabuku, Nambula Kachumi, Nelson Banda, Precious Njamba,

Richard Mwape, Shadrick Kaputa, Sue Gibbons, Yvonne Haching'anju, and Zigeville Ndlovu.
We would like to acknowledge several organizations whose materials have been adapted or used in this curriculum including: Elizabeth Glaser Pediatric AIDS Foundation, Exhale, The Guttmacher Institute, International HIV and AIDS Alliance, International Alliance for Youth Sports, International Labor Organization (ILO), International Sexuality and HIV Curriculum Working Group, Ipas, Johns Hopkins Bloomberg School of Public Health/Center for Communication Programs, Joint United Nations Program on HIV/AIDS (UNAIDS), Margaret Sanger Centre International, Mexican Institute for Research of Family and Population (IMIFAP), Mobilizing Access to Maternal Health Services in Zamba (MAMaZ), Motivational Centre for Africa's Transformation (MoCAT), National Institutes of Health (NIH), One Love Southern Africa Campaign, Peace Corps, Project Concern International, Population Council, Program for Appropriate Technology in Health (PATH), Queensland Health Australia, Sustainability Through Economic Strengthening Prevention an Support for Orphans and Vulnerable Children, Youth and Other Vulnerable Populations (STEPS OVC/Consortium) Zambia, United Nations Children's Fund (UNICEF), United Nations High Commissioner for Refugees (UNHCR), United Nations Population Fund (UNFPA), United States Agency for International Development (USAID), World Health Organization (WHO), and World Young Women's Christian Association (YWCA). A citation for the materials used from these organizations can be found in the footnotes at the beginning of each session and a complete reference is located in the "References" section at the end of this document. 
Zambian girls are faced with social isolation, economic vulnerability, and lack of appropriate health information and services-factors that prevent a healthy transition from girlhood into womanhood. They are faced with high rates of gender-based violence and unsafe sex-increasing their risk for unwanted pregnancy, HIV infection, and school dropout. This leads to a lack of economic resources and income-generating options, and a general lack of agency in shaping their lives. The root cause of these vulnerabilities is largely determined by girls' weak social, health, and economic assets.

The Adolescent Girls Empowerment Program (AGEP) aims to build these assets as an interconnected approach towards mitigating girls' vulnerabilities. The Population Council and partners have piloted and implemented a social, health, and economic asset-building program for vulnerable adolescent girls in Zambia. Girls joined groups of 25-30 girls, which meet once a week under the guidance of a female mentor. In weekly group meetings, girls are provided with training on health and life skills (HLS) and financial education (FE) and given the opportunity to interact to build strong relationships with other girls in their community.

\section{OVERVIEW OF AGEP}

The overall goal of AGEP is to facilitate the building of social, health, and economic assets in a safe and fun learning environment. Participants are equipped with life skills and knowledge to help maintain happy and healthy lifestyles, and be empowered with the confidence to assert their rights and protect themselves from harm and threats.

The 'safe spaces' component is at the core of AGEP. The girls groups, to which each girl belongs, are meant to provide a safe and supportive learning environment. Regular and reliable girls' group meetings, under the guidance of a female mentor from the same community, are critical in building social assets for vulnerable girls-including friendships, self-esteem, trusting relationships with adults, social support, etc.
The objectives of including this curriculum in AGEP are to:

- Increase adolescent girls' knowledge of reproductive health and sexuality;

- Reinforce and promote attitudes and behaviors that will lead to a better quality of life for adolescent girls; and

- Instill skills among adolescents to enable them to overcome the challenges of growing up and becoming responsible adults. These skills include communication skills, decision-making, assertiveness, setting goals, and resisting peer pressure.

\section{BENEFICIARIES}

AGEP participants are girls who are 10-19-years-old from vulnerable backgrounds. While some girls may be in school, the program is not meant to target in-school girls, nor are the groups meant to meet in school or be seen as school clubs. Special recruitment is done to ensure that out-of-school girls, young mothers, married girls, domestic workers, disabled girls, HIV-positive girls, and other profiles of vulnerable girls are included.

\section{Group structure}

Each group meets once a week in a time and location that is deemed appropriate by the girls, the community, and the mentor. Groups meet in various locations throughout the community and the meetings last between 1-2 hours.

\section{Meeting functions}

The meetings serve two functions. The first is for the mentor to facilitate a short training session. The training content over the course of the year varies from sexual and reproductive health and life skills to financial education (see separate Financial Education FE curriculum), and other content that is identified as relevant and appropriate. These sessions should be engaging, interactive, and make use of best practice youth learning principles - that is games, small group work, etc. 
The second function is for the meetings to provide a space and opportunity for girls to regularly interact with each other. During meeting times, they can share updates about their weeks, address any concerns they may have, laugh, sing, dance, express themselves, and in general, have fun. As cultivating this sort of environment is a primary aim of weekly girls group meetings, it is important that these groups not be run like a classroom. Mentors will have to ensure that during each meeting, girls have ample time for conversation and interaction, and should encourage an informal learning environment at all times.

\section{Age appropriateness}

This program was designed for girls from 10 to 19 years of age. However, some of the material contained in the curriculum may not be suitable for participants at the younger end of this age spectrum. Though participants will attend sessions with other participants closer to their age (groups of 10-14 year-olds and 15-19 year-olds formed in the first session), topics or activities that are more appropriate for younger adolescents (ages 10-14) or older adolescents (ages 15-19) are specified throughout the curriculum. They are marked with the following signs:

\section{0-14-year-olds only}

\section{5-19-year-olds only}

The final decision on how to present the material is at the discretion of the mentor

For more information about the Adolescent Girls Empowerment Program, please visit: http://www.popcouncil.org/projects/353 ZambiaAGEP.asp.

For any inquiries, please contact: agep@popcouncil.org.

\section{CURRICULUM STRUCTURE}

The curriculum for the weekly safe space meetings will cover a variety of topics including sexual reproductive health, life skills, HIV and AIDS, STIs, gender and gender-based violence, leadership, human rights, and financial education.

In addition to life skills and health topics, mentors will facilitate trainings for girls on financial education, which is found in a separate curriculum (see separate Financial Education curriculum ( FE ). The FE sessions will be integrated in between the life skills and health sessions. The suggested order for combining the two curricula is presented here:

\section{Introductory Sessions}

Session 1: What to Expect - Part 1

Session 2: What to Expect - Part 2

Session 3: Teamwork

Session 4: His and Hers (Gender Roles)

Session 5: Communication

Session 6: Self-Esteem

\section{FE Introduction to Financial Education}

Session 1: Dream Big!

Session 2: Why Save?

Session 3: Choose a Savings Goal

Session 4: Make a Savings Plan

Session 5: Learning about Banks and Bank Accounts

\section{Introductory Sessions}

Session 7: Goal Identification - The Road of Life

Session 8: Goal Setting and Achieving

Session 9: My Relationships 


\section{ROUND 1}

\section{Reproductive Health}

Session 1: Life Cycle

Session 2: My Body Is Changing - Am I Normal?

Session 3: How Does Pregnancy Happen, Anyway?

Session 4: Preventing Unintended Pregnancy (Contraceptives)

Session 5: Reproductive Myths

\section{Financial Education}

Session 6: Exploring Options for Earning Money

Session 7: Girls Money and the Risky Income Cycle

\section{Life Skills}

Session 1: I Have Healthy Relationships

Session 2: Reasons to Delay Sex

Session 3: Strategies to Delay Sex

Session 4: Passive, Assertive, Aggressive

\section{HIV and AIDS and STIs}

Session 1: HIV and AIDS

Session 2: Myth or Fact?

Session 3: HIV Testing and Counseling

\section{FE Financial Education}

Session 8: Know the Difference Between Needs and Wants Session 9: Control Spending

Session 10: Think About the Future: Money In and Money Out

Session 11: Save Regularly!

Session 12: Save in a Safe Place

Session 13: Dealing with Setbacks in Saving

\section{Gender and Gender-Based Violence}

Session 1: Sexual Exploitation

Session 2: How to Report and Avoid Cases of Sexual Violence

\section{Leadership}

Session 1: Leadership

Session 2: Community Service: Putting Leadership in Action

\section{ROUND 2}

\section{Reproductive Health}

Session 6: Sexual Desire

Session 7: Unsafe Abortion

Session 8: Abortion and Stigma

Session 9: Maternal Mortality

\section{Life Skills}

Session 5: Drugs, Alcohol and Other Mind Altering Substances Session 6: Peer Pressure

Session 7: Making Good Decisions

Session 8: How to Communicate with Adults

\section{Financial Education}

Session 14: Your Own Money Vs. Someone Else's Money Session 15: Talking About Money

Session 16: The DOs and DON'Ts of Talking About Money Session 17: Resolving Conflicts About Money

Session 18: Role-play Resolving Conflicts

Session 19: Our Journey to Good Money Management

\section{Human Rights}

Session 1: Human Rights and Children's Rights Session 2: Sexual and Reproductive Health Rights Session 3: HIV and AIDS and Human Rights

\section{HIV and AIDS and STIs}

Session 4: Risky Behavior

Session 5: The Relationship of STIs and HIV and AIDS

Session 6: Stigma and Discrimination in HIV-Positive People

\section{Gender and Gender-Based Violence}

Session 3: Rape and Gender Violence

Session 4: Preventing Unwanted Advances

\section{Life Skills}

Session 9: How to Communicate with a Partner

Session 10: Managing Stress, Anger, and Conflict

Session 11: Conflict Resolution and Problem Solving Skills 


\section{BEFORE THE PROGRAM BEGINS}

Mentors should look through the curriculum and thoroughly read as much of the background information as possible (i.e., facilitator notes at the beginning of each session and extra information provided in Appendix A: Additional Topical Information). This will help mentors gain a strong general sense of the topics that will be covered throughout the program, and an idea of where to find answers to any questions that participants may ask. This information for each session should be re-read just before conducting the corresponding session. Mentors should prepare any necessary materials before each session and ahead of time, thinking about their own values regarding young people and about the topics to be discussed.

\section{Collect and have on hand referral information for:}

1. Sexual/reproductive health services (including contraceptives)

2. HIV testing and counseling

3. How/where to report sexual or domestic violence

4. Psychosocial counseling referral for any vulnerable girls who have been abused or raped

5. Legal services

\section{Invite guest speakers}

Some topics and sessions may benefit from a guest speaker, especially those that the mentor does not feel confident about, or those that require technical or professional guidance. These topics may include unsafe abortion, sexual exploitation, rape, STIs, and HIV. Mentors are encouraged to invite a guest speaker or facilitator for these sessions.

To ensure the session is successful, mentor should invite the guest ahead of time provide the guest with a session guide that he or she is expected to facilitate, and make certain that all materials for the session are ready beforehand. The guest speaker should also be made aware of the principles and attitudes mentioned throughout the curriculum, so that contradictions are not created. Guest speakers should be notified up front that their participation is voluntary and they will not be paid.

\section{What if participants want to be paid for their time?}

The recruiters for the program should make it clear that participants will not receive money when participating. During the first session the mentor should remind participants that their involvement in this program is voluntary and they will not be paid. However, participants will gain many non-monetary benefits from the program by building skills, confidence, and knowledge.

\section{Know your audience}

Depending on the group, it may be necessary to change the approach to leading the sessions. For example, out-of-school girls may have lower literacy skills than in-school girls. For lower literacy groups, facilitators may want to draw more pictures and use more symbols when writing on the flipchart or chalkboard. Facilitators should also use simple language and be sure that the instructions are clear before starting any activity. Do not ask more than a few questions at the end of each activity.

It is important that mentors work with adolescent girls where and as they are, not where or as the mentor thinks they should be. Mentors should also check sessions for cultural acceptability. Be familiar with local cultural norms and adjust sessions accordingly.

\section{Be prepared}

Every training experience has the potential to bring challenges. The most effective way to minimize challenges is to be prepared. Mentors should know the material they will present, and they should practice facilitating the activities on their own or with a friend.

\section{GENERAL FACILITATION TIPS}

Below are some tips and methods to help build your capacity as a facilitator.

\section{A good facilitator:}

1. sees the participants as experts with information and skills to share, rather than seeing themselves as the only experts in the room.

2. encourages participants to learn from each other, and guides this process rather than providing direct instructions and lecture-style learning.

3. believes we learn by doing, experiencing, practicing, and feeling, rather than by memorizing, repeating, and recording information.

4. is organized, but flexible in changing methods based on participant needs.

5. is enthusiastic about the topic and participants.

6. keeps promises to the group (to let participants speak, take a break, etc.)

7. is patient and a good listener.

8. is prepared to handle strong emotions that may arise during discussions. 


\section{Before each session:}

1. Carefully read through all of the session's background notes and activities. Think about how you will perform each step and what you will add to every session.

2. Try to anticipate questions that may be asked, and know where to look for answers in the materials provided. If participants ask questions that you cannot answer right away, write them down and follow up on them before the next session, so that you can discuss them then.

3. Adapt the activities and group discussions to make them more appropriate to the age and education level of your participants.

4. Think about and plan for any issues that may arise during more "difficult" sessions with complex material or sensitive topics.

5. Think of local examples and ways to make the activities more relevant to the participants' daily lives and concerns.

6. When possible, work from easy to difficult subjects.

7. Have materials prepared beforehand.

\section{Additional facilitation tips:}

1. Have a "parking lot" for issues that arise during a session, but that are not relevant to the session objectives. You can come back to them at another time or simply explain at the end of the training that it was important, but outside of the topic of the training.

2. Capture important points on flipchart paper during discussions for use during the summary activities. It can be very challenging to both lead the discussion and write down all important points, so consider having someone assist you in writing down key points.

3. Whenever appropriate, identify next steps or possible solutions to problems.

4. Relate the information to what has been learned in previous sessions whenever possible.

5. Check to make sure you are not speaking more than the participants. If you find that you are doing most of the talking, encourage participants to answer each other's questions. For instance, if someone asks a question, open discussion to the participants with the inquiry: "Does anyone have an answer to that question?"
6. The way you hold your body will help effectively facilitate the group. For example, looking attentively and nodding makes them feel their contribution is important. Looking away can effectively tell the person not to talk or participate. Always face the person to whom you are speaking.

7. Have fun!

\section{TALKING ABOUT SENSITIVE ISSUES}

Many of the issues raised in this manual are linked to sex, relationships, and HIV, which are often seen as sensitive topics to both participants and facilitators. Some facilitators may feel that talking about sex and contraception with young people encourages young people to have sex. On the contrary, research shows that talking with adolescents about facts and consequences related to sex encourages them to delay sex and consider abstinence. However, facilitators should not assume the participants are not having sex.

Young people will often giggle with embarrassment when discussing topics related to sex or reproduction. Mentors should not let this discourage them or make them uncomfortable. Girls need accurate information on these subjects to make healthy choices and feel more comfortable with the changes they are experiencing. Let the embarrassment pass, wait for girls to settle down, and then focus on the information and skills they need.

\section{Tips for mentors to let participants know you are comfortable talking about} these issues:

1. Think about your own values and clarify how you feel about an issue before you discuss it with participants.

2. Be prepared and plan ahead. Find out as much as you can beforehand, so that you feel confident facilitating the session.

3. You do not have to know everything. Be honest with participants when you are not sure how to answer their questions. Turn the question into an investigative project and ask participants to help you find the answer. Tell them that you will also ask a health care provider or another expert and try to have answers for them at the next session.

4. Accept participants' slang terms. Don't be afraid to ask what they mean if you don't know.

5. Do not dismiss or look down on what participants know. Participants have been exposed to a variety of information and experiences. Their experiences have value and are important. 
6. Set your own limits. Participants will be excited because you are prepared to talk about topics that interest them. Few adults guide them or give them this knowledge, so they may ask questions that make you feel embarrassed. Be as open and honest as you can, but tell them when it is enough or when their behavior is disrespectful. Explain when you feel uncomfortable answering a particular question.

7. Do not answer personal questions about your own sexual experience. If these questions come up, let participants know that your role as a facilitator is not to discuss your own experience.

8. Stick to the facts. You might have personal opinions about the topic, or how you personally would act in a certain situation, but it is important to remain neutral and open so that the participants will feel free to ask any question and share their thoughts, fears, and opinions.

9. Get advice and help if you need it. Teaching life skills and reproductive health is not easy. If you had a difficult session, find someone you trust to talk with afterwards. However, respect the participants' privacy and do not share personal information that participants shared with you during the session, unless you feel they may be in danger. Information from participants may be shared in meetings between mentors, as long as the identity of the participant involved is not disclosed.

\section{Handling emotion}

Participants may get emotional during group meetings. Mentors should react sensitively and effectively when a participant becomes visibly upset during a session. Mentors should strive to ensure that participants feel safe and are not embarrassed so that the group can move past any awkwardness or discomfort. Ways for a mentor to deal with an emotional situation include: moving the discussion away from an upsetting topic, relating an anecdote, moving on to a new topic, or taking a break.

Participants may also get upset by some of the topics in the group meetings They may have doubts about themselves or may feel uncomfortable talking about issues related to sex with other adolescents. The discussion activities may remind them of their own uncomfortable situations they've been in before the meeting, at home or at school.

If a participant is upset by an activity, the mentor should try to talk to the participant privately in order to find out how and why the participant is uncomfortable. The mentor may suggest that the participant step out of the meeting space and should not force the upset adolescent to talk about what is upsetting her, but should be available to listen if the girl would like to talk. Listen to what the participant says. A mentor's role is to provide her with understanding, support, and assistance. The mentor should not tell the participant how she feels or how they think she should feel; instead, assure her that it is normal to feel upset.

Please note: As a mentor, you should be prepared to provide a participant who has been abused with contact information for psychosocial counseling. You should have this information on hand before the first session.

\section{WORKING WITH PARENTS}

Parents are co-educators in teaching life skills and reproduction to their children If teachers, community members, religious leaders, and parents can work together, then young people are more likely to emerge as well-rounded, healthy individuals. Unfortunately, it is not always easy to collaborate with parents.

Parents often have concerns when reproduction is taught and they may not feel comfortable or equipped to deal with these issues themselves.

\section{Tips for working with parents}

1. Keep parents informed about what you are doing and why.

2. Get the opinions of parents.

3. Talk with parents about their concerns and fears around reproductive health and HIV and AIDS. Do this through AGEP parents' meeting, home visits, and community days, etc.

4. Invite parents to meetings to discuss their concerns.

5. Know your community. Find out about its needs and concerns, as well as the skills and expertise of the parents. For example, a parent may be a nurse at a local clinic who could talk to the participants and give you advice and support.

6. Offer talks on parenting skills. Bring in experts to present their ideas, help improve parent-child communication, and share resources and materials.

7. Involve parents. Ask parents to check homework and assign activities that require participants to talk to their parents. For example, ask participants to interview their parents or family members about when they were young. 


\section{PARTICIPATORY TEACHING METHODS}

This curriculum uses participatory teaching methods, such as group discussion, brainstorming, role-play, small group work, educational games, and storytelling Participants or facilitators may object to some of the games and activities, initially seeing them as childish. Sometimes facilitators who are unfamiliar with participatory techniques would prefer to give a lecture, and may find facilitating a game or other interactive exercise a bit challenging. However, games and activities provide participants with opportunities to interact freely, and often generate discussion that cannot be yielded by other methods. They also provide participants with opportunities to practice using new skills (e.g., communication and decision-making). Remember, AGEP group meetings are meant to be a fun and relaxed environment, NOT one that resembles a classroom!

The advantages of active participatory methods include:

- Improved critical thinking skills

- Increased likelihood of participants remembering and sharing new information - Increased motivation

- Improved interpersonal skills

\section{Examples of participatory methods}

\section{Brainstorming}

A brainstorm is an exploration of ideas and is a great way to open a topic for discussion. During brainstorming, no one should judge or place value on an answer someone gives. Each answer is simply recorded on newsprint or a chalkboard. This activity encourages participants to expand their thinking about an idea and consider a topic from different angles and perspectives.

\section{Group discussion}

Group discussion brings out responses from participants on a particular topic, and provides opportunities for the facilitator to increase participant knowledge or correct misinformation. The effectiveness of the group discussion often depends on a facilitator's ability to use open-ended questions, which are questions asked by the facilitator that need more than a simple "yes" or "no" answer. These questions help to bring out feelings or thoughts about a topic or an activity.

1. "What did you learn from this activity?" is an open-ended question. "Tell me how this activity affected you?" is another example of an open-ended question. Open-ended questions often start with What, When, Why, or How.

2. "Did you learn anything?" is not an open-ended question, because the participant can simply say yes or no.
Role-play

Role-play provides the participants with an opportunity to experience a real-life situation, without having to take real-life risks. It is important that facilitators encourage participants to role-play realistic situations, and not ideal situations.

The rules of role-play are:

1. Discuss the situation within your own small role-play group.

2. Agree on a storyline.

3. Agree on who does what, involving everyone.

4. Rehearse.

5. Act out for the larger group.

\section{lcebreakers}

Icebreakers or energizers are quick, simple activities that help participants relax, become more comfortable, and (re)connect with each other while simultaneously energizing them focus and participate. Open each session with a quick icebreaker from the guide located in Appendix B: Participatory Facilitation Resources. Try to choose a new one each time, and try to limit time spent on these to about five minutes. In addition to opening each session with an icebreaker, they can be used in the middle of a session to "wake participants up" if energy levels in the group seem low, then known as "energizers". Participants themselves often have great ideas for energizers and icebreakers. If you wish, give participants a few options to choose from, or ask them for suggestions for a quick game or song to open a session.

\section{Group work}

This curriculum is full of activities that require organizing participants into pairs or small groups, which encourages teamwork and participatory and interactive learning. The instructions frequently direct facilitators to do this, but usually leave the method for dividing participants up to the facilitator. Appendix B: Participatory Facilitation Resources provides some common techniques for forming pairs and small groups.

Seating arrangements

To encourage participants to feel a sense of membership to a group and to participate fully, it is strongly recommended that they sit in a circle rather than in rows. This seating arrangement allows for eye contact between participants and the facilitator, creates a more relaxed atmosphere, and encourages participation. 


\section{SESSION STRUCTURE}

The AGEP Life Skills and Health Curriculum has 44 sessions. Each session is outlined as follows:
1. Session title
2. Session description
3. Learning objectives
4. Time
5. Materials
6. Pre-session preparation
7. Facilitator notes
8. Terms
9. Icebreaker
10. Review
11. Activities
12. Wrap-up
13. Practice activity

Session Title

The session title names the main topic covered in the session.

\section{Session Description}

The session description summarizes the activities undertaken in each session

\section{Learning objectives}

Learning objectives provide an overview of the learning aims and purpose of each session.

\section{Time}

A breakdown of the estimated time to be spent on each activity is provided at the beginning of each session and underneath each activity title. These general time frames have been assigned to aid in determining the division of time between each activity in a session so that all of the material can be covered. However, participants may want to explore some issues in more depth, or at other times they may work through the material more quickly. Allow participants flexibility with the space and time allocated to each part of a session. This will help them grasp 'take-home messages' associated with each session and develop an understanding of how to apply the information to their lives.

\section{Materials}

Materials needed to prepare for each session are listed. A set of training aids (including handouts, cards, charts, etc.) will be provided to facilitators for use with specific sessions. Be sure to bring these training aids to each session or store them someplace secure in the meeting area, as they should always be on hand for reference. If for some reason the training aids are forgotten or not available for a session, a copy (smaller version) of the training aid is provided at the end of most of the sessions in the curriculum. If no copy is provided adapt the session so that the training aid is not needed.

Girls will be provided with notebooks to use for note-taking and working on various activities throughout the program. Girls should be reminded to bring these with them to each session. Markers and a flipchart OR chalk and a chalkboard are needed for most sessions. When these materials are not available, adapt the session accordingly.

\section{Pre-session Preparation}

Preparation activities for each session are noted. It is important for the facilitator to complete these preparations before each session. Being prepared for the learning session will make the facilitator's job much easier and help the session to run smoothly. Review this information carefully.

\section{Facilitator Notes}

These notes provide details about relevant session background information for the facilitator, additional session-specific tips that may be helpful, and reminders about how facilitate each session.

\section{Terms}

Terms relevant to each session are listed and defined. These definitions can be referred to throughout the session as terms are discussed or if clarification of terms is needed. A comprehensive list of all terms in the curriculum is located in the Glossary of Terms.

\section{Icebreaker}

A specific icebreaker is suggested at the beginning of a session if one suits the topics covered in the session. If no particular icebreaker is specified, the facilitator is instructed to select one from Appendix B: Participatory Facilitation Resources - Icebreaker Activities. Icebreaker activities may also be suggested by participants themselves. 


\section{Review}

The review provides general instructions for revising the key points of the previous session(s), to discuss the results of any practice activities that were assigned between the previous and current session, and to answer any questions.

\section{Activities}

Step-by-step instructions for the learning activities are provided to guide the facilitator in helping participants learn and work with the concepts of the session. The steps are listed in the order in which they should be implemented and it is intended that the steps be followed as outlined. While a general script for each session is provided, facilitators should feel free to use their own words to explain each point.

Special features for the facilitator to note include the following:

= highlights specific open questions to ask participants, or further explanations or instructions to give them

[Square brackets] = the "correct" answer to expect from a technical question

$($ Parenthesis $)=$ additional instructions or information

\section{Wrap-up}

A suggested outline to wrap up each session normally includes instructions to ask participants to summarize what they have learned during the session while the facilitator fills in any key points they miss, address any questions or comments, and end the session on a positive note, with a clear take-away message.

\section{Practice Activity}

Practice activities are to help reinforce the skills and knowledge that were gained during the session. They should be discussed at the beginning of the next session. For some sessions, specific follow-up or practice assignments for participants to work on between sessions are provided. If suggested practice activities are not appropriate or are logistically challenging, facilitators should feel free to suggest one or two alternative things participants could do before the next session. These things should be simple, short activities, which enable participants to practice what they have learned in the session. It is important that assignments given are appropriate for age groups and stick to fairly simple tasks that do not require many resources to accomplish (i.e. "Ask someone about X", "Help a friend with Y, "Find out where $Z$ is available," "Write down three things that you..." etc.). 


$$
\begin{gathered}
\text { 三INTRODUCTORY } \\
\text { SESSIONS }
\end{gathered}
$$


1) What to expect* (part 1)

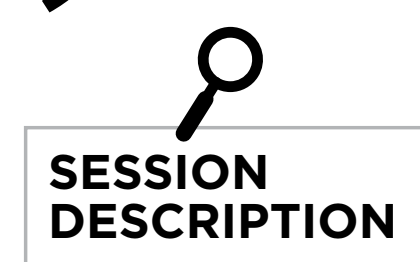

The facilitator explains the purpose of AGEP and leads a discussion on the meaning of empowerment.

OBJECTIVES
By the end of this
session, participants will
be able to:
- Define "empowerment"
- Understand what will
be covered during the
program and why
- Understand
expectations for
participation

MATERIALS
- Chalkboard and chalk OR
flipchart and markers
- Talking stick (a cane,
stick, or rolled up piece of
paper)
- Assorted colorful markers

- Introducing Safe Space and the Idea of Empowerment

(15 minutes)

- Group Formation and Mapping Exercise (15 minutes)

-Wrap-up (5 minutes)

- Practice Activity (5 minutes)

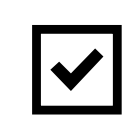

PRE-SESSION PREPARATION

- Read through the entire session and, if necessary, practice presenting the

activities

- Prepare all materials needed for the session 


\section{FACILITATOR NOTES}

Since this is the first session, you might be unsure of the literacy levels of the group. Be sure to offer all information in this first session in several forms, including written and spoken words and pictures, always using clear language.

See "Appendix B: Participatory Facilitation Resources" for additional games that can be used as icebreakers, energizers, or trustbuilding activities to start or spice up a session, or at the close of a meeting to end on a positive, team-building note. These are especially recommended for early sessions, as they focus on trust and relationshipbuilding within the group.

If participants are hesitant to talk you can use a "talking stick" to get things started. Explain that you, the facilitator, will pass the talking stick (a cane, stick, or rolled up piece of paper) to one participant. The participant with the talking stick shares, while everyone else listens. Then the participant passes the stick to another participant and that person talks while everyone else listens... and so on.

\section{TERMS}

\section{Icebreaker}

An activity used to "warm up" participants in preparation for core activities

\section{Energizer}

An activity used to establish or reestablish energy and enthusiasm among participants, especially if concentration is broken

\section{Empowerment}

Making someone stronger and more confident, especially in controlling their life and claiming their rights

\section{ICEBREAKER}

After girls are registered, separate them into two groups: Group 1: 10-14-year-olds and Group 2: 15-19-year-olds and run two separate sessions with the groups. This is to help prevent younger girls from feeling intimidated by the older girls and to prevent older girls from feeling that they are "too old" for the program as there are girls much younger in the group.

Once the groups are divided, proceed with the "Pass the Mask " icebreaker within each group:

Ask all the participants to stand in a circle, facing inward. Explain:

S I am going to make a face or a "mask" and make eye contact with the person on my left. She must try to copy or make the exact same mask, with her face, as if she were looking in a mirror. Then, she will turn to the left and change the first mask into a new one to pass on to the next person. We will "pass the mask" around the circle. Let's try it now, and remember to make eye contact and give the person enough time to make a really good copy of your mask with her face. Do not rush through it too quickly; give everyone time to copy your mask exactly.

Demonstrate the procedure before starting. 


\section{activity 1}

\section{GETTING TO KNOW EACH OTHER}

\section{(2O MINUTES)}

Divide the participants into pairs (see Appendix B: Participatory Facilitation Resources-Group Formation Activities for ideas). Explain to the participants that in each pair, one acts as a reporter and the other as a person being interviewed. Let participants know that they will be expected to report what they learn about their partner to the group.

They should cover the following questions:

-What is your name?

-What is something you like to do?

-What do you hope to get out of participation in these meetings?
After each participant has interviewed and been interviewed, ask them to sit in a circle.

\section{Explain:}

5 Now everyone will introduce their partner, explain to their group what their partner likes to do, and what their partner hopes to get out of these meetings.

While the participants share, record what they hope to get out of these meetings on the chalkboard or flipchart. After everyone has answered, look over the list and comment on which of these are covered in this program and which are not. 
activity?

\section{INTRODUCING SAFE SPACES AND THE IDEA OF EMPOWERMENT}

\section{(15 MINUTES)}

Ask:

What do you think is meant by the word "empowerment?"

After some discussion, share the Oxford Dictionary definition.

Say:

3 The official definition of empowerment is: "making someone stronger and more confident, especially in controlling their life and claiming their rights." (Nyanja Trans/ation: kupasiwa mpamvu zopeleka umoyo wako pasogolo, Bemba Translation: ukupelwa amaka ayaleta ubuyantashi mumweo wamuntu)

Discuss this definition.

Ask:

What do you think empowerment might look like in your own life? [e.g., being able to stand up to someone who is treating you unfairly, being confident to share your opinions, etc.]

\section{Explain the goal of AGEP:}

The goal of AGEP is to provide a safe and fun learning environment where you can be equipped with life skills and knowledge about your health and money management. The knowledge and skills that you gain in these groups, together with the friends that you will make, will help you maintain a happy and healthy life, and feel confident and empowered, including financially, to assert your rights and protect yourselves from harm and threats to your health.

Remind participants that their involvement in this program is voluntary. Then, allow time for the group to ask questions.

Tell the participants where and when the group will meet.

\section{Explain:}

Each meeting will include interactive activities of approximately one hour in length. Each meet ing will address a different topic (e.g., communication, relationships, money management) Meetings will be safe places for participants to discuss topics and questions that they may not otherwise get to talk about with adults and they should not feel embarrassed about anything that is discussed, any questions they may have, or any experiences they want to share. Participants are expected to attend each week. If girl misses several sessions in a row, the mentor will follow up to find out if that girl is all right. The activities are participatory. Participants are asked and encouraged to talk, share, discuss, have fun, and play at each meeting. 
activity 3

\section{GROUP FORMATION AND MAPPING EXERCISE}

\section{(15 MINUTES)}

Divide the two groups (10-14; 15-19) even further according to status: Group A: married, with children, or pregnant, and Group B: unmarried, without children and without current pregnancy. Groups should have a minimum of 20 girls and a maximum of 30 girls. For cases where there are more than 20 girls but no girls are married, with children, or pregnant, divide the girls by where they live/ geographic location.

\section{Explain:}

The group you are now in will be the group you meet with for the rest of the Adolescent Girls Empowerment Program sessions. That is, there will be one or more groups of younger girls (ages 10-14) who will meet (specify time and location if known), and one or more groups of older girls (ages 15-19) who will meet (specify time and location if known).

Distribute one piece of flipchart paper and an assortment of colored markers to each group.

\section{Explain:}

Now you should draw a small map of the place where we are meeting today. Draw 5-6 examples of the things that are at this location, such as buildings, paths, trees, other landmarks etc. The map should show key items/objects, and also their relative location from one another.

\section{Ask a few participants:}

5 Which places do you spend the most time in and why?

Now ask them to draw a map not just of the place where they are, but of their larger community.

\section{Explain:}

5 The map does not have to be perfect; it just needs to give a general idea of the main

places and where they are in relation to each other.

\section{Ask:}

5 Are there any other main places you realize that you have forgotten?

\section{Ask the pasticipants to agree on the following question:}

\section{Which places are safe or unsafe?}

Explain that participants should mark each safe place with a star on their maps. They can assign more stars to represent varying degrees of safeness.
Ark:

How long does it take to walk to the safest places from your homes?

[This may vary depending on the locations where participants live.]

How do you feel about the safety of the place we are meeting today?

If participants agree that the location of today's meeting is safe, ask the group to agree to continue to meet in this location for future AGEP sessions. (If the two groups [10-14 and 15-19] are supposed to meet in separate locations, have each group agree on the safety of their respective location). If participants can think of a safer (or more convenient) space to meet, look into this alternative and make any necessary arrangements to secure the space for regular AGEP meetings. 


\section{wrap-epp}

Ask participants to summarize what they have learned. Fill in any key points they miss.

Key Message: You will be participating in the AGEP over the course of the next two years. AGEP sessions are a safe space in which you will learn about reproductive health, financial education, and life skills to become empowered!

(NOTE TO FACILITATOR: This is a good wrap-up technique to use for any session.)

\section{Ask:}

What is the goal for AGEP?

[To provide a safe and fun learning environment where participants can be equipped with life skills and knowledge about their health and money management.]

Ask for any final questions or comments. Remind participants where and when the next meeting will take place, and what topics will be discussed.

Thank them for their participation

\section{Explain:}

$\int$ At the end of some sessions I will share a suggested activity that you can practice on your own to help reinforce the skills and knowledge that were gained during this session. These practice activities will be discussed at the beginning of the next group meeting.

\section{PRACTICE ACTIVITY}

Participants should explain the definition of empowerment to a friend. Together, participants and their friends should think of examples of empowered people in their community. 
2)

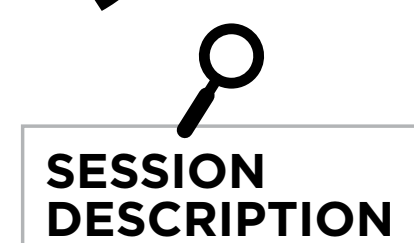

Participants create a list of ground rules

for all sessions, and

brainstorm a list of

community resources.

\section{What to expect* (part 2)}

\begin{tabular}{|c|c|}
\hline $\begin{array}{l}\text { OBJECTIVES } \\
\text { By the end of this } \\
\text { session, participants will } \\
\text { be able to: } \\
\text { • Establish, negotiate, and } \\
\text { agree on ground rules } \\
\text { as a group } \\
\text { - Have a list of } \\
\text { community resources } \\
\text { available to them for } \\
\text { reproductive health } \\
\text { gender-based violence, } \\
\text { and other services }\end{array}$ & $\begin{array}{l}\text { TIME } \\
1 \text { HOUR } \\
\text { - Icebreaker ( } 5 \text { minutes) } \\
\text { - Review (5 minutes) } \\
\text { - Ground Rules (20 minutes) } \\
\text { - Brainstorming Community } \\
\text { Resources and Contacts (20 } \\
\text { minutes) } \\
\text { - Wrap-up (5 minutes) } \\
\text { - Practice Activity (5 minutes) }\end{array}$ \\
\hline
\end{tabular}

\begin{tabular}{|c|c|}
\hline $\begin{array}{l}\text { MATERIALS } \\
\text { • Flipchart and markers } \\
\text { - A comprehensive list of local } \\
\text { community resources and } \\
\text { their contact information for: } \\
\text { - Sexual/reproductive } \\
\text { health services (including } \\
\text { contraceptives) } \\
\text { - HIV testing and counseling } \\
\text { - How/where to report } \\
\text { sexual or domestic } \\
\text { violence } \\
\text { - Psychosocial counseling } \\
\text { referral for any vulnerable } \\
\text { girls who have been } \\
\text { abused or raped } \\
\text { - Legal services }\end{array}$ & $\begin{array}{l}\text { PRE-SESSION } \\
\text { PREPARATION } \\
\text { - Read through the entire } \\
\text { session and, if necessary, } \\
\text { practice presenting the } \\
\text { activities } \\
\text { - Prepare all materials } \\
\text { needed for the session } \\
\text { - Talk with community } \\
\text { members to ensure that } \\
\text { you have included as } \\
\text { many people and places } \\
\text { as possible on your list } \\
\text { of community resources, } \\
\text { and that all contact } \\
\text { information is up-to-date } \\
\text { and correct }\end{array}$ \\
\hline
\end{tabular}

(It may be helpful to produce index cards with images of

these community resources.) 


\section{FACILITATOR NOTES}

Setting ground rules for the activities is essential for managing group sessions. They help maintain peace and order and set a framework in which participants can be respectful and productive. Rules should be kept visible for all sessions and referred to as needed throughout the modules.

The following are some sample ground rules:

- Listen to what other people say.

- No talking when someone else is talking.

- Be kind and give support.

- If people do not want to say anything, they do not have to.

- Do not laugh at what other people say.

- Insults are not allowed.

- The opinions and statements of all girls are valued equally.

- All experiences will be shared in a climate of privacy and trust.

- If you wish to speak, raise your hand and wait to be called upon.

- Questions are encouraged and may be asked at any time. There is no such thing as a stupid question.

- It is okay for the facilitator and learners to blush, feel embarrassed, or not know the answers to all of the questions.

- The facilitator also may choose not to answer a question in front of learners.

- Things shared will be kept strictly confidential. They will not be discussed outside the group. Do not judge people because of what they do or say.

\section{TERMS}

\section{Group Norms}

The standard behaviors and characteristics of a group

\section{Ground Rules}

Basic rules set to help you feel safe and respected, and maintain productivity

\section{Community Resource}

An organization, institution, group, or person in the community that provides assistance and support to those at risk

\section{ICEBREAKER}

Open the session with an icebreaker of your choice, or allow participants to suggest one. See "Appendix B: Participatory Facilitation Resources - Icebreaker Activities" for ideas. You may want to choose a longer icebreaker or trust-building activity because of the relatively short amount of time needed to cover the content in this session.

Ask participants what key points were covered in the last session (optional: throw a ball of paper around to encourage participation). Fill in any key points that are missed.

Go over any practice activities that were given, and ask if there are any questions. 


\section{activity 1}

\section{GROUND RULES}

(2O MINUTES)

\section{Ask:}

Are you familiar with ground rules or group norms?

Why do you think it is important to establish ground rules?

[to understand the limits and freedoms of a context, to improve team work, to ensure productivity and respect]

What are some real-life situations when it is important to have rules?

[e.g., when someone steals something, when there is a meeting and everyone talks at the same time, when someone speaks and others make negative comments about their contribution to the conversation, when everyone contributes to household chores, etc.]

\section{Explain to participants:}

Ground rules or group norms are set to help you feel safe participating in these meetings. While this is a participatory program, you will not be forced to participate more than you want. You can feel confident that this is a safe environment in which to share your thoughts and feelings, and that sharing your own questions or stories can help other girls who may have experienced or wondered about similar things. Ground rules help ensure that everyone will have a chance to be heard without judg- ment or ridicule, and their personal boundaries and privacy will also be respected.

Ask:

5 What are some ground rules you would like to set for these meetings?

[e.g., what is said is not repeated anywhere else; everyone should participate only if they want to; no putting someone else down for their feelings, opinions, or experiences; be respectful; listen and do not interrupt; etc.]

Record ideas for ground rules on a flipchart and post them for reference throughout the entire program.

(NOTE TO FACILITATOR: Write in simple terms (also using pictures) to accommodate for all literacy levels.)

\section{Now ask:}

5 What are some interactive punishments you would like to set for those who break the ground rules?

[e.g., the violator must do 10 frog jumps, the violator must write on the chalkboard or flipchart (or say out loud) three things they have learned so far today, the violator must sing one verse of a song, etc.]
Also record these responses on a flipchart paper and post them for reference throughout the entire program. Then explain to participants that they will now vote to agree on these rules by raising their hands. Explain that this vote will serve as a contract, meaning that the group has agreed to follow these rules in each girls group meeting.

Initiate the vote. If one or more girls do not raise their hand, ask why and discuss what should be changed to the rules in order for everyone to agree to them. 


\section{activity 2}

\section{BRAINSTORMING COMMUNITY RESOURCES AND CONTACTS}

(2O MINUTES)

Distribute the notebooks, which were provided by the AGEP project, to each girl.

\section{Ask:}

Which resources are currently available to you when it comes to your health, safety, and well-being - such as sexual reproductive health services, HIV testing, legal services, counseling, domestic or sexual violence services?

Write down their suggestions on a chalkboard or flipchart. Then share your list or index cards with images of local resources and contact information that you have gathered before the session. Emphasize the importance of turning to the services available in the community whenever participants, members of their families, or friends need assistance.
(NOTE TO FACILITATOR: If participants have mentioned any other resources that are not already included on your prepared list, let them know that you will follow-up on getting any additional contact information needed for those, and that you will provide it to them at the next meeting.)

\section{wrap-enp}

Ask participants to summarize what they have learned. Fill in any key points they miss.

$\sum_{m m}^{m}$

Key Message: Ground rules will help to make the AGEP sessions productive and respectful.

Ask for any final questions or comments. Remind participants where and when the next meeting will take place, and what topics will be discussed.

Thank them for their participation.

\section{PRACTICE ACTIVITY}

Between now and the next session, participants should think of and write down:

- One thing they do well, and

- One thing they would like to do better.

(NOTE TO FACILITATOR: Remember to find contact information for any additional resources that were listed by participants, so that you can provide it to them at the next session.) 


\section{3)

SESSION
DESCRIPTION:
(LIFE SKILLS)
Participants play a
game that requires
teamwork to learn the
benefits of working as
a team, and to build
trust and comfort
levels among group
members.

\begin{tabular}{l} 
OBJECTIVES \\
By the end of this \\
session, participants will \\
be able to: \\
- Define teamwork \\
- Identify why teamwork \\
is important \\
- Strengthen \\
teambuilding skills \\
\hline
\end{tabular}

1 HOUR, 10 MINUTES
- Icebreaker (5 minutes)
- Review (5 minutes)
- Elephant Race OR Human Knot
(30 minutes)
- Teamwork Discussion (20
minutes)
- Wrap-up (5 minutes)
- Practice Activity (5 minutes)

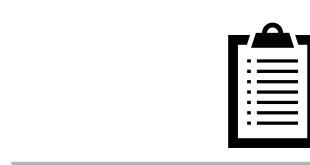

\section{MATERIALS}

- A playing area that is

at least 20 meters by 8 meters

- Two items that can be used as markers in a race (stones, tree branches,

hats, shoes, etc.) index cards with images of these community resources.)

\begin{tabular}{|l|}
\hline PRE-SESSION \\
PREPARATION \\
- Read through the entire \\
session and, if necessary, \\
practice presenting the \\
activities \\
- Prepare all materials \\
needed for the session \\
\hline
\end{tabular}




\section{FACILITATOR NOTES}

Teamwork skills give one the ability to positively relate with others so as to co-exist and to identify and complement the strengths of one another to contribute towards a common goal. The games in this session can be played with participants to build trust and develop comfort and openness within the group. Creating emotional and mental safety among participants is critical to their building social networks, developing friendships, learning how to trust, and then being able to open up, share and grow together.

\section{TERMS}

\section{Teamwork}

The ability to positively relate with others, to identify and complement the strengths of one another, and to contribute towards a common goal

\section{ICEBREAKER}

Open the session with the 'Making Rain' icebreaker.

Instruct participants to form a circle.

Explain:

As we go around the circle clockwise, each person will follow the motion of the leader. So you will begin the new motion after the person to your right has begun.

Choose a leader (or you can lead the first round) and do the following motions:

- Put palms together and rub hands together back and forth

- Click fingers

- Use hands to slap the tops of the thighs

- Stomp feet

The leader should continue the motion until every person in the circle is doing it. Once this happens, the leader should initiate the next motion. Continuous motion will produce a sound like a thunderstorm.

Repeat the cycle a few times. Once the leader has decided the icebreaker should end, she will just place her hands at her sides. This motion should travel around the circle, just as the other motions did, and allow silence.

\section{REVIEW}

( Ask participants what key points were covered in the last session (optional: throw a ball of paper around to encourage participation). Fill in any key points that are missed.

Go over the practice activity given last week, and ask if there are any questions.

(NOTE TO FACILITATOR: The following activities are divided by age group (see signs). After dividing the groups, Activities 1 and 2 should be undertaken simultaneously. However, if the group consists of girls with mixed ages, simply do the Activity 2.) 
activity 1

\section{ELEPHANT RACE}

\section{(30 MINUTES)}

The Elephant Race game is for 6 -30 players. The playing area should be 20 meters by 8 meters, with two marker items (stones, tree branches, hats, shoes, etc.) set up at one end of the area (see Box 1: Course Set-Up Diagram below).

\section{Explain to participants:}

5 The goal of this game is to be the first team to complete the course as instructed, and get back in your original team line.

Divide the group into two teams (see Appendix B: Participatory Facilitation Resources - Group Formation Activities for ideas). Instruct each team is to line up as shown in the diagram labeled "1st Run." One member of the team should be at the front of each team line, ready to run.

\section{Explain:}

I will start the race by shouting "Go!" The first member of each team runs out and around the cone, returning to their team line. Then, the first team member puts her hand between her legs (level with her knees). The second team member stands behind the first member and takes the first team member's hand (Demonstrate). They then run together around the cone and back to their team line (Demonstrate). These two team members do the same to the third team member forming a chain. After each turn running around the cone, the chain gets longer. If the chain breaks, then the team has to return to the start line and begin that particular run again.

\section{BOX 1: COURSE SET-UP DIAGRAM}
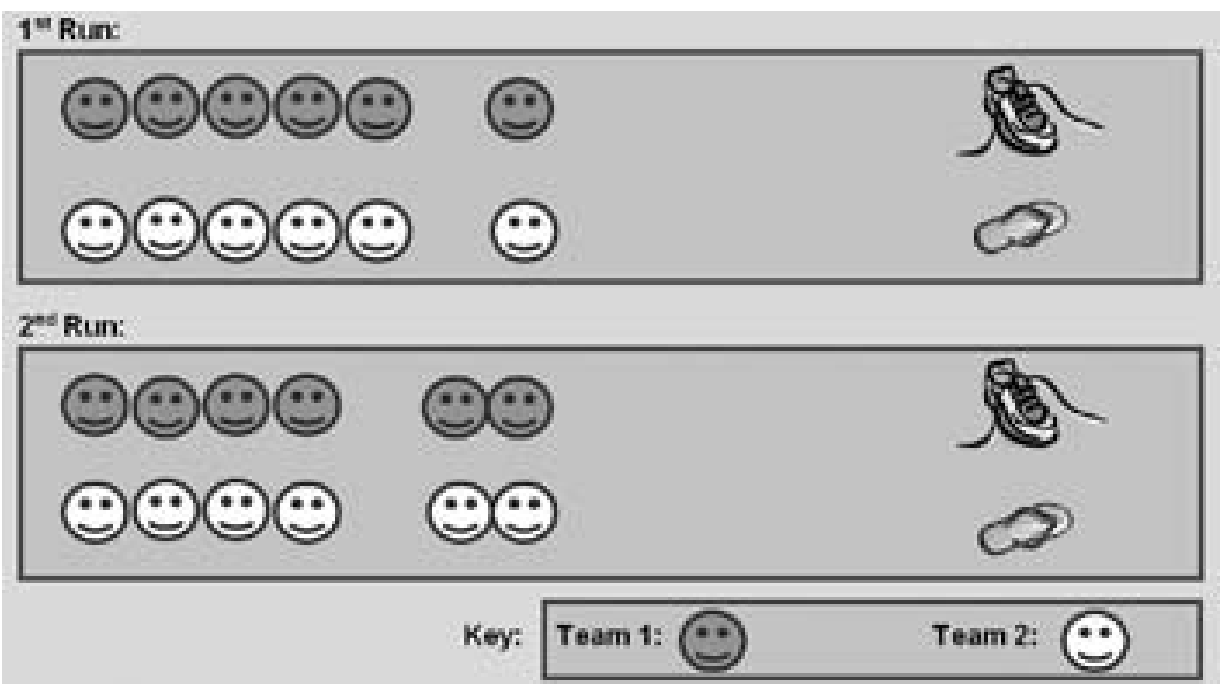

Key:

Team 1: $\odot \quad$ Team 2: $\because$

10-14-year-olds only

Ask:

5 - How did you feel playing the game?

- Was it possible to win the race by yourself without help?

-What reasons could there be for a chain/ handhold breaking?

- How do you ensure your chain/handhold does not break in the race? 


\section{activity 2}

\section{HUMAN KNOT}

\section{(30 MINUTES)}

(NOTE TO FACILITATOR: Participants taking part in this game should be warned before beginning that they need to be very careful not to hurt anyone by twisting their wrist, stepping on them, etc.)

Clear a space in which to form one or more circles of about eight to ten people.

\section{Explain:}

In this game, it is very important to follow instructions and listen to each other carefully, so that no one gets their wrist twisted or hurt. Everyone will stand in a circle, reach into the middle of the circle with both hands to get hold of the hands of two other people. Then, without letting go, you must job untangle the 'rope' to reform a circle without letting go of anyone's hands!
Say 'Go' and make sure each participant grabs the right hand of one person and the left hand of another person.

(NOTE TO FACILITATOR: If the group gets very good at this, variations can be made such as, no talking, or only whispering, etc.)

\section{Ask:}

- How did you feel playing the game?

- Was it possible to untie the knot by yourself without help?

-What reasons could there be for a handhold breaking?

- How do you ensure your handhold does not break in the knot? 


\section{activity 3}

\section{TEAMWORK DISCUSSION}

(2O MINUTES)

After completing the game(s) lead a group discussion with the following questions:

-What do we mean by the term "teamwork"? [Teamwork is when you work with those around you effectively and efficiently to meet your goal or target.]

-Why is it important to work as a team in sports? [to each contribute strengths towards the accomplishment of a goal - scoring!]

-Where do you think teamwork applies in your lives? How could we better our lives by using teamwork?"

Discuss teamwork further by touching on the following:

- All team games involve teamwork and would be very difficult, if not impossible, to complete successfully without it. Individuals are empowered when they work with others as a team. Teams reduce the vulnerability of individuals and groups, which enables them to progress farther in their goals.
- Teamwork involves supporting and aiding those around you. This applies in life as well. Your friends and family are part of your team, and you need to support and help each other to overcome challenges.

T-E-A-M can stand for:

T-together E-everyone A-achieves M-more!
Wrap-wp

Ask participants to summarize what they have learned. Fill in any key points they miss.

Key Message: By working together as a team, we can achieve more!

Ask for any final questions or comments. Remind participants where and when the next meeting will take place, and what topics will be discussed.

Thank them for their participation.

\section{PRACTICE ACTIVITY}

Participants should keep the idea of teamwork in the front of their minds. They should think about how teamwork can accomplish more while they are helping someone (a friend or family member) with an activity or task. 
4) His and Hers (Gender Roles)*

\begin{tabular}{l} 
SESSION \\
DESCRIPTION: \\
(GENDER AND \\
GENDER-BASED \\
VIOLENCE) \\
Participants identify \\
what society expects \\
of boys and girls, \\
and what society \\
discourages boys and \\
girls from doing. \\
\hline
\end{tabular}

\begin{tabular}{|l|}
\hline OBJECTIVES \\
By the end of this \\
session, participants will \\
be able to: \\
- Identify how gender \\
expectations can help \\
or limit them \\
- Strategize how to step \\
out of restrictive roles \\
- Cite one person who \\
has stepped outside \\
his/her gender role to \\
succeed
\end{tabular}

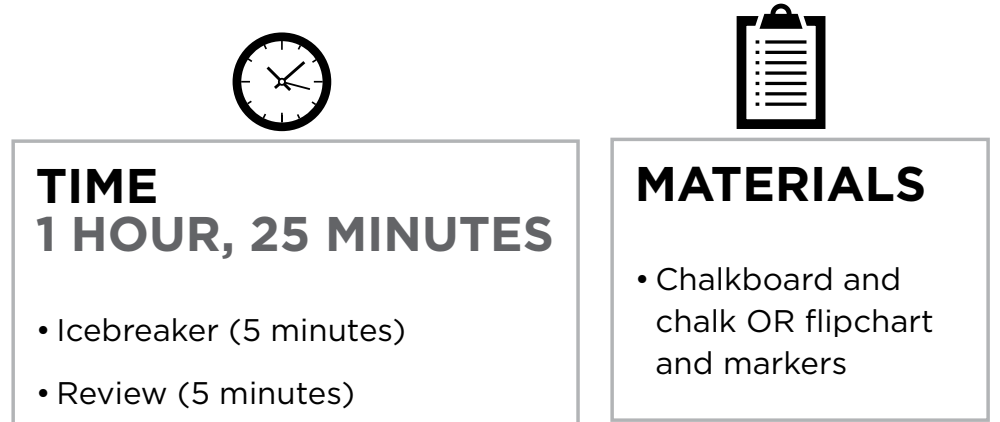

- Typical Zambian Days (20 minutes)

- Act Like a Boy/Act Like a Girl Role-play (20 minutes)

- Boy Box, Girl Box (15 minutes)

- She Did Something Different

(10 minutes)

- Wrap-up (5 minutes)

- Practice Activity (5 minutes)

PRE-SESSION
PREPARATION
- Read through the entire session
and, if necessary, practice
presenting the activities
- Prepare all materials needed for
the session
- Review the sample list of gender
roles in case participants have
a difficult time brainstorming a
thorough list
- Prepare a story about successful
local people, both male and female,
who have challenged gender
roles, or review and use the story
attached to this session (some
characteristics of people who
challenge gender roles may include:
sees jobs as equally appropriate for
men and women, values men's role
as caring for children, challenges
violence against women, advocates
for equality between men and
women, etc.)




\section{FACILITATOR NOTES}

Every culture has expectations of how men and women should act and what their roles are in society. These expected roles are known as gender roles. Fulfilling the roles expected by the community can give women or girls a sense of belonging. But these roles can also limit the activities and choices of women and girls, and make them feel less valued than men. When this happens, everyone (women, their family, and their community) suffers.

In most communities, women are expected to be wives and mothers. Many women like this role because it can be very satisfying and it gives them status in the community. Some women would prefer to follow other interests, or want to have only a few children, but their families and communities do not give them this choice. If a woman or girl is expected to have many children, she may have less chance to learn new skills or go to school. Most of her time and energy will be spent taking care of others' needs. Or, if a woman is unable to have children, her community may value her less than other women.

Most communities value men's work more than woman's work. For example, if a woman cooks, cleans, and cares for the children all day, it is often still her responsibility to continue to work to ensure her husband's comfort when he returns home from his office job. This is because his work is considered to be more important than her own. In similar scenarios, the woman's children will grow up thinking men's work is more important, and value the work and contributions of women less. Women are often considered more emotional than men, and are free to express these emotions with others. Men, however, are often taught that showing emotions like sadness or tenderness is unmanly, so they hide their feelings. Or they express their feelings in angry or violent ways that are more acceptable to men. When men are unable to show their feelings, children may feel more distant from their fathers, and men are less able to get support from others for their problems.

Gender stereotypes are generally used to describe the abilities of men versus those of women in the community in an oversimplified way. A stereotype is an oversimplified or biased description of a group. Stereotypes are often negative and harmful. Stereotypes are often recognized as being illogical even though many people still believe them.

\section{TERMS}

\section{Gender}

What a society or culture expects from you based on whether you are male or female (roles, behaviors, etc.)

\section{Gender Role}

Expectations of how men and women should act and what their roles are in society

\section{Gender Stereotype}

An oversimplified or biased description of the abilities of men and women

\section{Sex}

Whether a person is male or female; also a term used for sexual intercourse

\section{ICEBREAKER}

Open the session with an icebreaker of your choice, or allow participants to suggest one. See "Appendix B: Participatory Facilitation Resources - Icebreaker Activities" for ideas.

Go over any practice activities that were given, and ask if there are any questions.

\section{REVIEW}

0 Ask participants what key points were covered in the last session (optional: throw a ball of paper around to encourage participation). Fill in any key points that are missed.

Go over any practice activities that were given, and ask if there are any questions. 


\section{activity 1}

\section{TYPICAL ZAMBIAN DAYS}

\section{(2O MINUTES)}

Split participants into two groups (see Appendix B: Participatory Facilitation Resources - Group Formation Activities for ideas). Distribute one piece of flipchart paper and markers to each group. Ask one group to write (or tell) a story of what a typical Zambian adolescent girl does from the time she wakes up to the time she goes to sleep and ask the other group to do the same for a Zambian adolescent boy. When the story-writing is finished, have the groups present their stories.

\section{Ask:}

How are the typical days of a Zambian adolescent girl and boy different?

What main activities occupy an adolescent girl's life? And boy?

Would it be possible for girls to complete the activities that the boy usually does? And vice versa? 


\title{
activity 2
}

\section{ACT LIKE A BOY/ACT LIKE A GIRL ROLE-PLAY}

\author{
(35 MINUTES)
}

\section{Explain:}

5 We are about to do an exercise to discuss the term "gender roles" and learn how someone's gender roles are different from his or her sex.

Ask:

What sex are you? [female]

\section{Explain}

5 Your sex is whether you are a male or a female. It is the biological, physical fact of being born a boy or a girl.

Write the definition of "sex" on the board or flipchart.

\section{Ask:}

5 What are your gender roles - what are you expected to do? [e.g., cook, take care of children, sew clothes, keep the household clean, etc.]

\section{Explain:}

5 Gender roles are any expectations of a person based on their sex, that is what society or a culture expects from you based on whethe you are male or female.

Make sure participants understand that gender is determined by culture-it is how the community wants you to behave and think based on whether you are a man or a woman. If necessary, give the following example:

"A girl from America and a girl from Zambia have the same sex, but their gender roles are probably different because they were raised in different cultures. An adolescent girl from Zambia may be asked to stay home and take care of her brothers and sisters on the weekend, while an adolescent girl from America may drive her friends to the cinema."

\section{Ask:}

Do girls communicate differently than boys in this country?

Are girls able to make decisions as often as boys?

Are girls able to make the same kinds of decisions as boys?

How are relationships different for boys and girls?

How are consequences different for boys and girls?

Tell participants that we will now do a role-playing activity to help think about typical gender roles in Zambia.

\section{Explain the sules for developing sole-plays:}

Throughout the AGEP program we will do many role-plays. Each time I ask you to do a role-play in a group, you must first:

- discuss the situation as a group, then

- agree on a storyline, next

- agree on who does what making sure everyone is involved, then

- rehearse, and finally

- act out for the group.
Divide the participants into two groups (see Appendix B: Participatory Facilitation Resources - Group Formation Activities for ideas). Redistribute participants if the groups are not roughly equal sized. Present the following Scenario A to one group and Scenario B to the other group. Ask one group to create a 2-minute drama based on the scenario, where they act like girls. Ask the other group to create a 2-minute drama based on the scenario where they act like boys.

\section{Scenario A}

A mother and her daughter wake up in the morning. The mother grabs a broom and starts sweeping while the daughter grabs a bucket and goes to fetch water. After sweeping, the mother then starts washing clothes and the daughter gets back with a bucket filled with water and starts washing the plates. The daughter then goes to school. When the daughter gets back from school, the mother asks her to help prepare food for the family.

\section{Scenario B}

A father and his son wake up in the morning. The father gets an axe and starts chopping firewood while the son waters the gardens. The father then goes to work and the son goes to school. The son returns from school and goes to play with his friends.

When each group has developed and practiced their dramas, allow them to present their role-plays to the whole group. 


\section{activity 3}

\section{BOY BOX, GIRL BOX}

\section{(15 MINUTES)}

Draw two boxes on the chalkboard or flipchart. Write "girl" above one box and "boy" above the other box (see example).

\section{Ask:}

Thinking about what was presented in the roleplays and your own life experiences, what can you say girls are 'encouraged' or 'expected' to do by culture, country, community, family, peers, etc.?

Write these comments (one or two word summary, symbols or pictures) on the INSIDE of the "girl" box.

\section{Next ask:}

5 What are some things that girls are 'discouraged' from doing, or not 'expected' to do?

Write these comments on the OUTSIDE of the "girl" box.
Repeat the same procedure with the "boy" box. For example:

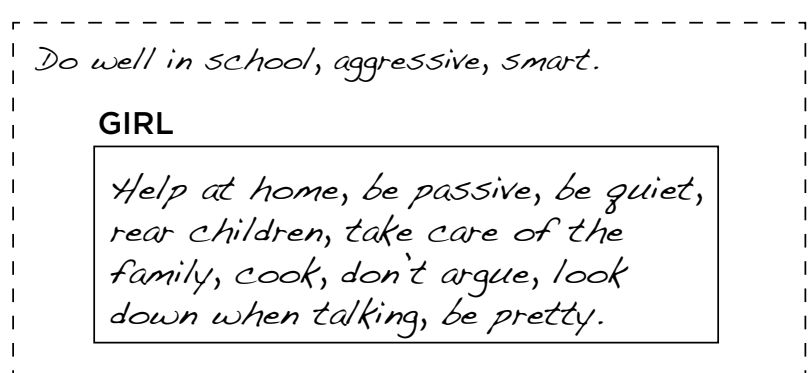

Bor
Be aggressive, work hard, go
to school, fight, ask a lot of
guestions, get married, have a lot
of kids, be the boss, be tough,
drink a lot.

Although the participants are girls, be sure to discuss the boy gender box as well. Explain that boys and girls are often expected to act a certain way just because they are boys or girls.

\section{Ark:}

$\bigcirc$ Is there something inside the boys' box that you wish was inside the girls? Why?

Is there something inside the girls' box that you wish wasn't there? Why?

Is there something outside the girls' box that you wish was inside it? 


\section{activity 4}

\section{SHE DID SOMETHING DIFFERENT}

\author{
(10 MINUTES)
}

Share the story of a local person who has challenged gender roles (thought of before the session), or read the story of Mayamiko, below:

\section{Mayamiko the Pilot}

Mayamiko has four brothers and no sisters. Her brothers all performed well at school; however, Mayamiko was performing better than all of her brothers at school. Her brothers felt very uncomfortable about her success at school. They told her that she was only a girl and that the best that could happen to her was to get married and become a housewife. Mayamiko had a goal and dreamed of becoming an airplane pilot. When she told people in her village what she wanted to do they laughed and said, "Women can't fly airplanes!" After years of studying and hard work, she went to university. At university she chose a subject that women usually do not study: aviation. She became the first woman pilot in the country. Now, everyone is proud of her success and she serves as a role model for both boys and girls.

\section{Ask:}

Is there someone from your community who has overcome obstacles to achieve his/her goal?

What was the goal?

What obstacles did he/she face?

How did he/she overcome the obstacles?

What was the end result?

\section{wrap-enp}

Ask:

Why is being aware of gender roles important in your life?

Ask participants to summarize what they have learned. Fill in any key points they miss.

$\left.\sum_{\text {man }}^{m}\right\}$

Key Message: Gender is influenced by cultural and social traditions, but gender roles can be challenged and changed!

Ask for any final questions or comments. Remind participants where and when the next meeting will take place, and what topics will be discussed.

Thank them for their participation

\section{PRACTICE ACTIVITY}

Ask participants to consider the following questions:

- What do you see boys doing "because they're boys" and what do you see girls doing "because they're girls"

- Do you see any girls who are not 'acting like a girl?' What is this person doing that is different? How is it interesting or good? 


\section{5) Communication}

SESSION
DESCRIPTION:
(LIFE SKILLS)
Participants
practice non-verbal
communication and
communicating about
sensitive topics, and
learn tips for effective
communication.

OBJECTIVES
By the end of this
session, participants will
be able to:
- Define and
demonstrate
effective non-verbal
communication
- Describe effective
communication skills
- List good listening
skills

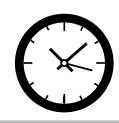

TIME

1 HOUR, 15 MINUTES

- Icebreaker (5 minutes)

- Review (5 minutes)

- Non-Verbal Communication (15 minutes)

- House-Tree-Dog (15 minutes)

- Tips for Effective

Communication (25 minutes)

-Wrap-up (5 minutes)

- Practice Activity (5 minutes)

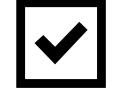

\section{MATERIALS}

- Large sheets of paper

(flipchart paper) and

markers for each group (or

notebooks and pencils)

\section{PRE-SESSION} PREPARATION

- Read through the entire session and, if necessary, practice presenting the activities

- Prepare all materials needed for the session 


\section{FACILITATOR NOTES}

Communication is the process of sending and receiving information or thoughts through words, actions, or signs. People communicate to share knowledge and experiences. Communication is a skill and forms the basis of all relationships. The quality of communication often determines the quality of a relationship.

Non-verbal communication or body language gives meaning to what is said and includes tone of voice, facial expressions (smiling, frowning, etc.), eye contact, body position (sitting, standing, pacing, leaning forward or backward), touch, and actions. Body language can influence communication negatively or positively.

Verbal communication is when one person talks and others listen and react. In relationships communication is usually informal. Communication misunderstandings and problems can happen when one person talks for too long, speaks too softly, interrupts the speaker, does not listen carefully, or when there are loud noises in the background or other distractions.

Listening carefully is essential for effective communication. Many times the listener is busy thinking about what they are going to say and does not pay close attention to what the speaker is saying. This can cause misunderstanding and confusion. It is important to listen closely to everything that is said without interrupting and then react afterwards.

\section{TERMS}

\section{Communication}

Process of sending and receiving information or thoughts through words, actions, or signs

\section{Non-verbal Communication}

Facial expressions, eye contact,

body position, touch, and actions

that give meaning to what is said

\section{Body Language}

See non-verbal communication

\section{Verbal Communication}

When one person talks and others listen and react

\section{Effective Communication}

Communication that avoids misunderstandings and improves relationships

\section{ICEBREAKER}

Open the session with the 'Telephone' icebreaker

Instruct all participants' line up such that they can whisper to their immediate neighbors, but not hear participants any further away.

\section{Explain:}

I'm going to come up with a phrase and whisper it to the first participant in line. Then this participant will whisper it as quietly as possible to her neighbor. The neighbor will then pass on the message to the next participant to the best of her ability. The passing will continue in this fashion until it reaches the participant at the end of the line, who says to the facilitator the message she received.

The game has no winner: the entertainment comes from comparing the original and final messages. Intermediate messages may also be compared; some messages will become unrecognizable after only a few steps.

\section{REVIEW}

( Ask participants what key points were covered in the last session (optional: throw a ball of paper around to encourage participation). Fill in any key points that are missed.

Go over any practice activities that were given, and ask if there are any questions. 


\section{activity 1}

\section{NON-VERBAL COMMUNICATION}

(15 MINUTES)

\section{Ask:}

5 What are some different ways to communicate? [e.g., smiling, talking, laughing, waving, talking with hands, writing, singing, etc.]

\section{Explain}

3 Much of communication is nonverbal. Nonverbal communication is used to express a variety of emotions. For example, someone can communicate agreement by nodding.

Divide participants into six groups (see Appendix $B$ Participatory Facilitation Resources - Group Formation Activities for ideas). Assign each group 2 to 3 feelings/actions from the following list and ask them to practice silently acting them out without letting the other groups see:

$\begin{array}{ll}\text { Anger } & \text { Worried/stressed } \\ \text { Shyness } & \text { Regretful } \\ \text { Rejection } & \text { Happy } \\ \text { Excitement } & \text { Yes } \\ \text { Satisfaction } & \text { No } \\ \text { Disappointment } & \text { Come here } \\ \text { Fear } & \text { Stop } \\ \text { Exhaustion/tired } & \text { Be quiet }\end{array}$

Instruct each group to act out their feelings/actions for the larger group, without speaking. Ask the other participants to guess what they are feeling.

After each group has acted out their emotions, facilitate a discussion about non-verbal communication using the following questions:

-What are other gestures or expressions that we commonly use? [e.g., nodding, folding arms, crossing legs, standing with legs wide, smiling, rolling eyes, etc.]

-Why do people use nonverbal communication instead of expressing themselves verbally? [it comes naturally, to show they are listening, to react without interrupting, etc.]

- Is it possible not to use nonverbal communication? [no, or at least very hard!]

- Can nonverbal communication contradict verbal communication? [e.g., a person is visibly upset but says she is "fine."] 


\section{activity 2}

\section{HOUSE-TREE-DOG}

(15 MINUTES)

Divide participants into pairs (see Appendix B: Participatory Facilitation Resources - Group Formation Activities for ideas). Give each pair one marker and one piece of paper. Explain:

This session will start with an exercise called "housetree-dog." The instructions are as follows:

- The exercise is to be done without talking

- Each pair sits facing each other, with the paper between them

- Both people hold the marker together and jointly draw a house, a tree, and a dog

- Still without talking, they should write their names on the picture

When all participants have finished, they should present their drawing to the group and describe their experiences creating it.

\section{Ask the following questions:}

$\Omega$-What happened?

-What did you encounter while drawing together?

- Was it difficult? Why?

- Did one person take control?

- How did this make the other person feel?

Write down key words described by each pair and further the discussion if needed.

\section{Explain:}

$\bigcirc$ Communication is so much a part of our daily lives that we take it for granted. It is not as easy as we might think to be a good communicator; it is a skill that requires practice. 
activity 3

\section{TIPS FOR EFFECTIVE COMMUNICATION}

\section{(25 MINUTES)}

\section{Explain:}

5 “Effective communication” refers to communication that avoids misunderstandings and

Ask: improves relationships.

$\int$ What do you think makes effective communication? [fill in any areas not mentioned from

\section{BOX 2: EFFECTIVE COMMUNICATION TIPS}

1. Clear communication occurs when the message the sender intends to convey is the same as the message that the receiver understands.

- People communicate both verbally and nonverbally.

- It is important to check that your message was understood correctly, especially if it involves a difficult or emotional topic.

2. In every situation, one of the most important techniques for good communication is listening well and with respect. However, cultural norms influence what kind of communication is considered appropriate.

3. Active and nonjudgmental listening can enhance communication. When you are listening:

- Try to understand the other person(s);

- Say things that validate the other person, such as "I can understand how you feel," or "Good point"; the tips in Box 2: Effective Communication Tips (below)]

Ask:

5 When you are trying to communicate, how does it feel to:

- Be interrupted or not be heard?

- Be criticized, called a name, or labeled?

- Make eye contact;

- Give positive nonverbal cues, such as a smile, nod, or pat on the back; and

- Ask for clarification.

4. Specific behaviors can enhance verbal communication. Common constructive behaviors include:

- Stating feelings and starting sentences with "I" rather than with "You";

- Acknowledging that all people have a right to their feelings and opinions;

- Avoiding being too directive, judgmental, or controlling;

- Stating as clearly as possible what you want or what you do not want; and

- Helping identify possible solutions to problems.

5. Many behaviors can impair communication.
- Be judged or made to feel guilty?

- Sense that the other person is trying to control the conversation?

- Receive negative nonverbal messages, such as being frowned at?

\section{Explain:}

$\bigcirc$ There are certain STRONG communication tips. When trying to effectively communicate, say:

- "I feel ..." The emotion that she is experiencing, e.g. "I feel scared and anxious."

- "When you..." What the other person did that caused her to feel the emotion, e.g. "When you drive quickly, it makes me feel afraid."

- "Because..." Why the action caused her to feel the emotion, e.g. "Because I know bad accidents can happen when people drive too quickly."

- "And I would like/want/need..." What she would like to have happen in order to feel better, e.g. "And I would like for you to please try to drive more slowly in the future."

Write these five steps on the chalkboard or flipchart.

(activity 3 continued on next page) 


\section{activity 3 (continued)}

\section{TIPS FOR EFFECTIVE COMMUNICATION}

\section{Explain:}

Now you will break into groups of five and role-play the following scenario to depict effective communication. Use the five tips we just discussed in your role-plays. Make sure to demonstrate good listening and respectful communication!

Read the following role-play scenario. Divide the participants into groups of five (see Appendix B: Participatory Facilitation Resources - Group Formation Activities for ideas). Allow participants time to plan and practice role-plays before asking them to present for the group.

\section{Role-play Scenario}

A mother asks her two daughters to walk to town and buy bread, flour, rice, and milk. The first and oldest daughter, Dorcas (aged 16) had promised to meet her friends in five minutes at the big tree, where they usually play, around the corner. She does not want to go to town. The second daughter, Naailah, is happy to go to town, but she is much younger (aged 9) and cannot walk to town alone because the route is steep and dangerous and she will not be able to carry all of the groceries. The girls need to negotiate the situation between themselves and their mother.
Ask:

Which feelings and emotions were communicated during the role-plays?

- Were they expressed verbally or nonverbally?

- How did communicating the emotions and feelings affect the outcome of the situation?

\section{Wrap-up}

Ask participants to summarize what they have learned. Fill in any key points they miss.

$\sum_{2 m}^{m}$ Key Message: Healthy communication can lead to a healthy relationship!

Ask for any final questions or comments. Remind participants where and when the next meeting will take place, and what topics will be discussed.

\section{Thank them for their participation.}

\section{PRACTICE ACTIVITY}

Participants should watch how nonverbal communication is used as they interact and communicate with family and friends. Then they should be prepared to share one example of nonverbal communication and how it affected the outcome of a situation. 
6)

\begin{tabular}{|l|}
\multicolumn{1}{|c|}{} \\
\hline SESSION \\
\hline DESCRRIITION: \\
(LIFE SKILLS) \\
$\begin{array}{l}\text { Participants learn } \\
\text { about sel-esteem and } \\
\text { self-irage, and identify } \\
\text { cualities they like in } \\
\text { themselves and each } \\
\text { other. }\end{array}$ \\
\hline
\end{tabular}

\section{Self-Esteem*}

\begin{tabular}{|c|c|c|c|}
\hline $\begin{array}{l}\text { OBJECTIVES } \\
\text { By the end of this } \\
\text { session, participants will } \\
\text { be able to: } \\
\text { - Define the term "self- } \\
\text { esteem" } \\
\text { - Describe the link } \\
\text { between self-esteem, } \\
\text { assertive behavior, and } \\
\text { good decision-making } \\
\text { - List qualities that they } \\
\text { most admire about } \\
\text { themselves } \\
\text { - List areas in which they } \\
\text { would like to improve } \\
\text { - Identify the strengths } \\
\text { of others in the group } \\
\text { - List qualities others } \\
\text { admire in them }\end{array}$ & $\begin{array}{l}\text { TIME } \\
1 \text { HOUR, } 20 \text { MINUTES } \\
\text { - Icebreaker (5 minutes) } \\
\text { - Review (5 minutes) } \\
\text { - Self-Esteem Building: "A Pat on } \\
\text { the Back" (20 minutes) } \\
\text { - Who Am I? (20 minutes) } \\
\text { - What is Self-Esteem? Where } \\
\text { Does it Come From? (20 } \\
\text { minutes) } \\
\text { - Wrap-up (5 minutes) } \\
\text { - Practice Activity (5 minutes) }\end{array}$ & $\begin{array}{l}\text { MATERIALS } \\
\text { - Chalkboard and chalk OR } \\
\text { flipchart and markers } \\
\text { - Paper and pens/pencils for } \\
\text { each participant } \\
\text { - Tape, pins, paper clips, } \\
\text { or clothespins for each } \\
\text { participant }\end{array}$ & $\begin{array}{l}\text { PRE-SESSION } \\
\text { PREPARATION } \\
\text { - Read through the entire } \\
\text { session and, if necessary, } \\
\text { practice presenting the } \\
\text { activities } \\
\text { - Prepare all materials } \\
\text { needed for the session }\end{array}$ \\
\hline
\end{tabular}




\section{FACILITATOR NOTES}

In working to develop ourselves into the people we'd like to become, it can be helpful for us to have an understanding about how we assess ourselves right now. This session is a first step in understanding our feelings about ourselves.

Self-esteem describes how people feel about themselves. This influences their actions towards others and what they can accomplish in life. People with high self-esteem may have a high regard for themselves. They know that they are a worthy of love and respect. They respect themselves. When people feel worthy of love and respect, they expect it from others.

Having self-esteem does not mean that you never get upset or angry with yourself. Everyone gets frustrated at times. But someone with high self-esteem can accept his or her mistakes and move on. If another person tries to convince or persuade him or her to do something they really do not want to do, people who feel good about themselves will be less likely to fall under another person's pressure. They will feel more confident that their own decision is the right one and will make their own choices based on their own desires, and not the desires and values of others.

The opposite is also true. People with low self-esteem may be more likely to fall under the influence of others, not trusting their own values or decisions. In order for young people to develop and effectively use life skills, they must have an understanding of their own worth. Believing they have self-worth, or building self-esteem, is an integral part of all life skills sessions in this curriculum.

\section{TERM}

\section{Self-Esteem}

How people feel about

themselves

\section{ICEBREAKER}

Open the session with an icebreaker of your choice, or allow participants to suggest one. See Appendix B: Participatory Facilitation Resources - Icebreaker Activities for ideas.

\section{REVIEW}

Ask participants what key points were covered in the last session (optional: throw a ball of paper around to encourage participation). Fill in any key points that are missed.

Go over any practice activities that were given, and ask if there are any questions. 
activity 1

\title{
SELF-ESTEEM BUILDING: "A PAT ON THE BACK"
}

\author{
(2O MINUTES)
}

(NOTE TO FACILITATOR: This is a short, fun, and "feel good" activity to raise self-esteem and build team spirit. It is conducted most successfully with a group that has been together for a while and knows each other well. You might use it during the self-esteem sessions or at any time for a "pick-me-up" and a group bonding experience.)

Give one sheet of paper, a pen, and something to attach the paper (tape, pin, paper clip, clothespin) to each participant.

\section{Explain}

5 We have all made an impression on each other in one way or another. We all have some positive things that we would like to say to each other, but sometimes we forget to tell each other the good things. This exercise gives us an opportunity to share with each other the impressions we have of each other and have some fun at the same time.

(NOTE TO FACILITATOR: It is important to stress that participants focus on positive and good things to avoid having anyone writing negative things on the cards.)

\section{Instruct:}

$S$ Now write your names on an upper corner of their papers and to make a symbol that represents you in the center. You could trace your hand, draw a star, heart, or sun-anything that represents you. Next, attach your papers to your backs.

Ask the participants to think about the different people in the room. Use the following questions:

- What positive words would you use to describe each person?

-What happy message would you like to give to different people in the room?

\section{Explain}

$\Omega$ When I say, "Go!" you should move around and write one (or two) word(s) on each other's papers (or draw symbols to represent those words).

When most seem to have finished, say, "Stop!" and let the participants remove their papers from their backs. There should be a great deal of joy and laughter as people see the positive feelings others have for them! 


\section{activity 2}

\section{WHO AM I?}

(20 MINUTES)

Make sure each participant has a notebook (or piece of paper) and pencil.

\section{Ask:}

Taking a moment to look at your own selfimage, what are the most important parts of you? How do you see yourself?

Invite participants to write 10 sentences that start with the words, "I am..." If participants are not able to write, ask them to draw a picture that includes 10 things to describe themselves. (Examples might be: "I am an intelligent young woman." Or "I am a really good friend to others.") Emphasize that this exercise will not be collected but is for their personal use only.

\section{Explain}

$\bigcirc$ Next, you should put a check mark next to the things you like about yourself. Put a question mark next to the things you want to change.

Ask participants to think about the following (they do not need to share their answers):

- In looking at your own lists, would you say that you feel positive about yourself in general, or are there many things you feel you need to improve on?

\section{activity 3}

WHAT IS SELF-ESTEEM? WHERE DOES IT COME FROM?

(20 MINUTES)

\section{Ask participants to lorainstorm:}

$\checkmark$ What is the meaning of the term, "self-esteem"? [how you see yourself, believing that you are worth a lot, personal strength, etc.]

List the answers on the flipchart or board.

\section{Explain:}

5 Having good self-esteem is an important part of building good decision-making, communication, and thinking skills.

Ask:

5 Where do you think self-esteem comes from? [how your parents raise you or treat you, belief in God image of girls or boys in the community, treatment by brothers, sisters, other family members, personal reflection on our lives, etc.]

Discuss each answer and jot them down on the flipchart or chalkboard.

\section{wrap-enp}

Have participants stand up, one by one, and read out what their papers (from Activity 1: A Pat On The Back) say about them. (e.g. "My name is and I am beautiful, powerful, smart, dynamic, strong, a true leader.") This can be a powerful reinforcement to self-esteem, as the participants actually "own" the statements by reading them aloud and sharing them with the group.

Ask participants to summarize what they have learned. Fill in any key points they miss.<smiles>[C]1CCCC1</smiles>

Key Message: Knowing which qualities to admire about yourself, and which qualities you need to strengthen can help build self-esteem.

Ask for any final questions or comments. Remind participants where and when the next meeting will take place, and what topics will be discussed.

Thank them for their participation.

\section{PRACTICE ACTIVITY}

Instruct participants to tell someone three things that they (the participant) like about them (the other person) to improve their selfesteem. 
7)

Goal Identification - The Road of Life*

\begin{tabular}{|l|l|}
\hline \multicolumn{1}{|c|}{} & \multicolumn{1}{|c|}{ SESSION } \\
\begin{tabular}{|l|l|}
\multicolumn{1}{|c|}{ DESCRIPTION: } \\
(LIFE SKILLS)
\end{tabular} & $\begin{array}{l}\text { OBJECTIVES } \\
\text { By the end of this } \\
\text { session, participants will } \\
\text { be able to: }\end{array}$ \\
$\begin{array}{l}\text { Participants draw a } \\
\text { "road map" of their } \\
\text { lives and visualize their } \\
\text { goals for the future. }\end{array}$ & $\begin{array}{l}\text { Reflect on their lives } \\
\text { and their resources } \\
\text { - Identify future goals } \\
\text { and the resources that } \\
\text { will help them achieve } \\
\text { their goals }\end{array}$ \\
\hline
\end{tabular}

\begin{tabular}{|l|}
\hline TIME \\
1 HOUR, 30 MINUTES \\
- Icebreaker (10 minutes) \\
- Review (5 minutes) \\
- The Road of Life (1 hour) \\
- Wrap-up (10 minutes) \\
- Practice Activity (5 minutes) \\
\hline
\end{tabular}

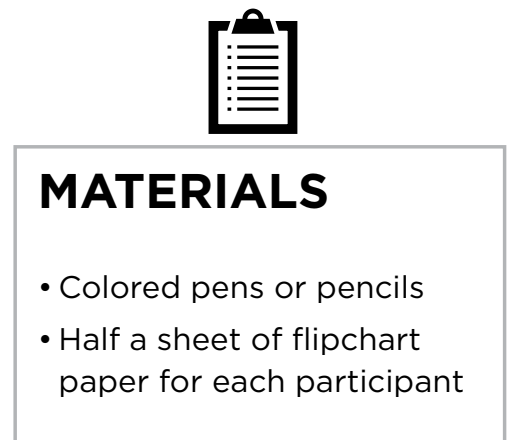

\begin{tabular}{|l|}
\hline PRE-SESSION \\
PREPARATION \\
- Read through the entire \\
session and, if necessary, \\
practice presenting the \\
activities \\
- Prepare all materials \\
needed for the session
\end{tabular}




\section{FACILITATOR NOTES}

None

\section{TERM}

None

\section{ICEBREAKER}

Open the session with the 'Mingle Mingle' icebreaker.

\section{Explain:}

5 I will shout out a general category. When I do, find others that have the same answer, and mingle with them or clump up to form a larger group. After 30 seconds, I will ask each group call out their answer to make sure there are not two groups with the same answer. If a person is unique and is the only one with an answer, that's okay.

Examples of mingles: favorite food; favorite football team; favorite drink; the kind of animal you like best; favorite color; dream job/career of choice; favorite place on earth. Ensure that participants bring out what they really want and engage in decision-making. Ask participants why they picked a particular choice, especially if they were the only ones in the group.

\section{REVIEW}

- Ask participants what key points were covered in the last session (optional: throw a ball of paper around to encourage participation). Fill in any key points that are missed.

Go over any practice activities that were given, and ask if there are any questions. 


\section{activity 1}

\section{THE ROAD OF LIFE}

\section{(1 HOUR)}

\section{Explain:}

In this exercise we will do a drawing to help us think about our lives so far, and where we will go in the future. We will draw some of the things or people, which have helped us, and those which can help us to achieve our goals. We are going to start by looking at our own lives so far. We are going to think of our lives as a road that we travel along. Sometimes the road is bumpy; sometimes it is smooth.

Give all of the participants a sheet of flipchart paper and some colored pens or pencils. Get them to spread out on tables or on the floor so they have plenty of room for drawing.

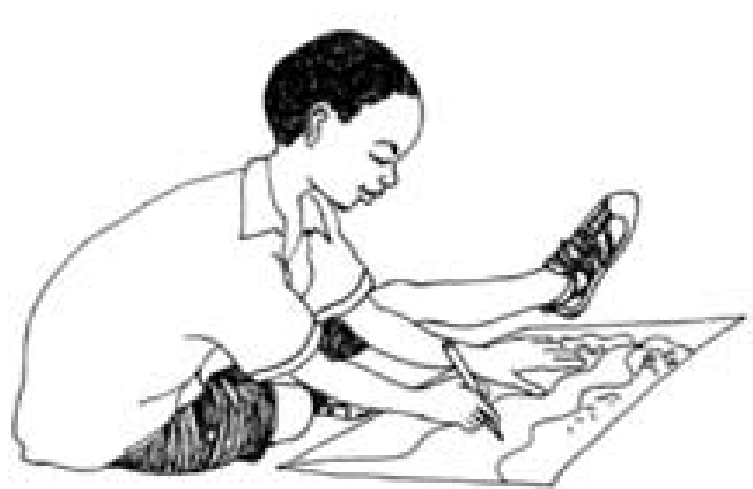

\section{Instruct:}

5 First draw yourself in the middle of the paper. Then draw a winding road from a bottom corner of the paper that winds up to the drawing of yourself, and then continue from there to a top corner.

Draw your own road on a chalkboard or flipchart paper for all participants to see a demonstration of the activity.

\section{Say:}

This is the road of your life. In the bottom corner, where the road starts, this is where you were born. Draw a picture of yourself as a tiny baby in the bottom corner.

\section{Ask:}

$S$ Now thinking about the road you have travelled between being born and now, what are three significant things that have happened in your life so far (good or bad things which have happened)?

Show the participants on your road where they should draw.

\section{Instruct:}

$\Omega$ Now draw something on the first part of their road to show those three events.
(NOTE TO FACILITATOR: It is better not to make particular suggestions about what to draw, as participants are likely to then draw what has been suggested.)

\section{Ask}

$\bigcirc$ Many of you have faced big challenges in your lives, but that you have continued along your roads. What are some things that have helped you along your road so far? [e.g., people, places, something within yourself]

Instruct participants to draw anything that has helped them on the first part of the road. Ask if participants have any questions or anything they want to share with the group so far.

Explain that now we are going to think about the future. Ask the following questions:

-Where is your road taking you?

-Where do you want to get to?

- Think of yourself in 5, 10 or 15 years' time, where will you be?

\section{Instruct:}

5 Now draw three things you want to achieve in the future (where you will be in 5,10 , or 15 years) on the next part of their road (the part between themselves now and the top of the paper). 


\section{activity 1 (continued)}

\section{THE ROAD OF LIFE}

Ask:

$\int$ Which things do you think will help you to achieve your goals?

\section{Instruct:}

$\int$ Now draw beside the road anything you think will assist you. For example, it could be people, places, or things within yourself.

\section{Explain:}

$\bigcirc$ Those of you who wish to, can put their roads on the wall. But if others do not want to, that's fine. The road drawing is for you to keep.

Encourage the group to walk around and look at each other's drawings. Ask describe their drawings to the group.

\section{(NOTE TO FACILITATOR: Remind the} group that everybody has a different drawing style, so the object is not to compare drawing ability, but to understand the events and the helpers in each other's lives.) if one or two people will to volunteer to

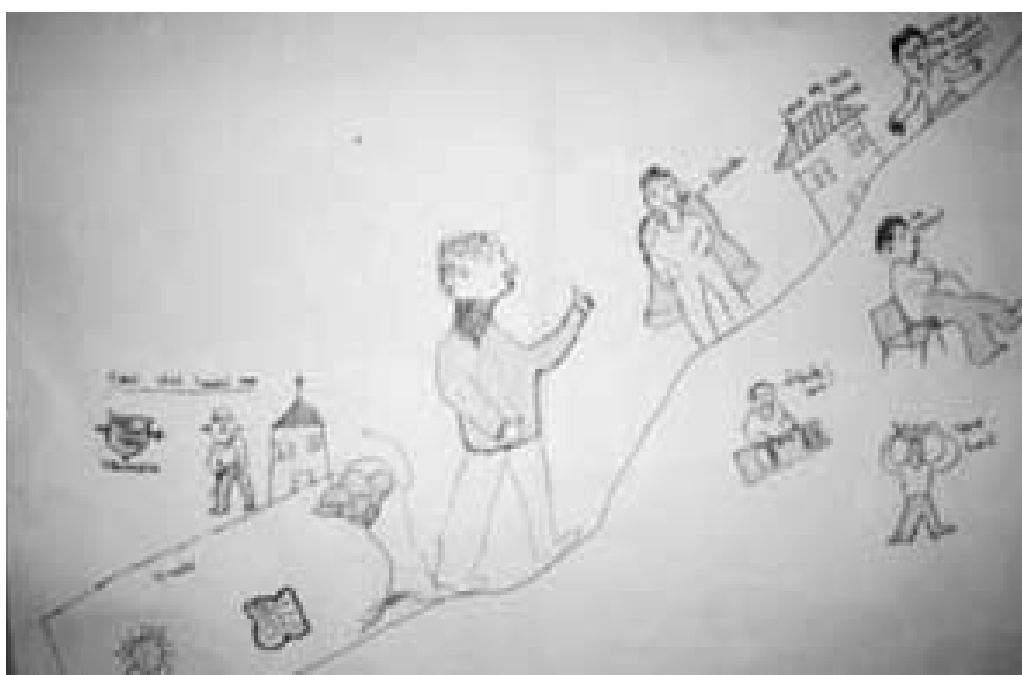

The 'Road of Life' as drawn by participants of Street Life in Lusaka.

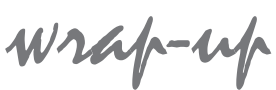

Instruct everyone to form a circle.

\section{Ask:}

-What were your reflections on the exercise?

-What was it like thinking about your lives so far?

- Was it hard or easy to think about the road of your life? - Does anybody want to share what one of their significant events was?

- Can anybody tell us which things have helped them on their journey so far?

What about the future?

- How was it to think about your goals and wishes for the future? Was it hard or easy?

- Does anybody want to tell the group one of their goals for the future?

-What were some of the things that will help you to achieve your goals?

- Are there things related to this you would like to learn more about?

(NOTE TO FACILITATOR: Be aware that the exercise may have brought up difficult feelings for some participants. Let participants know who they can go to if there are things they would like to talk more with someone about.)
Ask participants to summarize what they have learned. Fill in any key points they miss.

Key Message: Keep your goal(s) in mind! This will help you make the most of the resources around you on your path to achieving your dreams.

Ask for any final questions or comments. Remind participants where and when the next meeting will take place, and what topics will be discussed.

Thank them for their participation.

\section{PRACTICE ACTIVITY}

Participants should write (or think of) three things they can do or are already doing to get started on the path towards achieving their goals. Explain that if a participant cannot think of three steps, she should write (or think of) her goal and be prepared to share it with the group during the next session to get the group feedback on how she can get started towards achieving her goal. 


\section{8) Goal Setting and Achieving*}

SESSION
DESCRIPTION:
(LIFE SKILLS)
Participants learn what
goals are and practice
developing goals using
a basic outline.

OBJECTIVES
By the end of this
session, participants will
be able to:
- Define what a goal is
- Use a simple planning
process to set realistic
goals and objectives in
everyday life

○

TIME

1 HOUR, 20 MINUTES

- Icebreaker (5 minutes)

- Review (5 minutes)

- Football Exercise (25 minutes)

- Phases of Goal Setting (25 minutes)

- "I Can't" Funeral (10 minutes)

-Wrap-up (5 minutes)

- Practice Activity (5 minutes)

MATERIALS
- Chalkboard and chalk OR
flipchart and markers
- Football
- Pen and paper for each
participant

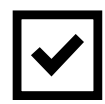

PRE-SESSION PREPARATION

- Read through the entire session and, if necessary, practice presenting the activities

- Prepare all materials needed for the session

- Locate an area where participants can play a quick game of football 


\section{FACILITATOR NOTES}

A goal is something that you want to achieve or accomplish. It can be something to do, someplace to go or something to have. Goals give us something to look forward to and can motivate us and give us energy. To set a goal, we must gather information and make decisions and choices. We must learn about what we want to achieve. Goals should be specific, practical and have a deadline. Something realistic and easy to manage makes achieving it easier and creates confidence to make other, greater goals. Thinking about the expected benefits can be motivating. To help reach a goal, it is helpful to have a plan with steps to achieve it, and also think about possible difficulties and how they can be overcome.

\section{TERM}

\section{Goal}

Something that you hope

to achieve, especially when much time and effort will be needed

\section{ICEBREAKER}

Open the session with an icebreaker of your choice, or allow participants to suggest one. See Appendix B: Participatory Facilitation Resources - Icebreaker Activities for ideas.

\section{REVIEW}

Ask participants what key points were covered in the last session (optional: throw a ball of paper around to encourage participation). Fill in any key points that are missed.

Go over any practice activities that were given, and ask if there are any questions. 


\section{activity 1}

\section{FOOTBALL EXERCISE}

(25 MINUTES)

Drop the football on the floor and let the participants play a quick game of football. If you do not have a football, make one out of plastic bags and string or ball up a piece of flipchart paper.

When they have finished:

\section{Explain:}

$\bigcirc$ In football, a goal is when you score to benefit your team. It is something you strive to do throughout the entire game - you and your team try to accomplish as many goals as you can in one game.

Now let's pretend we have front row seats for everyone in the room to see Brazil play against Chipolopolo/Zambia in the World Cup. When you arrive in the arena where the games are being held, you notice that there is something strange about the field. The players are kicking the ball around, but nothing is happening. There are no goals.

Without goals, the game does not have a purpose. Same in life: if you have no goals, you are just on the field aimlessly kicking the bal around.

Tell participants that in order to develop goals, one should use this simple outline (write it on the chalkboard or flipchart as you describe it)
Mission Statement: A brief sentence explaining what you want to accomplish (e.g., to go to teacher college)

WHAT: Be specific; explain the mission statement more here (e.g., to study to be a teacher)

WHO: The people who will help you toward your goals (e.g., parents, teachers, and school administrators)

WHERE: A place, anywhere in the world

(e.g., local and national colleges or schools)

WHEN: Set up a timeline and a specific date (e.g., study to take tests next year, to be in a teacher's college within three years)

HOW: Make lists of ideas to achieve goal-explain "to do" lists (e.g., research what teacher colleges exist in the area; talk to teachers back home; contact friends and relatives who could help; look in the newspaper and on the internet for information and, possibly groups to support me emotionally or financially)

WHY: Should refer back to the mission statement (e.g., because I have a lot to offer my community as a teacher) 


\section{activity 2}

\section{PHASES OF GOAL SETTING}

\section{(25 MINUTES)}

\section{Remind participants:}

5 Goals are very important in life, just as in football. Also like in football, when setting a goal you will miss a few shots. Famous Zambian soccer player, Christopher Katongo, did not walk off the field when he missed a shot. He is not considered a failure. Expect to have failures and challenges as you work towards your goals.

Draw a circle on the board and divide into 4 quarters. Start with the upper right quarter and go clockwise to explain the Four Phases:

Phase 1 - The Good Times. The period when everything is perfect. Life is beautiful.

Phase 2 - Problems Arise. The period when things fail. In this dark time, people tend to quit, give up. Seems like no answer in sight.

Phase 3 - Solutions to Problems. When you are determined to follow your goal, know that to each problem there is a solution. This requires creativity and being open to new ideas

Phase 4 - Growth. Once you have gone through the phases, you have grown and you are excited and ready for more. The circle starts all over again.
Divide the participants into small groups (see Appendix B: Participatory Facilitation Resources - Group Formation Activities for ideas). Redistribute participants if the groups are not roughly equal sized.

\section{Explain:}

5 In your small groups, you will write (or draw) out your own goals. Refer to the four phases when thinking about how you will do this. Follow the outline of the 1) Mission Statement, 2) What, 3) Who, 4) Where, 5) When, 6) How, and 7) Why like we discussed before.

Remember dreaming is FREE and does not cost a thing. So in this exercise, try to dream big, crazy, and be open to new things. Anything is possible if you really want to achieve it!

When participants have finished, have the small groups share with the larger group. 


\section{activity 3}

\section{“I CAN'T" FUNERAL}

(10 MINUTES)

Distribute pieces of paper to all participants.

\section{Explain:}

5 Now you will think of things you cannot do. Maybe you feel you cannot eat travel to the other side of the country to visit your aunt, or go to university to be a doctor, or be assertive with your big brother if you disagree with him. Write (or draw) these things on your piece of paper. Try to think of at least three things.

When the participants have finished writing,

Say:

5 We are gathered here today to say goodbye to someone who has been around for a long time. We are going to have a funeral for the things that we think we cannot do. It is important to believe in yourself- with strong self-esteem and well-planned goals, you can achieve anything you want. This is an "I can't" funeral because you can do these things you think you can't do. Don't allow others to tell you that you can't do something.
Instruct the girls to tear their "I can't" papers into small pieces.

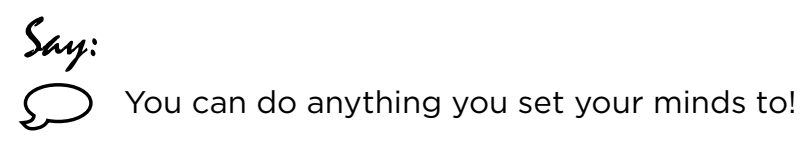

wrap-up

Ask participants to summarize what they have learned. Fill in any key points they miss.

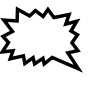

Key Message: Goals can be achieved by making realistic plans - Anything is possible if you really want to achieve it!

Ask for any final questions or comments. Remind participants where and when the next meeting will take place, and what topics will be discussed.

Thank them for their participation.

\section{PRACTICE ACTIVITY}

Ask participants to set a goal for what they want to achieve during their participation in safe spaces for the Adolescent Girls Empowerment Program (AGEP). Remind them that during the next session, these goals will be discussed. 


\section{9) My Relationships*}

SESSION
DESCRIPTION:
Participants draw a
representation of their
different types of
relationships and think
about how they value
each one.

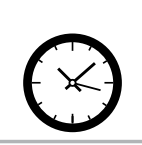

\section{TIME}

\section{HOUR, 5 MINUTES}

- Icebreaker (5 minutes)

- Review (5 minutes)

- Visual Representation of

Relationships (45 minutes)

- Wrap-up (5 minutes)

- Practice Activity (5 minutes)

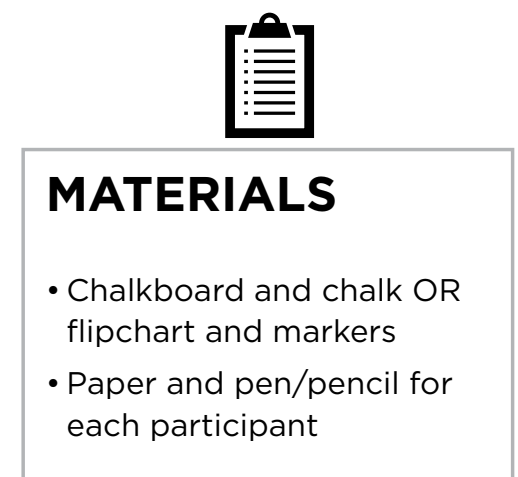

\begin{tabular}{|l|}
\hline PRE-SESSION \\
PREPARATION \\
- Read through the entire \\
session and, if necessary, \\
practice presenting the \\
activities \\
- Prepare all materials \\
needed for the session \\
\hline
\end{tabular}




\section{FACILITATOR NOTES}

Relationships can provide a source of support beyond what family or peer groups can offer. Adolescents may spend time with just one friend or a small group of friends. These friends can be quite important. They can help young people share ideas, thoughts and experiences without fear or betrayal. They may share experiences about bodily changes, which can help them to feel normal. In such friendly groupings, adolescents can explore and discover themselves as people; which is part of the search for identity. Adolescents tend to select friends with characteristics similar to their own as a way of confirming their own opinions and sense of self worth.

As young people move through puberty and adolescence, many begin to have boyfriends or girlfriends. Having a boyfriend or girlfriend can involve going places or spending time with someone in order to get to know him or her better or having feelings for each other and wanting to be more than just friends. This can be fun and exciting, but it can also create problems. For instance, young people may want to date before their parents think they are old enough or they may not feel ready to date but their parents or peers push them into it. Sometimes group activities are more comfortable and safer than individual or private dates.

\section{TERMS}

None

\section{ICEBREAKER}

Open the session with an icebreaker of your choice, or allow participants to suggest one. See Appendix B: Participatory Facilitation Resources - Icebreaker Activities for ideas.

\section{REVIEW} Ask participants what key points were covered in
the last session (optional: throw a ball of paper around to encourage participation). Fill in any key points that are missed.

Go over any practice activities that were given, and ask if there are any questions. 


\section{activity 1}

\section{VISUAL REPRESENTATION OF RELATIONSHIPS}

(45 MINUTES)

Today's session will help participants identify different types of relationships they have with people.

\section{Instruct:}

Everyone should use their pencil and notebook to make a personal list of their relationships and connections with other people.

For those who cannot write, they can come up with a list in their heads. Invite a few participants to share their lists voluntarily. Note on the chalkboard or flipchart the different kinds of relationships they mention, such as those with relatives, friends, or neighbors.

On the chalkboard or flipchart, draw a diagram of four concentric circles (like the one below).

Instruct participants to take out a blank piece of paper

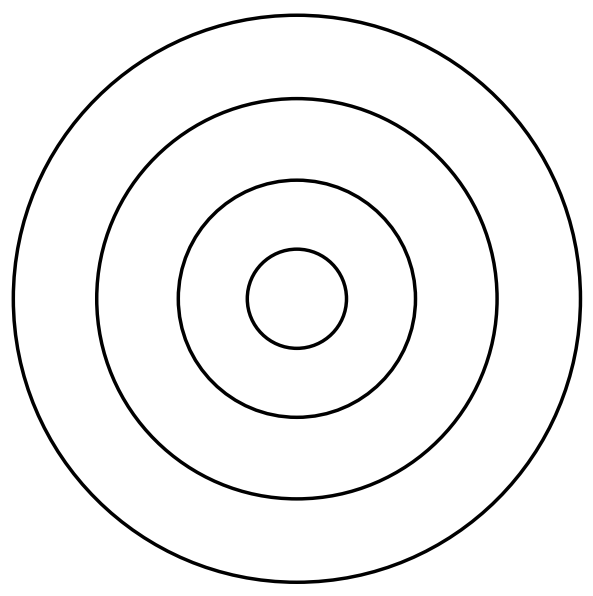

\section{Explain the following steps:}

5 Draw a series of four circles, from small to large, like the ones I have drawn. Use your whole sheet for the largest circle.

In the smallest circle, write your name (or draw a picture of yourself)

Think about the different people in your life. Just outside that small circle, write the names (or draw simple pictures) of those who are closest to you.

In the two outer circles, put the names (or pic tures) of those who are not as close.

Divide the participants into groups of three or four (see Appendix B: Participatory Facilitation Resources - Group Formation Activities for ideas), and instruct them to explain their drawings to the other members of their small groups. When the participants have had adequate time to explain their drawings, facilitate a discussion with the following questions.

- Did everyone in your group list the same kinds of relationships or were there differences?

- Did everyone place their family members, friends, neighbors, teachers, religious leaders, or others in the same circle or in different circles?

-What are some words that describe what you value in the people you feel closest to? [e.g., honest, respectful, sharing, caring, trusting, fun, safe, understanding, reliable, interesting, loving]

Write these words on the chalkboard or flipchart.
Explain:

I l am going to read some statements that ask you to think about what you have on your page. Think about these things quietly in your heads. Thinking about them will help you explore the qualities that you value most in your relationships.

Read the following statements, pausing between each so that participants have adequate time to think:

- Think about one person on your page whom you would like to have move closer toward the inner circle. Pick one word that most describes what you value in that person.

- Now think about one or two of the words on the board that you think people would say describe you.

- Think about what kind of friend you are to others, not just how other people are friends to you. Think about which qualities you could develop to become and even better friend?

Explain:

$\int$ Now you have thought about what qualities you value in relationships, choose one quality you value highly - either in yourself or in others - and celebrate it by writing it on your paper (or drawing what it represents) with decorative letters or in a creative style. As you write (or draw), think about what the word means to you. 


\section{Wrap-enp}

Ask participants to summarize what they have learned. Fill in any key points they miss.

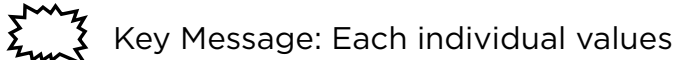
different characteristics in others, leading to many different types of relationships.

Ask for any final questions or comments. Remind participants where and when the next meeting will take place, and what topics will be discussed.

Thank them for their participation.

\section{PRACTICE ACTIVITY}

Instruct participants to think of three qualities that they like in a friend or family member. They should identify why those qualities are important to them and be prepared to share their thoughts in the next session. 


$$
\begin{gathered}
\text { REPRODUCTIVE } \\
\text { HEALTH }
\end{gathered}
$$


1) Life Cycle*

SESSION
DESCRIPTION:
(REPRODUCTIVE
HEALTH)
Participants learn
about the changes that
occur at each stage of
the life cycle, with a
focus on adolescence
and puberty.

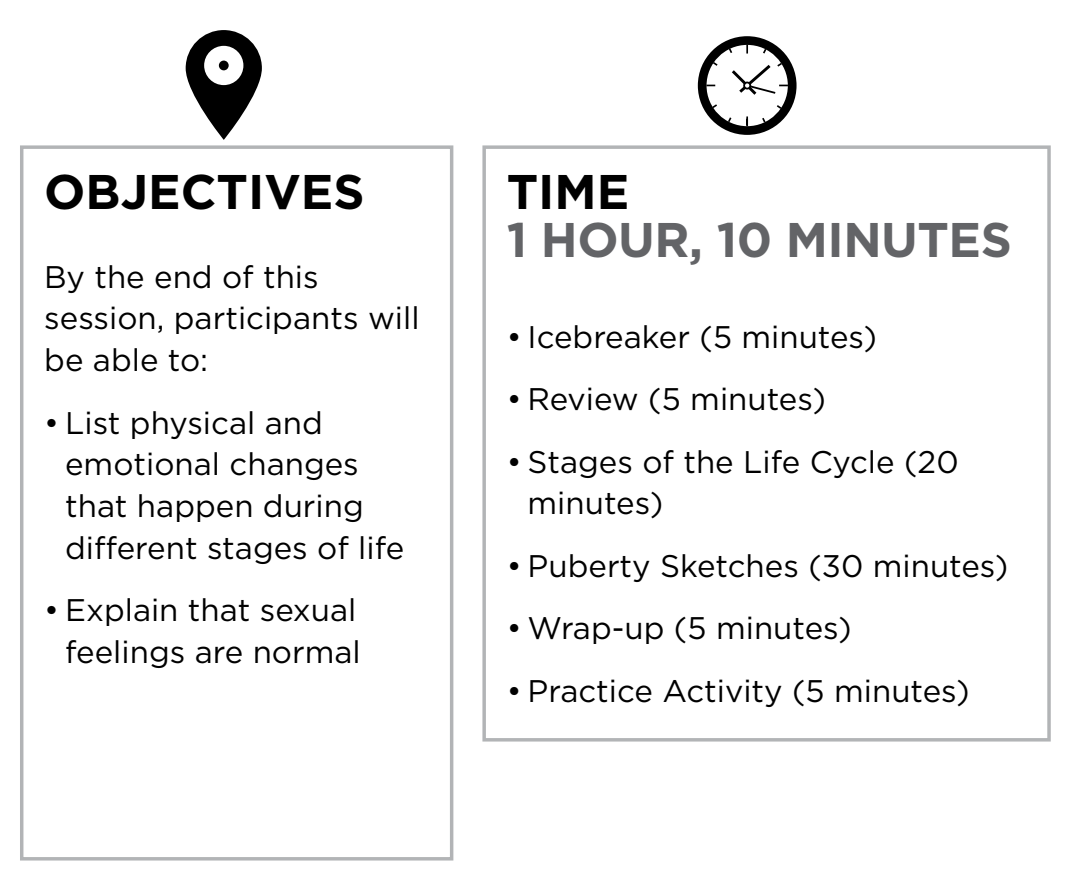

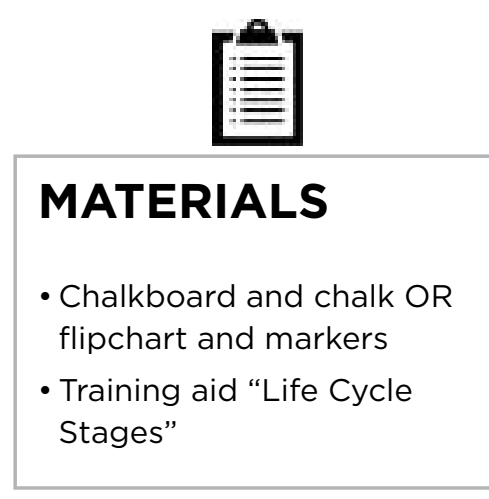

PRE-SESSION PREPARATION

- Read through the entire session and, if necessary, practice presenting the activities

- Prepare all materials needed for the session 


\section{FACILITATOR NOTES}

Humans grow and age through various stages in their lifetime, a process known as the human life cycle. Various points along this cycle of life offer individuals a range of growth and development, both on physical and emotional levels. As a person moves through life from one cycle to another, he or she also experiences a constant progression of cellular life, death and regeneration, from the moment of conception to the moment of death.

Table 1: Life Cycle Stages and Events in this session outlines different physical and emotional characteristics of each of the stages of the life cycle. Be familiar with the content of this chart before the session starts. Participants will be brainstorming the characteristics of each stage during the first activity, with information below to be filled in by the mentor as needed. Try to use local language terms in order to communicate effectively with the participants.

\section{TERM}

\section{Life Cycle}

The process of changes through which a human goes during their life, including infancy, childhood, adolescence, adulthood, and old age

\section{ICEBREAKER}

Open the session with the 'Simon Says' icebreaker:

\section{Explain:}

$\bigcirc$ You should follow instructions when I start the instruction by saying "Simon says..." But if I do not begin the instructions with the words "Simon says", then you should not follow the instructions!

Say something like "Simon says clap your hands" and clap your hands. The participants follow. Speed up the actions, always saying "Simon says" first. After a short while, omit the "Simon says" before your command. Those participants who do follow the instructions anyway are 'out' of the game. The game can be continued for as long as it remains fun.

\section{REVIEW}

(X) Ask participants what key points were covered in the last session (optional: throw a ball of paper around to encourage participation). Fill in any key points that are missed.

Go over any practice activities that were given, and ask if there are any questions. 


\section{activity 1}

\section{STAGES OF THE LIFE CYCLE}

(2O MINUTES)

Explain:

$\int$ This session is about the physical and emotional changes people go through as they grow up.

Write down the five stages of the life cycle (infancy, childhood, adolescence, adulthood, and older age) as headings on a chalkboard or flipchart.

Ask participants to brainstorm the physical and emotional characteristics of each stage:

-What can a baby do? How does a baby feel?

-What can a child do? How does a child feel?

-What can an adolescent do? How does an adolescent feel?

- An adult?

- Someone of old age?

(NOTE TO FACILITATOR: Since participants are adolescents, be sure to spend the most time focusing on the emotional and physical changes of the adolescent stage.)

Write the responses and comments on the chalkboard or flipchart. Facilitate a discussion if there is not agreement. Ask participants to think about their own experiences and their family situations. Make sure the physical and emotional characteristics outlined on Table 1: Life Cycle Stages and Events are mentioned. As each response is given, ask if everyone in the group agrees with the comments. Explore the most important ones in greater detail.

Use the Training Aid: Life Cycle Stages to show the stages of the life cycle and summarize the stages using the ideas from Table 1.

\section{TABLE 1: LIFE CYCLE STAGES AND EVENTS}

\begin{tabular}{|c|c|c|c|c|}
\hline $\begin{array}{c}\text { INFANCY } \\
\text { (Birth to } 3 \text { years) }\end{array}$ & $\begin{array}{l}\text { CHILDHOOD } \\
\text { ( } 4 \text { to } 12 \text { years) }\end{array}$ & $\begin{array}{l}\text { ADOLESCENCE } \\
\text { (13 to } 20 \text { years) }\end{array}$ & $\begin{array}{l}\text { ADULTHOOD } \\
\text { (20 to } 50 \text { years) }\end{array}$ & $\begin{array}{l}\text { OLD AGE } \\
(50 \text { years }+)\end{array}$ \\
\hline $\begin{array}{l}\text { Bond with parent } \\
\text { Get early needs met } \\
\text { Learn to trust } \\
\text { Experience touching } \\
\text { by another person } \\
\text { Develop gender } \\
\text { identity } \\
\text { Society ideas of } \\
\text { gender roles } \\
\text { Boys and girls touch } \\
\text { private parts and } \\
\text { wonder why girls } \\
\text { and boys private } \\
\text { parts are different } \\
\text { Can experience } \\
\text { orgasm } \\
\text { Toilet training } \\
\text { Erection of penis in } \\
\text { boys } \\
\text { Lubrication of va- } \\
\text { gina in girls }\end{array}$ & $\begin{array}{l}\text { Learning gender role } \\
\text { Beginning of inde- } \\
\text { pendent behavior } \\
\text { Childhood sex play } \\
\text { Same-sex friend- } \\
\text { ships } \\
\text { Masturbation or the } \\
\text { sexual stimulation of } \\
\text { the genitals usually } \\
\text { done with hands or } \\
\text { fingers } \\
\text { Family life education } \\
\text { may be taught } \\
\text { Beginning of pu- } \\
\text { berty } \\
\text { Vaginal discharge in } \\
\text { pre-pubescent girls }\end{array}$ & $\begin{array}{l}\text { Puberty } \\
\text { Menstruation in girls } \\
\text { Producing sperm in } \\
\text { boys } \\
\text { Onset of sexual desire } \\
\text { in both males and } \\
\text { females } \\
\text { Wet dreams in boys } \\
\text { Strong need for } \\
\text { independence with } \\
\text { difficulty giving up } \\
\text { dependent status } \\
\text { Emotional ups-and- } \\
\text { downs } \\
\text { Worry } \\
\text { Learning through } \\
\text { radio, advertising, tele- } \\
\text { vision ways to be an } \\
\text { adult man or woman } \\
\text { Masturbation } \\
\text { Experimentation with } \\
\text { boyfriends/girlfriends } \\
\text { Having sex } \\
\text { Possibility of family } \\
\text { planning decisions } \\
\text { Possibility of preg- } \\
\text { nancy or impregnating } \\
\text { someone }\end{array}$ & $\begin{array}{l}\text { Forming of long- } \\
\text { term sexual relation- } \\
\text { ships } \\
\text { Building closeness in } \\
\text { a relationship } \\
\text { Setting long-term } \\
\text { goals and making } \\
\text { plans to reach them } \\
\text { Possibility of family } \\
\text { planning decisions } \\
\text { Possibility of preg- } \\
\text { nancy and childbirth } \\
\text { for women } \\
\text { Possibility of father- } \\
\text { ing children for men } \\
\text { Family life educa- } \\
\text { tion for one's own } \\
\text { children } \\
\text { Reduced possibil- } \\
\text { ity of pregnancy for } \\
\text { women }\end{array}$ & $\begin{array}{l}\text { Need for touching } \\
\text { and affection } \\
\text { If healthy, con- } \\
\text { tinuing interest in } \\
\text { sex and ability to } \\
\text { perform } \\
\text { Menopause or when } \\
\text { women reach the } \\
\text { stage where they } \\
\text { can no longer be- } \\
\text { come pregnant } \\
\text { Grandparenthood } \\
\text { Death of a loved } \\
\text { one }\end{array}$ \\
\hline
\end{tabular}




\section{activity 2}

\section{PUBERTY SKETCHES}

(30 MINUTES)

\section{Ask:}

S Would some participants like to volunteer to speak about the physical and emotional changes of adolescence and puberty from their personal experiences?

(NOTE TO FACILITATOR: Participants can also speak about the experiences of someone close to them who has gone through puberty.)

Divide participants into groups of four (see Appendix B: Participatory Facilitation Resources - Group Formation Activities for ideas). Assign each group a specific physical or emotional change of puberty to use as a focus for a dramatic sketch (use Table 1: Life Cycle Stages and Events for ideas on the physical and emotional changes to assign). Give each group 5 minutes to prepare a 2-minute sketch to present to the entire group.

Use the remaining session time for participants to present their sketches. Wrap up by addressing any questions participants have about the physical and emotional changes of puberty.

\section{Wrap-up}

Ask participants to summarize what they have learned. Fill in any key points they miss.

$\sum_{m}$ Key Message: Each stage of life is associated with a normal set of physical and emotional changes.

Ask for any final questions or comments.

Remind participants where and when the next meeting will take place, and what topics will be discussed.

Thank them for their participation

\section{PRACTICE ACTIVITY}

Instruct participants to identify one infant, one child, one adolescent, and one old-aged person and think about how their life experiences are shaped by their life stage. Events for the life stages, such as the physical and emotional changes which we learned about today, should be considered. 
2)

My Body Is Changing - Am I Normal?*

\begin{tabular}{|l|l|}
\multicolumn{1}{|c|}{} \\
\begin{tabular}{|l|l|}
\hline \multicolumn{1}{l|}{ SESSION } & OBJECTIVES \\
DESCRIPTION: \\
(REPRODUCTIVE \\
HEALTH)
\end{tabular} & $\begin{array}{l}\text { By the end of this } \\
\text { session, participants will } \\
\text { be able to: }\end{array}$ \\
$\begin{array}{l}\text { Participants practice } \\
\text { communication skills, } \\
\text { discuss and draw } \\
\text { out the changes that } \\
\text { occur during puberty, } \\
\text { and discuss how they } \\
\text { can help each other } \\
\text { through puberty. }\end{array}$ & $\begin{array}{l}\text { and emotional changes } \\
\text { that occur during } \\
\text { puberty } \\
\text { - Understand that these } \\
\text { changes that occur } \\
\text { during puberty are } \\
\text { normal }\end{array}$ \\
\hline
\end{tabular}

TIME
1 HOUR, 20 MINUTES
- Icebreaker (5 minutes)
- Review (5 minutes)
- Physical and Emotional
Changes in Boys and Girls (20
minutes)
- Puberty: Is it normal (25
minutes)
- Making Puberty Easier (15
minutes)
- Wrap-up (5 minutes)
- Practice Activity (5 minutes)

\begin{tabular}{|l|} 
MATERIALS \\
- Chalkboard and chalk OR \\
flipchart and markers \\
- 4 large pieces of blank \\
paper and pens, pencils or \\
markers \\
- Training aids "Physical \\
Changes in Males at \\
Puberty" and "Physical \\
Changes in Females at \\
Puberty"
\end{tabular}

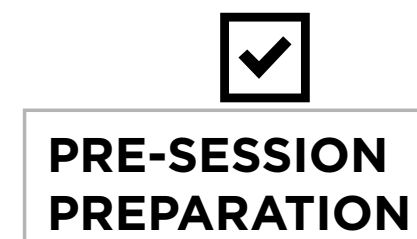

- Read through the entire session and, if necessary, practice presenting the activities

- Prepare all materials needed for the session 


\section{FACILITATOR NOTES}

Puberty is a time when the bodies of boys and girls physically change - bodies grow bigger and taller, genitals mature, and hair often starts growing in new places on the body. During puberty, a girl becomes physically able to become pregnant and a boy becomes physically able to father a child. New chemicals produced by the body, called hormones, create changes in the body and turn young people into adults. Puberty typically starts between ages 8 to 13 in girls, and ages 10 to 15 in boys, although some young people start puberty a bit earlier or later. People are different, so everyone starts and goes through puberty at their own pace. During puberty, young people are experiencing a major growth change. Puberty lasts for about 2-5 years. Some people grow four or more inches in one year. This growth during puberty will be the last time the body will grow taller. When the growth period is over, young people will be at their adult height.

When discussing the physical changes experienced during puberty, be sure to relate them to the emotional changes that go along with them.

\section{TERMS}

\section{Adolescence}

The period of time when people transition from childhood to adulthood, usually between ages 10 and 19

\section{Hormones}

A chemical substance produced in the body that controls and regulates the activity of certain cells or organs

\section{Puberty}

The physical and emotional changes that people go through during adolescence; results in sexual maturity and capability for reproduction

\section{ICEBREAKER}

Open the session with the 'Head and Shoulders' icebreaker:

\section{Explain:}

5 Touch the following body parts as they sing the following lyrics:

Head, shoulders, knees and toes, knees and toes, Head, shoulders, knees and toes, knees and toes,

And eyes and ears and mouth and nose,

Head, shoulders, knees and toes, knees and toes!

Modify the song to include body parts that change during puberty. For example:

Hips, shoulders, breasts and toes, breasts and toes, Hips, shoulders, breasts and toes, breasts and toes, And pimples and armpit hair and mouth and nose,

Hips, shoulders, breasts and toes, breasts and toes! Be creative with more song adaptations.

\section{REVIEW}

Ask participants what key points were covered in the last session (optional: throw a ball of paper around to encourage participation). Fill in any key points that are missed.

Go over any practice activities that were given, and ask if there are any questions. 


\section{activity 1}

\section{PHYSICAL AND EMOTIONAL CHANGES IN BOYS AND GIRLS}

(2O MINUTES)

Explain:

5 Adolescence is the time in everyone's life when they change from a child to an adult. Adolescence is the age between 10 and 19. This process of change is called 'puberty.' Today we are going to learn about the physical and emotional changes that occur during adolescence.

Divide girls into three groups (see Appendix B: Participatory Facilitation Resources - Group Formation Activities for ideas). Hand a piece of paper and pencils to each group.

Assign one of the following types of changes to each group: 1) boy's physical change, 2) girl's physical changes, 3 ) emotional changes.

\section{Explain:}

5 Now you will write (or draw) the changes that occur during adolescence in the category assigned to their group.

When they have finished writing down changes, ask two participants from each group to share their group's list. Write the responses on a chalkboard or flipchart.
Ask if the participants from other groups have any changes to add to the list. Help distinguish between physical and emotional changes. Point out any other changes that were not mentioned. Use Box 3: Physical Changes During Adolescence as a guide.

Explain:

$\int$ One of the biggest changes a girl experiences during adolescence is the start of menstruation.

\section{Ask:}

$\int$ What happens to girls in your community once they start menstruating? [they are seen as a woman, they stay inside during menstruation, they get married, etc.]

How do you feel about what happens to girls in your community once they start menstruating - is it good or bad, do you wish something different happened?

\section{BOX 3: PHYSICAL CHANGES DURING} ADOLESCENCE

\begin{tabular}{|l|l|}
\hline PHYSICAL CHANGES & PHYSICAL CHANGES \\
IN BOYS & IN GIRLS \\
\hline - Shoulders broaden & • Hips widen \\
- Facial hair & • Breasts develop \\
- Voice deepens & - Ovulation and \\
- Sperm production and & menstruation \\
- $\begin{array}{l}\text { ejaculation } \\
\text { - Wet dreams }\end{array}$ & \\
\hline
\end{tabular}

PHYSICAL \& EMOTIONAL CHANGES IN BOTH

- Grow in size

- Weight gain

- Pubic and underarm hair

- Genitals enlarge

- Acne

- Sexual feelings

- Changes in mood

- Feel embarrassed easily

- Feel closer to friends than family

- Feel shy

- Better able to reason and solve problems

- Rebel against parents, want to be independent

- Concerns about being normal

- Experimentation 


\title{
activity 2
}

\section{PUBERTY: IS IT NORMAL?}

\author{
(25 MINUTES)
}

Ask:

5 What does the word 'puberty' bring to mind? What other words do you think of when you hear the word 'puberty'?

Summarize responses to these questions.

\section{Remind participants:}

5 Puberty is a very exciting time in life filled with many positive feelings and changes. As we just discussed, these changes are both physical and emotional. Sometimes they can be challenging to deal with.

Share the following puberty messages with the participants:

- Puberty begins and ends at different ages for everyone. Participants go through puberty-

related changes (physical and emotional) at their body's own pace. This cannot be controlled and is biological (it is programmed in your body). This variation in change from person to person is normal.

- Girls often begin changes of puberty before boys. This difference in changing is also biological and is therefore normal.

- During puberty, the body produces increased hormones that cause physical changes in the body as well as changes in feelings and behavior. It is possible to feel very energetic and excited one moment and tired and upset or anxious the next. This emotional up and down is normal.

- During puberty, both girls and boys experience sexual desires. These feelings may involve physical changes, such as a rapid heart rate, a warm flush in the face and/or genitals when sexually excited. It is important to remember that these feelings of desire and/or night sexual excitement are normal and signs of a healthy body.

- A few ways to handle sexual excitement may include masturbation, fantasizing, physical activity such as football, or putting the mind on something else. Sexual excitement does not mean that one has to have sex. Nothing bad will happen if you do not have sex

- During puberty, boys' and girls' bodies change. Young people should be aware that as their bodies change, they may attract wanted and unwanted attention. The important to thing is to remember to feel good about yourself. Use strong communication skills to let someone know if the attention they are giving you makes you feel uncomfortable.

Show the group the Training Aids: Physical Changes in Females at Puberty and Physical Changes in Males at Puberty and briefly go over the illustrations of these changes.
Divide the participants into two groups (see "Appendix B: Participatory Facilitation Resources - Group Formation Activities" for ideas). Redistribute participants if groups are not of roughly equal size. Give each group two large pieces of blank paper.

\section{Explain:}

5 Now you will draw the body of a young male and the body of a young female, at the stage of life when they are going through puberty. Make sure to note the changes that the body is going through, and indicate those changes either within your drawings, or by adding words or symbols.

When participants have finished drawing, again, show the Training Aids: Physical Changes in Females at Puberty and Physical Changes in Males at Puberty.

\section{Ark:}

$\int$ Do your drawings look similar to the drawings on the charts?

Do you notice the differences in the four images?

Slowly read aloud the list of changes on the puberty handouts. 


\section{activity 3}

\section{MAKING PUBERTY EASIER}

(15 MINUTES)

Remind participants that while puberty is an exciting time of change, it can also be challenging.

\section{Ask:}

5 What are some things that could help one get through these changes? [social support from peers, talking to a mother, sister, aunt, or friend, get knowledge and information about bodily changes from health providers or books, keep busy to distract your mind, etc.]

What is one of the most embarrassing or challenging aspects of puberty for girls?

[e.g., soiling their pants/dress during menstruation, unwanted attention due to growing breasts, etc.]

What can your peers do to help minimize the embarrassment and make you feel more comfortable? [e.g., always carry extra menstrual hygiene items, bring extra clothes in case pants/dress is soiled, go shopping for bras or facial cleaners together, etc.]

What can you do to help each other?

\section{Wrap-up}

Ask participants to summarize what they have learned. Fill in any key points they miss.

Key Message: Boys and girls go through different physical and emotional changes during puberty - all of these changes are normal and represent a healthy body!

Ask for any final questions or comments. Remind participants where and when the next meeting will take place, and what topics will be discussed.

Thank them for their participation.

\section{PRACTICE ACTIVITY}

Instruct participants to talk to a friend about the body changes they are experiencing. 


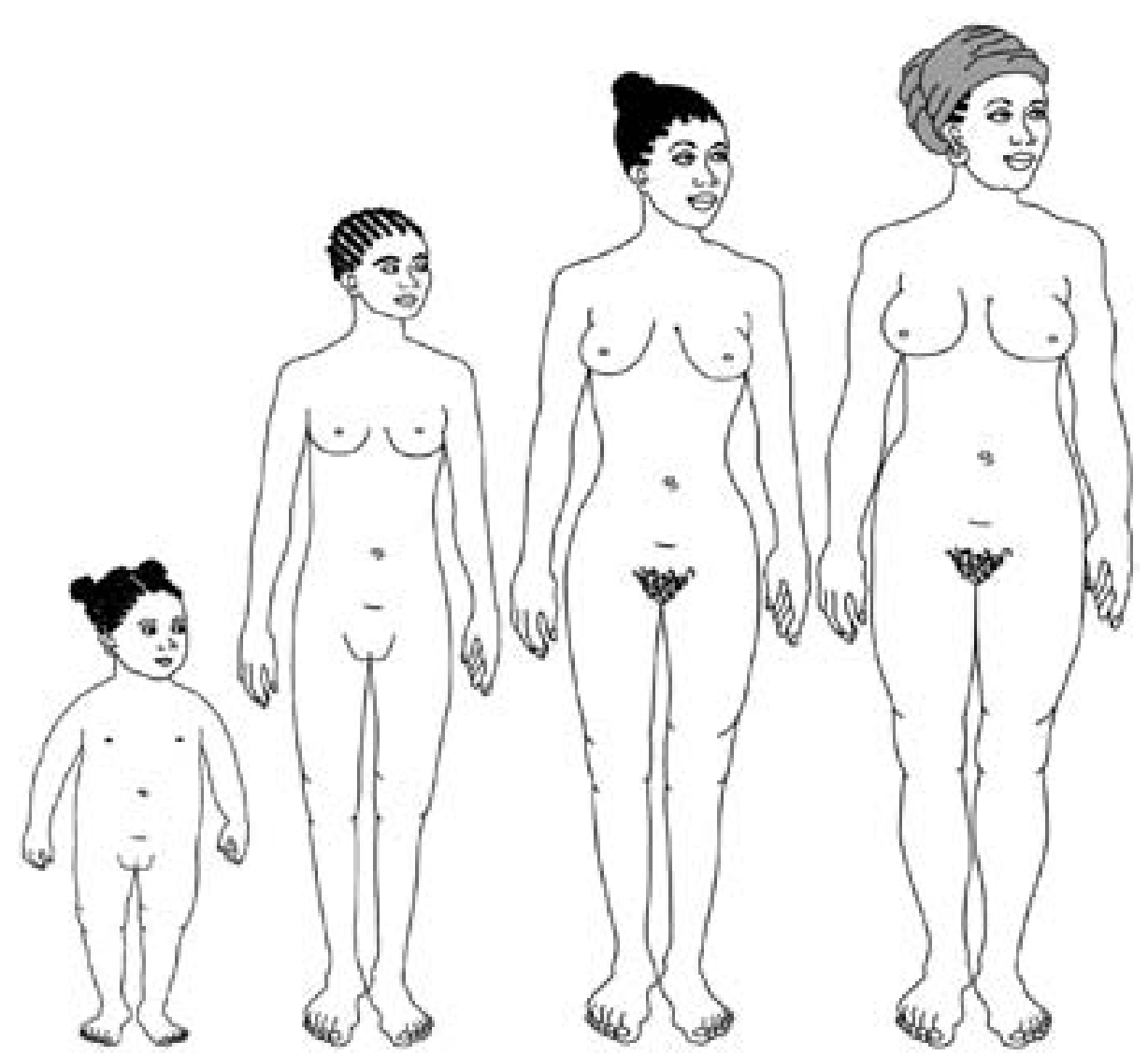

\section{PHYSICAL CHANGES IN FEMALES AT PUBERTY}

- Grows hair under arms and in pubic area

- Grows taller

- Gains weight

- Body becomes curvier

- Hips widen

- Breasts grow larger

- Starts menstrual period
- Skin becomes oilier and pimples may occur

- Increased perspiration/body odor

- On-set of sexual desire

- Emotional ups and downs

- Anxiety

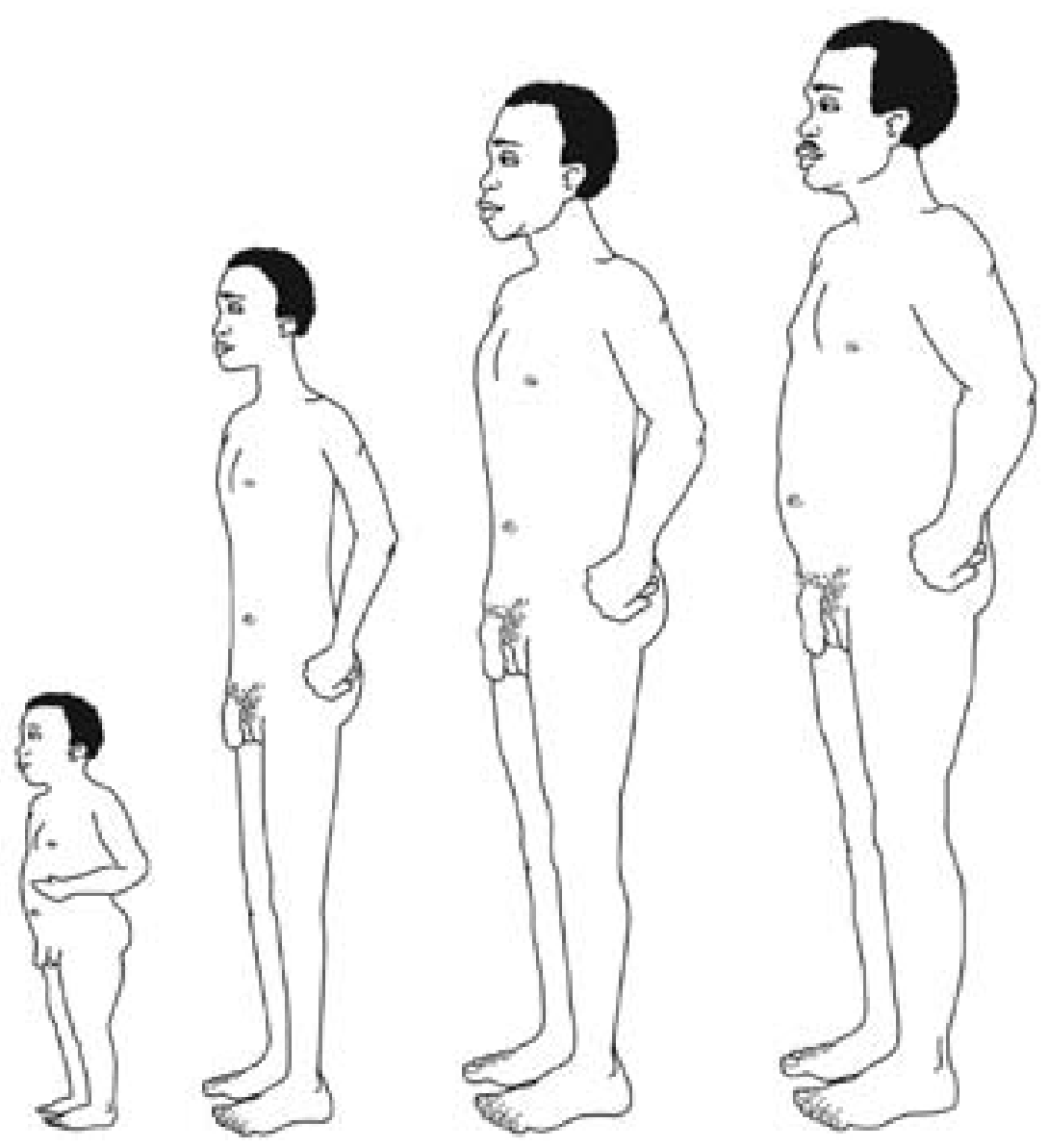

\section{PHYSICAL CHANGES IN MALES AT PUBERTY}

- Grows hair under arms, in pubic area, on face and chest

- Grows taller

- Gains weight

- Becomes more muscular

- Voice deepens

- Skin becomes oilier and pimples may occur
- Increased perspiration/body odor - Ejaculation happens/wet dreams occur

- Nipple development

- On-set of sexual desire

- Emotional ups and downs

- Anxiety 
3)

\begin{tabular}{|l|}
\hline SESSION \\
DESCRIPTION: \\
(REPRODUCTIVE \\
HEALTH) \\
Participants learn \\
the parts of the \\
reproductive system, \\
how menstruation and \\
pregnancy happen, \\
and about menstrual \\
hygiene.
\end{tabular}

\section{How Does Pregnancy Happen, Anyway?*}

\begin{tabular}{|l|l|}
\hline OBJECTIVES & $\begin{array}{l}\text { TIME } \\
\text { By the end of this } \\
\text { be able to: }\end{array}$ \\
- Describe the menstrual \\
cycle
\end{tabular} \mid $\begin{aligned} & \text { - Icebreaker (10 minutes) } \\
& \text { - Review (5 minutes) } \\
& \text { conception occurs } \\
& \text { System (25 minutes) } \\
& \text { - The Male Reproductive System } \\
& \text { (20 minutes) } \\
& \text { - One New Thing About Our } \\
& \text { Bodies (15 minutes) } \\
& \text { - Wrap-up (5 minutes) } \\
& \text { - Practice Activity (5 minutes) }\end{aligned}$

\section{v \\ PRE-SESSION PREPARATION}

- Read through the entire session and, if necessary, practice presenting the activities

- Prepare all materials needed for the session

- If desired and possible, ask an outside expert to help facilitate this session

- Be familiar with local resources that can help participants learn more about pregnancy (perhaps written material, or a clinic/ community health center) 


\section{FACILITATOR NOTES}

Depending on the availability of reproductive health experts in the community, you may ask an outside expert to facilitate this session. However, make sure the expert is indeed a content expert AND at ease working with young people.

\section{Male Reproductive System}

Under the penis there is a small bag of skin containing the testes. There are two of them and they produce sperm and testosterone. Testosterone is the male sex hormone and it makes pubic hair grow and boys' voices become deeper. Semen is the fluid that carries the sperm. Sperm makes babies when it joins up with women's eggs. Most of the time sperm is inside the body. There is only one exit for the sperm, which is through the hole at the end of the penis, called the urethra. When the penis is soft, that hole is used to urinate; when it is erect, it is used to release semen.

An erection occurs when the penis fills with blood and becomes hard and straight because a boy or man is sexually excited. Boys do not have any control over when this will happen, and it is normal for it to occur while a boy is sleeping. Having erections is not a sign that a boy needs to have sex. Ejaculation is when semen comes out of an erect penis due to sexual excitement. A man does not have to ejaculate every time he has an erection. If he waits, the erection will go down without causing any harm. Boys are not born with sperm; they begin to produce them during puberty and continue to produce them through his entire life. If the sperm is ejaculated into the woman's vagina, she may become pregnant. The semen can also carry diseases that could infect another person.

\section{Female Reproductive System}

The female external genital organs are called the vulva. It includes the two folds of skin called the labia, the clitoris, and the vagina. The external genitalia, or the labia, has two sets of rounded folds of skin called the outer and inner lips. Near the top of the lips, inside the folds, is a small cylindrical body called the clitoris. The clitoris has no other function than to help a woman have sexual pleasure. The vagina is where a man puts his penis during sexual intercourse. Also, menstrual blood and babies come out of the vagina. The vagina is an incredibly elastic muscle that can stretch wide enough to allow a baby to pass through.

Every female is born with thousands of eggs in her ovaries. Once a girl reaches puberty, a tiny egg matures in one of her ovaries and then travels down a fallopian tube on its way to the uterus. This release of the egg from the ovary is called ovulation. The uterus prepares for the egg's arrival by developing a thick and soft lining like a pillow. If the girl has had sex in the last few days before or the day after ovulation, by the time the egg arrives in the fallopian tube, there might be some sperm waiting to unite with the egg. If the arriving egg is united with the sperm (called fertilization) the fertilized egg travels to the uterus and attaches to the lining of the uterus (called implantation) and a pregnancy begins. If the egg is not fertilized, there is no pregnancy and the uterus does not need the thick lining it has made to protect the egg. It discards the lining, along with some blood, body fluids, and the unfertilized egg. All of this flows through the cervix and then out of the vagina. This flow of blood is called the "period" or menstruation. The blood and tissue usually leave the body slowly over three to seven days.

Be familiar with the training aids for this session "The Male Reproductive System," "The Female Reproductive System," "Reproductive System Cards," "The Process of Menstruation," and "How Pregnancy Happens"). Also see "Appendix A: Additional Topical Information Reproduction and Pregnancy" for more information.

Be prepared to share resources with participants about how they can learn more about pregnancy, perhaps written material, or a clinic/community health center.

Be prepared to discuss how girls can take care of themselves during menstruation. You should know what women in the area use during menstruation; this includes what sanitary supplies are available locally.

Bring in examples to show. For example, in some places tampons may be available, while in other places they may use cotton wool, cloth or pads.

There are aspects of this session that should be checked for cultural acceptability. Be familiar with local cultural norms and adjust sessions accordingly. 


\section{TERMS}

\section{Bladder}

The sac where urine is collected

before excretion

\section{Cervix}

The neck-like passage from the

uterus to the vagina

\section{Clitoris}

A sensitive area near the top of the opening of the vagina that helps a woman have sexual pleasure

\section{Ejaculation}

Release of semen from the penis

during orgasm

\section{Erection}

The stiffened and swollen state of erectile tissue, especially that of the penis, usually as a result of sexual arousal

\section{Fallopian Tubes}

Tubes which connect a woman's

ovaries to her uterus

\section{Fertilization}

The fusion of a male sperm cell and a female egg; necessary before an egg can begin to grow into an embryo

\section{Implantation}

An event that occurs early in human pregnancy when a fertilized egg adheres to the uterus wall

\section{Labia}

The two folds of skin, or lips, at the opening of the vagina

\section{Menstrual Cycle}

The period of time beginning on the first day of a woman's period until the day before she begins her next period

\section{Menstrual Hygiene}

Taking care of oneself in a clean, safe and healthy way during menstruation

\section{Menstruation}

When blood leaves a woman's body through the vagina, because the egg that was released into her uterus was not fertilized; signifies that a woman or girl can become pregnant if she has sexual intercourse; occurs around once a month for most women, and is commonly called the "monthly period"; usually lasts between three and seven days

\section{Ovulation}

The periodic release of a mature egg from the ovary, which usually happens around the middle of a woman's menstrual cycle

\section{Ovaries}

A pair of organs that contain a female's eggs or ova

\section{Ovum}

The mature female reproductive cell, which can produce an embryo after fertilization by sperm

\section{Penis}

The male sex organ. It provides passage for both urine and semen; places sperm in the woman's vagina during sexual intercourse

\section{Scrotum}

The pouch of skin containing the testicles

\section{Sperm}

Male reproductive cells, which fuse with eggs during fertilization

\section{Testicles}

These are two egg-shaped organs in front of and between a man's thighs; each testicle produces and stores sperm, which can fertilize a woman's egg during sexual intercourse

\section{Urethra}

The duct which conveys urine (in males and females) and sperm (in males) outside the body

\section{Uterus}

Where a fertilized egg grows and develops when a woman becomes pregnant; also called the womb

\section{Vagina}

Female sex organs with the functions of sexual intercourse and childbirth

\section{Vas Deferens}

The duct that conveys sperm from the testicles to the urethra

\section{Vulva}

External female genital organs

\section{ICEBREAKER}

Open the session with the 'Charades' icebreaker:

Divide the group into two teams (see "Appendix B: Participatory Facilitation Resources Group Formation Activities" for ideas). Distribute the same number of slips of paper to each team. Have participants think of phrases or concepts related to pregnancy or have already learned and write them on the slips of paper. Choose a neutral timekeeper/scorekeeper, or have the teams take turns.

\section{Explain}

๑ A player from one team chooses a slip from the other team's basket. Without speaking, the player must use gestures and actions to help his/her team members guess what is written on the slip, within three minutes. A team gets one point for each correct guess. If no one can from their team can guess in threeminutes, then their team does not get a point. Then it is the turn of a player from the other team to do the same with a new slip of paper.

\section{REVIEW}

Ask participants what key points were covered in the last session (optional: throw a ball of paper around to encourage participation). Fill in any key points that are missed.

Go over any practice activities that were given, and ask if there are any questions. 


\section{activity 1}

\section{THE FEMALE REPRODUCTIVE SYSTEM}

(25 MINUTES)

Show the Training Aid: The Female Reproductive System. Sort through the Training Aid: Reproductive System Cards for the female reproductive system labels. Choose cards with female reproductive system labels and distribute them to participants.

\section{Explain:}

$\bigcirc$ Now I will call on the participants with cards and ask them to read the card out loud (if the participant cannot read, you should help) and say the name of the female reproductive system part in the local language. Then come to the Training Aid: Female Reproductive System and match the card with its location.

Ensure that all of the cards are matched correctly with their location on the chart. Then explain in more detail the various parts, pointing to them on the Training Aid: Female Reproductive System, as you go along. The parts should include:

\section{External Organs}

- The vagina is the opening to the uterus (womb)

- Menstrual blood and babies come out of the vagina.

- During sexual intercourse, a man puts his penis into the vagina.

- The vulva refers to the external organs. These include:

- Two folds of skin, or "lips" are called the labia

- Near the top of the lips, inside the folds, is the clitoris. The clitoris is very sensitive and is to help a woman have sexual pleasure.

\section{Internal Organs}

- Each female egg is called an ovum. Every female is born with thousands of eggs, which are so small that they cannot be seen by the naked eye.

- The eggs are produced in the ovaries.

- The fallopian tubes connect the ovaries to the uterus (womb)

- The uterus is the womb where babies grow.

- The cervix is a neck-like passage connecting the uterus to the vagina.

\section{Explain:}

$\int$ As we have discussed previously, during puberty, females start menstruation. This means they are physically capable of becoming pregnant. But being physically able to get pregnant does not mean that they are physically, emotionally or financially ready to do so.

Show the Training Aid: The Process of Menstruation and explain the following:

1 Menstruation happens for most women about once a month, and that is why it is commonly called the "monthly period." It usually lasts between three and seven days. It is a sign that a girl or woman can become pregnant if she has sexual intercourse.

\section{Ask:}

Why does menstruation happen?

[Every month the ovaries release an egg that waits in the fallopian tubes between 5-7 days to see if it will be fertilized with sperm. If the egg does not meet sperm, the lining of the womb is shed and comes out as blood through the woman's vagina. This is the monthly period or menstruation.]

\section{Explain:}

Some girls may begin to menstruate at age nine or ten; others may not get their first period until a few years later. A woman knows that she has started her period when a little blood comes out of her vagina. The blood comes out slowly, like a dribble. It is important to anticipate when each month she will start bleeding, so she can wear a sanitary pad or other protection to prevent clothing stains.

Some women have physical and/or emotional symptoms around the time of menstruation, including:

- Cramping, bloating, and sore breasts

- Food cravings

- Mood swings and irritability

- Headache and fatigue

(activity 1 continued on next page) 


\section{activity 1 (continued)}

\section{THE FEMALE REPRODUCTIVE SYSTEM}

While most girls menstruate monthly, some girls will be irregular. It may take the body a while to adjust to all the changes taking place. Her menstrual cycle will probably become more regular with time.

\section{Explain:}

$\int$ Now we are going to discuss menstrual hygiene - that is how to take care of yourself in a clean, safe, and healthy way during menstruation. l'm going to show you some examples of what is used to maintain menstrual hygiene during monthly periods.

Discuss the following methods and show examples if you have them:

Clean pieces of cloth: These are cut to fit in the panty area by sewing several layers of cotton cloth on top of each other. These must be clean. They must be washed thoroughly and hung in a private but sunny place to dry. They should not be shared.

Toilet tissue: Girls and women can use a thick, long wad of toilet tissue. Sometimes toilet tissue is too rough, and it can irritate the skin. It also may not be sufficient to absorb the quantity of blood.
Pads or sanitary napkins: These are designed to fit the panty area close to the body. They have strips of tape that keep them attached to the panties, and the panties help to hold the pads close to the opening of the vagina. Pads have a plastic lining to minimize the spill of blood. If a woman uses pads, she needs to throw them down a pit latrine, bury them, or burn them after use. They should not be left in the garbage pile or flushed down the toilet.

Tampons: These are small, compressed cotton objects, formed into solid, tube-like shapes, which are pushed up into the vagina during menstruation. The cotton softens as it absorbs the blood that comes into the vagina from the uterus. Attached to the tampon is a strong, soft cotton string, which hangs out of the vagina. Pulling this string removes the tampon. A girl must always wash her hands before and after inserting a tampon. Tampons need to be changed often; they can cause infection if left in. One should never leave a tampon in for more than eight hours.

\section{Explain:}

$\int$ Whatever a girl uses, she should change it frequently to avoid staining or odor. If a girl's panties or clothes get stained with blood, she can soak them in cool, mildly salty water. Hot water will cause the blood to set and remain as a permanent stain. 


\section{activity 2}

\section{THE MALE REPRODUCTIVE SYSTEM}

\author{
(20 MINUTES)
}

Show the Training Aid: The Male Reproductive System. Sort through the Training Aid: Reproductive System Cards for the male reproductive system labels. Choose cards with male reproductive system labels and distribute them to participants.

\section{Explain:}

Now I will call on the participants with cards and ask them to read the card out loud (if the participant cannot read, you should help) and say the name of the male reproductive system part in the local language. Then come to the Training Aid: Male Reproductive System and match the card with its location.

Ensure that all of the cards are matched correctly with their location on the chart. Then explain in more detail the various parts, pointing to them on the Training Aid: Male Reproductive System, as you go along. The parts should include:

\section{External Organs}

- The penis has the capacity to be limp or erect; it is very sensitive to stimulation.

- Part of the penis is covered by the foreskin in men who are not circumcised. The penis provides passage for both urine and semen.

- The penis places sperm in the woman's vagina during sexual intercourse.
- The testes are two egg-shaped organs in front of and between the thighs.

- Each testicle produces and stores sperm, which can fertilize a woman's egg to begin pregnancy, beginning at puberty.

- The testes are contained in a pouch of skin called the scrotum.

\section{Internal Organs}

- Sperm travel through the vas deferens duct to the testicles.

- From the testicles, sperm is excreted outside the body via the urethra.

- The urethra also serves as a passage for urine to exit the body, which has been stored in the bladder.

\section{Ask:}

5 Do you know how a female gets pregnant, or how babies are made?

[Fertilization takes place when a male sperm cell meets a female egg. After the male puts his penis in the female vagina and ejaculates, ejaculated sperm swim up through the cervix into the uterus to the fallopian tubes. If a mature egg is present, fertilization can take place. Sperm can fertilize an egg up to seven days after inter- course. If an egg is fertilized, it will move into the uterus (womb) where it will grow.]

Show the Training Aid: How Pregnancy Happens to help facilitate your explanation. 


\section{activity 3}

\section{ONE NEW THING ABOUT OUR BODIES}

(15 MINUTES)

Put participants into groups of two or three.

\section{Explain:}

$\bigcirc$ What is one new thing you learned today about menstruation or reproduction?

How may this new information improve

your health, now or in the future?

Invite participants to share their comments with the larger group.

\section{Whap-wa}

Thank the participants for discussing an often embarrassing but normal and necessary subject.

Ask participants to summarize what they have learned. Fill in any key points they miss.

Key Message: After going through puberty, women and girls begin menstruating and become capable of pregnancy.

Explain:

$\int$ Although pregnancy is normal and you may be physically capable of getting pregnant, it is important to have children by choice and not by chance. This topic will be discussed in the next session.

Ask for any final questions or comments. Remind participants where and when the next meeting will take place, and what topics will be discussed.

\section{PRACTICE ACTIVITY}

Instruct participants to explain to a friend how pregnancy happens. 


\section{THE FEMALE REPRODUCTIVE SYSTEM}

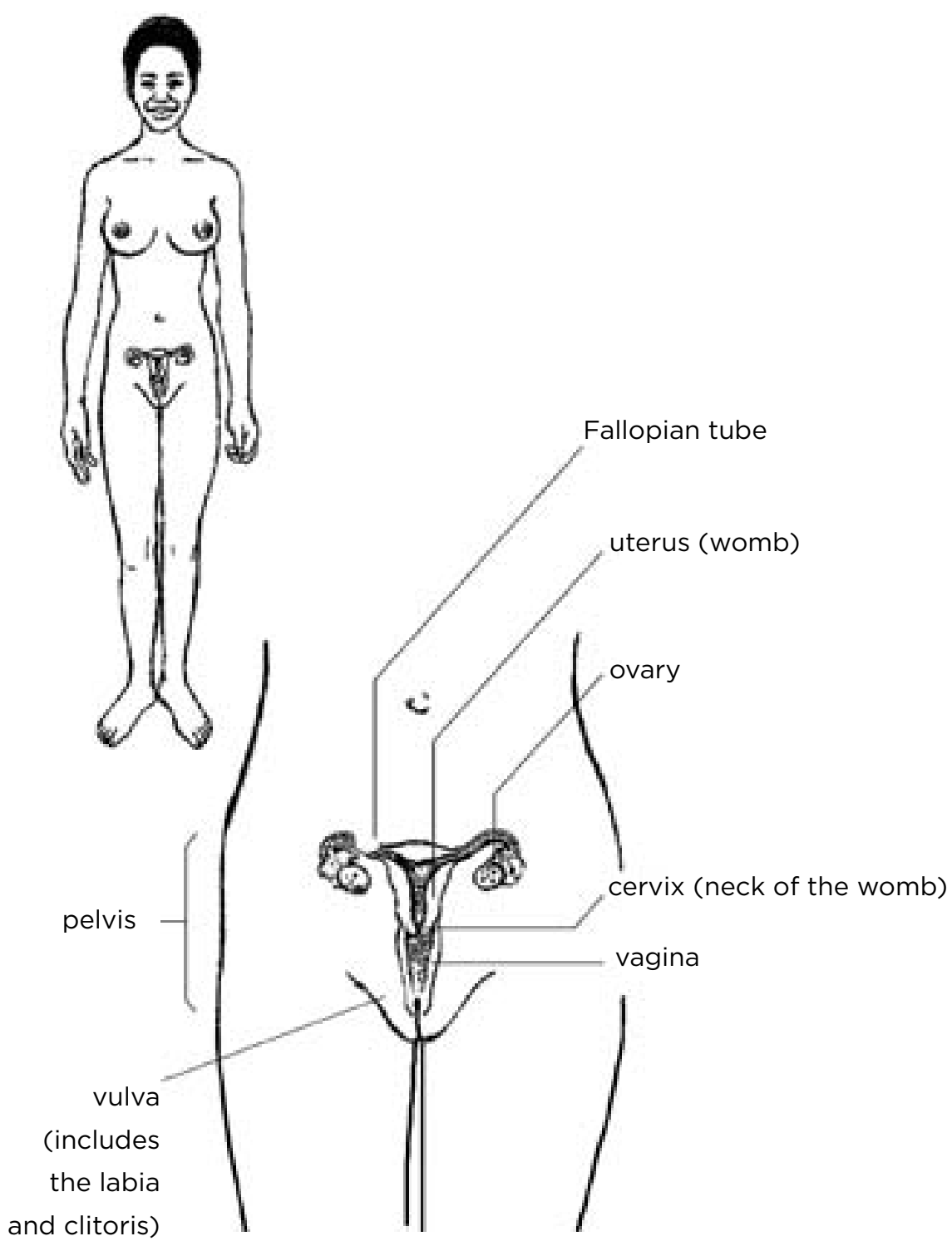

\section{THE MALE REPRODUCTIVE SYSTEM}

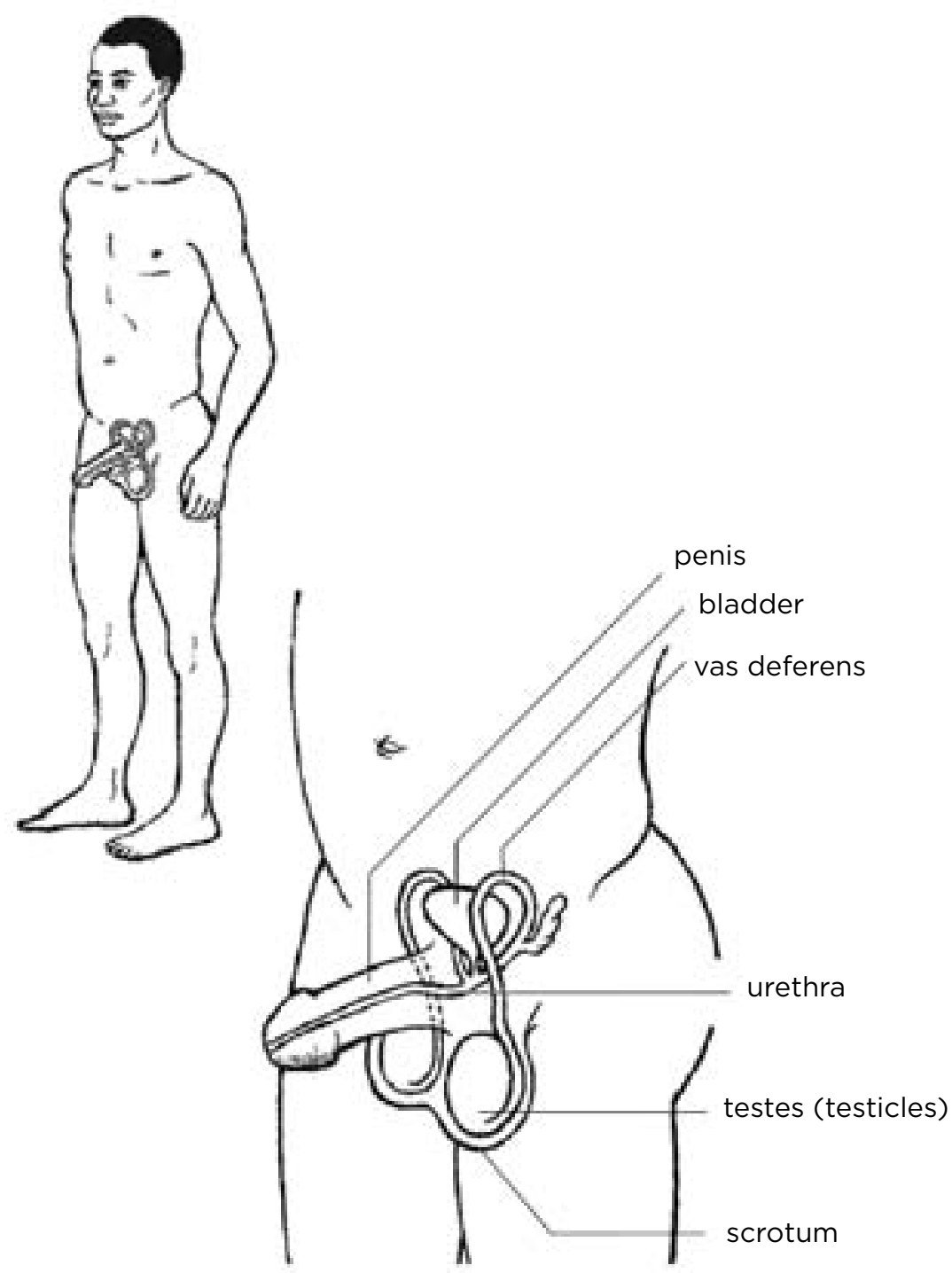




\section{THE PROCESS OF MENSTRUATION}

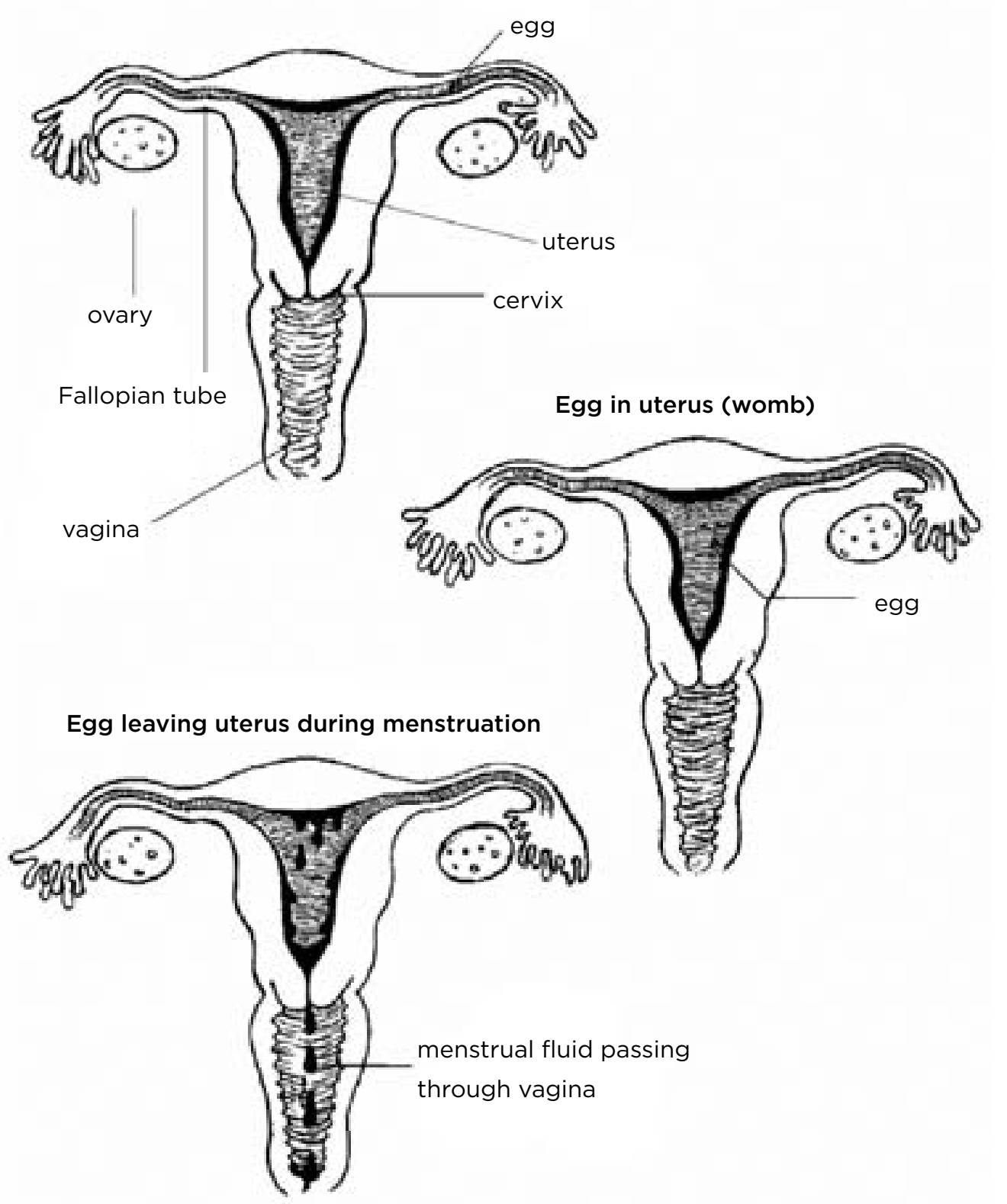

\section{HOW PREGNANCY HAPPENS}

Sperm meeting egg in fallopian tube

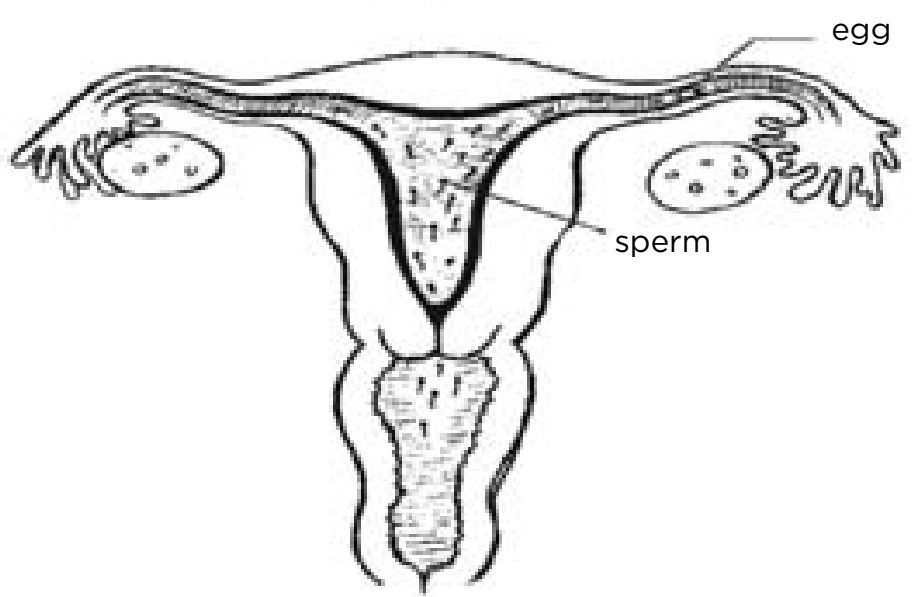

Fertilized egg implanted in the uterus

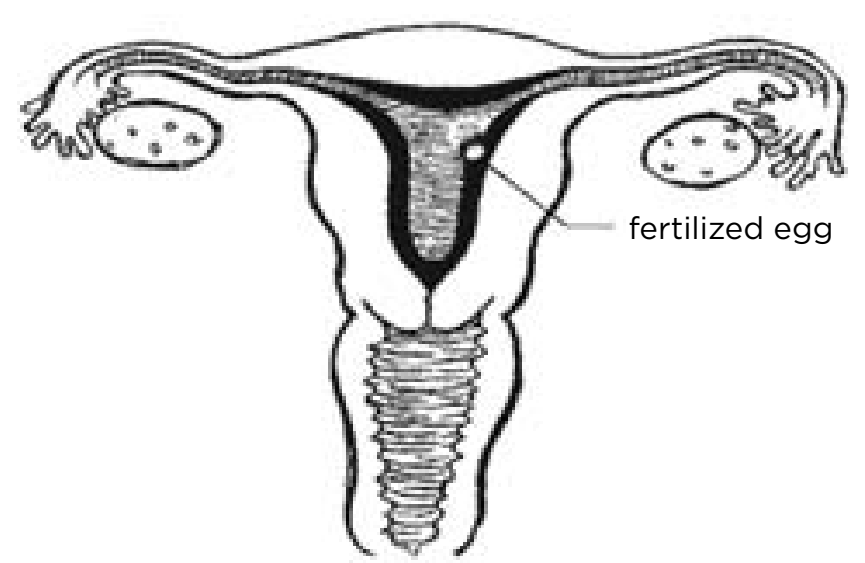


4)

\begin{tabular}{|l|}
\hline SESSION \\
DESCRIPTION: \\
(REPRODUCTIVE \\
HEALTH) \\
Participants will learn \\
about different types of \\
contraceptives, where \\
they can be obtained \\
and how they are used.
\end{tabular}

\section{Preventing Unintended Pregnancy (Contraceptives)*}

OBJECTIVES
By the end of this
session, participants will
be able to:
- Name at least two
advantages of using
contraceptives
- Identify where to go in
the community to get
contraceptives.
- Understand the
benefits and risks
of different types of
contraceptives

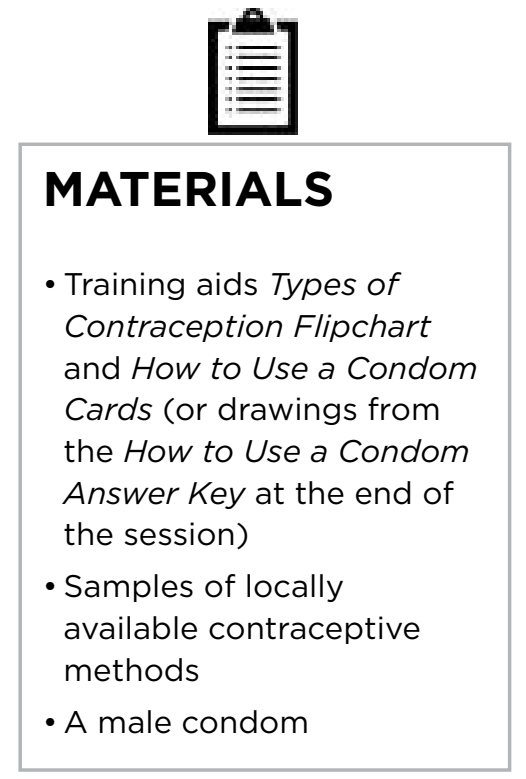

TIME

1 HOUR, 5 MINUTES

- Icebreaker (5 minutes)

- Review (5 minutes)

- I Know It's Good For Me, But.. (30 minutes)

- How to Use a Condom (15 minutes)

-Wrap-up (5 minutes)

- Practice Activity (5 minutes)

PRE-SESSION
- Read through the entire
session and, if necessary,
practice presenting the
activities
- Prepare all materials
needed for the session
- Identify where to go in
the community to get
contraceptives.
- If desired and/or possible,
invite a local expert to be
a guest speaker for this
activity, and ask them
to bring some examples
of different types of
contraceptives




\section{FACILITATOR NOTES}

There is no evidence to suggest that teaching this material causes young people to have sexual intercourse. In fact, studies from many countries show that good family life education classes actually postpone or delay sexual activity. Make it clear that since most people have sexual intercourse at some point, it is important to know about contraception.

You may want to invite a local midwife, nurse, peer outreach person or staff from an NGO working on family planning to come to talk about contraceptive methods and where participants can go to get contraceptives. This guest could lead Activity 1 of this session. Share the session plan, specifically for Activity 1 , with the guest so that she/he will know what is expected. Invite her/him to attend the whole session.

Always present abstinence as the most effective method of contraception for young people. You may want to encourage adolescents to delay sexual activity, but young people may already be sexually active when you begin presenting this material. Abstinence is the best and only certain way to prevent unwanted pregnancy and HIV infection. However, if young people have decided to have sexual intercourse and are sexually active, they should have information about how to use condoms correctly to reduce, but not eliminate the risk of HIV transmission. Using condoms correctly for every act of sexual intercourse can significantly reduce the risk of HIV transmission, STIs, and unwanted pregnancy.

Adolescents can safely use any contraceptive method. However, while all methods are medically safe for young people, some may be more appropriate than others. Contraceptives can help to prevent unwanted teenage pregnancies and to delay or space pregnancies. Contraception means preventing pregnancy. There are many different contraceptive methods. Most are reversible; that is, a woman is able to become pregnant after she has stopped using the method. Each contraceptive method has its advantages and disadvantages. Some provide temporary contraceptive protection while others are permanent. Some, such as the male and female condom, protect against sexually transmitted infections while others do not Some are for women and some for men. Effective- ness is closely linked to correct and consisten use of methods, particularly condoms, injectables, natural family planning, oral contraceptives, and withdrawal. Men can participate in family planning by sharing in decision-making about contraceptive use.

When teaching about contraception, it is important to guard against letting personal biases influence professional behavior. You can play an important role by providing them with factual information and supporting young people to make their own decisions and good choices for their future, based on their knowledge and reproductive goals. Keep your personal values regarding contraception out of the discussion. Provide factual information about all the different methods and continue to reinforce the concept that people who choose to have sexual intercourse should act responsibly and use contraception.

(NOTE TO FACILITATOR: Emergency Contraceptives are not specifically mentioned in this session, but any questions about them can be answered by referring to Appendix A: Additional Topical Information - Emergency Contraception.) 


\section{TERMS}

\section{Abstinence}

Refraining from sexual activity, the only 100 percent effective method for avoiding unwanted pregnancy and sexually transmitted infections, including HIV

\section{Condom}

A barrier device commonly used during sexual intercourse to protect against pregnancy, sexually transmitted diseases, and HIV transmission, infection, or (re)infection

\section{Contraceptives}

Methods for preventing pregnancy; also known as family planning HIV

Human immunodeficiency virus, the virus that causes AIDS and is transmitted through blood, semen, vaginal fluid and breast milk

\section{Sexually Transmitted Infections (STIs)}

Infections that are transmitted through sexual contact: anal, vaginal or oral

\section{Unintended pregnancy}

A pregnancy that is unwanted or mistimed

\section{ICEBREAKER}

Open the session with an icebreaker of your choice, or allow participants to suggest one. See Appendix B: Participatory Facilitation Resources - Icebreaker Activities for ideas.

\section{REVIEW}

- Ask participants what key points were covered in the last session (optional: throw a ball of paper around to encourage participation). Fill in any key points that are missed.

Go over any practice activities that were given, and ask if there are any questions. 


\section{activity 1}

\section{KNOW IT'S GOOD FOR ME, BUT..}

(30 MINUTES)

Introduce the guest speaker (or not, if a speaker is not available).

\section{Explain:}

Today's session will focus on the benefits of abstinence as well as show the different modern contraceptives, and explain the advantages and disadvantages of each. Feel free to ask questions during the presentation about the different methods.

\section{Ask:}

5 Which methods for preventing pregnancy do you know of?

After participants share the methods they know, go through the Training Aid: Types of Contraception Flipchart (a chart of the same is provided at the end of this session) to discuss the names, method and level of protection, and pros and cons for each method. Then break participants into five groups (see Appendix B: Participatory Facilitation Resources - Group Formation Activities for ideas) and instruct them to discuss the following question in their group:

- Which method do you think would be best when someone starts to have sex?

After the groups have brainstormed, ask a few participants from each group to present their ideas.
(NOTE TO FACILITATOR: Encourage participants to ask questions. If they are slow to ask questions about each method, either have them write their questions down on paper or you can think about the questions that are common to girls/women in the community and ask the questions for them.)

Tell participants where they can get each type of contraceptive in the community.

\section{Explain}

It is important to discuss family planning and contraceptive use with one's partner, especially if married. Like brushing our teeth, eating vegetables or doing homework, even though we know that something is good for us, sometimes we still don't do it. For example, we just heard many really good reasons for using contraceptives, but not everyone uses them.

\section{Ask:}

Why do some girls not practice abstinence? [e.g., forced sex, want to get pregnant, do not know how to tell 'no' to partner, want to have sex, do not foresee consequences, desire for sexual connection with partner, peer-pressure]
Why do some girls who are sexually active not use contraceptives?

[too expensive, stock-outs (lack of supply), preferred method not available, against beliefs, fear of side effects, disapproval from partner, tried and did not like, believe they are too young or too old to need it, heard discouraging stories from others, fear it is unsafe, health provider discourages, cannot access a health provider to get information/ prescription, etc.]

Why do some boys not practice abstinence? [see reasons as girls]

What are the reasons why some boys who are sexually active do not use contraceptives?

[see reasons for girls, more focus on how contraceptives fall in the realm of females]

What could be done to help boys or girls to use contraception in the future?

[increase access to providers and chemists, decrease cost, ensure supplies of many different methods to choose from, encourage male involvement in contraceptive choice, clear myths surrounding contraceptives, etc.] 


\section{activity 2}

\section{HOW TO USE A CONDOM}

(15 MINUTES)

Use the Training Aid: How to Use a Condom Cards (or draw the visuals from the How to Use a Condom Answer Key below), each card of which illustrates one of the eight steps on how to use a condom including:

1. check expirations date;

2. open package;

3. squeeze tip of condom;

4. roll condom down;

5. have sex;

6. withdraw penis from vagina:

7. remove condom; and

8. tie condom closed and dispose of properly.

Ask for eight volunteers and give them each one card. Then,

\section{Instruct:}

$\int$ The eight participants will stand at the front of the room and put themselves in the correct order for the procedure of using a condom.

Now we need another volunteer to come and check if the procedure is in the correct order. If the order is not correct, the volunteer will ask the girls with the cards to move around until they are in the correct order.

Once the girls are standing in the correct order (double check with How to Use a Condom Answer Key), walk the group through each step, demonstrating each step with a male condom inhand. If possible, ask a volunteer to demonstrate each step.

\section{HOW TO USE A CONDOM ANSWER KEY}

STEP 1: Inspect the condom by checking the expiration date. Do not use if there are any tears or it is past the expiration date.

STEP 2: Carefully open the condom package by pushing the condom to one side. Do not use your teeth or fingernails to open the package.

STEP 3: Squeeze the tip of the condom.

STEP 4: As soon as the penis is hard, place the condom on the tip of the erect penis. While holding onto the tip, unroll the condom down the shaft of the penis all the way to the base. Either the male or the female can do this step.

STEP 5: Holding the condom at the base, the man enters the woman's vagina to have sex.

STEP 6: After sex (immediately after ejaculation), hold the condom at the base of the penis and withdraw from the vagina while the penis is still erect.

STEP 7: Carefully remove the condom.

STEP 8: Tie a knot on the condom to prevent spilling and carefully dispose of the condom.

\section{REMEMBER:}

- It is important to talk to your partner about using a condom before sex.

- Do not use cooking or vegetable oil, baby oil, hand lotion or petroleum jelly for lubrication. These will cause the condom to deteriorate. If a condom breaks, immediate withdrawal is recommended. A new condom can then be used.

- Do not reuse the condom. Use a new condom for each act of sexual intercourse.

- Condoms should never be used more than once.

- Lubricated condoms (for vaginal or anal sex) must be put on before any genital contact.

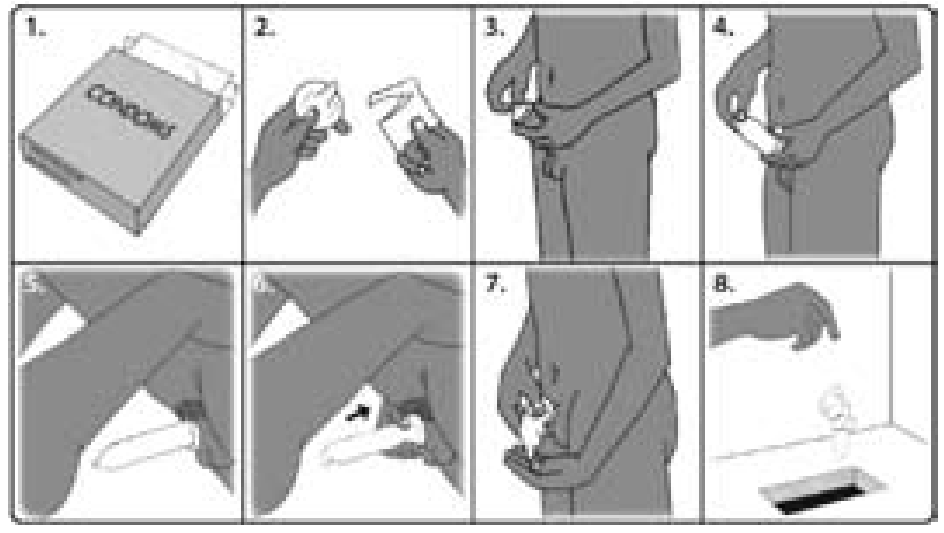

\section{Wrap-up}

Thank the participants for discussing an often embarrassing but normal and necessary subject.

Ask participants to summarize what they have learned. Fill in any key points they miss.

Key Message: Abstinence is the best way to prevent pregnancy. Contraceptives also prevent pregnancy, and condoms can prevent against unintended pregnancy as well as HIV and other sexually transmitted diseases.

\section{Explain:}

$\int$ Although pregnancy is normal, having children by choice, not by chance, is best for the mother, the baby, the family and the nation. Abstinence is the only foolproof way to prevent against unwanted pregnancy and unwanted sexually transmitted diseases.

Remind participants of places in the community where they can access contraceptives and other family planning counseling.

Ask for any final questions or comments. Remind participants where and when the next meeting will take place, and what topics will be discussed.

\section{PRACTICE ACTIVITY}

Participants should ask a friend what contraceptive methods they have used, which one they liked best, and why. 


\section{TYPES OF CONTRACEPTIVES*}

\section{$\begin{array}{ll}\text { METHOD } & \text { Protection against } \\ \text { What it is and how it works } & \text { STIs/HIV? }\end{array}$}

STIs/HIV?

\section{Other characteristics}

\section{BARRIER METHODS (TEMPORARY “USER-CONTROLLED” METHODS THAT BLOCK THE SPERM FROM REACHING THE EGG)}

\section{Male condom}

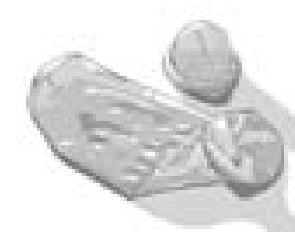

A thin latex sheath rolled onto the erect penis before intercourse that prevents sperm from entering the vagina.
Yes

- It is one of the two methods that offer double protection, against pregnancy and infection, thus may also protect against infertility and cervical cancer

- It enables men and boys to protect themselves and their partners. - It is easily available.

- It must be put on during sexual activity prior to intercourse.

- Some people find that it reduces sensation.

- It may break or leak, especially if used incorrectly.

\section{Female condom}

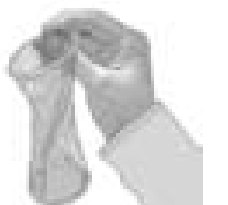

A lubricated plastic sheath with two rings. One remains outside the vagina, covering part of the labia, and the other is placed in the vagina, covering the cervix. It forms a pouch that collects the semen.
Yes

- It can be inserted hours before sexual activity begins.

- It enables women and girls to protect themselves and their partners.

- It is noticeable during sex, and insertion may require practice.

- It is expensive in comparison with the male condom.

\section{PERMANENT SURGICAL METHODS}

\section{Vasectomy, male sterilization \\ A simple, outpatient operation in which the vas deferens is cut and tied. Sperm then are harm- lessly reabsorbed into the man's body, rather \\ than entering the semen. It does not change a man's ability to have sex, feel sexual pleasure, or ejaculate.}

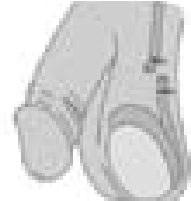

\section{Female sterilization,} tubal sterilization

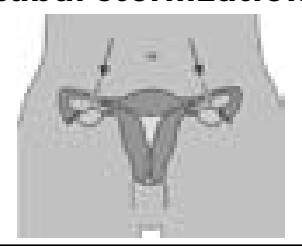

No

A surgical procedure to cut and tie (tubal ligation), or block, the fallopian tubes, preventing the sperm and egg from meeting. It does not change a woman's ability to have sex or to feel sexual pleasure.
- Vasectomy is not effective until three months after the surgery. - This is a permanent method.

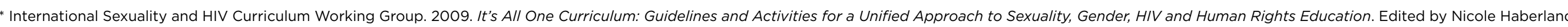
and Deborah Rogow. 


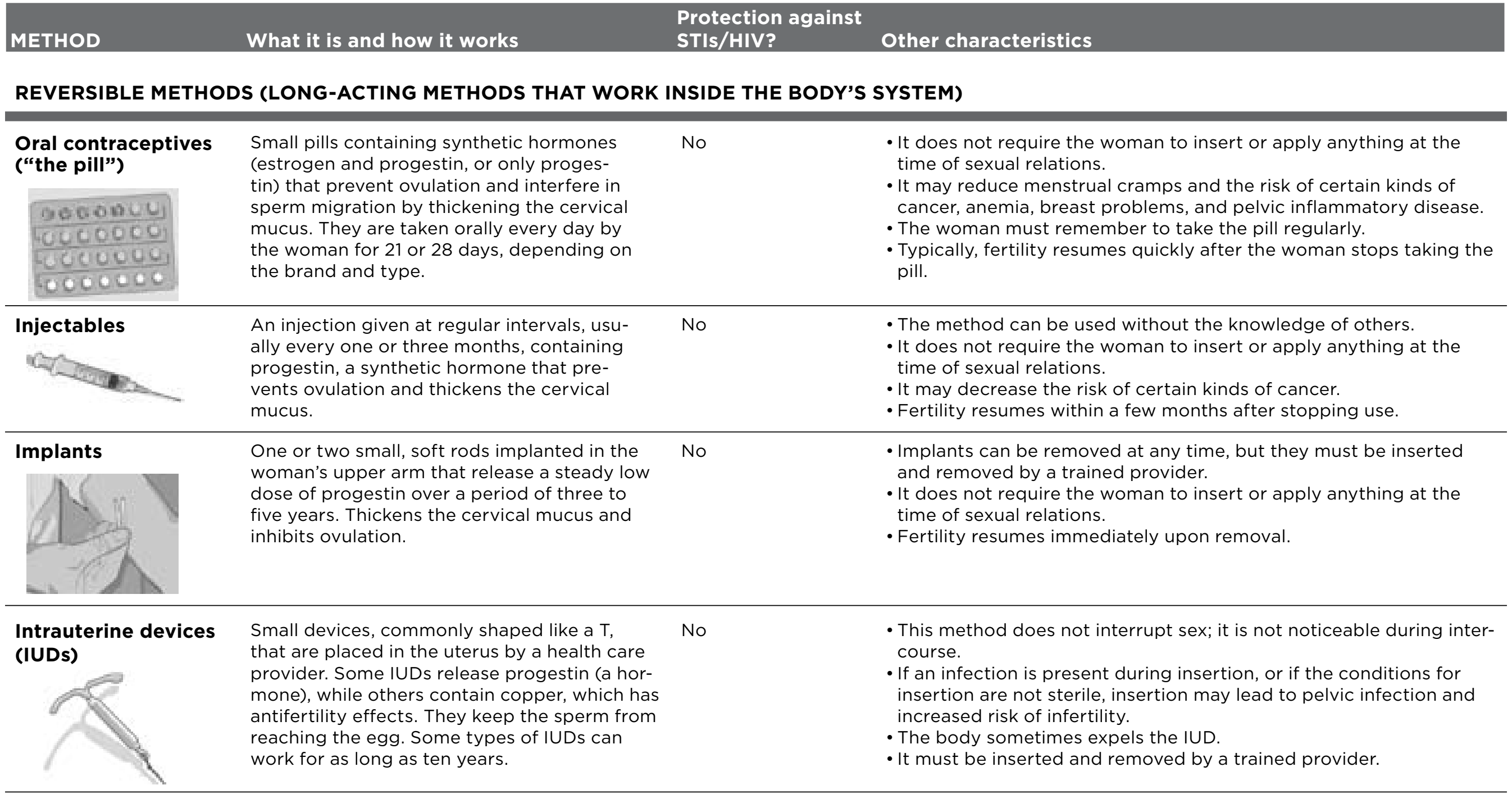




\begin{tabular}{|c|c|c|c|}
\hline METHOD & What it is and how it works & $\begin{array}{l}\text { Protection against } \\
\text { STIs/HIV? }\end{array}$ & Other characteristics \\
\hline
\end{tabular}

\section{“NATURAL”/TRADITIONAL METHODS (METHODS THAT REQUIRE SPECIFIC BEHAVIORS AND AN UNDERSTANDING OF ONE'S BODY)}

\section{Lactational amenorrhea method

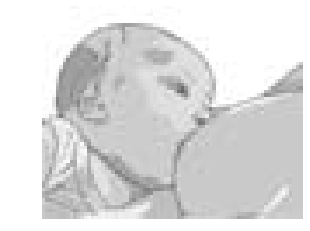 \\ For breastfeeding women only. Breastfeeding causes the body to produce hormones that can prevent ovulation. As contraception, this meth- od is effective only during the first six months of breastfeeding or until the woman has resumed menstruation (whichever comes first), and only if the baby is fed only breastmilk and on de- mand.}

\section{Withdrawal}

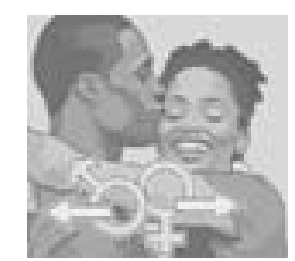

\section{No}

Pulling the penis out of the vagina and away before ejaculating prevents sperm from entering the vagina. This method can be effective if used correctly and consistently.

\section{No}

- Breastfeeding is free and has positive health effects for the mother and the baby.

- The lactational amenorrhea method (LAM) may be difficult for women who need to be away from their baby regularly.
Calendar or
Many women have menstrual cycles that are
CycleBeads methods
fairly predictable in terms of how often a new cycle starts. CycleBeads (used for the Standard Days Method) and the calendar are two meth- ods that a woman can use to identify the fertile days during which she can abstain from sex or
use a barrier method of contraception.

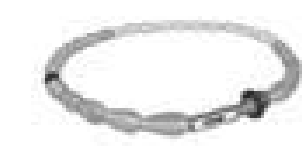

- This method is most practical for women with regular cycles.

- Withdrawal is always available and free.

- It is considerably more effective than not withdrawing.

- It depends on the man's self-control and ability to predict

ejaculation; women have no control with this method.

- It interrupts sex and may lessen pleasure. 


\section{5) Reproductive Myths*}

\begin{tabular}{|l|}
\multicolumn{1}{c|}{} \\
\hline SESSION \\
DESCRIPTION: \\
(REPRODUCTIVE \\
HEALTH) \\
Participants discuss \\
myths about \\
reproduction, and learn \\
that some myths can \\
be harmful.
\end{tabular}

\begin{tabular}{|l|}
\hline OBJECTIVES \\
By the end of this \\
session, participants will \\
be able to: \\
- Differentiate between \\
reproductive system \\
facts and myths \\
- Apply knowledge \\
of the reproductive \\
system to dispel myths \\
\hline
\end{tabular}

1 HOUR, 30 MINUTES
- Icebreaker (10 minutes)
- Review (5 minutes)
- Reproduction Myths (45
minutes)
- Large Group Game (20
minutes)
- Wrap-up (5 minutes)
- Practice Activity (5 minutes)

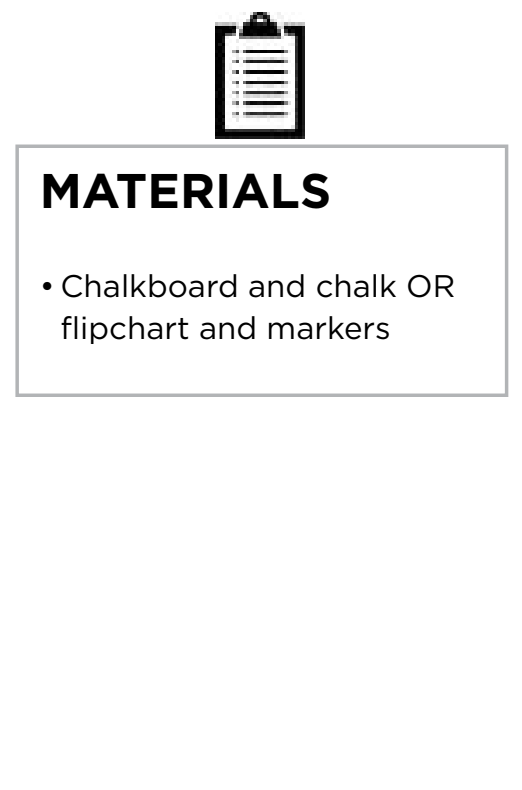

\begin{tabular}{|l|}
\hline PRE-SESSION \\
PREPARATION \\
- Read through the entire \\
session and, if necessary, \\
practice presenting the \\
activities \\
- Prepare all materials \\
needed for the session \\
- Find out some common \\
local myths about \\
reproduction
\end{tabular}




\section{FACILITATOR NOTES}

A myth is a traditional story or collection of stories told among a group of people, that may be based on a truth or real story, but is not true. It often is based on the cultural ideals or commonly held beliefs or emotions in a community. Myths form part of the beliefs of a community or society. A fact is something that is true and has been proven with evidence.

Although most young people have some basic information about sex and reproduction, they often still firmly believe in many myths around reproduction. It is important to let participants talk about these tales they have grown up with in order to bring the myths out into the open so they can be dispelled and replaced with facts. Myths can range from the less harmful to the highly consequentia ones, like those concerning sexual health. Partial information, incorrect information, or culturally embedded myths can lead adolescents to make dangerous, wrong decisions for themselves. Long-held, culturally approved beliefs or myths that peers swear are true are often extremely difficult to change. But the misinformation must be cleared away and real facts provided, so that choices can be based on knowledge instead of ignorance.

\section{TERMS}

\section{Myth}

A belief that is told by a group of people, which may be based on truth, but is untrue

\section{Fact}

A truth, which can be backed up by evidence

\section{ICEBREAKER}

Open the session with the 'Telephone' icebreaker.

\section{Explain}

5 Everyone should line up such that you can whisper to your immediate neighbors, but not hear participants any further away. I'm going to whisper a phrase to the first participant in line, then that participant whispers it to her neighbor, and so on.

Come up with a phrase and whisper it to the first participant in line. Then this participant whispers it as quietly as possible to his or her neighbor. The neighbor then passes on the message to the next participant to the best of her ability. The passing continues in this fashion until it reaches the participant at the end of the line, who tells the group the message she received.

(NOTE TO FACILITATOR: The game has no winner-the entertainment comes from comparing the original and final messages. Intermediate messages may also be compared; some messages will become unrecognizable after only a few steps.)

\section{REVIEW}

(7) Ask participants what key points were covered in the last session (optional: throw a ball of paper around to encourage participation). Fill in any key points that are missed.

Go over any practice activities that were given, and ask if there are any questions. 


\section{activity 1}

\section{REPRODUCTION MYTHS}

(45 MINUTES)

Ask:

5 What are some things that you know are true? What are some things that you know are not true?

\section{Explain:}

A myth is a belief that is told by a group of people, which may be based on truth, but is untrue. Most young people have some basic information about sex and reproduction. Some of it is true and some of it may not be true. It is important to learn which information is myth and which is fact. This is because it can lead to dangerous uninformed choices if someone only has part of the information or the wrong information, especially about sexual and reproductive health issues.

"Facts" are what is known to be true; events that have actually occurred; and things that are real, actual, and can be proved. For example, if you throw a ball in the air, it will come down. "Myths" are ideas, sayings or beliefs that people create and are not or cannot be proven.

\section{Ask:}

What are some examples of facts?

[anything that is known to be true, e.g., if you throw something in the air it falls down, the sky is blue, we are girls, I am good in math, etc.]

What are some examples of myths?

[e.g., opinions, beliefs, fables, stories or fantasies that are not true]
Write their responses on the board

Ask:

5 How is the definition of "myths" different from the definition of "facts"?

[Myths are distorted or misunderstood facts.]

\section{Explain}

Usually, myths are a mixture of truths and untruths passed around verbally within a community, to explain an issue that people do not understand. For example, in some communities, people say that if a woman thatches a roof, she will go blind. (Adapt the example so that it is an appropriate and relevant myth in your community.)

Emphasize that while some myths are quite harmless, many of them can be dangerous because they are the opposite of known facts and acting on them can lead a person into trouble or negative consequences. For example, some people say that a pregnant woman should not eat eggs, while the fact is that eggs can provide needed protein to a pregnant woman's diet.

Ask:

5 What are some myths that you have heard about how the reproductive system works?

Collect the information without discussion. Once a list of myths has been collected, divide participants into groups of four (see Appendix B: Participatory Facilitation Resources - Group Formation Activities for ideas).
Assign several of the myths by reading them out participants have identified along with myths from the Activity Sheet 1: Reproduction Myths and Facts located at the end of this session, to each group.

\section{Explain:}

$\int$ Now use your knowledge to dispel each myth Things we have discussed in previous sessions may help you dispel the myths, so use your memories!

The younger group of girls may need help in applying the knowledge they gained from previous sessions to dispel these myths. The facilitator may need to interact with this group to probe participants and guide them down the appropriate explanatory pathway.

Ask a representative from each smaller group to reassemble into one large group. Allow others to ask questions or comment. End the activity by emphasizing the following points:

- There are many myths and misconceptions about reproduction, and acting on them can have negative consequences.

-When making decisions about reproduction, only consider the facts.

- If someone is not sure about the facts, they should ask a knowledgeable person, such as a counselor, doctor, or nurse, and not rely on friends who may not have accurate information. 


\section{activity 2}

\section{LARGE GROUP GAME}

(2O MINUTES)

\section{Explain:}

5 The group is going to play a game that will focus on signs of female and male fertility, specifically menstruation and wet dreams.

This game will help you to identify and correct myths around fertility.

Divide the group into two teams (see Appendix B: Participatory Facilitation Resources - Group Formation Activities for ideas), and place the two teams on opposite sides of the room.

\section{Explain:}

5 I am going to read a statement to the first member of one team. Then that member should consult with the rest of the team to determine whether the statement is a "myth" or "fact." Then the member who I asked the question reports the team's response. If the response is correct, that team gets one point Then I will ask for an explanation of why the statement is a "myth" or "fact."

Read one of the following "Myth or Fact?" statements (below) to the first member of Team A. Once the first player responds, say whether the answer is correct and mark the score on the flipchart or chalkboard. Award one point for each correct answer. If the answer was correct, ask the player to say why this is correct; i.e., explain why the statement is a myth or a fact. If the explanation was incorrect, provide the right response and briefly explain why. Continue the same procedure with Team B.

\section{Myth or Fact?}

- The blood coming from a woman during menstruation means that she is sick.

[MYTH - if an egg is not fertilized, the body dispels blood and tissue during a woman's monthly menstruation]

- Cold drinks do not cause menstrual cramps.

[FACT - menstrual cramps are caused by muscle spasms in the uterus during or between menstruation]

-Women should not eat spicy or sour foods during menstruation.

[MYTH - women can eat any food they want during menstruation]

- If a woman misses her period, this could mean she is pregnant.

[FACT - monthly periods signify that a woman's egg has not been fertilized; missing a monthly period may mean that the woman's egg has been fertilized, in other words, she is pregnant]
- If men do not ejaculate, sperm will collect and make their penis or testicles burst.

[MYTH - if men do not ejaculate, sperm are stored until they fatigue, at which point they break down and are reabsorbed by/recycled into the body in

the same way food or old blood cells are absorbed by the body]

- It is perfectly safe for a woman to wash her hair or take a bath during her period.

[FACT - there is no risk to a woman washing anything during her period]

- Having menstrual blood means a woman is dirty.

[MYTH - having menstrual blood is a healthy and normal occurrence in women signifying that her egg has not been fertilized]

-When a boy or a man has a wet dream, it means he needs to have sex.

[MYTH - men and boys have wet dreams as a result of erections, which occur during their sleep; these erections are normal, healthy, and do not indicate a need for sex]

-When a man has an erection, he must always ejaculate.

[MYTH - many times men have erections without ejaculating; if the man waits for some time, the erection will go away without ejaculation] 


\section{activity 2 (continued)}

\section{LARGE GROUP GAME}

- Most boys have wet dreams during puberty.

[FACT - having wet dreams during puberty is normal and healthy for all boys]

- If a penis is touched a lot, it will become permanently larger.

[MYTH - the size of a penis varies for each man or boy; penis growth is determined by genetics and other health related issues, such as diet;

no permanent growth in the size of a penis is associated with touch, though, a penis may appear to be larger after it is touched because it will form an erection, but an erection only a temporarily increases its size]

- If a person jumps over the legs of a pregnant woman the child will look like the jumper.

[MYTH - only an ultrasound can show an image of an infant before birth]

- If a person masturbates a lot, they will go blind. [MYTH - there are no long-term consequences associated with masturbation and the only shortterm consequences may be chaffing or soreness on the private parts]
After you have read each of the myths and facts,

\section{Explain:}

5 Now for the final round, each team must tell the group two things that they have heard about menstruation and wet dreams. If Team A tells first, Team B must tell if these things are a "myth" or a "fact" and why.

Give points for the final round. Add up the score and announce the winning team. wrap-up

Ask participants to summarize what they have learned. Fill in any key points they miss.

Key Message: Be careful to have the right information about reproductive health issues to make smart and informed decisions!

Ask for any final questions or comments. Remind participants where and when the next meeting will take place, and what topics will be discussed.

\section{PRACTICE ACTIVITY}

Have participants collect reproductive health myths from among their family and friends. 


\section{ACTVTr S SHEET1 \\ REPRODUCTION MYTHS AND FACTS}

MYTH: One cannot get pregnant with one sexual act.

FACT: One runs the risk of pregnancy each and every time one has unprotected sex.

MYTH: One cannot get pregnant when one has sex for the first time.

FACT: One can get pregnant the first time one has sex.

MYTH: Use two condoms for double protection.

FACT: Using two condoms does not provide extra protection, and may in fact increase the chance that one or both condoms will break.

MYTH: The safest time to have sex is between periods.

FACT: For women with menstrual cycles between 26 to 32 days, the fertile time is from 8th to 19th day or halfway between periods. This is the least safe time to have sexual intercourse. However, for adolescents menstruation can be very irregular, so if a girl is going to have sex, it is safer to use a condom or other method of contraception.

MYTH: Boys touching a girl's breasts will make them grow bigger.

FACT: Boys touching a girl's breasts will not affect their size.

MYTH: Contraceptives are only for married people.

FACT: Contraceptives can be used by anyone.

MYTH: A girl needs her parent's permission to find out about contraceptive use and reproductive health.

FACT: Knowledge about contraceptives can safeguard one against consequences of unprotected sex like unplanned pregnancies and STIs. Knowledge of reproductive health makes one fully aware of one's body, its functions and its care. So, it is not necessary to seek parent's permission for it. Adolescent reproductive health and development policy in Zambia gives young people the right to access information and services.

MYTH: Ejaculating during the night ("wet dreams") is harmful to the health of boys. FACT: Ejaculating while sleeping is normal and natural for boys during adolescence and is not harmful.

MYTH: A woman becomes "dirty" or "untouchable" during menstruation.

FACT: Menstruation is normal and occurs with all women. The blood that comes out is not dirty.
MYTH: One should not take a bath during menstruation.

FACT: Menstruation is natural and there is no restriction regarding having a bath. In fact, it is very important to keep the body clean during this time, to avoid infection of the reproductive tract.

MYTH: If the hymen is broken then the girl is not a virgin.

FACT: The hymen can break even without sexual intercourse, by certain physical activities like sports, exercise, and the use of tampons during menstruation. Sometimes the hymen may be loose or absent and there is no breaking of the hymen.

MYTH: The use of herbs can help a girl return her virginity.

FACT: A girl's virginity cannot be restored once she has had sexual intercourse. However, she can still decide to start practicing abstinence, even after losing her virginity.

MYTH: Contraceptive use is harmful for health

FACT: Using contraceptives is a method for improving the family's health and women's reproductive health.

MYTH: Contraceptive pills make women barren

FACT: The use of pills does not make a woman barren. Most women find that on discontinuing the pill, they become pregnant within three months.

MYTH: A girl can prevent pregnancy by washing her vagina with Coca Cola or Sprite immediately after sexual intercourse.

FACT: Washing the vagina with Coca Cola or Sprite after intercourse does not prevent pregnancy.

MYTH: Condoms have holes and are laced with viruses.

FACT: Condoms do not have holes and do not allow HIV to pass. HIV can only get through if the condom has been damaged or torn. The presence of microscopic pores in some condoms does not matter much, since HIV cannot move on its own and is often attached to white blood cells, which are much larger than the virus. Condoms have of two or three layers of latex, and pores would have to be lined up in order for the virus to pass through. Then, enough of the virus (more than 15,000) would have to pass through to cause infection. The authors of a study investigating leakage concluded that if a condom does not break, it provides 10,000 times more protection than no condom at all. 


\section{6) Sexual Desire'}

\begin{tabular}{|l|}
\multicolumn{1}{c|}{} \\
\hline SESSION \\
DESCRIPTION: \\
(REPRODUCTIVE \\
HEALTH) \\
Participants discuss \\
common myths about \\
sexual desire.
\end{tabular}

\begin{tabular}{|l|}
\hline OBJECTIVES \\
By the end of this \\
session, participants will \\
be able to: \\
- Understand sexual \\
desire \\
- Identify correct \\
information about \\
sexual desire \\
\hline
\end{tabular}

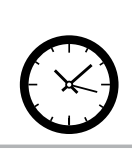

\section{TIME}

1 HOUR, 5 MINUTES

- Icebreaker (5 minutes)

- Review (5 minutes)

- Sexual Desire - What is the

Truth? (45 minutes)

-Wrap-up (5 minutes)

- Practice Activity (5 minutes)

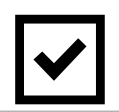

\section{MATERIALS}

None

PRE-SESSION PREPARATION

- Read through the entire session and, if necessary, practice presenting the activities

- Prepare all materials needed for the session 


\section{FACILITATOR NOTES}

There are many ways that people experience sexual desire - a longing for sexual expression or a feeling of sexual attraction. There is no one "normal" way to experience sexual desire. Virtually every person experiences sexual desire, sometimes of an intense nature. People may feel desire for another person (of the same sex, of the other sex, or both). Or they may feel generalized desire that is not necessarily attached to another person. Within an intimate relationship, one person may feel sexual desire more than the other. People's level of sexual desire may change over a short time or over the course of their lives. They may experience sexual desire until the end of their lives, although their physical response may change with age. People experience sexual desire in response to a wide range of stimuli. Personal preferences, life experiences, and cultural norms all influence these responses.

Various social, emotional, and physical factors shape people's desire to express themselves sexually. These factors often are interrelated. Some factors are related to the body, such as hormone levels, alcohol and certain drugs, fatigue, or illness. Some factors are related to emotions, such as feeling respected and understood in a relationship or having suffered an experience of sexual abuse. The social environment can also influence the expression of desire.

For example:

- A lack of privacy or feelings of nervousness and shyness can make it harder to express desire.

- Gender norms make some boys feel that they are supposed to want sex even when they do not. In contrast, females, young people, people with disabilities, and those attracted to the same sex may be taught that expressing their sexual desire is somehow wrong.

People often confuse sexual desire or attraction with other emotional or physical experiences. Sexual desire is not the same as love, although it is often confused with love. A person can experience sexual desire with or without love. For example, a person may feel sexual desire for someone whom he or she barely knows. Sexual desire is not the same as a physical sexual response. For example, a boy or man may have an erection without feeling desire. Or he may experience desire without having an erection. Sexual desire is not the same as sexual activity. A person experiencing sexual desire may choose to act on it or not. Sexual activity may or may not spring from desire. Engaging in sexual activity may or may not increase desire.

For many people, fantasy may create or increase desire. Thinking about a sexual act is normal, not shameful. Fantasizing about an act does not necessarily mean wanting to engage in that act. It does not mean the person having the fantasy is going to act upon it.

\section{TERMS}

\section{Sexual desire}

A longing for sexual intimacy or expression, or feeling of sexual attraction

\section{Sexual activity}

Activities associated with sexual intercourse

\section{ICEBREAKER}

Open the session with the 'Group Massage' icebreaker.

\section{Explain:}

5 The group should stand in a circle and turn sideways so that each person is facing the back of the person in front of them. People behind then massage the shoulders of the person in front of them and after a minute or so they turn and massage the person who was massaging them.

\section{REVIEW}

7 Ask participants what key points were covered in the last session (optional: throw a ball of paper around to encourage participation). Fill in any key points that are missed.

Go over any practice activities that were given, and ask if there are any questions. 


\section{activity 1}

\section{SEXUAL DESIRE - WHAT IS THE TRUTH?}

(45 MINUTES)

\section{Explain:}

$\bigcirc$ Today we are going to discuss the topic of sexual desire. Sexual desire resembles a longing for sexual expression or a feeling of sexual attraction.

People often confuse sexual desire or attraction with other emotional or physical experiences. Sexual desire is not the same as love, although it is often confused with love. A person can experience sexual desire with or without love. For example, a person may feel sexual desire for someone whom he or she barely knows.

Sexual desire is not the same as a physical sexual response. For example, a boy or man may have an erection without feeling desire. Or he may experience desire without having an erection.

Sexual desire is not the same as sexual activity. A person experiencing sexual desire may choose to act on it or not. Thinking about a sexual act is normal, not shameful. Fantasizing about an act does not necessarily mean wanting to engage.

First, we will complete a true-or-false exercise.

Read each statement from the Activity Sheet 2: Sexual Desire - What Is The Truth located at the end of this session. After reading one statement, encourage discussion by asking:

- How many of you think that statement is true? Who thinks it is false?

If no one offers the correct answer, ask questions to help the group reach the correct response (provided in Activity Sheet 2: Sexual Desire - What Is The Truth?). Offer the correct an- swer yourself only if no one in the group comes up with it. Be sure to ask if anyone still has a question or comment. Continue this process for each statement on the activity sheet.

Divide the participants into four groups (see Appendix B: Participatory Facilitation Resources - Group Formation Activities for ideas), and ask them to discuss the following topics among their groups:

-What were some of the things you thought were true at the beginning of the session that turned out to be myths?

-What effect can this kind of misinformation have on our feelings about ourselves and our sexuality? [e.g., can make us think we're doing something wrong that is actually right or vice versa, can make us feel like our bodies are doing abnormal things which are actually normal, etc.]

-What do you notice about society's messages about male desire compared with its messages about female desire? [e.g., society emphasizes male sexual desire as a positive male trait while female sexual desire is seen as promiscuous and negative]

-What effect do you think such widely held myths can have on sexual relationships? [e.g., can cause practices, which lead to unwanted pregnancies or HIV infection, can cause stigma or discrimination against certain people who are seen as behaving in ways seen as unacceptable when their behaviors are actually natural and healthy, etc.]

-Why do you think we get different messages about male and female desire?

- Do you think it is okay for us to get different messages about male and female desire?

\section{wrap-enp}

Ask participants to summarize what they have learned. Fill in any key points they miss.

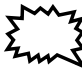

Key Message: Feeling sexual desire is normal, though people experience sexual desire on different levels and to different extents.

Ask for any final questions or comments. Remind participants where and when the next meeting will take place, and what topics will be discussed.

Thank them for their participation.

\section{PRACTICE ACTIVITY}

Instruct participants to ask their friends if they have experienced sexual feelings and how they dealt with them. 


\section{ACTIVITY SHEET 2 \\ SEXUAL DESIRE - WHAT IS THE TRUTH?}

Statement 1 Most women do not really desire sex

Answer 1 False. Most women do desire sex. However, if a woman does not get pleasure from sex, she may lose interest.

Statement 2 If you desire sex, you have to have it.

Answer 2 False. Sexual desire does not have to lead to sexual activity. In fact, people can enjoy feeling "turned on" without wanting to have sex.

Statement 3 The social expectation that women should not want sex can affect their level of desire.

Answer 3 True. Sexual desire is affected by social expectations. If a woman thinks she should not want sex, she may suppress or deny her desire.

Statement 4 If a boy gets an erection, it means he wants to have sex; if a girl's vagina lubricates, it means she wants to have sex.

Answer 4 False. Erections and lubrication can occur for no reason or for reasons not related to desire. For example, most males wake up with an erection in the morning because their bladders are full. Teenage boys often get spontaneous erections that are not related to sexual desire or excitement.

Statement 5 Some women want to have sex more than their sex partners do.

Answer 5 True. Levels of sexual desire vary by individual and circumstance. In some couples, or at some points in life, a woman may desire sex more than her partner does.

Statement 6 People have sexual fantasies about things that they do not desire to experience in real life.

Answer 6 True. Fantasies are often just fantasies. A person may not want to experience the fantasy.

Statement 7 Fear of becoming pregnant or of becoming infected with a STI can affect sexual desire.

Answer 7 True. Emotional states, such as fear, can affect a person's sexual desire.

Statement 8 Everyone's level of sexual desire changes over time and with different circumstances.

Answer $8 \quad$ True. "Normal" levels of sexual desire vary widely and change. Sexual desire is affected by physical, emotional, and social factors. If a person's level of desire is causing him or her a problem, the person can talk with a sexual health professional.
Statement 9 If you are male, then you want to have sex all the time.

Answer $9 \quad$ False. Men do not always desire sex. They experience variations in their levels of desire, as do all people.

Statement 10 Most older people still feel sexual desire.

Answer $10 \quad$ True. Many people experience some sexual desire throughout their lives. However, sexual desire may decrease with age. If a society frowns on elderly people's sexuality, their level of desire may be affected by stigma.

Statement 11 If a man does not get an erection in a sexual situation, he does not desire the person he's with.

Answer $11 \quad$ False. A man may not get an erection in a sexual situation for many reasons, including medical conditions (for example, diabetes or heart disease), the use of certain drugs, and emotional factors (such as anxiety about sexual performance, anger at the other person or about someone else, or because he is preoccupied).

Statement 12 Some medications affect sexual desire.

Answer 12 True. A decrease in sexual desire is one side effect of some medications. Some medications such as Viagra increase erectile function and are taken specifically for that purpose. Doctors frequently do not discuss the sexual side effects of medications with their patients. If side effects are a concern, consult a physician or pharmacist.

Statement 13 A person can feel sexual desire for someone he or she does not love.

Answer 13

someone and not desire to have sex with them, and you can desire to have sex with someone whom you do not love.

Statement 14 It is normal for men not to want sex sometimes.

Answer 14 True. No one, whether male or female, always wants to have sex.

Statement 15 If you desire sex, you will become sexually excited.

Answer 15 False. Sometimes people do desire sex but do not become sexually excited. This situation happens to most people at some point. It is not something to worry about 
7) Unsafe Abortion*

\begin{tabular}{|l|}
\hline SESSION \\
DESCRIPTION: \\
(REPRODUCTIVE \\
HEALTH) \\
Participants discuss \\
the meaning of \\
abortion and risks of \\
various types of unsafe \\
abortions. \\
\hline
\end{tabular}

\begin{tabular}{|l|}
\hline OBJECTIVES \\
By the end of this \\
session, participants will \\
be able to: \\
- Define abortion \\
- Describe five \\
complications of \\
unsafe abortion \\
- Understand the \\
Termination of \\
Pregnancy (TOP) Act
\end{tabular}

1 HOUR, 10 MINUTES
- Icebreaker (5 minutes)
- Review (5 minutes)
- Define Abortion (15 minutes)
- Why Girls and Women Procure
Abortions OR Legality of
Abortion in Zambia (15 minutes)
- Safe and Unsafe Abortions OR
Abortion Risks (20 minutes)
- Wrap-up (5 minutes)
- Practice Activity (5 minutes)

\begin{tabular}{|l|}
\hline MATERIALS \\
- Chalkboard and chalk OR \\
flipchart and markers \\
- A list of providers and \\
health centers in the \\
community where safe \\
abortions can be obtained \\
- Training aid Safe and \\
Unsafe Abortions \\
\hline
\end{tabular}

\section{田 \\ PRE-SESSION PREPARATION}

- Read through the entire session and, if necessary, practice presenting the activities

- Prepare the list of providers and health centers in the community where safe abortions can be obtained

- Prepare other materials needed for the session

- If desired and/or possible, invite a guest or trained mentor to help facilitate the activities in this session 


\section{FACILITATOR NOTES}

The term abortion in its common usage refers to the early termination of a pregnancy, resulting in the death of the embryo or fetus. However, technically, abortions can be induced or deliberate, or spontaneous or natural (also known as a miscarriage). Induced abortion is usually referred to simply as abortion. It is currently legal in many countries around the world and is practiced safely by trained health care providers. Abortion is legal in Zambia. Some unsafe methods of abortion that have been tried by girls include:

- Chemical abortions

- Overdose of quinine (malaria medication)

- Herbal medications

- Mechanical methods including piercing the uterus using sharp objects

- Taking concentrated solutions such as quencher, millet chuff and tea leaves

Many women have died from unsafe abortions or have developed health problems. Some immediate health complications include severe bleeding or infection, which can lead to death. Some women suffer from long-term problems that mean that the woman may never get pregnant again or that she may live in constant pain.

A girl or woman who has recently had an abortion needs to consider contraception options. She should make a plan for getting contraception immediately after the procedure. If the abortion was not carried out by a skilled provider, the woman may not have access to contraceptives. An adult who is aware of this situation can assist the girl in seeking medical care and contraceptive counseling.

Whatever the circumstance of the pregnancy, having an abortion is a serious decision that requires careful consideration of one's values, beliefs, and life situation. A girl or woman faced with an unwanted pregnancy should seek counseling to learn about all the safe and legal options that are available to her.

\section{TERMS}

\section{Abortion}

The early termination of pregnancy resulting in the death of the embryo or fetus

\section{Embryo}

A developing human that has not yet reached the fetus stage, usually from the time of conception until around two months after conception

\section{Fetus}

A developing human that is past the embryo stage but not yet born (usually from two months after conception until birth)

\section{Induced abortion}

The termination of pregnancy by removal or expulsion of the fetus before it is able to survive independently

\section{Miscarriage}

The spontaneous end of a pregnancy at a stage where the fetus is incapable of surviving independently, also known as a 'Spontaneous abortion'

\section{Skilled Provider}

A person qualified in the practice of medicine

\section{Spontaneous Abortion}

See Miscarriage

\section{Unsafe Abortions}

Abortions performed under unsafe conditions (without a skilled provider and/or with minimal medical standards) posing a high risk of complications for the mother

\section{ICEBREAKER}

Open the session with an icebreaker of your choice, or allow participants to suggest one. See Appendix B: Participatory Facilitation Resources - Icebreaker Activities for ideas.

\section{REVIEW}

(7) Ask participants what key points were covered in the last session (optional: throw a ball of paper around to encourage participation). Fill in any key points that are missed.

Go over any practice activities that were given, and ask if there are any questions.

NOTE TO FACILITATOR: Because of the sensitive nature of the subject of abortion, this session has entirely separate learning activities for participants in the group of younger ages (10-14) and older ages (15-19). Before the session, be sure to identify providers who provide safe abortion in the area and share the information with the participants during the discussion. Safe abortions may be provided by trained public health providers or providers from private or NGO clinics, e.g. Marie Stopes International (MSI) and Planned Parenthood Association of Zambia (PPAZ) 
activity 1

\section{0-14-year-olds only}

\section{DEFINE ABORTION}

(15 MINUTES)

Break participants into small groups (see Appendix B: Participatory Facilitation Resources - Group Formation Activities for ideas) and ask them to discuss:

-What is abortion?

[early termination of a pregnancy resulting in the death of the embryo or fetus]

-What are some different kinds of abortions?

[unsafe abortion, spontaneous abortion, induced abortion, abortions by different methods, etc.]

Regroup and have participants share their ideas. Listen to misconceptions and clarify that abortion is the early termination of a pregnancy.

\section{Explain:}

3 There are two kinds of abortions:

spontaneous abortion, also known as a miscarriage, when a pregnancy ends naturally, and

Induced abortion, when a woman chooses to end her pregnancy because of medical reasons to save the mother's life, or is done voluntarily because the woman and/or father do not want the baby.

activity 2

10-14-year-olds only

\section{WHY GIRLS AND WOMEN PROCURE ABORTIONS}

(15 MINUTES)

\section{Explain:}

$\int$ Women and girls have abortions for many different reasons.

\section{Ask:}

Ask:

Why might a woman or girl decide to have an abortion?

[Women or girls may decide to have an abortion because:

- they cannot afford or manage to rear a child (whether a first child or another child)

- they don't want to become a parent at the time of the pregnancy

- they want to finish their education

- their relationship with their partner is becoming difficult, or they are not in a stable relationship and do not want to rear a child alone

- the pregnancy threatens their physical or mental health, or

- they became pregnant as a result of sex that was forced or otherwise coerced.]
What are some examples of situations where a woman or couple wants to continue a pregnancy, but they may end it by abortion?

[They may decide this because of:

- genetic, behavioral, or environmental factors may cause serious medical risks (even death) for the fetus,

- unhappiness about the sex of the fetus (mostly in places where society unjustly places greater value on sons than daughters), or

- pressure to have an abortion because of personal or economic situations, health status, or other reasons - such pressure may come from another person (for example, a parent, boyfriend, or health care provider) or in countries with coercive population policies, the government may pressure women to have abortions.] 


\title{
activity 3
}

SAFE AND UNSAFE ABORTIONS

\author{
(20 MINUTES)
}

Ask:

SDo you know any young women who have had an abortion?

Would you like to share what happened to these young women?

What are some of the risks during an unsafe abortion?

[bleeding to death from cuts on the uterus or cervix, anemia (iron deficiency), pelvic

abscess from using unclean materials, tetanus from unclean material, and infertility]

\section{Explain:}

Trained health professionals can reduce these risks during an abortion. When abortions are legal, they are more likely to be performed by trained health professionals. In Zambia, it is only legal to get an abortion when the physical or mental health of the mother is in danger, the birth of another child puts the physical or mental health of existing children at risk, or it is known that the infant will be born with a serious disability. In evaluating these conditions, the age and living environment of a woman should be considered. But many women and girls get abortions for other reasons, like those we discussed. So many women and girls use unsafe methods to perform abortions including chemical abortions, overdoses of malaria medication, and piercing the uterus with sharp objects.

Abortion is a simple and safe procedure when provided under proper conditions. These include having a skilled provider, appropriate and sterile equipment, and access to early treatment for any potential complications.

As you explain, show the illustrations from Training Aid: Safe and Unsafe Abortions to facilitate their understanding. 

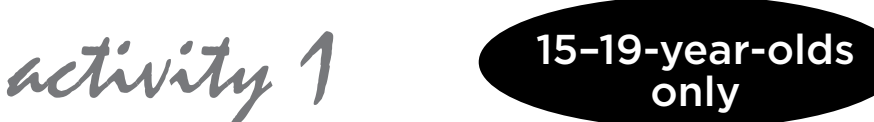

\section{DEFINE ABORTION}

(15 MINUTES)

\section{Ask:}

$S$ Does anyone know where safe abortion is provided in your community? [see the list of providers and health centers in the commu-

nity where safe abortions can be obtained,

which you prepared beforehand]

Divide participants into four groups (see Appendix B: Participatory Facilitation Resources - Group Formation Activities for ideas). Ask them to discuss amongst themselves the following questions:

-What is a spontaneous abortion?

[A spontaneous abortion is a pregnancy that ends spontaneously (called a miscarriage) or that happens by choice before the baby is big enough to live outside the uterus (before 28 weeks).]

-When do spontaneous abortions occur?

[Most spontaneous abortions occur in the first 12 weeks of pregnancy.]

-What is an induced abortion?

[An induced abortion is a pregnancy that is ended for medical reasons to save the mother's life or is done voluntarily because the pregnant woman and/or father do not want the baby.]

- How can induced abortions be performed safely? [The safest way to induce an abortion is to have it performed by a trained health provider.]

activity 2

15-19-year-olds only

\title{
LEGALITY OF ABORTION IN ZAMBIA
}

\author{
(15 MINUTES)
}

Explain:

Abortion is legal in Zambia under the circumstances laid out in the Termination of Pregnancy Act.

Discuss the below information with the group (If necessary, refer to Appendix A: Additional Topical Information - Zambia's Abortion Act and Regulations.)

- The Termination of Pregnancy Act, which was enacted in Zambia in 1972 and amended in 1994, deems abortion legal in Zambia under certain conditions. These conditions include:

- when there is a risk to the life, or to the physical or mental health, of the pregnant woman

- when the birth of another child would have a negative effect on the physical and/or mental health of already existing children (more negative than the effect of terminating pregnancy), and

- when the child would be born with a serious mental or physical disability.
- In the evaluation of these conditions, the age and living environment of women should be considered.

- The abortion must be approved by three medical personnel-including one doctor who is a specialist-and performed in a clean, safe and registered environment by a registered medical practitioner. The woman must also choose to have an abortion in a free and informed manner without coercion.

- Complications from unsafe abortions can include depression, severe bleeding, perforation of the uterus and intestines, damage of the genital tract, infections, infertility and even death. 


\section{activity 3}

\section{ABORTION RISKS}

\section{(2O MINUTES)}

Divide participants into three groups (see Appendix B: Participatory Facilitation Resources - Group Formation Activities for ideas). Each group should discuss:

- Which methods have you heard that teenage girls use to abort?

[chemicals, overdose of malaria medication, herbal medications, surgery, drinking concentrated liquids, etc.]

Ask each group to share their responses with the larger group. Write the answers on the board. For each method, discuss if it is safe and what happens to girls who have used this method.

\section{Explain:}

$\int$ We need five volunteers to role-play a scenario. Volunteers will be: a mother, a daughter and a friend of the girl, a juju woman and a doctor, to perform a role-play of the following scenario.

Use the Abortion Scenario in the box in the middle column. After the volunteers act out the role-play for the group, ask:

- Have you ever witnessed or heard of what happened in the role-play?

- Do you know any young women who have had an abortion?

\section{Abortion Scenario}

The daughter is in grade nine and she has just discovered that she is pregnant. Fearing what might happen when her parents discover that she is pregnant, she visits her friends and opens up to them about the pregnancy. The friends tell her how angry and disappointed her parents will be and the shame she will bring on the family. One of her friends further mentions that she has heard an elderly woman who is well known for juju in the community can terminate the pregnancy. The pregnant girl secretly visits the juju woman who gives her some herbs to insert in her vagina. Upon reaching home the girl goes straight into the bathroom to insert the herbs and a few minutes later she passes out and is taken to the hospital. After some time, a doctor comes to inform the mother that her daughter has a serious complication because she was trying to terminate a pregnancy using unsafe methods.

-If so, what happened to them?

-What are the risks of unsafe abortion? [bleeding to death from cuts on the uterus or cervix, anemia (iron deficiency), pelvic abscess from using unclean materials, tetanus from unclean materials, and infertility.] 15-19-year-olds only
Lead a discussion on the following statistics:

- Unsafe and poorly performed abortions are a major cause of maternal mortality in Zambia.

According to data from five major hospitals across Zambia, a total of 616 women obtained safe induced abortions between 2003 and 2008 .

- In contrast, the number of women admitted to the hospitals with abortion-related complications (including complications from spontaneous abortion) increased from about 5,600 in 2003 to more than 10,000 in 2008-and totaled 52,791 over the six years.

- In other words, about 85 times as many women were treated for abortion complications as underwent safe, legal abortion in these five key hospitals. Unsafe abortions raise the risk of maternal death.

\section{Ask:}

5 Do you remember where safe abortion is provided in your community? [review the list of providers and health clinics where safe abortions can be obtained in the community, which you prepared beforehand]

Emphasize that safe abortion is not a form of birth control and refer back to the importance of using contraceptives to prevent unwanted pregnancy. 


\section{Wrap-wp}

Facilitate a discussion about unsafe abortion using the following questions:

- How can unwanted pregnancies be prevented?

[by practicing abstinence or using contraceptive methods correctly and consistently]

-Where can adolescents find more information about ways to prevent pregnancy?

[from local health clinics, from the chemist, from

informational materials, asking other adults, research in books or on the internet]

Key Message: Girls and women have many different reasons for obtaining abortions; in order to protect the health and safety of a mother, all abortions should be performed by a trained health professional.

Ask for any final questions or comments. Remind participants where and when the next meeting will take place, and what topics will be discussed.

Thank them for their participation

\section{PRACTICE ACTIVITY}

Participants should ask their friends in the community if they know anyone who has had an abortion and note their friends' reactions to the idea of abortion. 


\section{8) Abortion and Stigma*}

SESSION
DESCRIPTION:
(REPRODUCTIVE
HEALTH)
Participants complete
activities designed to
help them think about
their comfort levels
and values around the
subject of abortion,
and how society's view
of abortion relate to
stigma.

\begin{tabular}{|l|}
\hline OBJECTIVES \\
By the end of this \\
session, participants will \\
be able to: \\
- Clarify their values \\
concerning abortion \\
- Describe how stigma \\
affects individual and \\
societal views and \\
reactions to abortion \\
\hline
\end{tabular}

\begin{tabular}{|l|}
\hline TIME \\
55 MINUTES \\
(10-14-year-olds) \\
OR \\
1 HOUR, 25 MINUTES \\
(15-19-year-olds) \\
- Icebreaker (5 minutes) \\
- Review (5 minutes) \\
- Understanding Abortion Stigma \\
(15 minutes) \\
- Comfort Continuum (20 \\
minutes) \\
- Cross the Line (30 minutes) \\
- Wrap-up (5 minutes) \\
- Practice Activity (5 minutes)
\end{tabular}

\begin{tabular}{l} 
MATERIALS \\
- Three paper signs \\
labeled "A Lot," "A \\
Little" and "Not At All" \\
- Tape \\
- Masking tape or string, \\
approximately 2-3 \\
meters long, to mark \\
a line on the floor \\
(if neither tape nor \\
string is available, ask \\
participants to pretend \\
that there is an \\
imaginary line across \\
the floor) \\
- Training aid "Comfort \\
Continuum Cards" \\
\hline
\end{tabular}

\section{田 \\ PRE-SESSION PREPARATION}

- Read through the entire session and, if necessary, practice presenting the activities

- Prepare all materials needed for the session

- Arrange the room so there is space for participants to move around

- Review the statements provided in Activity Sheet 3: Cross the Line Statements to select the ones you will use (provided at the end of this session); if necessary, revise or adapt some of them to better fit your group - Be familiar with Zambia's Termination of Pregnancy (TOP) Act (see "Appendix A: Additional Topical Information - Zambia's Abortion Act and Regulations") 


\section{FACILITATOR NOTES}

Stigma from abortion is the discrediting of individuals as a result of their association with abortion. People who are affected by abortion stigma include adult women and young women who have had an abortion. Sometimes individuals who work in health facilities that provides abortion, and supporters of women who have had abortions, including partners, family, and friends may also be stigmatized. Stigma is influenced by a person's values, such as how important certain beliefs, principles, or ideas are.

Values clarification activities are important for discussing the issue of young women and abortion. Many people have mixed feelings about abortion in general, and some may feel even more conflicted about a girl's or a young woman's termination of pregnancy.

This session is designed to help participants reflect on their level of comfort discussing abortion services. Participants are encouraged to reflect on their life experiences that influenced these comfort levels and how they relate to societal norms on abortion.

\section{TERMS}

\section{Abortion Stigma}

The discrediting of individuals as a result of their association with abortions

\section{Stigma}

Severe disapproval of, or discrimination against, a person on the grounds of characteristics that distinguish them from other members of a society

\section{Value}

A personal measure of worth, such as how important certain beliefs, principles or ideas are to someone

\section{ICEBREAKER}

Open the session with an icebreaker of your choice, or allow participants to suggest one. See Appendix B: Participatory Facilitation Resources - Icebreaker Activities for ideas.

\section{REVIEW}

7. Ask participants what key points were covered in the last session (optional: throw a ball of paper around to encourage participation). Fill in any key points that are missed.

Go over any practice activities that were given, and ask if there are any questions. 
activity 1

\section{UNDERSTANDING ABORTION STIGMA}

\section{(15 MINUTES)}

Seek out four volunteers for a role-play.

\section{Explain:}

5 Of the four volunteers, we need one to act as a girl who has just had an abortion, two to act as sisters, and to act as a mother.

Instruct the volunteers to role-play the following scenario for the group:

\section{Role-play Scenario}

The girl has just recovered from an abortion, and since there is no one at home she decides to prepare a meal. Her two sister return from school and she has saved them some of the meal. The two sisters push the meal away and start telling her off for touching the kitchen utensils when she knows she is unclean because of the abortion she underwent. The mother returns home and finds the two sisters shouting and the girl crying. The mother then explains to the two sisters that what their sister underwent is a medical procedure just like any other medical procedure and that she would not transmit anything to them.

Ask:

5 How would you describe what happened in the role-play?

\section{Explain}

$\Omega$ A theme of the role-play was 'abortion stigma.' This means the discrediting of individuals as a result of their association with abortions.

\section{Instruct:}

$\Omega$ Now think quietly (inside your heads) about your feelings about someone who has had an abortion.

\section{Explain}

Those thoughts are related to their how you see or 'value' someone who has had an abortion. The term 'value' can have different meanings. One is the actual worth of an object or an item in a given currency. Another meaning involves a more personal measure of worth, such as how important certain beliefs, principles or ideas are to someone. The things, ideas, beliefs and principles that are of worth shape your values and these values help us to define who are. 


\section{activity 2}

\section{COMFORT CONTINUUM}

\section{(2O MINUTES)}

Tape the three signs from the Training Aid: Comfort Continuum Cards on the floor or the wall in an open area of the room where there is enough room for participants to move around (if cards are not available make them yourself on large pieces of paper). Place the signs in order in a row to indicate a continuum as illustrated below:

\section{NOT AT ALL}

\section{A LITTLE}

\section{A LOT}

\section{Explain}

SD Now l'm going to read some statements. After I read each statement, move along the continuum to a position, i.e. towards a card, which best represents your feelings.

Read the statements in Box 4: Comfort Continuum Statements aloud allowing time for participants to move around on the continuum between each statement. Encourage participants to be honest about their feelings and to resist being influenced by where other participants are placing themselves.

As participants arrange themselves, choose volunteers at different points along the continuum.

\section{Ask:}

SDhy are you standing there?

If, based on someone's explanation, participants want to move to another point on the continuum, encourage them to do so.
Once you have finished reading the statements, ask participants to return to their seats.

Ask:

5 What are your feelings about the activity?

Try to make sure you hear from some girls who had different types of responses. Refer to the reasons participants gave about their place on the continuum to facilitate a brief discussion about the different responses and levels of comfort in the room using the following questions:

- What observations do you have about your own responses to the statements? Other people's responses?

- Were there times when you felt tempted to move with the majority of the group? Did you move or not? How did that feel?

\section{BOX 4: COMFORT CONTINUUM} STATEMENTS

- How comfortable are you discussing abortion with your family members?

- How comfortable are you discussing abortion with your friends?

- How knowledgeable are you about your country's laws on abortion services?

- How comfortable are you with the idea of every woman and girl being able to access safe abortion services?
-What about your responses to the statements surprised you? How about other people's responses?

- What did you learn about your own and others' comfort levels on abortion?

-What observations do you have about the group's overall level of comfort with abortion (not individual people's responses)?

Now participants should reflect on the life experiences, which influenced their levels of comfort or discomfort.

\section{Explain:}

$\int$ Now you should imagine how a different set of life experiences might have led to a different level of comfort with abortion.

Ask a few people to share their thoughts on this.

Explain:

$\bigcirc$ Different levels of comfort with abortion impact the way society reacts to women when they seek or have had an abortion, women's feelings about themselves when they have an abortion.

(NOTE TO FACILITATOR: If questions arise during the discussion, for example on abortion laws and policies in Zambia, be prepared to provide correct information (See previous activity and/or Appendix A: Additional Topical Information - Zambia's Abortion Act and Regulations). 


\section{activity 2}

\section{CROSS THE LINE}

\section{(30 MINUTES)}

(NOTE TO FACILITATOR: This activity brings participants' different views on abortion to the surface and address the connection between abortion and stigma. It helps participants understand how stigma affects people's diverse views and experience with abortion. Use the statements from Activity Sheet 3: Cross the Line Statements, which you selected and/ or adapted for the group in preparation for the session. Plan to begin with easier statements and move to more difficult ones. Try to end with a broad statement, such as the last one on the activity sheet.)

Mark a line on the floor, approximately 2-3 meters long, with masking tape or string. (If neither tape nor string is available, ask participants to pretend that there is an imaginary line across the floor.)

\section{Explain}

S Now you should all stand on one side of the line. I will read a series of statements and you should step entirely across the line when a statement applies to you. There is no "in between," which means you must stand on one side of the line or the other. Try very hard not to talk during the activity unless you need to ask me a question. Remember there are no right or wrong answers!

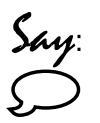

Cross the line if you had fruit for breakfast this morning.
Once some people have crossed the line, give participants an opportunity to observe who crossed the line and who did not.

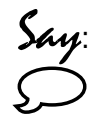

Observe who crossed the line and who did not ... Notice how it feels to be wherever you are.

Identify someone who crossed the line and someone who did not cross the line.

\section{Ask them}

Could you please explain your response to the statement?

If someone is the only person who did or did not cross the line, ask them what that feels like. Then instruct all participants to move back to one side of the line.

Repeat this for several of the statements on Activity Sheet 3: Cross the Line Statements about abortion located at the end of the session. Select the statements that most apply to your group of participants. Begin each statement with, "Cross the line if ..." After participants have moved, follow up each statement with, "observe who crossed the line and who did not ... notice how it feels to be wherever you are ... now please all move back to the same side of the line."
Debrief in particular the last statement on the activity sheet. If everyone in the group crossed the line, discuss this commonality. If everyone did not cross the line, discuss how these different views affect people's work on abortion care and the broader social climate for abortion in that setting.

After all the statements have been read, ask participants to take their seats and discuss the experience with the following questions:

- How did you feel about the activity?

-What did you learn about your own and others' views on abortion?

- Were there times when you felt tempted to move with the majority of the group? Did you move or not? How did that feel?

-What did you learn from this activity?

-What does this activity teach us about the stigma surrounding abortion?

- How might stigma affect women's emotional experience with abortion? How would it affect women's family members?

- How might fear of stigma cause some women to seek abortions that may be unsafe? 


$$
\left\{\begin{array}{l}
\text { A } \\
\text { A } \\
\text { an } \\
\text { an } \\
\text { ta } \\
\text { Th } \\
\text { In } \\
\text { P }
\end{array}\right.
$$

\section{ACTIVITY SHEET 3}

\section{CROSS THE LINE STATEMENTS}

\section{Cross the line if:}

- You were raised to believe that abortion should not be openly discussed

- At some point in your life, you believed abortion is wrong

- You were raised to believe that abortion is a woman's right

- You have been asked to keep someone's abortion a secret

- You have ever felt uncomfortable talking about abortion

- You have ever heard a friend or family member talk in a derogatory manner about women who have had abortions

- You or someone you are close to has had an abortion

- You have ever avoided the topic of abortion to avoid conflict

- You believe all women deserve access to safe, highquality abortion services 


\section{9) Maternal Mortality*}

SESSION
DESCRIPTION:
(REPRODUCTIVE
HEALTH)
Participants will explore
the issue of maternal
mortality and learn
ways in which they can
help reduce maternal
mortality in their
communities. They
will identify maternal
danger signs and ways
to prevent maternal
death.

OBJECTIVES
By the end of this session,
participants will be able to:
- Understand risks of
pregnancy
- Recognize that not
knowing the maternal
danger signs can delay
decision-making when
a maternal complication
occurs
- Feel confident that they
know the maternal danger
signs
- Mention actions that
can be taken to prevent
maternal deaths

1 HOUR, 30 MINUTES
- Icebreaker (5 minutes)
- Review (5 minutes)
- Maternal Emergency/Mortality
Story (25 minutes)
- Recalling Signs of Pregnancy
Complications (15 minutes)
- Maternal Danger Signs (30
minutes)
- Wrap-up (5 minutes)
- Practice Activity (5 minutes)

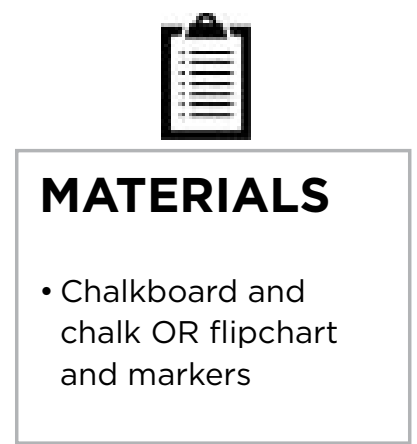

\section{田 \\ PRE-SESSION PREPARATION}

- Read through the entire session and, if necessary, practice presenting the activities

- Learn and practice the poses from Box 5: Maternal Danger Poses

- Prepare all materials needed for the session 


\section{FACILITATOR NOTES}

If a woman or girl chooses to keep her pregnancy, it is particularly important for her to avoid taking unnecessary medications, drugs, and alcohol. Taking the recommended vitamins and mineral supplements (especially iron and folic acid) is very important (including before pregnancy, if possible). She should also visit an antenatal-care provider, from whom she can get medical checkups and can learn about her pregnancy, potential danger signs, and childbirth. Women infected with HIV should take anti-HIV medication to prevent the fetus from becoming infected and to maintain their own health. Treatment with anti-HIV medicines during labor and delivery is critical for reducing the risk of transmitting HIV to the baby.

Several studies have shown that the outcomes for adolescents who receive good antenatal care are no different from those of older women. However, antenatal care may not be available, and even if it is available, adolescents are more likely to seek care later in their pregnancies or to not seek antenatal care at all. They may not recognize the signs of pregnancy, may want to hide a pregnancy, may not realize care is available or may not be able to afford the fees charged. There are several medical and social reasons to delay childbearing.

For more information on childbirth and safe motherhood, refer to Appendix A: Additional Topical Information - Childbirth and Breastfeeding.

\section{TERMS}

\section{Antenatal Care}

The care of women and their children before birth

\section{Danger Signs}

Warnings of an impending hazard or negative outcome

\section{Maternal Emergency}

When a woman who is pregnant delivering her baby or in the first 42 days after giving birth experiences a problem or complication and must be rushed to the health center immediately

\section{Maternal Mortality}

Maternal mortality is the death of a woman from a cause related to pregnancy or childbirth

\section{Placenta}

The organ that transfers nutrients from the mother to the fetus, which is dispelled after giving birth, also known as afterbirth

\section{ICEBREAKER}

Open the session with the 'How are you, my partner?' icebreaker.

\section{Explain}

Everyone must find a partner. Then you will sing, while pointing a finger at each other:

How are you my partner.

How are you today,

We shall dance in a circle,

I'll show you the way,

sing talalalala,

Sing talalalala,

Sing talalalala,

I'll show you the way.

Instruct participants to move at $90^{\circ}$, one clockwise and the other in an anti-clockwise direction, when they reach the 'sing talalala' part.

\section{REVIEW}

(7) Ask participants what key points were covered in the last session (optional: throw a ball of paper around to encourage participation). Fill in any key points that are missed.

Go over any practice activities that were given, and ask if there are any questions. 


\section{activity 1}

\section{MATERNAL MORTALITY/EMERGENCY STORY}

(25 MINUTES)

Read the story (below):

Ask:

\section{Explain}

As we have seen in Charity's story, pregnancy and childbirth can be physically and mentally strenuous times for a woman. Sometimes, this can result in the death of a mother during or as a result of pregnancy or childbirth.

Next, write the words "maternal emergency" on a chalkboard or flipchart.
5 What do you think the term "maternal emergency" means?

[when a woman who is pregnant, delivering her baby or in the first 42 days after giving birth experiences a problem or complication and must be rushed to the health center immediately]
What were some of the signs of maternal emergency that Charity experienced? [obstructed labor (stuck in birth canal), fever, infection, etc.]

Discuss the difference between the two terms.

\section{Explain:}

5 Knowing the signs of danger during pregnancy and acting quickly during a maternal emergency can prevent a maternal death.

\section{Charity's Story}

Charity is 15 . She spends her time in school, studying at home, and performing household chores. A few times she went out with a man whom she met near school. He gave her gifts and a bit of money that she used to pay for her schoolbooks, and she had sex with him. She asked him about using condoms, which she had learned about at school, but he told her not to worry. She didn't like him much, so she decided not to see him again. Soon, however, Charity realized she was pregnant. When she told her parents, her father beat her, but her parents did not throw her out of their house. She dropped out of school after a few months and went to live with an aunt in another town. Her family agreed that the aunt would rear the child so that no one would know about Charity's pregnancy. When she went into labor, the aunt told her to stay strong, that the baby would come out on its own. However, the baby became stuck in the birth canal. The aunt called a local midwife, who came and cut Charity with a razor to make the opening of the vagina wider, so the baby could come out. The baby came out quickly and Charity thought she would soon return to her old life, sadder but wiser. Within a few days, however, she found that the area where she had been cut had become infected. Within a few more days, Charity developed a high fever. Her aunt wanted to take Charity to the hospital, but Charity refused. She was afraid that someone at the hospital would discover that she had been pregnant. When her fever became much worse the next morning, her aunt called an ambulance anyway, but it was too late. Charity died a few hours after arriving at the hospital.
Ask:

What could Charity or her aunt have done differently to avoid maternal mortality?

[present in the hospital earlier, take antibiotics for the infection, deliver the baby in a hospital, etc.] 


\section{activity 2}

\section{RECALLING SIGNS OF PREGNANCY COMPLICATIONS}

(15 MINUTES)

Instruct participants to make a circle and make them count off 1, 2; 1, 2;1, 2, etc. Each person who called "1" turns to the person who called " 2 " on their right and asks them to form a pair by facing each other.

\section{Explain}

Think of people in your community who died or were harmed during pregnancy, childbirth, or after childbirth. Then discuss by telling your partner what happened.

Ask:

Would anyone like to share their story with the group?

What prevented the women in the stories from getting emergency care at the health center or hospital in time?

[make sure participants mention the following: no one knew that the woman was in serious danger, the family did not decide on time to take the woman to the health center/hospital, transport was not available, was too costly or took too long to arrange, distance to the health center or hospital was too far and the pregnant mother and her family did not start on time, they feared that the mother might die before reaching the health center, the family sought emergency care first from the tradi-

tional birth attendant or traditional healer, and the mother and her family members didn't believe the health center could save her life and the baby's life.]

Ask:

5 What have you observed with women who suffered a complication during pregnancy, delivery, or the first 42 days following childbirth?

What indicated to you the woman's life was in danger?

[e.g., mother began fitting (seizure), mother bled, mother was still in labor after a whole day and night, etc.]

\section{Explain:}

5 The stories from our community have reminded us of what can happen if we delay in rushing pregnant women to the health center who have maternal complications during pregnancy, delivery and in the first 42 days following childbirth. 


\section{activity 3}

\section{MATERNAL DANGER SIGNS}

(30 MINUTES)

Explain:

$S$ There are many maternal danger signs. We are going to act out 10 of the signs by doing body poses.

For each danger sign, do its body pose (listed in Box 5: Maternal Danger Poses below) and ask everyone to join you in repeating the same pose. While participants repeat the pose, ask them:

-What does the sign we are acting out mean?

(NOTE TO FACILITATOR: Learn the poses from Box 5: Maternal Danger Poses in advance of the exercise.)

As participants guess, tell or confirm the sign and then explain what the sign means and what to do in a situation where the sign occurs in real life (as listed below for each sign). Set the cards corresponding to the correctly guessed poses to the side.

\section{Instruct:}

5 Now you should repeat the 10 body poses in a row, saying the names of each sign out loud in unison. Go through the 10 poses and names 2-3 times to be sure you know them

\section{Explain}

These are signs that you should watch for if you yourselves or people in your families or communities are pregnant, delivering or gave birth within the last 42 days. If you see any of these signs, you should rush to the nearest clinic.

\section{BOX 5: MATERNAL DANGER POSES}

\section{Severe headache}

Body pose: Hold the side of your hand on your forehead pretending to have a terrible headache.

Explanation: Severe headache means the woman may start fitting. Don't delay. Go to the clinic so the health workers can prevent the fitting.

\section{Swollen hands, feet or face}

Body pose: Touch the places that will be swollen one after the other. Touch the top of your foot; hold one of your wrists; put your hands on the sides of your face and puff up your face. Explanation: Swollen hands, feet or face means that the woman may start fitting. Don't delay. Go to the clinic so the health workers can prevent the fitting.

\section{Fitting}

Body pose: Hold your hands up in the air and let your head fall to one side while shaking your hands and whole body. Explanation: Fitting is often preceded by a severe headache and swollen hands, feet and face. Don't delay. Rush to the clinic for help.

\section{Severe bleeding}

Body pose: Hold your hands flat, face down above your lap and push away from your body to remind us that the blood flows away from the womb.

Explanation: Bleeding during pregnancy means something is wrong. A mother who keeps bleeding after childbirth can die in a few hours. For both cases, rush her to the clinic.

\section{Fever/chills in the days after childbirth}

Body poses Cross your arms on your shoulders and shiver: Explanation: Fever/chills in the days after childbirth is caused by a serious infection that can cause death or sterility (a sterile man or woman cannot have children). Don't delay. Rush her to the clinic.

\section{Foul smelling discharge}

Body pose: Wave your right hand down from your lap area with a facial expression of a foul smell to show that the flow from the womb has an offensive odor.
Explanation: Foul smelling discharge also indicated infection. Don't delay. Rush her to the clinic. Do not go to the chemist/patent medicine vendor for help.

\section{High fever during pregnancy}

Body pose: Cross your arms on your shoulders and shiver hold your hands flat, face down above your lap and push away from your body to show that there is flow away from the womb.

Explanation: High fever during pregnancy can mean infection or malaria and are dangerous for both the baby and the mother. Don't delay. Rush her to the clinic.

\section{Prolonged labor (more than 12 hours)}

Body pose: Put your two knees on the floor, hold tightly to the right side of your waist, press your left hand on the floor and wriggle in pain

Explanation: If labor lasts more than 12 hours, something is wrong. Don't delay. Rush to the clinic.

\section{Hand, foot or cord comes out first}

Body pose: Push your right hand out in front of you; push your foot out in front. Pull your hand out from your belly button.

Explanation: If the baby's hand, foot or cord comes first, the birth canal may be too small. It will be difficult or impossible for the baby to come out. If the baby comes out, it will tear the mother's birth canal hurting both the baby and the mother. Don't delay. Rush to the clinic. The baby will not come out without medical assistance.

\section{Placenta or afterbirth does not come out $\mathbf{3 0}$ minutes} after childbirth

Body pose: Be on your two knees, hold out your two hands in a receiving position above your lap and open out with an expression on your face showing anxiety. Explanation: If the placenta does not come out after 30 minutes after childbirth, something is wrong. Don't delay. Rush to the clinic. 


\section{Wrap-up}

Ask participants to summarize what they have learned. Fill in any key points they miss.

Key Message: Be aware of the signs of emergency in pregnant women or women who have given birth in the last 42 days so that they can be rushed to the nearest clinic so that the mother and baby can be saved.

Ask for any final questions or comments. Remind participants where and when the next meeting will take place, and what topics will be discussed.

Thank them for their participation

\section{PRACTICE ACTIVITY}

Participants should discuss a childbirth or pregnancy experience with a female relative or close friend who has given birth or been pregnant. 


$$
\text { 三LIFE SKILLS }
$$




\section{1) I Have Healthy Relationships*}

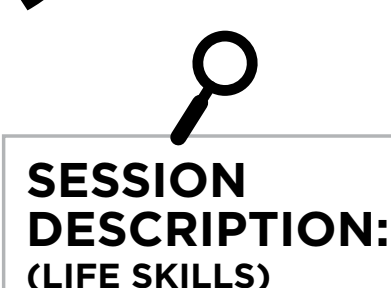

Participants think about different types of love and what love means in different situations. Participants explore whether various behaviors represent healthy or unhealthy types of love.

OBJECTIVES
By the end of this session,
participants will be able to:
- Define the term "love"
- Describe the differences
between love for a family
member, a friend, or a
partner
- List the qualities they
expect from family,
friends, and a partner
- List their own
responsibilities in love
relationships with family,
friends, and partners
- Identify how the need for
money/consumer goods
affects sexual decisions
- Strategize how to avoid
unhealthy relationships
and transactional sex

1 HOUR, 25 MINUTES

- Icebreaker (5 minutes)

- Review (5 minutes)

-What Does the Word "Love"

Mean? (10 minutes)

- Love Between Partners

(Husbands and Wives and

Boyfriends and Girlfriends) OR

Thandiwe's Story (20 minutes)

- The Dance of Love (30 minutes)

- Wrap-up (10 minutes)

- Practice Activity (5 minutes)

\section{䁬 \\ MATERIALS \\ 四 \\ PRE-SESSION PREPARATION}

- Paper and pen/pencil for each participant

- Decorated signs with different messages

on love (one per participant; see Activity 4 instructions for ideas)

- Tape

- Dance music, or the mentor should be prepared to sing a song
- Read through the entire session and, if necessary, activities

- Prepare all materials needed for the session practice presenting the 


\section{FACILITATOR NOTES}

A friendship can be a particularly fulfilling relationship involving intimacy, trust and honesty. In early adolescence, friendships are often established between boys and girls based on trust, shared feelings and thoughts. Sometimes there is a deep attraction that is not necessarily sexual, but just a preference for that friend over everyone else. The relationship provides love, closeness, affection, tenderness, and care.

Love is a complex emotion, and every person may define love differently based on his or her own experience with loving relation-

ships. Generally, love refers to a deep feeling of fondness, attraction, respect, caring and understanding for another person, despite their weaknesses or faults. It is important to remember that sexual intercourse is not the only way of showing love to someone. Also, having sex does not mean that two people will fall in love. Remember, love is about respect and caring for each other. Love is never a good reason to do anything that puts your health and future at risk.

Becoming a couple means that a person will start on a new, undiscovered path of experience and will live through many profound changes. Falling in love means loving in a new way and learning to care for our health and our life's goals. If we have the proper skills, we can establish a healthy relationship that promotes our well-being and the proper care of our physical, emotional, and sexual health. During this stage in their development, teens can practice having healthy, loving, and constructive relationships, in which both members can learn to become better individuals, a better couple, and better members of society.

It can be helpful to spend some time in the Life Skills sessions talking about the whole idea of love and relationships. Questions like, "What is love?" and "What qualities would I look for in a partner or husband or wife?" can help a young person to visualize what they want, so they can avoid unhealthy relationships. You might introduce the topic with a brief discussion of girls' goals, hopes, and dreams. Many have the dream that they will find a good partner with which to share their lives. We will be exploring these hopes in this session.

\section{TERMS}

\section{Friendship}

A particularly fulfilling relationship

involving intimacy,

trust and honesty

\section{Love}

A strong feeling of affection towards something or someone

\section{ICEBREAKER}

Open the session with the 'Smela Smela Song' icebreaker:

Start the song by singing "Smela Smela iwe." Everyone should respond "Taikonda". As the leader, you can call "Smel Smela iwe" unlimited times, but should be looking for anyone in the group to leave the leadership with. When the leader (you, in the first round) finds a favorite partner, the leader should put their hand on the shoulder of that person and say "Baby ndakuyanda." Everyone responds "Aaaahhh," then leader says "ndakuyanda ng'e butter" respondents "Aaaaahhh", again leader says "Butter ili better" respondents "Aaaahh". The one selected automatically becomes the leader and leads the icebreaker (activity)

Leader - Smel, Smela iwe (Smile, smile you/dear)

Respondents - Taikonda (We like/love it)

Leader - Smel, Smela iwe

Respondents - Taikonda

Leader - Smel, Smela iwe

Respondents - Taikonda

Leader - Smel, Smela iwe

Respondents - Taikonda

Leader - Baby ndakuyanda! (Baby I need you)

Respondents - Aaaaahhh!

Leader - Ndakuyanda ng'e butter (I need you like butter)

Respondents - Aaaaahhh!

Leader - Butter ili better! (Butter is better)

Respondents - Aaaaahhh!

By the end of the icebreaker, almost everyone should have a turn to be a leader.

\section{REVIEW}

Ask participants what key points were covered in the last session (optional: throw a ball of paper around to encourage participation). Fill in any key points that are missed.

Go over any practice activities that were given, and ask if there are any questions. 


\section{activity 1}

\section{WHAT DOES THE WORD “LOVE” MEAN?}

(10 MINUTES)

Ask:

SWhat does love mean to you?

Get feedback from participants and discuss briefly.

Divide learners into small groups (see "Appendix B: Participatory Facilitation Resources - Group Formation Activities" for ideas). Write the following questions on the chalkboard or flipchart and ask participants to discuss them in their small groups:

- Is love the same for men and women?

- Do women have a greater capacity for love than men do? Why?

- Do you believe in love at first sight? Why?

- In what ways is love important to all of us?
- Is hate the opposite of love? If not, what is?

- Can you love more than one person at a time?

- Is jealousy always a part of love?

-Are loving and being in love the same thing?

- How do you know when you love someone?

- How do you know when you are loved?

Bring the group back together to discuss any key issues that arose during each small group's discussion. 


\section{LOVE BETWEEN PARTNERS (HUSBANDS AND WIVES OR BOYFRIENDS AND GIRLFRIENDS)}

(2O MINUTES)

Divide participants into pairs (see Appendix B: Participatory Facilitation Resources - Group Formation Activities for ideas).

\section{Explain:}

Each pair should take turns describing to each other three qualities, which you would show to a partner whom you love (a sister, mother, other family member, etc.), and three qualities that you would expect from a partner who loves you (husband, boyfriend, etc.).

When girls have finished discussing, call everyone back to a full circle. Ask them to share their ideas. If there are some clear differences in the qualities of love described between partners and those described for sisters, brothers, or friends, point these out to participants. Ask them to define these differences more clearly. Encourage them to try to explain why these differences exist.
Ask:

$\int$ In this culture, does love equal sex? Does love equal marriage?

If love does not equal marriage, what, at least, are the minimum levels of respect which they think each member of the couple should show each other?

End with a brief discussion of the following quote: "One kind of love says: I care about you and I want to understand you so that you are happy, because your well-being is my well-being; I want to be with you, I want to share my life with you, I want to support you and I want you to support me whenever necessary, so that we can both be free alone and together, and responsible for ourselves and for our actions."

-Jose Luis Alvarez-Gayou 


\section{activity 3}

\section{THANDIWE'S STORY}

\section{(20 MINUTES)}

Divide participants into four smaller groups (see Appendix B: Participatory Facilitation Resources Group Formation Activities for ideas). Read Thandiwe's story (below) to everyone:

\section{Explain to the first two groups:}

5 Pretend it is years later, and that Thandiwe has been able to stick to her decision not to have sex for money or special gifts. Make a list of benefits for Thandiwe sticking to her decision and develop a role-play showing what helped her stick to her decision. (For example, maybe she asked for help and advice from a trusted adult, or she stayed away from places where older men would be present, etc.)

\section{Thandiwe's Story}

Thandiwe is beautiful and smart. When her peers started having sex with older men for money or special gifts, she decided this was not for her. The only consequence she sees to this is getting a disease or pregnant. She wishes to advance in school, but her family wishes her to stay home to help her mother. She is not sure what will happen if she does not have the money to pay for her own school fees, but she is sure she will stick to her decision to wait and have sex when she loves the person and not to have sex for money.

\section{Explain to the other two groups: \\ 5 Pretend it's three years later and that Thandi-} we was not able to stick to her decision to not have sex for money or special gifts. Ask these two groups to make a list of consequences for Thandiwe not sticking to her decision and develop a role-play showing challenges that kept her from sticking to her decision. (For example, maybe she got tired of being the

only girl in her group without nice clothes and a cell phone or her best friend did this so she went along, etc.).

When the small groups have finished their role-plays, discuss with all participants the following questions:

-Why do girls your age have sex with other men in exchange for money or gifts?

[they need the money/gift to survive - i.e., buy food, pay house rent, pay school fees, it makes them feel special, peer pressure]

\section{5-19-year-olds} only

- Why are relationships with older men in exchange for money and gifts unhealthy relationships?

[it puts young girls at a higher risk of getting infected with HIV because older men are more likely to already be infected with HIV, when someone is giving you money or a gift it makes it hard to negotiate if and when you want to have sex with this person, and the insist that they use a condom]

-What are some of the skills you have learnt so far that can help you avoid unhealthy relationships?

[self-esteem, goal identification, communication, savings so that you have your money instead of depending on men for money, etc.] 


\section{activity 4}

\section{THE DANCE OF LOVE}

(30 MINUTES)

(NOTE TO FACILITATOR: Before beginning, you will need to have prepared enough signs so that there is one per participant. These can be decorated with hearts, bubbles, or other symbols. On the signs, write messages that participants will later look at to decide whether or not they represent healthy ways of feeling or expressing love. Some examples that do not represent healthy kinds of love could be: "Suffering," "If you go away I will die," "Tolerating pain, so you won't leave," and "You are mine." Some examples of healthy or nourishing love could be: "Generosity," "Sharing," "Telling everything," and "Giving explanations." To generate more discussion and thought, it is good to include messages that are not obvious, like "always wanting to be near you" and "wanting to be everything to you.")

\section{Explain:}

5 Now we are going to do some dancing! Everyone stand up and move your chairs to the side to create a dance floor.

Spread the signs out on the floor. Divide the chalkboard or flipchart into two columns and write: "Love is..." in one column, and "Love is not..." in the other column.

\section{Instruct:}

5 When the music (or singing) starts, begin dancing around the signs. When the music stops, place your foot over a sign and pick it up.
Start the music and let it play (or sing a song if you are unable to play music) for about a minute. Stop the music and ask participants to read the messages on the signs they picked up, and decide in which column it belongs. Using tape, the participants can stick the signs in the column they chose. Ask the group to sit in a circle.

\section{Ask:}

5 Does everyone agree with the column chosen for each sign?

\section{Explain:}

Influenced often by their culture and society's definition of "romantic" love, many teenagers often tolerate unhealthy qualities in their relationships, such as jealousy, possessiveness, suffering, manipulation, and sex under pressure and without protection, putting themselves at risk of unwanted pregnancies and sexually transmitted infections. These things are not aspects of healthy love.

Healthy or nourishing love promotes space, freedom and respect, and encourages growth. If the relationship ends after nourishing love, a person will grieve, but will not be devastated.

Teenagers who are in relationships based on nourishing love recognize and accept differences, and above all, take into consideration the needs and desires of their partner, ensuring their sexual health.
Lead a discussion by asking the following questions:

-What differences are there between unhealthy and healthy/nourishing love?

[e.g., responses: unhealthy love often makes a person feel powerless, selfish, enabling, manipulated, dependent, immature, desperate, that they cannot be themselves, healthy/nourishing love involves trust, commitment, faith, acceptance, communication, and is a decision or choice for both partners]

- How does culture influence your definition of love?

[e.g., in Zambia, we are naturally close with our grandparents, but in other places children may rarely see their grandparents, have no relationship with them, and feel only a little love for them

- How does healthy/nourishing love encourage pregnancy prevention in teenagers?

[e.g., supportive partners communicate - they take both their own ideas and needs and their partners ideas and needs into consideration to make healthy sexual choices to reach a reproductive outcome desired by both partners, and may also support a partner in obtaining (paying for, learning about, escorting to clinic) condoms or contraceptives] 


\section{Whap-wp \\ Ask participants to summarize what they have learned. Fill in any key} points they miss.

Key Message: Love is a powerful emotion, which everyone experiences differently. Be careful with love to avoid unhealthy relationships!

Go over some tips for keeping love and relationships healthy:

- Enjoy falling in love

- As the relationship progresses, observe and assess whether it is the one you want.

- Relationships with older men for money and gifts are not healthy as they increase the risk of HIV and other STI infections and create dependency.

- When conflict and pain are more common in a relationship than happiness and fulfillment, then it may be time to consider ending the relationship.

- In love, be realistic

- When a relationship ends, think of the positive things you gained and use them in your new relationships.

Ask for any final questions or comments. Remind participants where and when the next meeting will take place, and what topics will be discussed.

Thank them for their participation.

\section{PRACTICE ACTIVITY}

Participants should identify someone they love and reflect on how their relationship with that person has evolved over time. 
2) Reasons to Delay Sex*

\begin{tabular}{|c|c|c|c|c|}
\hline $\begin{array}{l}\text { SESSION } \\
\text { DESCRIPTION: } \\
\text { (LIFE SKILLS) } \\
\text { Participants discuss } \\
\text { a role-play and think } \\
\text { about why it can be } \\
\text { important to delay sex. }\end{array}$ & $\begin{array}{l}\text { OBJECTIVES } \\
\text { By the end of this session, } \\
\text { participants will be able to: } \\
\text { - List reasons to delay } \\
\text { sexual activity }\end{array}$ & $\begin{array}{l}\text { TIME } \\
1 \text { HOUR, } 20 \text { MINUTES } \\
\text { - Icebreaker (5 minutes) } \\
\text { - Review (5 minutes) } \\
\text { - Delaying Sex Role-play (15 } \\
\text { minutes) } \\
\text { - Reasons to Delay Sex ( } 45 \\
\text { minutes) } \\
\text { - Wrap-up (5 minutes) } \\
\text { - Practice Activity (5 minutes) }\end{array}$ & $\begin{array}{l}\text { MATERIALS } \\
\text { - Chalkboard and } \\
\text { chalk OR flipchart } \\
\text { and markers }\end{array}$ & $\begin{array}{l}\text { PRE-SESSION } \\
\text { PREPARATION } \\
\text { - Read through the entire session } \\
\text { and, if necessary, practice } \\
\text { presenting the activities } \\
\text { - Prepare all materials needed for } \\
\text { the session }\end{array}$ \\
\hline
\end{tabular}




\section{FACILITATOR NOTES}

Abstinence is a voluntary, conscious, deliberate decision not to do something. In the context of sexual intercourse, HIV, and unplanned pregnancies, abstinence is understood as not having sexual intercourse until marriage. Abstinence is the best and only certain way to prevent HIV transmission and unplanned pregnancy. Each time a young person performs an act of abstinence; he or she successfully postpones sexual intercourse. Even people who have already had sexual intercourse can decide to abstain from now on. This is called secondary abstinence.

Telling youth to abstain or say no to sex is not enough; young people should be guided on ways to achieve abstinence and must see the benefits of abstaining in their lives. Young people need support and skills to successfully abstain. Gaining self-esteem and having self-control in all matters, including sex, are best developed early in life.

There may be pressure from peers who claim everyone is having sex, or pressure from partners who argue that sex is the best way to prove love and affection, or pressure from older friends and relatives who say having sex is a way to show that you are an adult. Adolescents may not feel they have many choices, but you can explain to young people that they can say no to sex. You can help them develop refusal skills by counseling them about abstinence or delaying sexual activity. One way to do this is to help them imagine situations in which they might find themselves and help them practice saying no.

When discussing peer pressure, assertiveness, and responding to persuasion (in this session and later sessions), groups frequently discuss ways to say "no" to sex. It is useful to spend some time discussing the reasons to delay sex. If participants do not truly understand why to say "no," the process of behavior change has not really begun.

\section{TERMS}

\section{Abstinence}

Refraining from sexual activity, the only 100 percent effective method

for avoiding unwanted pregnancy and sexually transmitted infections, including HIV

\section{Secondary Abstinence}

The choice to stop having sex after one is no longer a virgin

\section{ICEBREAKER}

Open the session with an icebreaker of your choice, or allow participants to suggest one. See Appendix B: Participatory Facilitation Resources - Icebreaker Activities for ideas.

\section{REVIEW}

X Ask participants what key points were covered in the last session (optional: throw a ball of paper around to encourage participation). Fill in any key points that are missed.

Go over any practice activities that were given, and ask if there are any questions. 


\section{activity 1}

\section{DELAYING SEX ROLE-PLAY}

\author{
(15 MINUTES)
}

Find six volunteers (Edward, Edward's mother,

Edward's father, Maria, Maria's sister, Maria's mother, Maria's father) who are willing to do a role-play.

\section{Explain}

5 I will explain the role-play situation to you. Next you will take a few minutes to talk with each other, make a plan and practice the roleplay. Then, present the role-play to the whole group.

While the volunteers practice the role-play, introduce the idea of abstinence, or delaying sex until after marriage, until older, until more responsible, and so forth.
When the volunteers have finished practicing the role-play, ask them to present.

\section{Explain}

$S$ We are now going to watch a common situation between two young people. While you watch the role-play, the group should think about the reasons why these young people should delay their sexual activity.

\section{Delaying Sex Role-play}

Edward is 17 years old and helps his uncle in his shop. His parents are hardworking and hold traditional values. They believe that young people should not have sex before marriage. Edward is quite shy but would like to have sex because most of his friends say that it is great.

Maria is 14 but appears and acts older. Her sister became pregnant when she was 15 and her parents were very upset. Maria hasn't known Edward very long. She has just finished three classes on AIDS and really does not want to get HIV. She is afraid, however, that she might lose Edward if she refuses to have sex with him. 


\section{activity 2}

\section{REASONS TO DELAY SEX}

(45 MINUTES)

After the role-play ends, explore the situation with the group by making two lists on the chalkboard or flipchart: "Reasons for Saying Yes" and "Reasons for Saying No."

\section{Ask:}

5 What were some reasons to have sex in the role-play? [to prove their love to each other, to prevent their relationship from ending, because they are curious about sex, because everyone else is having sex, because it felt right, because one partner convinces the other that there will be no problems, if both are comfortable with the decision]

What were some reasons to delay sex in this role-play? [fear of pregnancy, fear of an STI, family expectations not to have sex, allow the relationship to grow more first, other forms of affection are possible, religious values do not approve of sex before marriage, do not feel ready, are too young, not the right person to have sex with]

Go through the "Reasons to Say Yes" list from the first question and discuss:

-What are the good reasons?

- Less convincing ones?

-What might be the consequences of each situation?

-What should Edward and Maria do?

-What reasons might be the strongest or most important for them?

Now, focus on the "Reasons to Say No" list and attempt to expand on it with the group by asking:

- Are there any additional reasons to delay sex that your group can think of?
Explain:

Now we are going to come up with a working list that you all agree on as the top 10 reasons to delay sex.

Facilitate the group to formulate the list. Use Box 6: Top 10 Reasons to Delay Sex for ideas if needed. Write the reasons on a flipchart paper so it can be posted for future reference.

\section{BOX 6: TOP 10 REASONS TO DELAY SEX}

1. Fear of pregnancy - "No sex" is 100 percent effective in preventing pregnancy.

2. Fear of STIs or HIV and AIDS - HIV and other STIs are transmitted through sexual intercourse.

3. Family expectations - Parents expect "no sex" until marriage.

4. Fear of violence - In a sexual situation, there is the possibility of being forced to have sexual intercourse.

5. Friendship - Allow time for the friendship to develop.

6. Drinking involved - Alcohol can lead to poor decisions (such as having sex without condoms).

7. Religious values - Values may preclude sex before or outside of marriage.

8. Not ready - You feel too young or just not ready.

9. Waiting for the right person - You want the person to truly love you before you have sex.

10. Wait until marriage.

\section{wrap-enp}

Ask participants to summarize what they have learned. Fill in any key points they miss.

$\sum_{1}^{3}$ Key Message: There are many significant reasons to delay having sex including preventing pregnancy, HIV and other STIs.

Ask for any final questions or comments. Remind participants where and when the next meeting will take place, and what topics will be discussed.

Thank them for their participation

\section{PRACTICE ACTIVITY}

Instruct participants to talk to a close friend about the reasons to delay sex. 


\section{3) Strategies for Delaying Sex*}

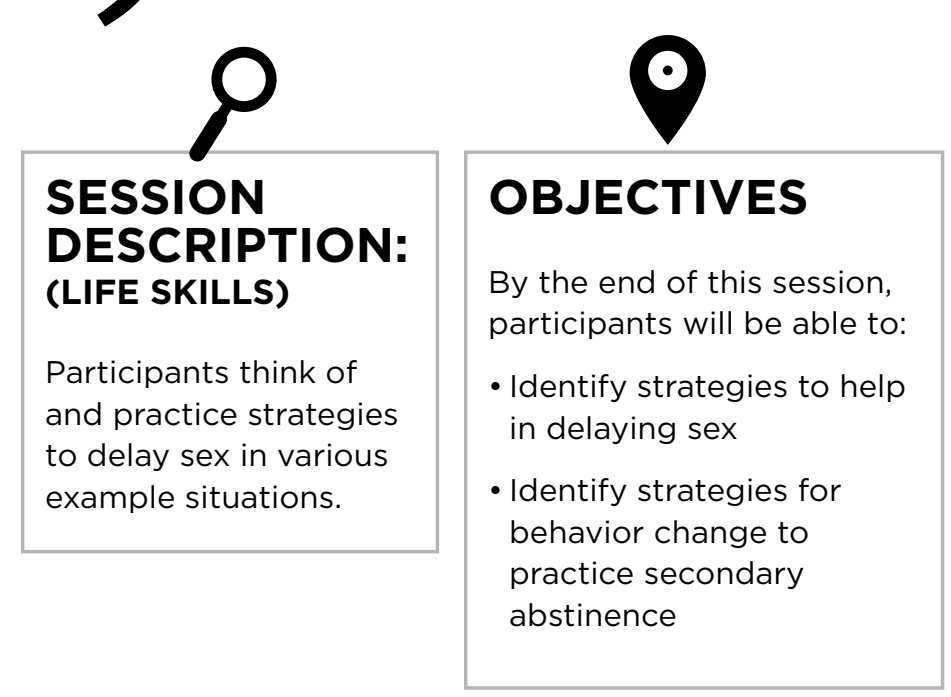

TIME
1 HOUR, 20 MINUTES
(10-14-year-olds)
OR
1 HOUR, 35 MINUTES
(15-19-year-olds)
- Icebreaker (5 minutes)
- Review (5 minutes)
- 'Hot Spots' in Delaying Sex (15
minutes)
- Delaying Sex Situations (45
minutes)
- Secondary Abstinence and
Behavior Change (15 minutes)
- Wrap-up (5 minutes)
- Practice Activity (5 minutes)

\begin{tabular}{|l|}
\hline MATERIALS \\
• Chalkboard and \\
chalk OR flipchart \\
and markers \\
- 3 large (preferably \\
life-size) pieces of \\
paper and enough \\
markers for each \\
participant \\
- Training aid \\
"Delaying Sex \\
Scenario Cards" \\
\hline
\end{tabular}

\begin{tabular}{|l|}
\hline PRE-SESSION \\
PREPARATION \\
- Read through the entire session \\
and, if necessary, practice \\
presenting the activities \\
- Prepare all materials needed for \\
the session \\
- Depending on the number of \\
participants you have, you may \\
need to create some additional \\
"Delaying Sex Scenario" Cards \\
- there should be one scenario \\
card for each group, and about \\
5 participants per group \\
\hline
\end{tabular}




\section{FACILITATOR NOTES}

\section{TERMS}

See Life Skills - Session 3: Reasons to Delay Sex for list of pertinent terms.
1. Have Reasons: Write out a list of specific reasons for why it is good to wait. Talk them over with someone who supports you. Check your list from time to time to remind yourself.

2. Have a Plan: Know what situations might make it hard to stick with your choice. Decide ahead of time what you'll do to avoid or deal with them, such as leaving a scene when being pressured to have sex. It can be hard to go against the crowd and make your own choices. Congratulate yourself for sticking to your plan.

3. Notice the Pressures and Sources: Pay attention to messages in music, videos, and movies telling you to play sex. Think about what your friends and family tell you about abstaining.

4. Get Support: Hang out with peers who know about and respect your decisions. Avoid people who might pressure or force you. If pressured, threaten to tell someone in authority (relative, teacher, pastor, chief or police). Learn to say "No!" forcefully and "No, no, no" repeatedly. Give a reason such as "I'm not ready" or "I've decided to wait until l've achieved my academic goals." Respond with assertive arguments for why you should not play sex: "You say that if I love you I could play sex, but if you really care about what happens to me in my future, you wouldn't insist," or "You say that it is time for me to pay you back, but I don't have to pay you back by playing sex."

\section{ICEBREAKER}

Open the session with an icebreaker of your choice, or allow participants to suggest one. See Appendix B: Participatory Facilitation Resources - Icebreaker Activities for ideas.

\section{REVIEW}

( Ask participants what key points were covered in the last session (optional: throw a ball of paper around to encourage participation). Fill in any key points that are missed.

Go over any practice activities that were given, and ask if there are any questions. 


\section{activity 1}

\section{'HOT SPOTS' IN DELAYING SEX}

(15 MINUTES)

Split participants into small groups (3-5 groups) (see Appendix B: Participatory Facilitation Resources Group Formation Activities for ideas). Distribute a large piece of paper to each group and a marker to each participant.

\section{Entacin}

$\int$ Each group should draw a human body on their paper. The best way to do this is to have one person lay on the paper while the other group members trace her. Then draw, identify, and label female body parts on the figure.

\section{Explain}

$\bigcirc$ The hotspots we identified often become physically 'hot' during or before sexual activity. If we are aware that they will react to sexual feelings or actions, we can learn to have more control over our sexual activity and make it easier to delay sex. For example, if we know where our sexual hotspots are, we can ask a partner not to touch them so that they do not become aroused, and we are not as tempted to have sex.

When participants have drawn and labeled the female body parts on their figures:

\section{Explain:}

S Next you should circle or star 'hot spots,' which are involved in sexual activity. These body parts are the ones we need to think

about and be aware of when deciding to delay sex.

When participants have finished with the female body on one side of the paper, instruct them to flip the paper and do the same activity for the male. 


\section{activity 2}

\section{DELAYING SEX SITUATIONS}

(45 MINUTES)

Briefly review the Top 10 Reasons to Delay Sex discussed at the end of the last session.

\section{Explain}

5 We have come up with a lot of good reasons to delay sex, but sometimes delaying sex can be difficult. This is especially true if both partners love each other and truly want to be more intimate and physical. It may be helpful to come up with some strategies to make delaying sexual activity easier.

If girls are not still in the three small groups from Activity 1, ask them to return to their groups. Give each group a card from the Training Aid: Delaying Sex Scenario Cards (scenarios also listed at the end of this session).

\section{Explain}

In your groups, you should read your situation card and come up with some suggestions to help the two people to delay sex. Think about the following questions:

- What are some ways for them to avoid sexual situations?

-What will make it easier for them to delay sex?
After the groups have finished working on their suggestions, instruct:

$\Omega$ Now each group will present the scenario on their card and their list of ideas on how to delay sex. We will discuss all the ideas together and come up with a list of strategies to delay sex that the whole group agrees on

As the group discusses strategies, write them down on a flipchart paper so that the list can be posted in the area where you usually meet. Possible ideas of how to delay sex include those mentioned in Box 7: Strategies for Delaying Sex.

The final suggestion on this list may raise a number of questions or a great deal of interest. If the group wants to talk about different ways to show affection other than sex, take this opportunity to explore what the group believes to be other options. If there is time, instruct:

5 Now we will create a list of the other ways, besides sexual intercourse, that we can show affection to our partners.

Spend time discussing if the suggested alternatives to sexual intercourse present risks of their own (kissing, rubbing, masturbating, oral sex, etc.). This may lead you to further discussions about alternatives to sex, as well as risk behavior and the different levels of risk.

\section{BOX 7: STRATEGIES FOR DELAYING SEX}

- Go to parties and other events with friends

- Decide how far you want to "go" (your sexual limits) before being in a pressure situation.

- Decide your alcohol or drug limits before a pressure situation arises or do not use alcohol or drugs at all.

- Avoid falling for romantic words or arguments.

- Be clear about your limits. Do not give mixed messages or act sexy when you don't want sex.

- Pay attention to your feelings. When a situation is uncomfortable, leave.

- Get involved in activities (e.g., sports, clubs, hobbies, church).

- Avoid "hanging out" with people who might pressure you to have sex.

- Be honest from the beginning, by saying you do not want to have sex.

- Avoid going out with people you cannot trust.

- Avoid secluded places where you might not be able to get help.

- Do not accept rides from those you do not know or cannot trust.

- Do not accept presents and money from people you cannot trust.

- Avoid going to someone's room when no one else is at home.

- Save your own money so that you do not have to economically depend on boys or men.

- Explore other ways of showing affection than sexual intercourse. 


\section{activity 3}

\section{SECONDARY ABSTINENCE AND BEHAVIOR CHANGE}

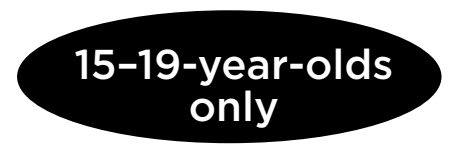

\section{(15 MINUTES)}

\section{Explain:}

It's never too late to choose abstinence. You can still decide to stop sexual activity even if you have already had sex. Sometimes people realize that they weren't ready for sex the first time and choose secondary abstinence.

Ask:

What does secondary abstinence mean to you? [the choice to stop having sex after one is no longer a virgin]

\section{Explain}

Sometimes it takes a lot of effort to change your behavior if you have already started having sex. This is because it is no longer a choice to delay a behavior, but a choice to change a behavior. Let's try to think of behavior change regarding secondary abstinence.

\section{Ask:}

What happens before thinking about secondary abstinence?

[still having sex, not yet considered abstinence]

What happens when someone thinks about secondary abstinence?

[consider the idea of no longer having sex, think of the reasons why this is a good idea or a bad idea, consider how the idea would shape your life, no decision made yet]
What happens when someone prepares for secondary abstinence?

[make a firm commitment to no longer have sex, think of how you will tell your partner, maybe discuss the idea with friends, peers, or a mentor]

What happens when someone takes action towards secondary abstinence?

[actively decide to no longer have sex, inform partner, or make a pledge to self if there is no partner]

What happens when someone maintains secondary abstinence?

[negotiate abstinence if an opportunity to have sex arises, avoid peer pressure or partner pressure to have sex]

What are some tips for maintaining secondary abstinence?

[avoiding people, places, things, and situations which weaken your self-control, find other ways to show your love and appreciation (e.g. kissing, hand holding, hugging) but be sure that these ways of expression do not lead to sex, be confident and committed to your decision!]

\section{Wrap-up}

Ask:

What is one strategy that you can use to delay sexual activity?

Ask participants to summarize what they have learned. Fill in any key points they miss.

Key Message: There are many strategies for delaying sex.

Ask for any final questions or comments. Remind participants where and when the next meeting will take place, and what topics will be discussed.

Thank them for their participation.

\section{PRACTICE ACTIVITY}

Instruct participants to visit places where they can find recreation within their community. Emphasize that these recreation places should be safe spaces, where they do not put themselves at risk. 


\section{DELAYING SEX SCENARIO CARDS}

Kaunda and Natasha have been seeing each other for six months now. They have not had sex yet but find it difficult to control their sexual feelings for each other. Natasha has promised herself not to have sex until she is older, and so far Kaunda has respected that wish. Natasha has been thinking about how much she likes Kaunda. One of their friends, who lives on his own, is going to have a party, and they are invited. Kaunda says he will bring some beer and that maybe they could stay all night. Natasha thinks about her promise to herself but also thinks it would be great fun to be alone with Kaunda.
Anne is 16 and lives with her mother and three younger siblings. Her mother works in the market and most of the time is able to support the family's needs. However, Anne has to cater for her personal needs, like clothes, sanitary towels, or anything else she needs for herself. Sometimes, her mother asks her to help buy food or medicine when she can't work or when her business at the market is slow. Anne spends time with Joseph who is 25 and lives in their neighborhood. He has a job as a taxi driver and often buys Anne new clothes, or gives her some extra money when she asks him. The last time that Anne went to Joseph's place he demanded that now she owes him and has to have sex with him the next time she comes. Anne needs money this week, but does not want to have sex with Joseph.
Mwamba and Chilombo are very serious about their relationship and would like to get married in a few years. Chilombo has invited Mwamba over to her house for the afternoon. Mwamba knows that Chilombo's parents will not get back until evening. This could be a good time for sex for the first time. Mwamba has been learning about pregnancy, HIV and AIDS, and STIs, and he is not sure he wants to have sex yet. However, he feels Chilombo would like to have sex and will probably tease him or tell her girlfriends if he doesn't.
Bupe met a young man Miyoba, at school. She was attracted to him because he is good looking and a good athlete. He said hello to her after school and gave her a small, beautiful presentfor future friendship, he said. He invited her to go for a walk to the river. Bupe is attracted to him but feels uncomfortable about the situation. However, she must give him an answer soon.
Jenala is in grade 10 and in a relationship with Monde who is at College. Jenala and Monde have been going to parties and movies together but have never had sex. Jenala's friends share their first sexual experience with her and tell her that it is ok for her to have sex with Monde since they love each other. Jenala thinks of how she will ask Monde to have sex with her. 


\section{4) Passive, Assertive, Aggressive*}

\begin{tabular}{l|}
\hline \multicolumn{1}{c}{} \\
SESSION \\
DESCRIPTION: \\
(LIFE SKILLS) \\
Participants learn \\
about attacking and \\
avoiding behaviors, \\
and perform role-plays \\
to practice identifying \\
passive, assertive and \\
aggressive behaviors. \\
\hline
\end{tabular}

\begin{tabular}{|l|}
\hline OBJECTIVES \\
By the end of this session, \\
participants will be able to: \\
• Define the terms \\
"passive," "assertive," and \\
"aggressive" \\
•Identify passive, assertive, \\
and aggressive behaviors \\
\hline
\end{tabular}

1 HOUR, 20 MINUTES
- Icebreaker (5 minutes)
- Review (5 minutes)
- Passive, Assertive, Aggressive
(30 minutes)
- Role-plays (30 minutes)
- Wrap-up (5 minutes)
- Practice Activity (5 minutes)

MATERIALS
- Chalkboard and
chalk OR flipchart
and markers
- Copies of
Activity Sheet 4:
Passive-Assertive-
Aggressive Chart
provided at the end
of this session (for
each participant)
or write content on
the chalkboard or
flipchart ahead of
time if copies are not
available

\begin{tabular}{|l|}
\hline PRE-SESSION \\
PREPARATION \\
- Read through the entire session \\
and, if necessary, practice \\
presenting the activities \\
Prepare all materials needed for \\
the session
\end{tabular}




\section{FACILITATOR NOTES}

Assertiveness is an important skill for getting along with others. Being assertive means standing up for yourself and being straightforward and honest with yourself and others about what you need and want. Being assertive can help you protect yourself from dangerous situations and can help you resist peer pressure to do things that you are uncomfortable doing. People who are not assertive are often submissive, and are often called passive. Passive means allowing what happens to happen without taking initiative to make a change. Even if they are being treated poorly, they do not stand up for themselves. People who are not assertive often lack the confidence and self esteem to stand up for their own needs and to protect their feelings or body from being hurt. Assertiveness is very different from being aggressive. People who are aggressive are rude and unkind. They do not care about other people's feelings. Being too aggressive is not very good for your emotional health because, deep down, you will feel bad about being unkind. Certain qualities and features, or attributes, are characteristic of people with aggressive or assertive personalities.

If you prepare the flipchart or board before the session, it can be helpful to add a picture to each word to make the definitions clear. Or, you might prefer to brainstorm the

flipchart with the group during the session.

\section{TERMS}

\section{Aggressive}

Delivering a message forcefully without thinking of the other person's feelings; expressing oneself in a confrontational manner

\section{Assertive}

Delivering a message by honestly expressing one's thoughts and feelings; being direct and clear without putting down the rights of others; showing mutual respect

\section{Attack}

Take aggressive action against

\section{Attributes}

A quality or feature that is characteristic of someone

\section{Avoid}

Keep away from

\section{Passive}

Accepting or allowing what happens, or what others do, without active response or resistance

\section{ICEBREAKER}

Open the session with an icebreaker of your choice, or allow participants to suggest one. See Appendix B: Participatory Facilitation Resources - Icebreaker Activities for ideas.

\section{REVIEW}

A Ask participants what key points were covered in the last session (optional: throw a ball of paper around to encourage participation). Fill in any key points that are missed.

Go over any practice activities that were given, and ask if there are any questions. 


\section{activity 1}

\section{PASSIVE, ASSERTIVE, AGGRESSIVE}

(30 MINUTES)

\section{Explain}

$\bigcirc$ We are going to have a brainstorming session for two words: "attacking" and "avoiding." We will start with the word "attacking." When I say go, you will call out what the word means to you. Gol

Note the ideas on the flipchart or chalkboard. Allow a few minutes and switch to "avoiding." There may be good and bad feelings expressed about each word.

If participants did not cover the following examples during the brainstorm, explain that some examples of attacking and avoiding behaviors are:

\section{Explain}

In this session we are going to talk in depth about these different kinds of behavior. "Attacking" behavior, when someone explodes or interrupts and persists is a type of behavior we call "aggressive".

\section{Ark:}

5 What are some examples of aggressive behavior? [see list of 'attacking' behaviors below]

When it seems clear that the group understands the connection between "attacking" and "aggressive," move on to the "avoiding" description.

Explain:

5 You have also told me what "avoiding" means to you, and thought of ideas like sulking in silence or trying to forget about something.

Ask: This type of behavior is called "passive."

5 What are some examples of passive behavior? [see list of 'avoiding' behaviors below]

\section{Instruct:}

5 Now think about the feelings associated with both attacking and avoiding behavior.

\section{Avoiding}

Withdrawal

Sulking in silence

Taking it out on the wrong person

Saying that you are being unfairly treated

Talking behind someone's back

Feeling ill

Being polite but feeling angry

Feeling low and depressed

Not wanting to hurt the other person

Trying to forget about the problem
Ask:

5 - Which type of behavior is better?

- Are either of them the best type of behavior?

- Is there another way to act?

- What would be a better approach to interactions with each other?

Allow the answers to these questions to lead to the idea of "assertiveness".

Ask:

What does "assertive" behavior mean?

[delivering a message by honestly expressing one's thoughts and feelings, being direct and clear without putting down the rights of others; showing mutual respect]

\section{Explain:}

$\int$ To be "assertive", it is not necessary for someone to be in the powerful or powerless position-in other words, it is not necessary to attack or avoid. Instead, it is possible to reach a balance between those two behaviors. We call this type of behavior "assertive."

Distribute copies of Activity Sheet 4: Passive - Assertive - Aggressive Chart to each participant (or write the content on the chalkboard or flipchart if copies are not available). Review each of the definitions with the group. Ask participants to give you examples of each type of behavior. 


\section{activity 2}

\section{ROLE-PLAYS}

(30 MINUTES)

\section{Explain}

5 Now we will do two role-plays to help us fully understand the differences between passive, assertive, and aggressive behavior. While you watch the role-plays, try to identify any passive, assertive, or aggressive behavior

Ask for two volunteers to do Role-play 1 (below). Instruct them through the role-play while the rest of the group watches.

After Role-play 1, lead a discussion with the following questions:

- Is Paulo's behavior passive, assertive, or aggressive? [aggressive]

\section{ROLE-PLAY 1}

Paulo has been seeing Chikondi for about one month now. He wants her to come to his house because his parents are not home. Because he often talks about getting into a more physical relationship, Chikondi feels pressured to be alone with Paulo. She tries to speak about her feelings a few times, but Paulo keeps interrupting her. Chikondi, her head down, finally says to Paulo, in a soft voice, "I know you'll think I'm silly, but..." Paulo interrupts again, approaches Chikondi nose to nose, and says loudly with his hands on his hips, "You are silly, and not only that, you're childish too!" Chikondi hangs her head down, looks at the ground, and agrees to go to Paulo's house.
- What did Paulo do to make you decide he was aggressive (include what he said, how she said it, and the body language he used)?

[answers may include:

- Body Language: moving closer to Chikondi and occupying her physical space; standing "nose to nose" or with "hands on hips"

- Interrupting

- Speaking in a loud voice

- Insulting Chikondi by calling her "childish"]

- Is Chikondi's behavior passive, assertive, or aggressive? [passive]

-What did she do to make you decide she was passive (include what she said, how she said it, and the body language she used)?

\section{ROLE-PLAY 2}

Tana has been upset with Kamel. When she sees him, she says, "Kamel, I need to talk to you right now. Could we talk where no one is around?" Moving to another room, Tana sits straight with her hands on the table and looks Kamel in the eye. She says in a calm but firm voice, "I've thought about your suggestion for our date, but I feel uncomfortable about it. I think we need more time to be close friends before being alone. I really like you and I know you'd like for us to be alone, but l'm not ready for that yet. Is that OK with you?" [answers may include:

- Body Language: head down, soft voice

- Giving in to the will of others

- Putting herself down - "I know you'll think I'm silly, but ..."]

Follow the same procedure for Role-play 2 (below).

Use the following questions to lead a discussion on Role-play 2:

- Is Tana's behavior passive, assertive, or aggressive? [assertive]

- What did she do to make you decide she was assertive (include what she said, how she said it, and the body language she used)?

[answers may include:

- Spoke in calm, firm voice

- Discussed her needs; made her feelings clear

- Checked to see if Kamel was comfortable with her statements

- Body language - faced Kamel, looked him in the eye] 


\section{wrap-up}

Ask participants to summarize what they have learned.

Fill in any key points they miss.

$\sum_{2 m}^{m}$ Key Message: Reach a balance between attacking and avoiding by being assertive.

Ask for any final questions or comments. Remind participants where and when the next meeting will take place, and what topics will be discussed.

Thank them for their participation.

\section{PRACTICE ACTIVITY}

Participants should practice being assertive among their peers. Inform them that they should be prepared to share their experiences practicing assertiveness in the next session. 


\section{ACTIVITY SHEET 4}

\section{PASSIVE-ASSERTIVE-AGGRESSIVE CHART}

\section{PASSIVE BEHAVIOR}

- Giving in to the will of others

- Hoping to get what you want without actually having to say it

- Leaving it to others to guess or letting them decide for you

- Taking no action to assert your own rights

- Putting others first at your expense

- Remaining silent when something bothers you

- Apologizing a lot

- Acting submissive-for example: talking quietly, laughing nervously, sagging shoulders, avoiding disagreement, hiding face with hands

\section{ASSERTIVE BEHAVIOR}

- Telling someone exactly what you want in a way that does not seem rude or threatening to them

- Standing up for your own rights without putting down the rights of others

- Respecting yourself as well as the other person

- Listening and talking

- Expressing positive and negative feelings

- Being confident, but not "pushy"

- Staying balanced-knowing what you want to say; saying "I feel" not "I think"; being specific; using "l" statements; talking face-to-face with the person; no whining or mocking; using body language that shows you are standing your ground, and staying centered

\section{AGGRESSIVE BEHAVIOR}

- Expressing your feelings, opinions, or desires in a way that threatens or punishes the other person

- Standing up for your own rights with no thought for the other person

- Putting yourself first at the expense of others

- Overpowering others

- Reaching your own goals, but at the sake of others

- Dominating behaviors-for example: shouting, demanding, not listening to others; saying others are wrong; leaning forward; looking down on others; wagging or pointing finger at others; threatening; or fighting 


\begin{tabular}{|c|c|c|c|c|}
\hline & $\begin{array}{c}\text { Alcol } \\
0\end{array}$ & $\otimes$ & Altering & $\nabla$ \\
\hline 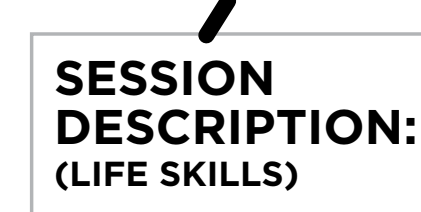 & 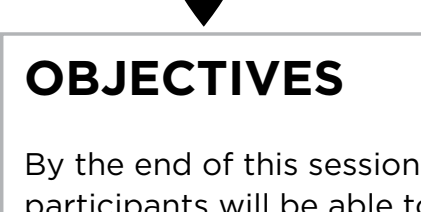 & 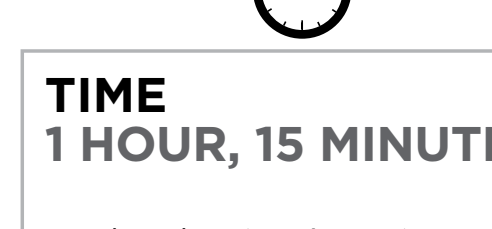 & MarerentL & 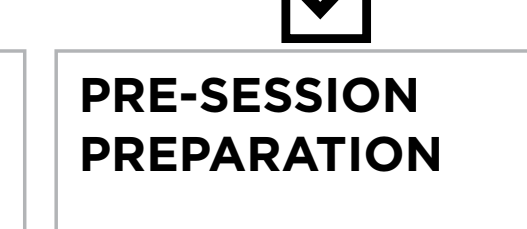 \\
\hline$\equiv$ & \pm & 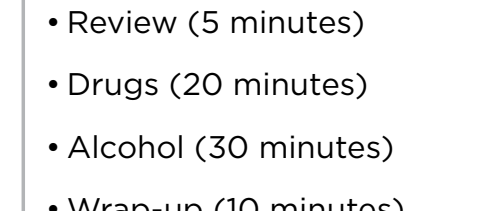 & & $=$ \\
\hline
\end{tabular}




\section{FACILITATOR NOTES}

Drugs and mind-altering substances have been a consistent part of the human experience. Historically, various botanical substances were used in religious ceremonies and traditional rituals for spiritual transcendence. This collection has been expanded to include today's man-made substances. Drugs have become commonplace, used and abused to escape reality or deaden life's disappointments.

Every day young people use drugs, alcohol and other mind-altering substances that damage their health and compromise their well-being. The reasons for this are varied and complex. Some young people fall prey to the use of substances like alcohol and tobacco through clever advertising strategies designed to win consumption of these products. Others use drugs to lessen feeling of failure, disappointment and emotional pain. Some seek the new experience and thrills drugs promise! Others use drugs for no other reason than to feel part of the group (to belong). The teen years are known to be a time when young people will want to experiment and without fully thinking through possible consequences.

Whatever the motivation, experimentation with drugs and alcohol can turn into persistent use with serious side effects. When addiction or excessive use results, both the individual and his/her family suffer!

\section{TERMS}

\section{Addiction}

The condition of being dependent on a substance, thing, or activity

\section{Alcoholic}

An individual who consumes alcohol in access and has difficulty functioning without alcohol

\section{Alcoholism}

The addiction to alcohol

\section{Depressants}

Drugs which reduce the functioning of nervous activity; makes the body react slowly

\section{Drugs}

Substances other than food which affect the chemistry and function of the body causing changes in behavior, e.g.

dagga, mandrax, glue, marijuana, kachasu and other forms of alcohol. Substances intended for use in the treatment or prevention of disease, e.g. Panadol, chloroquine, and fancida

\section{Drug Abuse}

The habitual taking of illegal or addictive drugs; considers the frequency, attitude toward, effects of, and physiological responses caused by the use of drugs, and the age and level of dependency of the user

\section{Drug Use}

The consumption of drugs

\section{Hallucinogens}

Drugs which cause hallucinations changing the way a person sees, hears, or feels

\section{Medicine}

A drug used for the prevention or treatment of a disease

\section{Mind-Altering Substances}

Drugs that affect brain function resulting in alterations in perception, mood, consciousness, cognition, and behavior

\section{Recreational Drugs}

Drugs used for enjoyment

\section{Stimulants}

Drugs which increase the level of nervous activity to make the body speed up

\section{ICEBREAKER}

Open the session with an icebreaker of your choice, or allow participants to suggest one. See Appendix B: Participatory Facilitation Resources - Icebreaker Activities for ideas.

\section{REVIEW}

$\circlearrowleft$

Ask participants what key points were covered in the last session (optional: throw a ball of paper around to encourage participation). Fill in any key points that are missed.

Go over any practice activities that were given, and ask if there are any questions. 


\section{activity 1}

\section{DRUGS}

(20 MINUTES)

\section{Explain}

$\Omega$ The term "drug" generally includes medicines, substances used for the treatment or prevention of disease. Drugs of this type are generally easily available, though some may require a prescription. 'Mind altering substances' are also drugs, but they are used to achieve altered states of consciousness. Both can harm the body, both can be abused.

Drugs used for the treatment or prevention of disease are called medicine. But even medicine can harm if used excessively or improperly. When we are sick, medicinal drugs may be given in prescribed doses to cure our illness. Medicinal drugs are legal, meaning they are permitted by law, in certain doses. Some non-medicinal drugs are legal, like tobacco or alcohol.

Many drugs are illegal, meaning they are not permitted by the law and someone can get in trouble for using them. These drugs usually have extreme effects on the mind and body. Some examples of illegal drugs in Zambia include: cocaine, heroin, mandrax, opium, and cannabis commonly known as chamba.

The "use" and "abuse" of drugs and alcohol are not the same. Use of drugs may come before abuse of drugs and does not necessarily lead to abuse. Drug abuse is not defined by frequency of drug use alone but also considers the age of the drug user, physiological responses, levels of dependency, attitudes about substance use, and the effects that the drug Ask: uses has on other areas of the user's life.

$\int$ What are some examples of different types of medicine that can be abused? [e.g., Cortem can be used for treating malaria, but if deliberately taken in high doses, it can terminate an unwanted pregnancy, which is regarded as an abuse of that drug, also Panadol may be ideal for aches and pains, but can be abused if taken for any and every slight discomfort]

\section{Explain:}

$\bigcirc$ Drugs used to create an altered state of consciousness are called mind-altering substances. Drugs that speed a person up are called "stimulants", e.g. tobacco, cocaine, and angel dust. Drugs that slow a person down are called "depressants," e.g. alcohol, sleeping pills. Drugs that change the way a person feels, sees and hears are called "hallucinogens", e.g. Mandrax, dagga. There is still another category of substances used neither medicinally nor recreationally but to alter the body's function-

\section{TABLE 2: DRUGS AND THEIR SIDE EFFECTS}

\section{DRUG SIDE EFFECTS}

\section{Nicotine (the substance}

in cigarettes) A highly

addictive stimulant

Increases heart rate conblood vessels causing

\section{Alcoho}

Addictive depressant

Drunkenness loss of coordi-

nation personality changes interferes with learning and memory increase in accidents increase in destructive acts

Marijuana Altered perception slowed

Hallucinogen, stimulant and depressant (all)

\section{Inhalants}

Jenkem, gasoline mind reflexes poor memory short attention span.

altering substance ing nonetheless. These would include drugs like diet pills. Tobacco and alcohol are among the most widely used "recreational" drugs.

Ask:

5 What are some examples of these types of drugs? [see example responses in Table 2: Drugs and Their Side Effects below]

What are their possible side effects? [see example responses in the table below] What do these drugs look like? [plants, cigarettes, pills, liquid substances, beer, wine, liquor, etc.]

How are these drugs used?

[smoked, chewed, inhaled, injected, drank]

Ask:

What does the term "addiction" mean? [the condition of being dependent on a substance, thing, or activity]

\section{Explain}

$\bigcirc$ Drug addiction occurs when the normal functions of the body are altered in such a way that the body begins to require the drug to function. Addiction can be psychological or physical, depending on the drug. The person who is addicted cannot function normally without the drugs of addiction. Many people cannot function without the stimulant caffeine found in coffee, tea and an assortment of softies. Some cannot socialize without alcohol or dagga. Without the drugs, the addict feels poorly, is anxious and restless and may even neglect himself or herself. Drug addiction is a serious problem requiring professional help to break the habit. 


\section{activity 2}

\section{ALCOHOL}

(3O MINUTES)

\section{Explain}

5 Alcohol is the most common mood-altering drug in Zambia.

\section{Ask:}

$\int$ How does alcohol consumption affect the mind and body?

[possible responses include:

- if you drink a lot of alcohol over a period of time it can seriously damage your body and mind

- alcohol acts as a depressant on the body. It slows our reflexes, constricts blood vessels and influences the way we see and interpret events around us,

- drinking too much can make men impotent (they can't keep an erection), and

- for a pregnant woman, drinking can damage her unborn child.]

\section{Explain}

5 People exhibit different responses to alcohol based on body weight, amount of alcohol consumed, presence of other drugs in the system, general health and how recently the Ask: person has eaten.

5 What does "alcoholism" mean? [the addiction to alcohol] What is an "alcoholic"?

[someone who consumes alcohol in excess and has difficulty functioning without alcohol]
Explain:

Alcoholics cannot control their drinking. Alcoholism can affect anyone - young, old, rich or poor. It is a myth that most alcoholics are living on the fringes of society. Alcoholics are people you see in your everyday routines. Alcoholism tends to run in families; children of alcoholics are much more likely to have a drinking problem than children of nonalcoholic parents. It is possible that alcoholics have a different chemical make-up that might be passed from one generation to the next.

Developing an awareness of the dangers of alcohol may enable young people like you to resist pressures to drink in excess. Knowing when to stop is a part of this awareness.

\section{Ask:}

What are some warning signs that someone's drinking is becoming a problem?

[possible responses include:

- drinking very fast; gulping your drinks,

- hiding your drinking from friends and family drinking in secret,

- feeling badly or frightened after drinking too much,

- feeling that you need a few drinks to get your confidence level up,

- drinking early in the day,

- losing control when you drink saying or doing things you regret, and
- not remembering what you did after a night of drinking.]

What are some possible health problems that alcoholism can cause?

[possible responses include:

- memory loss,

- liver and heart damage,

- "black-outs,"

- shaky balance, and

- mood swings; may have outbursts of violence or depression while drinking]

What are some serious consequences can result from alcohol and drug use?

[possible responses include:

- young people's normal growth and development is often stopped,

- drug abuse and addictive behaviors interfere with the establishment of healthy relationships,

- drug use impairs judgment in critical areas,

- accidents, missed opportunities unintended pregnancies, academic failure and STI infections are more likely when you can't think straight, and

- drug addiction and alcoholism also diverts needed financial resources from more constructive endeavors] 


\section{wrap-epp}

\section{Ask:}

5 Why do people use drugs? Alcohol?

[drugs: for fun/recreation, for medicinal purposes, to experiment, to look 'cool,' etc., alcohol: for fun/recreation, to 'feel better,' to look 'cool,' etc.]

What are some of the effects of drug and alcohol use? [memory loss, bad decision-making, more exposure to HIV and unplanned pregnancy, loss of coordination, etc.]

What are the dangers involved with drug and alcohol abuse?

[permanent damage to liver, heart, and/or brain, defects in unborn child of pregnant woman, neglect of family, hygiene, and job, impotence in men, etc.]

What drugs do young people use in your community? What drugs do adults use?

What alternatives are there to drug and alcohol use for young people?

[playing games (especially sports), drinking soda, starting a business, doing homework, helping parents, hanging out with friends, visiting the cinema or other social events, etc.]
Ask participants to summarize what they have learned. Fill in any key points they miss.

Key Message: Drugs and alcohol have many negative consequences, which young people should be careful to avoid.

Ask for any final questions or comments. Remind participants where and when the next meeting will take place, and what topics will be discussed.

Thank them for their participation.

\section{PRACTICE ACTIVITY}

Participants should teach a peer or younger sibling/child about the long-term side effects of alcohol and drug use. 


\section{6) Peer Pressure}

\begin{tabular}{|l|l|}
\hline $\begin{array}{l}\text { SESSION } \\
\text { DESCRIPTION: }\end{array}$ & $\begin{array}{l}\text { OBJECTIVES } \\
\text { Participants role-play } \\
\text { to explore ways of } \\
\text { resisting peer pressure. }\end{array}$ \\
\hline & $\begin{array}{l}\text { Participants will be able to: } \\
\text { situations faced by young } \\
\text { people } \\
\text { - List several strategies for } \\
\text { dealing with peer pressure } \\
\text { - Identify the strategies } \\
\text { they are most comfortable } \\
\text { with }\end{array}$ \\
\hline
\end{tabular}

1 HOUR, 10 MINUTES
- Icebreaker (5 minutes)
- Review (5 minutes)
- Peer Pressure Role-plays (50
minutes)
- Wrap-up (5 minutes)
- Practice Activity (5 minutes

\begin{tabular}{|l|}
\hline MATERIALS \\
• Various props for \\
the role-plays such \\
as empty bottles, \\
radios with tape \\
players, cloth or \\
clothes, and others \\
- Training aid "Peer \\
Pressure Scenario \\
Cards" \\
\hline
\end{tabular}

\section{四 \\ PRE-SESSION PREPARATION}

- Read through the entire session and, if necessary, practice presenting the activities

- Prepare all materials needed for the session 


\section{FACILITATOR NOTES}

Peer influence does increase during adolescence, but the influence of caring adults can remain strong if a strong relationship has been established during earlier years. Most peer pressure for young people is just as subtle as it is for most adults.

This is why practicing saying 'no' to peer pressure is important. Finding creative ways to refuse alcohol, tobacco, drugs, and sex requires humor and lots of practice. Each young person can help develop his or her own ways of saying no, but it's your job to help them practice these so that they are prepared if the offer is more subtle or more direct than what was expected. A lot of this will depend on the age and attitude of the child, and the most important thing is to make sure the child is comfortable with what he or she wants to say.

The idea behind Training Aid: Peer Pressure Scenario Cards is to create situations that a young person might actually face and allow the group to process the best way to handle these situations. When creating your roleplay scenarios, it is best for you to explore with your community the most common risk situations a young person might face in your area. Develop the role-plays from these situations.

You may wish to highlight peer pressure as one of the most powerful issues in the life of anyone, especially a young person. It is important to think about and practice approaches to peer pressure when attempting to develop the skills necessary to lead a healthy, positive life.

\section{TERMS}

\section{Peer Pressure}

Influence on another person's decisions or the exertion of

influence on someone to manipulate them into following certain behaviors or beliefs of people in their social group

\section{ICEBREAKER}

Open the session with an icebreaker of your choice, or allow participants to suggest one. See Appendix B: Participatory Facilitation Resources - Icebreaker Activities for ideas.

\section{REVIEW}

( Ask participants what key points were covered in the last session (optional: throw a ball of paper around to encourage participation). Fill in any key points that are missed.

Go over any practice activities that were given, and ask if there are any questions. 


\section{activity 1}

\section{PEER PRESSURE ROLE-PLAYS}

(50 MINUTES)

Divide the group into five small groups (see Appendix B: Participatory Facilitation Resources - Group

Formation Activities for ideas), and give each a card from the Training Aid: Peer Pressure Scenario Cards (scenarios also listed at the end of this session). For illiterate groups, identify girls in each group who can read out the scenario. If there is no one who can read, read the scenario on the card to each group.

\section{Explain}

5 Meet with your group to talk about the peer pressure situation on the card. Come up with a realistic reaction or response for the problem. Then you will create a role-play showing the situation and how the young person resists peer pressure, and finally perform it for the larger group.

(NOTE TO FACILITATOR: Emphasize that the solution presented in the role-play should be realistic. Often, when adults do this activity, the solution seems to be easy- the character "just says no" or preaches the right way to live and everyone accepts it. When young people do the role-play, it is seldom that simple. The reason peer pressure is so powerful is that young people want to "fit in." They care what other people their own age feel and think about them. The exercise is most valuable if the small groups develop some realistic strategies to help themselves out of these situations without making them "lose face" or become ostracized by their friends. When doing this exercise with young people in your community, note the strategies that they use, as these may be the most effective ones available to them.)

After each group of participants finishes presenting a role-play, process the situation and responses with the entire group by asking the following questions:

-Was the role-play realistic?

- Would the resistance demonstrated actually work in the situation?

- Is this a common situation in our communities? 


\section{activity 2}

\section{PEER PRESSURE DISCUSSION}

\section{(15 MINUTES)}

Lead a discussion on the following questions:

- What is peer pressure?

[social pressure by members of one's peer group to take a certain action, adopt certain values, or otherwise conform in order to be accepted]

-What types of peer pressure do you face?

[e.g., pressure to wear certain clothes, pressure to like certain things, pressure to do certain things, pressure to try alcohol or drugs, pressure to have sex, etc.]

-Where does peer pressure come from?

[peer pressure may be present at school, home, or in the community]

-Why does peer pressure arise?

[someone may tell you what to do, sometimes you think it in your own head - feeling different from the group, sometimes it happens naturally if you and your peers normally do certain activities or have certain habits]
- How can one avoid or manage peer pressure?

[hang out with people who have the same interests as you, say 'no' using assertive techniques, stand-up for someone to help them feel it is okay to do what they choose, try not to judge others]

-Where can someone go for help if they face too much peer pressure?

[e.g., older siblings, close friends, parents, teachers, community leaders, mentors, etc.]

\section{wrap-up}

Go around the room and ask each participant:

-What is one specific strategy that you would be comfortable using to resist peer pressure?

This activity may help you to gauge how likely it is for participants to use these strategies for their own situations.

Ask participants to summarize what they have learned. Fill in any key points they miss.

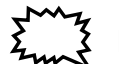

Key Message: Peer pressure is common during adolescence, but remember, it is always okay to say 'no.'

Ask for any final questions or comments. Remind participants where and when the next meeting will take place, and what topics will be discussed.

Thank them for their participation.

\section{PRACTICE ACTIVITY}

Participants should practice resisting peer pressure (or standing up for others who are experiencing it). They should be prepared to share their experiences in the next session. 


\section{PEER PRESSURE SCENARIO CARDS}

1. A group of girls are sitting together and talking about the latest fashions. They start making fun of one of the girls who has not been able to buy any new clothes lately. The girls say that she doesn't have the money. The other girls tell her that she should ask for money from Paul, her neighbor who is 10 years older than she is. The girl says that she knows he would give the money, but then he would eventually expect her to have sex with him.

Create a role-play showing how this girl could handle this situation assertively.
2. A group of secondary school girls are at a dance.

They are dancing and

having a really good time

together. One of the girls in

the group takes out some

alcohol from her hand-

bag. She starts drinking and tries to get the others to drink, too. She says that there is more to drink outside and tries to pressure her friends to join her in drinking. Some of her friends agree.

Create a role-play showing how the friends who do not agree could handle this situation.
3. A group of girls are talking about boys at their secondary school. Most of them say they have had sex, and they are teasing one about the fact that she has not had sex and she is still a virgin.

Create a role-play showing how this girl could handle this situation assertively.
4. A group of friends are chatting about their boyfriends during break time. Each of them is bragging about how much time she spends with her boyfriend instead of studying. One of the friends tells the others the importance of education and spending time studying, instead of just being with a boyfriend.

Create a role-play showing how the girl uses her negotiation skills and assertiveness to influence her friends positively.
5. A group of friends are hanging out near the market. They are talking about how bored they are. They really wish they had something to do. One of them suggests that they go to the grocery store and steal some chocolate. Some of the friends agree-excited to do something on this boring day! As the group walks to the store, one of them is not comfortable with the idea and suggests that they go to her place and revise some exam questions together. To convince her friends not to steal, she explains to them the dangers of stealing. She also explains how exciting and fun it will be for all the friends to study together and learn from one another.

Create a role-play showing negative and positive peer pressure and the benefits of avoiding negative peer pressure. 


\section{7) Making Good Decisions*}

\begin{tabular}{l|l|}
\multicolumn{1}{l|}{} \\
\begin{tabular}{|l|l|}
\multicolumn{1}{l|}{ SESSION } \\
DESCRIPTION: \\
(LIFE SKILLS)
\end{tabular} \\
\begin{tabular}{l|l|} 
Participants discuss \\
the steps involved \\
in making good \\
decisions, and learn \\
the importance of \\
considering the \\
consequences of each \\
decision they make.
\end{tabular} & $\begin{array}{l}\text { OB the end of this session, } \\
\text { participants will be able to: } \\
\text { - List the four "Good } \\
\text { Decision-Making Steps" } \\
\text { - Describe some of the } \\
\text { important factors to } \\
\text { consider in decision- } \\
\text { making }\end{array}$ \\
\hline
\end{tabular}

1 HOUR, 20 MINUTES
- Icebreaker (5 minutes)
- Review (5 minutes)
- Small Group Work (20 minutes)
- Did I Make a Decision Today?
(20 minutes)
- Decisions and Consequences
(20 minutes)
- Wrap-up (5 minutes)
- Practice Activity (5 minutes)

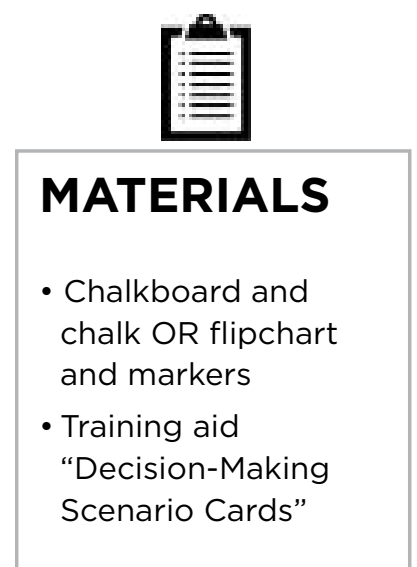

\section{四 \\ PRE-SESSION PREPARATION}

- Read through the entire session and, if necessary, practice presenting the activities

- Prepare all materials needed for the session 


\section{FACILITATOR NOTES}

A decision is a choice that we make between two or more possible options. We all make decisions every day. We will need to make more and more decisions as we go through life and some of these decisions will affect us the rest of our lives.

One of the most important parts of decision-making is looking ahead to see what might happen if you do something. This is called predicting outcomes or understanding consequences. The better you are at predicting outcomes, the better you will be at making decisions that result in the outcomes or consequences you want.

Key steps for good decision-making include:

- Describe the problem, situation, or issue that needs a decision.

- Get more information if you have questions about the situation.

- Think about the possible consequences or outcomes of each course of action.

- Think about your personal and family values, and which courses of action are consistent with these values.

- Think about the ways in which your decision may affect other people.

- Choose the decision that seems most appropriate based on your knowledge, values, morals, religious upbringing, and present and future goals.

- Re-think the decision and how you feel about it.

- Be sure you carefully considered all the alternatives and feel comfortable with the choice you made.

\section{TERMS}

\section{Consequences}

Good or bad things that can result

from a decision or action

\section{Decision}

A choice between two or more options

\section{Decision-Making}

The process of reaching a decision

\section{Process}

A series of actions or steps taken to achieve something

\section{ICEBREAKER}

Open the session with an icebreaker of your choice, or allow participants to suggest one. See Appendix B: Participatory Facilitation Resources - Icebreaker Activities for ideas.

\section{REVIEW}

O

Ask participants what key

points were covered in the last session (optional: throw a ball of paper around to encourage participation). Fill in any key points that are missed.

Go over any practice activities that were given, and ask if there are any questions. 


\section{activity 1}

\section{SMALL GROUP WORK}

\section{(2O MINUTES)}

\section{Explain:}

5 Good decision-making skills can help someone avoid risky activities. For instance, if you are thinking of trying to drink alcohol, you have to decide between 'yes': doing it, and 'no': not doing it. You might decide to do it if you see other people around you who are doing it and having fun, but are not aware of the dangers it can bring like we Ask: discussed in the session about alcohol.

5 What steps might young people take if they have to decide something crucial?

What should they do first? Next?

Should they seek advice? From whom?

Divide participants into seven small groups (see $A p$ pendix B: Participatory Facilitation Resources - Group Formation Activities for ideas). Give each group a card from the Training Aid: Decision-Making Scenario Cards (scenarios also listed at the end of this session).

Explain:

$\bigcirc$ Each group should:

- Discuss the situation on the card.

- Decide what the people in the scenarios who are trying to make a decision should do first.

- List the steps that the people should take in trying to reach their decision.

- Finally, as a group, discuss the situation and make a decision for the scenario on the card.

- Then, on the flipchart or part of the chalkboard, write (or draw) the steps to making a decision, what decision the group would make for the scenario, and the reasons for the final decision.

(NOTE TO FACILITATOR: You may wish to emphasize that the actual decision the groups reach is less important than understanding the "process" someone might go through to make such a decision and the factors to be considered.) 


\section{activity 2}

DID I MAKE A DECISION TODAY?

(20 MINUTES)

\section{Instruct:}

$\int$ Now I want you to think about this day, from when you woke up to right now.

\section{Ask each participant:}

5 What is one decision you have made today?

Pick one decision point, based on the most popular response (e.g., what to wear, what to eat, who to talk to, which way to walk to the market/club), and lead a discussion on it with the group. Emphasize that we make decisions every day but we often don't think about them.

\section{Instruct}

$\int$ Turn to the person next to you and explain about a time when you have made a difficult decision. Make sure you tell the person what the decision was and what happened as a result of it.

\section{Explain}

In order to make good decisions, it is important to follow four steps. The steps are:

1. Stop and think.

2. Consider the consequences of your decision. (Consequences are good or bad things that can result from your decisions or actions.)
3. Know the facts.

4. Execute your decision

Now let's look at the list of decision-making steps you made with your groups from the first activity, and see how those steps compare to these four.

Most of the steps participants listed should fit into one of the four steps above (i.e., talking to a friend or trusted adult could be part of considering the consequences and knowing the facts).

\section{Explain}

$\int$ Talk to the person sitting next to you again and see if they went through these four steps when making their decision. If they did not, discuss how these four steps could have been helpful. 


\section{activity 3}

\section{DECISIONS AND CONSEQUENCES}

(2O MINUTES)

\section{Explain}

The next activity is a "decision points" game and is an opportunity for you to practice making decisions. I am going to read a story about Oto and Beatrice. Whenever I stop the story, you should clap your hands twice (CLAP, CLAP). Clapping means Beatrice and Oto need to stop and make a decision. You will work together to make a decision for Beatrice and Oto.

READ:

A young man, named Oto, stops his car to talk to a girl, named Beatrice, and eventually he asks if she wants a ride.

STOP, clap your hands twice (CLAP, CLAP), and ask:

Consequences:

-What could happen if Beatrice gets in the car with Oto?

- What can happen if she doesn't get in the car?

Know the facts:

- What does Beatrice know about Oto?

-What does she know about others who have accepted rides from Oto? Or others like him?

\section{READ:}

Beatrice accepts the ride and Oto offers to stop by the bar and buy her a beer on the way home.

STOP, clap your hands twice (CLAP, CLAP), and ask:

Consequences:

-What could happen if Beatrice agrees to have a beer with Oto? -What could happen if Beatrice doesn't have a beer with Oto?

Know the facts:

-Why is Oto offering Beatrice a beer?

-Does Beatrice know about the effects of alcohol on herself? On Oto?

- How will she get home if Oto is drunk?

\section{READ:}

Beatrice tells Oto that she will go to a bar with him if he agrees to have one beer only and then take her home. He agrees. Inside the bar he orders one beer each and then several more for himself, until he is drunk. Beatrice tries to leave the bar, but Oto grabs her and harasses her. Beatrice is able to make it outside the bar but once she gets outside she sees that it is dark. She needs to get home.

STOP, clap your hands twice (CLAP, CLAP), and ask:

Consequences:

- How could she get home safely?

-What could happen if she tries to walk? Or goes and waits for him?

-What could happen if she contacts a friend or family member?

Know the facts:

-What are her other options?

- Can she ask someone else? Or call a person for help?

End the session by leading an overall discussion on the story with the following questions:

-What were the decision points within this story? [when Oto asks Beatrice if she wants a ride, when Oto buys Beatrice a beer, when Beatrice wants to get home]

-What were the consequences of Beatrice's decisions? [her decision to get in the car with Oto led to him buying her a beer, which led to him harassing her, which led to her wanting to get home and not knowing how]

- Would you have made similar decisions if you were in the same situation?

- Why or why not? wrap-enp

Remind participants of the importance of accepting responsibility for your decisions and their consequences.

Ask participants to summarize what they have learned. Fill in any key points they miss.

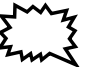

Key Message: Decisionmaking skills will help you to avoid the negative consequences of decisions and positively shape your lives!

Ask for any final questions or comments. Remind participants where and when the next meeting will take place, and what topics will be discussed.

Thank them for their participation.

\section{PRACTICE ACTIVITY}

Instruct participants to practice the following good Decision-making skills that we discussed today:

1. Stop and think.

2. Consider the consequences

3. Know the facts.

4. Execute your decision. 


\section{DECISION-MAKING SCENARIO CARDS}

1. You are a 15-year-old girl living in a small town. You are taking care of four younger siblings, and you cannot find money for food. You have a friend near the market who has been offering you nice gifts and buying some food for you. Recently, he has suggested that you should meet together at a rest house (inn or motel). What will you do?
2. You are a 20-year-old man, and you have recently married. You and your wife are students at the university. You want to start a family, but you also want to finish your degrees and get jobs. Your wife has suggested using something to prevent pregnancy.
3. You are a 12-year-old girl who is in the final term of primary school. You have been washing clothes for neighbors on the weekends to earn money, most of which you have saved. You were planning to use these savings to purchase a new dress for your cousin's wedding, which is in one month. Your older sister is in her final term at secondary school and wants to go to college to get a diploma in computer science. She is confident that this will help her find a job. She asks you for money to contribute to her school-fees.
4. You and your boyfriend are in love and you plan to be married. You have been abstaining from sex until after you get married, but it is becoming harder and harder to abstain as time passes. Lately, your boyfriend has been suggesting that you have sex now. After all, you are truly committed to each other and are getting married anyway.
5. You are a 17-year-old girl in secondary school. Your anti-AIDS club has been very active lately, and you have been thinking a lot about AIDS. You think that your past experiences may have put you at risk to be HIV-positive, but you are afraid to know for sure. A close friend has suggested that you get an HIV test.
6. You are a 16-year-old girl who is not enrolled in school. Along with helping your mother with household chores and taking care of your younger brothers and sisters, you try to earn some extra money on the side by selling eggs at the market. You planned to buy books with this money so that you could study even though you are not in school. One day your friend found your saved cash under your mattress when she was visiting. She is now trying to convince you to use the money at the salon to get your hair done and to buy lotions and perfumes.
7. You are a 20-year-old boy just entering the final grade in secondary school. Your father died several years ago, and your uncle has paid your school fees for the last few years. Your uncle has just died, and now there is no one to pay for your final year in school. You are hopeful that you can get a placement at university if you are able to take the college entrance exams. But because there is no money for school, you are considering trying to find some work for a few years and returning to school later. 


\section{8) How to Communicate with Adults*}

\begin{tabular}{|l|}
\hline SESSION \\
DESCRIPTION: \\
(LIFE SKILLS) \\
Participants practice \\
skills for dealing with \\
situations when they \\
may disagree with an \\
adult or wish to ask \\
for something from an \\
adult.
\end{tabular}

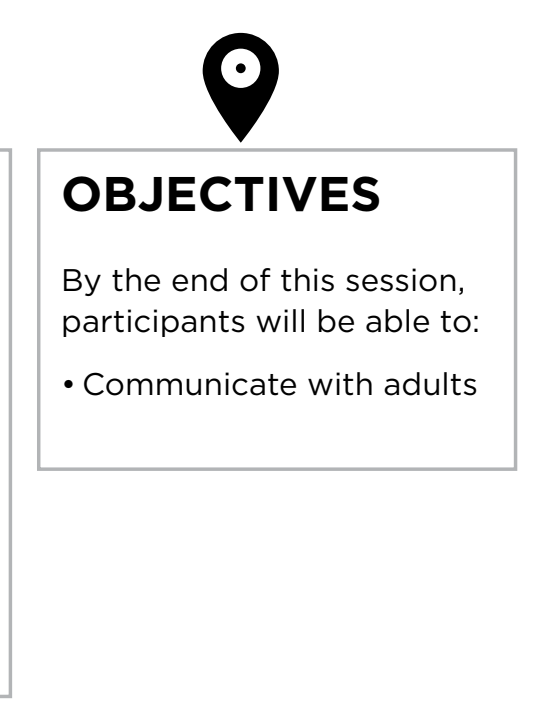

TIME
- Icebreaker (5 minutes)
- Review (5 minutes)
- How to Handle Disagreements
(25 minutes)
- How to Communicate with
Adults (20 minutes)
- Wrap-up (5 minutes)
- Practice Activity (5 minutes)
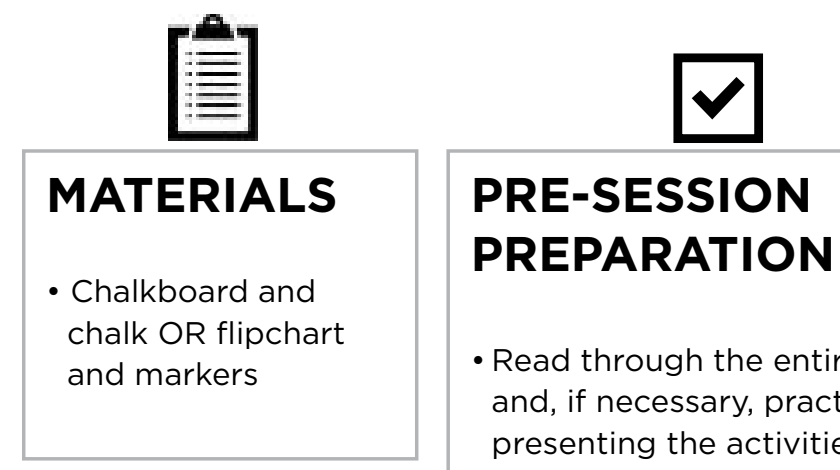

- Read through the entire session and, if necessary, practice presenting the activities

- Prepare all materials needed for the session 


\section{FACILITATOR NOTES}

See Introductory Sessions - Session 5: Communication

\section{TERMS}

See Introductory Sessions -

Session 5: Communication

\section{ICEBREAKER}

Open the session with an icebreaker of your choice, or allow participants to suggest one. See Appendix B: Participatory Facilitation Resources - Icebreaker Activities for ideas.

\section{REVIEW}

$\circlearrowleft$

Ask participants what key points were covered in the last session (optional: throw a ball of paper around to encourage participation).

Fill in any key points that are missed.

Go over any practice activities that were given, and ask if there are any questions. 


\section{activity 1}

\section{HOW TO HANDLE DISAGREEMENTS}

\section{(25 MINUTES)}

\section{Ark:}

5 How do you usually communicate with adults?

What are some examples of how you communicated with adults when you were very young?

What are some examples of how you communicate with adults now?

How has the way you communicate with adults changed over time?

What are some disagreements you have had with your parent/guardian in the past six months?

Divide the group into pairs (see Appendix B: Participatory Facilitation Resources - Group Formation Activities for ideas). Assign each pair of participants a disagreement from their answers to the last question. If you need additional disagreements, use the following:

- Your parent/guardian told you not to spend time with a certain boy. Your older sister saw you with the boy and reported it to your parent/guardian.

- Your mother wants you to wake up early in the morning to help with the household chores but you want to sleep in.

- Your father/guardian saw you drinking alcohol.
Explain:

5 In each pair, one person is the adolescent and the other is the parent. Together, you will make a role-play about the disagreement. Then switch roles and have another disagreement.

Find three groups to volunteer to perform their argument for the rest of the participants. After each roleplay, ask the group:

-What helped the adult understand the adolescent?

-What didn't help/made it harder for the adult to understand the adolescent?

- How could the situation be improved?

-What could the adolescent and the adult do to understand each other better? 


\section{activity 2}

\section{HOW TO COMMUNICATE WITH ADULTS}

(2O MINUTES)

\section{Explain:}

In addition to the strong communication skills learned in previous sessions - including assertiveness, there are specific skills that youth can use to improve communication with parents/guardians. These are called the "convincing" skills:

- Be prepared: Know what you are asking for and think through the consequences of your request.

- Pick the right time: When the situation at home is relaxed.

- Be calm: Present your topic calmly and with facts.

- Listen to what your parents or guardians have to say: Consider their point of view and whether they might be right. Remember that parents generally have your best interest at heart.

\section{Instruct:}

I am going to read out some scenarios. For each scenario, we will have a discussion on how the people in the scenario could practice "convincing" skills.
Read the following scenarios and go lead a discussion to apply the "Convincing" skills to each scenario:

- Scenario 1: Ana wants to ask her parent or guardian to help her go back to school.

- Scenario 2: Maria's father has been pressuring her to go out with one of his friends.

- Scenario 3: Sonya wants to ask her mother to go with her to get birth control pills.

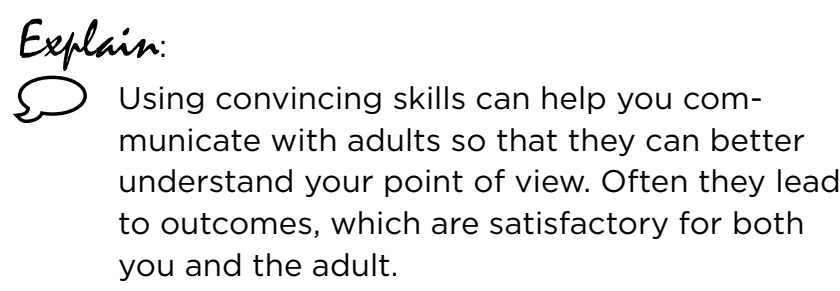
you and the adult.

\section{wrap-epp}

Ask participants to summarize what they have learned. Fill in any key points they miss.

Key Message: Good communication skills help when asking an adult for something or in resolving disagreements with adults.

Ask for any final questions or comments. Remind participants where and when the next meeting will take place, and what topics will be discussed.

Thank them for their participation.

\section{PRACTICE ACTIVITY}

Instruct participants to practice the following four convincing skills we learned today when speaking to an adult:
1. Be prepared
2. Pick the right time
3. Be calm
4. Listen to what your parents say 
9)

SESSION
DESCRIPTION:
(LIFE SKILLS)
Participants learn
the importance of
good communication,
think about the
consequences of
having sex, and role-
play to practice talking
to a partner about sex.

\begin{tabular}{|l|}
\hline OBJECTIVES \\
By the end of this session, \\
participants will be able to: \\
- Outline steps for decision- \\
making on assessing \\
whether to start or \\
to continue a sexual \\
relationship \\
- Name at least two \\
advantages to \\
communicating with a \\
partner \\
- Demonstrate how to talk \\
to a partner
\end{tabular}

TIME
1 HOUR, 25 MINUTES
- Icebreaker (5 minutes)
- Review (5 minutes)
- Talking to Your Partner About
Sex and Sexual Health Issues (5
minutes)
- Am I Ready? (20 minutes)
- Talking to My Partner (40
minutes)
- Wrap-up (5 minutes)
- Practice Activity (5 minutes)

15-19-year-olds only

\begin{tabular}{|l|l|}
\hline - Chalkboard and \\
chalk OR flipchart \\
and markers \\
Pen and paper for
\end{tabular}$\quad \begin{aligned} & \text { - Read through the entire session } \\
& \text { and, if necessary, practice } \\
& \text { presenting the activities } \\
& \text { - Prepare all materials needed for } \\
& \text { the session } \\
& \text { - Review the questions in Activity } \\
& 2 \text { and adapt based on their } \\
& \text { relevance to the girls in your } \\
& \text { group - that is, if they are } \\
& \text { sexually active or not } \\
& \text { - Review the list of role-play } \\
& \text { options in Activity } 3 \text { to see if } \\
& \text { there are other ideas that would } \\
& \text { be more relevant to the girls in } \\
& \text { your group }\end{aligned}$




\section{FACILITATOR NOTES}

If participants have initiated sexual activity or already have a child, then the questions in Activity 2 should be adapted to include both girls thinking about being sexually active and those who have already started.

\section{TERMS}

None

\begin{abstract}
were given, and ask if there are any questions.
\end{abstract}

Go over any practice activities that

\section{ICEBREAKER}

Open the session with an icebreaker of your choice, or allow participants to suggest one. See Appendix B: Participatory Facilitation Resources - Icebreaker Activities for ideas.

\section{REVIEW}

Ask participants what key points were covered in the last session (optional: throw a ball of paper around to encourage participation)

Fill in any key points that are missed. 


\section{activity 1}

\section{TALKING TO YOUR PARTNER ABOUT SEX AND \\ SEXUAL HEALTH ISSUES}

(5 MINUTES)

\section{Explain:}

5 Communication is an important part of a sexual relationship. Communication with a sex partner is important for ensuring that both people are consenting to engage in sexual activity.

Effective communication can help people protect their own and their partners' well-being. This protection includes: guarding against sexually transmitted infections, including HIV, protecting against unwanted pregnancy, and reducing the likelihood of a conflict that could lead to violence.

Communication can also increase mutual trust and pleasure. Communication is important for clarifying expectations and limits. Such expectations and limits may relate to: feelings, the exchange of money or material goods, or other factors. Gender norms often affect the way people communicate - or do not communicate - about sex.

Everyone can learn to communicate comfortably and effectively about sexuality. Practicing helps! 


\section{activity 2}

15-19-year-olds

AM I READY?

(2O MINUTES)

\section{Explain}

$\int$ It is beneficial to date someone your own age; you will have more in common and find it easier to communicate about mutual needs and limits. Also, men who are older have likely had more sexual partners in the past and are more likely to be infected with HIV or other STIs then boys your own age. That means that your risk of getting infected with HIV or other STIs is higher when you have sex with an older man than with someone your own age.

Remember, as we discussed in a previous session, you can still refuse even if you have started having sex.

Distribute a pen or pencil and paper to each participant.

\section{Instruct:}

5 On your paper, you should write the numbers 1 to 10 on the left side. I am going to read 10 questions and you should write the answer: yes or no (or draw a $\mathbf{O}$ (yes) or $\mathbf{X}$ (no)). Your paper will be an "Am I ready" checklist to help you to think about the right things when making decisions related to sex, whether for the first time or if you have already started having sex.
Read the following questions, waiting for girls to write their responses between each one:

- Would my parents approve of me having sex now if they knew?

- If I get pregnant, am I responsible enough to provide for the baby's emotional and financial support?

- Does the man I'm with make me feel good about myself?

- Will I be glad when I am older that I lost my virginity at the age I am now?

- If the relationship breaks up, will I be glad I had sex with this person?

-Am I sure no one is pushing me into having sex?

- Am I able to comfortably talk to my partner about sex, and his sexual history?

- Am I absolutely sure my partner is not infected with an STI or HIV?

- Do I know how to talk about using condoms or other methods to prevent pregnancy, HIV and STIs?

- Do I feel safe with my partner?
Explain:

$\int$ Going through this checklist of questions can be part of decision-making skills: "Stop and Think," "Consider Consequences," "Know the Facts" and "Execute your Decision"

\section{Ask}

$\int$ Do most girls ask themselves these questions before initiating sexual activity or continuing sexual activity?

Why is it important to ask these questions before initiating or continuing sexual activity? to evaluate whether or not initiating or continuing the sexual activity is the right decision and if so, if it is being done in the safest and healthiest way]

\section{Explain}

If you answered no to any of the questions on the checklist, then you should consider not starting a sexual relationship or perhaps ending the one you are in. Decisions today affect a girl's future, so best to be sure before starting or continuing sexual activity. Going through this checklist of questions can be part of decision-making skills we learned in Session 7: "Stop and Think," "Consider Consequences," "Know the Facts," and "Execute your Decision." 


\section{activity 3}

\section{TALKING TO MY PARTNER}

\author{
(40 MINUTES)
}

\section{Ask:}

5 What are the benefits of talking to partners about relationship or sexual issues?

[ensuring both people are consenting to sexual activity, protect own and partner's well-being (against STIs, HIV, unwanted pregnancy, conflicts leading to violence), increases trust and pleasure, clarify expectations]

\section{Explain:}

We can use strong communication skills when talking to our partners. Remember the STRONG communication we discussed in previous sessions:

"I feel ..." The emotion that she is experiencing, e.g. "I feel scared and anxious."

"When you..." What the other person did that caused her to feel the emotion, e.g. "When you drive quickly, it makes me feel afraid."

"Because..." Why the action caused her to feel the emotion, e.g. "Because I know bad accidents can happen when people drive too quickly."

"And I would like/want/need..." What she would like to have happen in order to feel better, e.g. "And I would like for you to please try to drive more slowly in the future."

\section{5-19-year-olds only}

Instruct participants to form into groups of four.

\section{Explain:}

5 Now we are going to practice communicating with a partner. Each group should prepare two 3-minute role-plays. The first role-play will show how things can go wrong when talking to a partner and the second role-play should demonstrate how communication can work to resolve situations when using the strong communication skills. Some ideas for role-play scenarios are:

- Talking to a partner about using a condom.

- Talking to a partner about delaying sex.

- Asking a partner to share his feelings about your relationship-for example deciding to be only with each other, if they have other partners.

- Asking a partner to go for joint STI or HIV testing.

- Asking a partner if he can cut back on drinking.

- Talking about getting support for you to complete your studies.

After sufficient practice time, allow each group to perform both role-plays. After each role-play, discuss how the role-play demonstrated strategies for how to talk to partners.

\section{wrap-enp}

\section{Explain:}

5 The choices you make today will affect you tomorrow. Before you engage in sex or continue a sexual relationship it is important for you to practice decision-making skills (Stop and Think, Consider Consequences, Know the Facts) to make sure you are making a decision that will be good for you.

Ask participants to summarize what they have learned. Fill in any key points they miss.

$\sum_{m m}^{m} \frac{1}{3}$

Key Message: Talking to a partner can be challenging, but girls can use strong communication skills to ask for what they need in order to have a healthy and happy relationship.

Ask for any final questions or comments. Remind participants where and when the next meeting will take place, and what topics will be discussed.

Thank them for their participation.

\section{PRACTICE ACTIVITY}

Participants should ask their friends a few of the questions from the "Am I Ready?" checklist and see what kind of responses they get. 
10) Managing Stress, Anger, and Conflict*

\begin{tabular}{|l|} 
SESSION \\
DESCRIPTION: \\
(LIFE SKILLS) \\
Participants learn \\
what stress means, \\
symptoms of stress, \\
and tips for managing \\
anger and resolving \\
conflict.
\end{tabular}

\begin{tabular}{|l|}
\hline OBJECTIVES \\
By the end of this session, \\
participants will be able to: \\
- Define conflict \\
- Use "l" statements to \\
express their feelings \\
- Distinguish between \\
appropriate and \\
inappropriate responses \\
to anger \\
- Successfully deal with \\
situations that cause \\
stress, anger, and/or \\
conflict \\
\hline
\end{tabular}

1 HOUR, 30 MINUTES
- Icebreaker (5 minutes)
- Review (5 minutes)
- Managing Stress (20 minutes)
- Dealing with Anger (25
minutes)
- Anger and Conflict Role-play
(25 minutes)
- Wrap-up (5 minutes)
- Practice Activity (5 minutes)

\begin{tabular}{|l|}
\hline MATERIALS \\
- Chalkboard and \\
chalk OR flipchart \\
and markers
\end{tabular}

PRE-SESSION
PREPARATION
- Read through the entire session
and, if necessary, practice
presenting the activities
- Prepare all materials needed for
the session




\section{FACILITATOR NOTES}

\section{Managing Stress}

Stress occurs on a daily basis and can be healthy. Sometimes, though, stress can be overwhelming and adolescents may have trouble dealing with it. Adolescents are faced with a number of issues and make many major decisions, such as the decision to have sexual intercourse, the kind of career they want, what they want to do in the future, how to manage their money wisely and save for the future, or the attempt to develop a unique identity, which contribute to their burden of stress.

Too much stress can seriously affect your physical and mental well-being. Overtime, recurrent stress can lower self-esteem, decrease academic effectiveness and create a cycle of self-blame and self-doubt. Stress is unique and personal to each of us. What is relaxing to one person may be stressful to another. The key to reducing stress is to find strategies that help you as an individual.

\section{Effects of Anger and Conflict}

Unresolved anger or conflict can cause people to feel indifference, resentment, or rage. It can lead to physical or verbal violence, withdrawal, depression, mean gossip, or even addiction or other self-destructive behavior.

When anger and conflict are unresolved, relationships can be damaged and youth can suffer social consequences such as rejection, teasing, or humiliation. It is important to be able to manage anger and conflict effectively.

\section{TERMS}

\section{Stress}

A state of mental or emotional strain or tension resulting from adverse or demanding circumstances

\section{Well-Being}

A state of being comfortable, healthy, or happy

\section{ICEBREAKER}

Open the session with an icebreaker of your choice, or allow participants to suggest one. See Appendix B: Participatory Facilitation Resources - Icebreaker Activities for ideas.

\section{REVIEW}

7 Ask participants what key points were covered in the last session (optional: throw a ball of paper around to encourage participation). Fill in any key points that are missed.

Go over any practice activities that were given, and ask if there are any questions. 


\section{activity 1}

\section{MANAGING STRESS}

(2O MINUTES)

\section{Ask:}

5 What do you understand by the word "stress"? [a state of mental or emotional strain or tension resulting from adverse or demanding circumstances]

After some discussion, explain the following: Stress can be defined as the body's reaction to a change that requires a physical, mental or emotional adjustment or response. It is commonly experienced as a feeling of tension, anxiety or pressure. When you are under stress you may experience the following feelings, thoughts, behaviors, and physical symptoms.
Review Table 3: Symptoms of Stress below.

Ask:

5 When was a time when you were under stress?

Divide participants into groups of four or five (see Appendix B: Participatory Facilitation Resources Group Formation Activities for ideas).

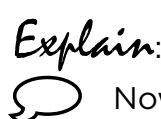

Now discuss different techniques that can be used to help manage stress for a few minutes. Then we will return to the large group and a representative from each of the smaller groups will share the stress management techniques you discussed.

\section{TABLE 3: SYMPTOMS OF STRESS}

\begin{tabular}{|llll|}
\hline Feelings & Thoughts & Behaviors & Physical \\
- Anxiety & - Self-criticism & - Stuttering & - Tight muscles \\
- Irritability & - Difficulty concentrating & - Difficulty speaking & - Cold or sweaty hands \\
- Fear & or making decisions & - Crying & - Headaches \\
- Moodiness & - Forgetfulness or mental & - Acting impulsively & - Back or neck problems \\
- Embarrass- & disorganization & - Nervous laughter & - Sleep disturbances \\
ment & - Preoccupation with the & - Yelling at friends/family & - Stomach aches \\
& - future & - Grinding teeth & - More colds \& infections \\
& - Repetitive thoughts & - Jaw clenching & - Fatigue \\
& & - Increased smoking, alcohol or & - Rapid breathing \\
& & - Other drug use & - Pounding heart \\
& & - More prone to accidents & - Shaking hands
\end{tabular}

As each group presents, write a list of the techniques they mention for managing stress on the chalkboard or flipchart. After each group has presented, mention any techniques that participants did not list, using Box 8: Stress Management Techniques on the next page as a guide.

\section{Explain:}

5 There are many different ways to manage unhealthy stress, and everyone needs to find ways that work best for them! 


\section{BOX 8: STRESS MANAGEMENT TECHNIQUES}

1. Take a Deep Breath!: Stress often causes us to breathe shallowly, and this almost always causes more stress! Try taking a minute to slow down and breathe deeply

2. Talk It Out: Keeping feelings inside can increase stress. Sharing your feelings with a friend, family member, teacher, or church leader can help you see your problem in a new way. Even if it is slightly embarrassing, asking for help soon after a problem occurs may help you avoid serious problems later. Writing down thoughts and feelings can also help clarify the situation and give you a new perspective.

3. Take a "Minute" Vacation: You cannot always run away, but you can dream. Take a moment to close your eyes and imagine a place where you feel relaxed and comfortable. Notice all the details of your chosen place, including pleasant sounds, smells and temperature.

4. Pay Attention to Physical Comfort: Be as physically comfortable as the situation will allow. Wear comfortable clothing. If it's too hot, go somewhere where it's not. If your chair is uncomfortable, move. Do not wait until your discomfort turns into a real problem.

5. Get Physical: When you feel nervous, angry or upset, release the pressure through exercise or physical activity. Try to find some- thing you enjoy and make regular time for it. This can be anything from playing a game with friends to doing some regular physical work that you like doing. Running, walking or dancing can be done anywhere. Working in the garden, cleaning, or playing with younger children can relieve stress, relax you, and energize you! Remember, your body and mind work together

6. Take Care of Your Body: Healthy eating and adequate sleep fuels your mind as well as your body. Avoid eating too much caffeine and sugar. Well-nourished bodies are better able to cope with stress, so eat well.

7. Laugh: Maintain your sense of humor, including the ability to laugh at yourself. Share jokes and funny stories with your friends. Laughter is good for you!

8. Manage Your Time: Plan ahead. Make a realistic schedule for yourself and include time for stress reduction. Trying to take care of everything at once can seem overwhelming. Instead, make a list of what you have to do then do one thing at a time, checking them off as they're completed. Do the most important or unpleasant ones first, and then the rest of your day will be less stressful. Recognize when you are most stressed and allow yourself some reasonable breaks, like taking a walk or otherwise changing your scenery.
9. Know Your Limits: A major source of stress is people's efforts to control things over which they have little or no power. When in a stressful situation, ask yourself: is this my problem? If it isn't, leave it alone. If it is, can you resolve it now? Once the problem is settled, leave it alone. Do not agonize over the decision, and try to accept situations you cannot change. There are many circumstances in life beyond your control.

10. Must You Always Be Right?: Do you get upset when things don't go your way? Consid er cooperation or compromise rather than confrontation. It may reduce the strain and help everyone feel more comfortable.

11. Have a Good Cry: Big boys and girls do cry. A good cry during stressful times can be a healthy way to bring relief to your stress, and may prevent a headache or other physical consequences of stress. However, crying daily can be a sign of depression.

12. Look for the Good Things Around You: It is easy to see only the negative when you are stressed. Your thoughts can become like a pair of very dark glasses, allowing little light or joy into your life. Commit yourself to actively noticing five good things around you, like positive or enjoyable moments or interactions. 


\title{
activity 2
}

\section{DEALING WITH ANGER}

\author{
(25 MINUTES)
}

\section{Explain}

5 Anger is a completely normal, usually healthy, human emotion that ranges from mild irritation to intense rage. When it gets out of control and turns destructive, it can lead to problems. Like other emotions, it causes physical changes. When you get angry, your heart rate, blood pressure, and energy hormone levels go up. You could be angry at a specific person or event. Worrying about personal problems or remembering traumatic events can also cause you to feel angry.

Anger is a natural, adaptive response to threats and inspires powerful, often aggressive, feelings and behaviors, which allow us to defend ourselves when attacked. A certain amount of anger is necessary for survival. We cannot, however, physically attack every person or object that irritates or annoys us; laws, social norms, and common sense place limits on how far our anger can take us.

\section{Ask:}

5 What are some inappropriate expressions of anger?

[yelling, hitting, humiliating someone, namecalling, damaging property, throwing things, or refusing to help someone in need]
What are some appropriate expressions of anger?

[calmly expressing an opinion, leaving the situation, or counting to ten before reacting]

\section{Explain}

Anger can be managed. The goal of anger management is to reduce both your emotional feelings and the physical responses that anger causes. You cannot get rid of, or avoid, the things or the people that make you angry,

\section{BOX 9: ANGER MANAGEMENT TIPS}

- Ask yourself if this will matter ten years from now? Chances are, you will see things from a calmer perspective.

- Tell yourself, "it's frustrating, and it's understandable that I'm upset about it, but it's not the end of the world and getting angry is not going to fix anything.

- Have you ever done the same thing to someone else, even if by accident. Do you get angry at yourself? Ask yourself if the person did it on purpose. In many cases, you will see that they were just careless or in a rush, and really did not mean you any harm.

- Remind yourself that getting angry is not going to fix anything, and that it won't make you feel better nor can you change them, but you can learn to control your reactions.

\section{Ask:}

5 What are some ways to manage anger?

[see Box 9: Anger Management Tips below for possible responses]

List the brainstormed ways to manage anger on a chalkboard or flipchart.

(activity 2 continued on next page) (and may actually make you feel worse).

- Try counting to ten before saying anything. This may not address the anger directly, but it can minimize the damage you will do while angry. Or try counting to ten with a deep slow breathe in between each number. Deep breathing helps people relax.

- Imagine a relaxing experience. Close your eyes, and travel there in your mind. Make it your angerfree place.

- Non-strenuous physical activities, like walking, can relax your muscles and help you feel much calmer.

- Give yourself time and space alone. Physically move away from situations that make you angry. 


\section{activity 2 (continued)}

\section{DEALING WITH ANGER}

\section{(25 MINUTES)}

\section{Explain:}

5 People use a variety of both conscious and unconscious processes to deal with their angry feelings. The three main approaches are expressing, suppressing, and calming.

- Expressing your angry feelings in an assertive, not aggressive, manner is the healthiest way to express anger. To do this, you have to learn how to make clear what your needs are, and how to get them met, without hurting others. Being assertive doesn't mean being pushy or demanding; it means being respectful of yourself and others.

- Anger can be held in by not thinking about it or focusing on something positive. The purpose is to convert your anger into more constructive behavior. However, keeping anger in is not always the best strategy. If anger is not allowed out it can cause physical and emotional harm. Anger turned inward may cause hypertension, high blood pressure, or depression. Or people can become hostile and critical, which can negatively affect their relationships with others.

\section{- You can calm down inside. This means not} only controlling your behavior, but also controlling your internal responses, taking steps to lower your heart rate, calm yourself down, and let the anger go away.
Psychologists now say that it is dangerous to express all of your angry feelings because it can actually make you angrier and does not help resolve the situation. It is best to find out what makes you angry, and then develop ways to keep those things from making you angry.

Sometimes, our anger and frustration are caused by very real, unavoidable problems in our lives. Not all anger is wrong, and often it is a healthy, natural response to difficult times. Not all problems have a solution. In these situations, try not to focus on finding the solution, but on how you handle the problem. 


\section{activity 3}

\section{ANGER AND STRESS ROLE-PLAY}

\author{
(25 MINUTES)
}

Divide participants into groups of four or five (see Appendix B: Participatory Facilitation Resources Group Formation Activities for ideas).

\section{Instruct:}

$S$ Together with your group, brainstorm a scenario to act out about someone who is angry and/or stressed. To come up with ideas for the scenario, think of a time when you were very angry or in a stressful situation, and try to reenact it. Use the tips we discussed to deal with stress and anger to act out a 1-2 minute role-play and resolve the scenario.

After groups have decided on a scenario, ask the groups to present their role-plays. Discuss what happened in the role-plays with the following questions:

-What happened in the role-play?

- How did you feel in that role? Why did you have that feeling?

-Was the problem solved in the role-play? How? -What would you change about the role-play?

-What advice would you give the person in the role-play?

-What have you learned that can help you the next time you face a similar situation?

\section{wrap-enp}

Ask:

$S$ Which strategy will you try next time you feel stress?

Which strategy will you try next time you feel anger?

Ask participants to summarize what they have learned. Fill in any key points they miss.

Key Message: Recognizing and managing stress and conflict can lead to positive outcomes.

Ask for any final questions or comments. Remind participants where and when the next meeting will take place, and what topics will be discussed.

Thank them for their participation.

\section{PRACTICE ACTIVITY}

Participants should practice the tips we discussed today for minimizing their anger and stress. They should be prepared to explain how the tips affected the outcomes of their stress/anger situations during the next session. 
11)

Conflict Resolution and Problem Solving Skills*

\begin{tabular}{|l|}
\hline \multicolumn{1}{|c|}{} \\
\hline SESSION \\
DESCRIPTION: \\
(LIFE SKILLS) \\
Participants learn \\
conflict resolution and \\
problem solving skills \\
that are essential for \\
dealing with conflict \\
situations.
\end{tabular}

\begin{tabular}{|l|}
\hline \multicolumn{1}{|c|}{} \\
\hline OBJECTIVES \\
By the end of this session, \\
participants will be able to: \\
- Understand elements \\
of conflict and different \\
methods of resolving \\
conflict \\
- Understand steps in \\
problem solving \\
\hline
\end{tabular}

1 HOUR, 30 MINUTES
- Icebreaker (5 minutes)
- Review (5 minutes)
- Tug of War Game (15 minutes)
- Conflict Role-play (20 Minutes)
- Conflict Resolution and
Peacemaking Rules (30
minutes)
- Wrap-up (10 minutes)
- Practice Activity (5 minutes)

\begin{tabular}{|l|}
\hline MATERIALS \\
- Chalkboard and \\
chalk OR flipchart \\
and markers \\
- A long rope, twisted \\
sheet or cloth \\
- Tape or string to \\
mark a border on \\
the floor \\
- Ball \\
\hline
\end{tabular}

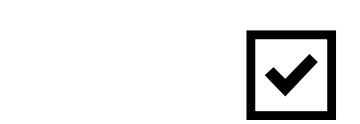

\section{PRE-SESSION} PREPARATION

- Read through the entire session and, if necessary, practice presenting the activities

- Prepare all materials needed for the session

- Prepare the board or 3 separate sheets of flipchart paper with information on the following topic areas: Peacemaking Rules; Core Values in Conflict Resolution (see information to be written on flipchart paper in Activity 2) 


\section{FACILITATOR NOTES}

Everyone has worries and problems in their lives. Some are big problems and some are smaller ones. We can learn to solve problems or conflicts as much as possible and to live positively with conflicts that we cannot solve. Some difficult conflicts are those between people with competing views and interests. We learn and feel strong by looking at how we have solved conflicts in our lives before. We can use the same ways again for other conflicts. We can also imagine new ways to solve conflicts and put them into action. This type of conflict resolution is a demanding problem-solving skill. We can understand our conflicts better by looking at why they happen. We can then think of ways to avoid them. We can imagine how we would like our lives to be. Then we can look at what steps we can take to make our dreams come true.

\section{TERMS}

\section{Conflict}

A serious disagreement or argu-

ment, typically one that lasts a

while

\section{Conflict Resolution}

Methods, strategies and/or processes involved in facilitating the peaceful ending of social disagreement or problem

\section{Communication Blockers}

Barriers or things that interfere with good communication

\section{Positive Conflict}

A conflict which is functional or constructive

\section{Negative Conflict}

A conflict which is dysfunctional

\section{ICEBREAKER}

Open the session with an icebreaker of your choice, or allow participants to suggest one. See Appendix B: Participatory Facilitation Resources - Icebreaker Activities for ideas.

\section{REVIEW}

- Ask participants what key points were covered in the last session (optional: throw a ball of paper around to encourage participation). Fill in any key points that are missed.

Go over any practice activities that were given, and ask if there are any questions. 


\section{activity 1}

\section{"TUG OF WAR GAME"}

\section{(15 MINUTES)}

Divide participants into two groups (see Appendix B: Participatory Facilitation Resources - Group Formation Activities for ideas). Place an object on the floor between the two groups that represents a border. Place a long rope, twisted sheet, or cloth across the border so that half of the rope is on either side.

\section{Explain}

$\bigcirc$ Now we will play a game to see how conflict arises. Each team will pull on opposite ends of the rope. Whoever crosses the border loses.

After a few attempts, ask:

\section{Explain}

$\int$ In life we experience both positive and negative conflicts. A positive conflict could be something like having to choose what to wear, what to eat, etc. Negative conflicts may be something like choosing to fight over talking it out. Both are conflicting dilemmas. The later examples, however, have serious consequences that may even be life threatening.

\section{Ask:}

5 What are some negative conflicts that can occur within family relationships?

How does it impact the individual, family, community, etc.?

Were there any conflicts within the group?

If there was a conflict, what was it?

Was the conflict resolved?

(Nyanja Translation: chipangano,

Bemba Translation: ukumfwana/ukwampana

pamo)

If it was resolved, how? 


\section{activity 2}

\section{CONFLICT ROLE-PLAY}

\section{(2O MINUTES)}

Divide participants into groups of four or five (see Appendix B: Participatory Facilitation Resources Group Formation Activities for ideas). Assign the groups one of the following scenarios (below)

\section{Explain}

5 Use your group's scenario to develop a roleplay. You can also think of your own scenario if you do not like the one assigned to you.

After participants have practiced their role-plays, allow about a short time for each group to perform their role-play. After each performance, ask participants:

What was the relationship between the two persons?

What was the nature of the conflict?

Was the role-play realistic?

What other conflicts may arise?

Could this situation be avoided or handled differently? If so, how?

What was the impact of the conflict on the individual, family, community, etc.?

List responses to the questions on a chalkboard or flipchart and discuss each point.

\section{Explain:}

5 Good communication during a conflict can help resolve the situation. However, there are things that interfere with 'good' communication during a conflict, such as name-calling, cursing insulting, and accusations, etc. These are called "communication blockers."

\section{Role-play Scenarios}

Daniel is upset because his mother told him he was not allowed to go to a football game with his friends on Saturday afternoon, even though he had already made plans with his friends. What should Daniel say to his mother?

Alice has a big exam at school on Friday. On Thursday afternoon, she realizes that she is not well prepared for the exam and is worried that she will not pass. Her sister wants Alice to help her make dinner, but Alice wants to study. What should Alice do?

Isaac notices that his friend Joseph is wearing the same jacket that was stolen from him last week. Joseph tells him that another friend let him borrow the jacket. How should Isaac talk to Joseph?

Margaret stopped seeing her boyfriend George. Now he is telling other boys at school that they had sex, even though it is not true. What should Margaret say to George?
Write the term "communication blockers" on the chalkboard or flipchart.

\section{Ask:}

5 What are some other "communication blockers"? [e.g., interrupting, ignoring, sarcasm (Nyanja Translation: kulalata/kupusisa/maseti'ngi, Bemba Translation: ukusauka/amasetin'gi), insulting, threatening, stereotyping (statements which label people and make them angry/resentful, Nyanja Translation: kucitu olo kuona vintu munjila yamene uganizila weka loko simwamene vilili, Bemba Translation: ukucita olo ukumona ifintu munshila iyo wemwine wafinmwena nangu tefyo fili), judging, blaming, starting opinions as fact, expecting someone to read your mind, hitting, punching, slapping, screaming, etc.]

List answers on the flipchart or chalkboard and discuss.

Explain

$S$ "Communication-blockers" can lead to violence. In fact, violence is increasing in many countries. The environments in which many young people grow up do not encourage peacemaking attitudes and behaviors. While young people need to know how to avoid conflicts and how to resolve them peaceably, it is equally important for them to know how to survive in a hostile climate. They need to practice different methods of resolving conflicts to see which ones are more effective. 


\section{activity 3}

\section{CONFLICT RESOLUTION AND PEACEMAKING RULES}

\section{(3O MINUTES)}

Explain:

Conflict is natural and happens in almost every relationship. Since conflict is unavoidable, we must learn to manage it. Conflict is a sign of a need for change and an opportunity for growth, new understanding, and improved communication. It is normal for people to disagree, but it is important to address conflict with the people involved and resolve these disagreements in a constructive and healthy way.

\section{Ask:}

5 What are some of the techniques you have learned through AGEP for resolving conflict? [see Box 10: Tips for Conflict Resolution for possible responses]

\section{BOX 10: TIPS FOR CONFLICT RESOLUTION}

Respond, don't react. If you keep your emotions under control you have a better chance of hearing what the other person is trying to say.

Listen carefully without interrupting. Ask questions and wait for and listen to answers.

Acknowledge the other person's thoughts and feelings. You do not have to agree with the other person to acknowledge his or her feelings.

Give respect to get respect. Treat people the way you would like to be treated if you were in the same situation.

Communicate clearly and respectfully so your viewpoint can be understood.

Identify points of agreement and points of disagreement. Agree wherever you can. Your underlying interests may be more alike than you imagine.

Be open to change. Open your mind before you open your mouth.
Look forward, not backward. Live in the present, plan the future, do not dwell on the past.

Stay focused on the topic at hand. Don't expand an argument. If there are a number of issues, deal with them, one at a time.

Work together. Commit to working together and listening to each other to solve conflicts.

Conflicts don't have to end with a winner and a loser. Try to find a solution that is acceptable to both parties.

Be creative. Generate silly options to begin thinking "outside of the box" of original positions.

Be careful not to give in simply to avoid conflict or maintain harmony. Agreements reached too early usually do not last.

Be specific when problem solving. Clarify terms that each person may interpret differently.
Write a list of responses on the chalkboard or flipchart. Use Box 10 if needed.

\section{Explain}

An "l" statement is a useful way to share your opinion or perspective without placing blame on someone else. For example, instead of saying, "You made me feel angry" you can say, "I feel angry." Using an "I" statement is a constructive way to convey your message without making any demands. "I" statements should be clear, concise, and free of judgment. Remember when we practiced this at the beginning of the program (see Introductory Sessions - Session 5: Communication)?

Ask:

5 What are some "l" statements that can help adolescents cope with or avoid a conflict? [e.g., "That upsets me, and I would like to talk with you about it," "It hurts my feelings when...," "It upsets me when...," "I think we should talk about this situation. Tell me how you feel about..."]

(activity 3 continued on next page) 


\section{activity 3 (continued)}

\section{CONFLICT RESOLUTION AND PEACEMAKING RULES}

Write the following on the chalkboard or flipchart (if you have not already prepared them on flipchart paper before the session):

\section{Peacemaking Rules}

1. Identify the problem

2. Focus on the problem, not the person

3. Attack the problem, not the person

4. Listen with an open mind

5. Treat the other person's feelings with respect

6. Take responsibilities for your own actions

\section{Core Values in Conflict Resolution}

1. Cooperation

2. Affirmation (Nyanja Translation: kuvomekeza, Bemba Translation: ukulapa/ukusuminisha)

3. Empowerment

4. Neutrality

5. Confidentiality

\section{Instruct:}

5 Reform your groups from the role-play activity and use the role-play scenarios to practice how you would use "'l' Statements," "Peacemaking Rules," and "Core Values in Conflict Resolution" to resolve conflicts.

When participants have practiced their role-plays using the "Peacemaking Rules" and "Core Values in Conflict Resolution" ask a few to present.

\section{Wrap-enp}

Ask participants to summarize what they have learned. Fill in any key points they miss.

$\sum_{m}^{m}$ Key Message: Good problem-solving skills can make conflict resolution easier and lead to better outcomes for all people involved!

Ask:

5 What is the difference between a positive and negative conflict?

[positive conflict- a conflicting dilemma without serious consequences, and negative conflict- a conflicting dilemma with serious consequences]

What are three 'Communication Blockers' that contribute to negative conflicts?

[interrupting, ignoring, sarcasm, etc.]

What are three strategies to avoid conflicts? [respond - don't react, communicate clearly, work together]

What are three methods for resolving conflicts? ["l" statements, cooperation, listen with an open mind]

Ask for any final questions or comments. Remind participants where and when the next meeting will take place, and what topics will be discussed.

Thank them for their participation.

\section{PRACTICE ACTIVITY}

Participants should practice avoiding conflicts. During the next session, they should be prepared to share how they avoided a conflict, or how they observed someone else avoid a conflict. 


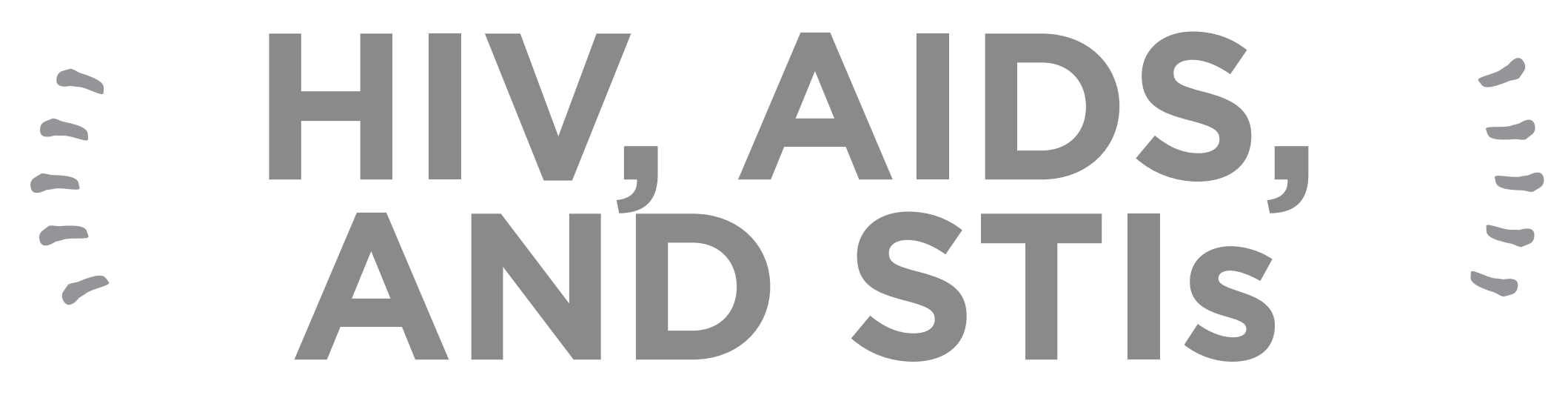




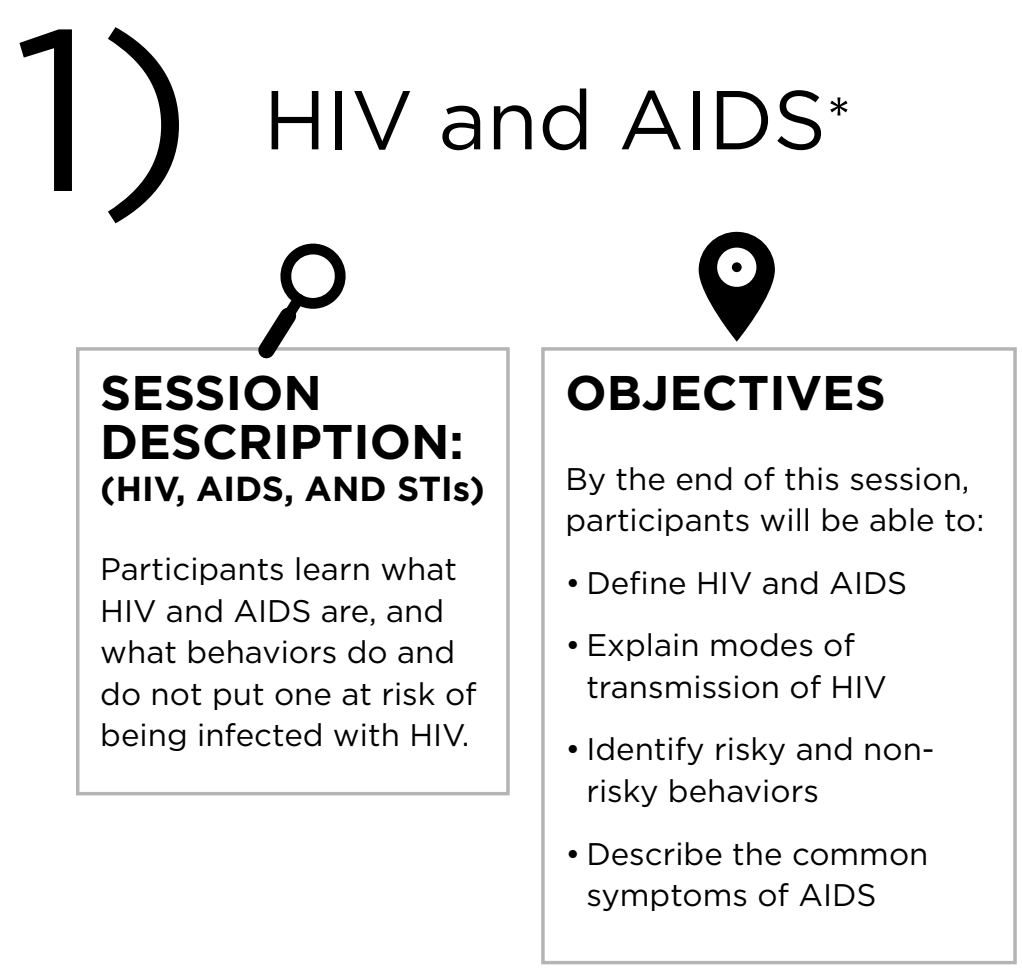

\begin{tabular}{|c|c|c|}
\hline $\begin{array}{l}\text { TIME } \\
1 \text { HOUR, } 35 \text { MINUTES } \\
\text { - Icebreaker ( } 5 \text { minutes) } \\
\text { - Review ( } 5 \text { minutes) } \\
\text { - Shaking Hands ( } 25 \text { minutes) } \\
\text { - HIV and AIDS Overview (15 } \\
\text { minutes) } \\
\text { - Definition of HIV and AIDS } \\
\text { and Modes of Transmission (15 } \\
\text { minutes) } \\
\text { - Risky and Non-Risky Behaviors }\end{array}$ & $\begin{array}{l}\text { MATERIALS } \\
\text { - Index cards or slips } \\
\text { of paper (several per } \\
\text { participant) } \\
\text { - Training aid } \\
\text { "Multiple Concurrent } \\
\text { Partners Chart" }\end{array}$ & $\begin{array}{l}\text { PRE-SESSION } \\
\text { PREPARATION } \\
\text { - Read through the entire session } \\
\text { and, if necessary, practice } \\
\text { presenting the activities } \\
\text { - Prepare all materials needed for } \\
\text { the session } \\
\text { - Prepare small pieces of paper or } \\
\text { index cards for each participant } \\
\text { as instructed (see Activity } 1 \\
\text { advance preparation) }\end{array}$ \\
\hline
\end{tabular}




\section{FACILITATOR NOTES}

There are over 34 million people living with HIV and AIDS worldwide. Over half of them live in sub-Saharan Africa. AIDS is spreading among young people in Africa faster than in any other age group. Of all adults in Zambia, $14 \%$ are HIV positive (adult women - $16 \%$, adult men - $12 \%$ ). Young females are much more likely to be infected than their male counterparts. Among those aged 15-19, rates are $6 \%$ among females and $4 \%$ among males. Among those aged $20-24,12 \%$ of females are infected, versus only $5 \%$ of males. The number of persons dying in Zambia as a result of AIDS is estimated at 31,000 per year, leaving behind a growing number of AIDS orphans, currently estimated at 680,000.

\section{How Is HIV Transmitted?}

HIV is passed between people in three ways:

1. Sex: Penetrative sex with an HIV-infected person where the penis enters the vagina, anus, or mouth of another person. Vaginal and anal sex is considered much higher risk for HIV transmission than oral sex.

2. Blood to blood: From an HIV infected person's blood to another person's blood through an opening in the body such as a cut, from a transfusion or by sharing something that cuts or pierces the skin (knife, razor, needle). This includes sharing circumcision knives, needles, tattooing, or ear piercing, with someone who has HIV.
3. Mother to child: HIV can be passed from a mother who is HIV infected to her baby during pregnancy, at the time of birth, or through breastfeeding.

The majority of people in Zambia are infected with HIV by having sex with someone who is HIV infected. It is important to note that a person suffering from other STIs is eight to ten times more likely to contract HIV. HIV cannot survive in air, water, or on things people touch.

\section{Protecting Against HIV}

In this session, help young people understand that there are many ways to express sexual feelings that do not risk unplanned pregnancy or sexually transmitted infections. Touching, fantasizing, caressing, massaging, masturbating, talking, kissing, whispering, hugging, singing, dancing, and holding hands are ways of showing and receiving affection from a partner. Abstinence from all types of sexual intercourse is the best and only certain way to prevent HIV infection.

Latex condoms have been proven to be an effective barrier of HIV. They can, however break or leak especially when used incorrectly. It is important for older, sexually active adolescents to understand how to use a condom correctly and that they must be used for every act of sexual intercourse to protect against HIV infection. Condoms offer the best protection against the spread of HIV during sexual intercourse with a partner whose HIV status is unknown. Some behaviors present more of a risk for HIV than others. These are summarized in Box 11: Risky and NonRisky Behaviors on the next page. 


\section{FACILITATOR NOTES}

For more information, see Appendix A: Additional Topical Information - Tips for Teaching about HIV and AIDS, Background Information on HIV and AIDS, and Frequently Asked Questions about HIV and AIDS.

(NOTE TO FACILITATOR: Because the number of people infected with HIV changes frequently, facilitators should undertake a quick internet search to amend the statistics mentioned in these notes.)

\section{BOX 11: RISKY AND NON-RISKY BE-}

\section{HAVIORS}

\section{Definitely a Risk}

- Sharing needles for drug use

- Sharing needles for ear piercing

- Having sexual intercourse without con-

doms

\section{Probably a Risk}

- Being born to a mother who is HIV-

positive

- Getting a blood transfusion

\section{Probably Not a Risk}

- Sharing a toothbrush

- Having sexual intercourse with a person

using a condom

- Deep or (open mouth) kissing

\section{Definitely Not a Risk}

- Abstaining from sexual intercourse

- Kissing

- Being close to a person with HIV who is

coughing

- Donating blood
- Using a public telephone

- Shaking hands with a person with HIV

- Hugging or talking to a person with HIV or AIDS

- Going to school with a person who has AIDS

- Sharing plates, utensils, glasses or towels used by someone with HIV or AIDS

- Using swimming pools, toilet seats, doorknobs, gym equipment, or telephones used by people with HIV or AIDS - Having someone with HIV or AIDS spit, sweat or cry on you

- Being sneezed at or coughed on by a person with HIV or AIDS

- Being bitten by a mosquito (no risk of HIV, but risk of malaria!)

- Having sexual intercourse with a person who has been tested for HIV, found negative, and engaging in a mutually monogamous and faithful relationship with that person

\section{TERMS}

\section{AIDS}

Acquired Immune Deficiency Syndrome; the final stage of HIV disease, which causes severe damage to the immune system

\section{HIV}

Human Immune Deficiency Virus; the virus that causes AIDS and is transmitted through blood, semen, vaginal fluid, and breast milk

\section{Immune System}

The body's natural defense system for fighting off disease

\section{ICEBREAKER}

Open the session with an icebreaker of your choice, or allow participants to suggest one. See Appendix B: Participatory Facilitation Resources - Icebreaker Activities for ideas.

\section{REVIEW}

A Ask participants what key points were covered in the last session (optional: throw a ball of paper around to encourage participation). Fill in any key points that are missed.

Go over any practice activities that were given, and ask if there are any questions. 


\section{activity 1}

\section{SHAKING HANDS}

(25 MINUTES)

ADVANCE PREPARATION: Cut many small pieces of paper. Mark the papers as follows:

Group 1: One piece with a small ' $x$ ' in the corner

Group 2: One piece with a small ' $z$ ' in the corner

Group 3: Three pieces with a small ' $c$ ' in the corner

Group 4: Three pieces with the instructions 'Don't follow any of my directions

Group 5: On the rest of the pieces write 'Follow all of my directions'

(NOTE TO FACILITATOR: If girls are not literate, carefully explain the instructions for groups 4 and 5.)

Distribute one piece of paper to each girl as they enter the learning space. Tell them that each paper has special instructions on it. Inform them to keep the special instructions secret and to follow the instructions.

\section{Explain}

5 Now stand and shake hands with three people. When you shake hands with someone, that person must sign your paper. Make sure you move around the room while you do this!

Once the participants have collected three signatures, have them take their seats. Ask participants with the ' $z$ ' and the ' $x$ ' on their papers to stand up. Then ask everyone who shook hands with a standing person to stand up. Continue this until everyone is standing, except for the non-participants with papers that read 'do not follow any of my instructions.

\section{Explain}

5 Now pretend the person with the paper marked with an ' $x$ ' was infected with HIV and instead of shaking hands, that person had unprotected sexual intercourse with the three people whose signatures she collected. Also pretend that the person with the paper marked ' $z$ ' was infected with genital herpes and instead of shaking hands, that person

had unprotected sexual intercourse with three people whose signatures she collected.

\section{Ask:}

$\int$ Those that are still seated, why haven't you been standing?

[We were told not to follow any instructions.]

\section{Explain}

3 These people chose to abstain from sexual intercourse, and were therefore protected from HIV and STIs.

Ask participants to check if they had a ' $c$ ' marked on their paper. If so, tell them they can sit down.

Explain: had used condoms and were not at significant risk for infection.
Tell all participants to sit and remind them that this was only a game. Lead a group discussion about the game by asking the following questions:

- How did person ' $x$ ' feel?

- How did person ' $z$ ' feel?

- How did you feel towards others when you found out they were infected?

- How did people who were instructed not to participate in the exercise feel at beginning?

- And then later?

-Who had a 'do not follow my instructions' paper but got signatures anyway?

-Why did you get signatures anyway?

-What does this tell us about people's behavior?

- How did the people who discovered they had used condoms feel?

- How did the people feel to find out they might have been infected?

- Is it possible to know who is infected and who is not by looking at them?

Show and explain the Training Aid: Multiple Concurrent Sex Partners Chart (also provided the end of this session) depicting how a sexual network of people with multiple partners can quickly connect many different people and spread disease. 


\section{activity 2}

\section{HIV AND AIDS OVERVIEW}

(15 MINUTES)

Give two slips of paper to each participant.

\section{Instruct:}

$\int$ Write on each paper (or draw an illustration representing) something that you have heard people in your community say about HIV or AIDS (this does not have to be something you agree with).

Collect all the slips of paper and shuffle them. Divide participants into four groups (see Appendix B: Participatory Facilitation Resources - Group Formation Activities for ideas), and deal out the slips of paper to the groups at random. Explain:

Now each group should sort out their slips of paper into three categories: 'AGREE', 'DISAGREE' and 'DON'T KNOW'.

Write these categories on the chalkboard or flipchart. When all the groups have finished, reassemble. Have each small group present to the main group any statement they found difficult to reach agreement on. The main group can offer opinions on the difficult statements. 


\section{activity 3}

\section{DEFINITION OF HIV AND AIDS AND MODES OF TRANSMISSION}

\section{(15 MINUTES)}

Ask:

5 What is HIV?

[Human Immunodeficiency Virus]

\section{Explain}

5 The definition of HIV:

The name indicates that it is a virus found in humans, that makes the immune system deficient (lacking in something), and therefore weakens the system. The immune system is the body's defense against disease. With a damaged immune system the body is exposed to a range of infections and diseases. The person becomes weaker and eventually develops AIDS.

\section{Ask:}

5 What is AIDS?

[Acquired Immune Deficiency Syndrome]

\section{Explain:}

5 The definition of AIDS:

Acquired means that it is passed from one person to another; it does not just develop spontaneously. It is passed from exposure to an infected person's blood, sexual fluids or breast milk. AIDS is a condition where the body's immune system is destroyed by HIV. It has no cure and eventually kills the infected person. It can be controlled with drugs, but they are costly and not widely available.

Ask:

$\int$ How can you catch HIV?

[sexual intercourse, blood transfusion (donated blood is now screened), pregnancy, childbirth, breastfeeding, sharing knives, needles, or syringes (for circumcision or drug use)]

Tell girls the answers if they do not mention all of them. Then,

\section{Explain}

HIV is different from other diseases because it does not pass through air. We cannot catch it from being in the same room as an infected person or by hugging or touching a person. We cannot catch it from an infected person coughing or sneezing on us or by drinking from the person's cup.

But we can choose to not become infected if we abstain from sex or always use a condom when having sex. HIV can be prevented by being in a mutually faithful relationship with an uninfected person and by never sharing needles or other equipment such as razors, circumcision knives.
Ask:

5 Is HIV is easy or difficult to catch?

[HIV is easy to catch if one is not careful, i.e., having unprotected sex. Certain factors increase the chances of catching HIV such as having STIs, being uncircumcised (for males), etc.]

\section{Explain:}

3 There is no cure for AIDS, however there are ways to treat the symptoms. Treatment means the use of a drug, injection, or intervention that can cause symptoms to become less painful or pronounced or cause them to disappear altogether. It is important for people with HIV and AIDS to eat a nutritious diet to fight infection and disease and to stay energetic, strong, and productive. Nutrition and HIV are strongly related to each other. People who are malnourished are more likely to progress faster to AIDS, because their bodies are weak and cannot fight infection. 


\section{activity 4}

\section{RISKY AND NON-RISKY BEHAVIORS AND PRACTICES}

(15 MINUTES)

\section{Explain}

You will now have a chance to assess your own risk of being infected with HIV, if you do certain things. I am going to read a list of items, and you will tell me whether each statement puts you at risk for HIV.

Before reading each statement on the list of "HIV Risk Assessment Statements" (below), ask:

If you do this, are you at risk of being infected with HIV?

Read each statement from the list of "HIV Risk Assessment Statements" below. Ask participants to share their opinions and discuss with the group for each of the following statements:

\section{HIV Risk Assessment Statements}

- If you hug, kiss or massage your friend. [Not a risk

- If you don't protect yourself when handling blood. [Risk]

- If your sexual partner has sex with others. [Risk]

- If you drink beer or other kinds of alcohol. [Risk can lead to other risky behavior]
- If you masturbate. [Not a risk]

- If you are bitten by mosquitoes. [Not a risk (for HIV, but is a risk for malaria!)]

- If you allow semen or vaginal fluid to touch your normal skin, but not mucus membranes around the penis, vulva, anus or the mouth. [Slight risk, if you have a scratch or the fluid does reach a mucus membrane]

- If you have sex with more than one person. [Risk]

- If you or your partner has had an STI in the past. [Risk]

- If you share a razor with a person with HIV or AIDS. [Risk]

- If you only have sex with one partner. [Less risky if you are BOTH faithful, use protection and have both been tested for HIV and STIS]

- If you live, work or play with a person with HIV or AIDS. [Not a risk]

- If you don't know if your sexual partner is HIV positive or has an STI. [Risk]

- If you have injections, tattoos, or piercings. [Risk if needles are shared]
Facilitate a discussion with the following questions:

- Does knowing that some things are definitely or probably a risk worry you?

- Did you learn any new information?

- Do you have any questions about any behaviors we did not list today?

- If you were explaining information on risky or nonrisky behaviors to a friend, what would you say first? 


\section{optional activity}

\section{HIV AND AIDS IN ZAMBIA}

(10 MINUTES)

Instruct participants to describe the situation of HIV and AIDS in Zambia or in their community. Some things they may choose to describe about the situation are:

- Some people still refuse to accept that the disease exists.

- There is no cure for it.

- It ends in death.

- It is killing people in their 20s, 30s, and 40s, when they are most productive.

- It kills couples and leaves many orphans.

- Because so many people are sick with the disease, the hospitals cannot cope.

- Even those who know about the disease have not changed their behaviors.

- The impact of HIV and AIDS affects everybody.

\section{optional activity}

\section{IF SOMEONE SAYS...}

(3O MINUTES)

Write the following statements on the board:

- "I'm not worried about having sex with Mary she's a nice girl and her mother is a teacher. You only have to worry about dirty girls."

- "You hugged that guy with AIDS. Are you crazy?"

- "I don't believe James has HIV. He looks so healthy."

- "I feel sorry for people who got AIDS from a blood transfusion. But most other people have brought it on themselves."

- "I know you're not supposed to be able to get HIV from eating with someone, but l'm not eating any food with Jomo, especially if he has cooked it.

Suppose these doctors are wrong and two years from now they find out you can get AIDS that way."

- "If we really wanted to get rid of AIDS, we'd test everybody and take everyone who was HIVpositive to a deserted island."

Divide participants into groups of six (see Appendix B: Participatory Facilitation Resources - Group Formation Activities for ideas).

\section{Explain}

$\int_{1}$ In your groups, you will practice being HIV and AIDS educators who are responding to inaccurate or judgmental statements about HIV and AIDS. Each member of your group will take turns reading a statement from the list above and practice responding to it as if they were a peer educator. After each response, other group members should react

to the response by answering the following questions:

- What part of the statement did you react to?

- How did you feel about the AIDS educator's response?

Continue until each group member has had a chance to answer a question and ask a volunteer to respond as a peer educator.

Facilitate a discussion with the following questions:

-What was this activity like for you?

-Which statements were challenging to respond to? Which statements made you angry? Embarrassed? Confused?

- Did any of the statements try to make other people angry or embarrassed? If not, why would people say these kinds of things?

- What kind of statements about HIV or AIDS do you hear from your friends and acquaintances? How will you respond to these statements? 


\section{whap-up}

Read the following scenario:

\section{Awa's Story}

When Awa's husband died, she thought that he may have died from AIDS. She was very worried that she may also be infected. Awa got tested and learned that she was HIVpositive. Awa had joined a group that helped her start her own business. Her business is important because it is her family's only source of income. When everyone began to suspect that Awa was HIV-positive, they acted differently. Some of the women whispered when Awa came in and no one would sit near her at the meetings. Awa's son told her that everyone in the village knew that his father had died of AIDS. Some of them were saying that Awa gave the disease to her husband! She often thought, "How can they think this? I have always been a faithful wife. My husband was the only man I have ever had sex with in my life!" Worse yet, Awa's business was not going well. Even her best customers stopped buying from her. People who used to greet her warmly now turn away when they see her. It seems they are afraid to be near her, afraid they will get AIDS if they touch anything she has touched.
Find a volunteer to come to the front of the room to pretend to be Awa.

\section{Instruct:}

5 The rest of you will take turns visiting Awa to offer her support. Tell her some practical things she can do, and comfort her. Remember to treat her as you would like to be treated if you were in her situation.

Ask participants to summarize what they have learned. Fill in any key points they miss.

$\sum_{n m}^{n n y}$ Key Message: HIV and AIDS are incurable and affect millions of people worldwide. Practicing non-risky behaviors protects you from HIV and AIDS.

Ask for any final questions or comments. Remind participants where and when the next meeting will take place, and what topics will be discussed.

Thank them for their participation.

\section{PRACTICE ACTIVITY}

Participants should discuss with a friend about what puts someone at risk for HIV and how those risks can be avoided. 
MULTIPLE CONCURRENT PARTNERS CHART

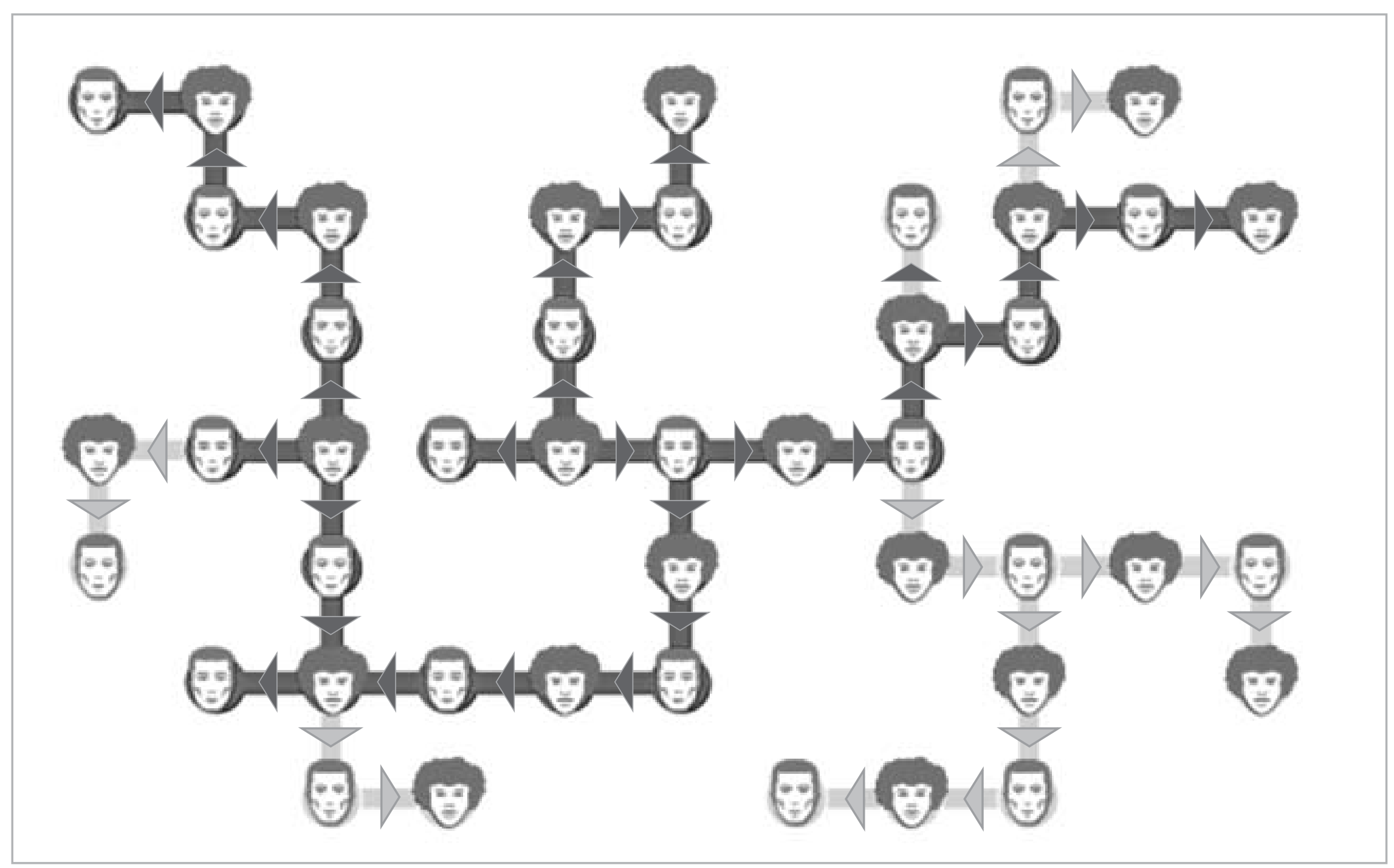




\section{2) Myth or Fact?}

\begin{tabular}{|l|}
\hline \multicolumn{1}{|c|}{} \\
SESSION \\
DESCRIPTION: \\
(HIV, AIDS, AND STIS) \\
Participants learn \\
whether various \\
statements are myths \\
or facts about HIV and \\
AlDS through a fun, \\
participatory guessing \\
game. \\
\hline
\end{tabular}

\begin{tabular}{|c|c|}
\hline $\begin{array}{l}\text { OBJECTIVES } \\
\text { By the end of this session, } \\
\text { participants will be able to: } \\
\text { - Differentiate between } \\
\text { myths and facts related to } \\
\text { HIV }\end{array}$ & $\begin{array}{l}\text { TIME } \\
1 \text { HOUR, } 30 \text { MINUTES } \\
\text { - Icebreaker (5 minutes) } \\
\text { - Review (5 minutes) } \\
\text { - Myth or Fact (45 minutes) } \\
\text { - HIV Rumors Role-play ( } 25 \\
\text { minutes) } \\
\text { - Wrap-up (5 minutes) } \\
\text { - Practice Activity (5 minutes) }\end{array}$ \\
\hline
\end{tabular}

MATERIALS
- Chalkboard and
chalk OR flipchart
and markers

\begin{tabular}{|l|}
\hline PRE-SESSION \\
PREPARATION \\
- Read through the entire session \\
and, if necessary, practice \\
presenting the activities \\
- Choose the statements you \\
will use for Activity 1 from \\
Activity Sheet 5: HIV and AIDS \\
Statements (provided at the \\
end of this session) \\
- Prepare all materials needed for \\
the session \\
- Look through the provided \\
statements and select which \\
ones you will use for the activity
\end{tabular}




\section{FACILITATOR NOTES}

The activities in this session are fun exercises that blow away some of the myths and misunderstandings surrounding HIV and AIDS. Remember, do not simply read through all the statements one by one; that would defeat the purpose of the exercise. You must keep the exercise quick and spontaneous to avoid it becoming boring.

If you'd like, you can add energizers from Appendix B: Participatory Facilitation Resources - /cebreaker Activities or quick breaks in between 10-15 minute sessions of reading statements.

\section{TERMS}

None

\section{ICEBREAKER}

Open the session with an icebreaker of your choice, or allow participants to suggest one. See Appendix B: Participatory Facilitation Resources - Icebreaker Activities for ideas.

\section{REVIEW}

Ask participants what key points were covered in the last session (optional: throw a ball of paper around to encourage participation). Fill in any key points that are missed.

Go over any practice activities that were given, and ask if there are any questions. 


\section{activity 1}

\section{MYTH OR FACT}

\section{(45 MINUTES)}

\section{ADVANCE PREPARATION: Read through the list of} myths and facts on the Activity Sheet 5: HIV and AIDS Statements at the end of this session and choose a selection that you will use in this session. Pick a handful of statements depending on the time available and the capability of your group. Choose statements that are appropriate for the age of your group. Be sure to include some statements from each of the provided lists.

Move the tables and chairs to one side, and ask participants to stand in the center of the room whilst you run through the rules of the activity.

\section{Explain}

This session will blow away some of the myth and misunderstandings surrounding the topic of HIV and AIDS. During this activity, try to remember what we discussed and learned in the previous session about HIV and AIDS.

When we begin, stand, scattered around the room, facing the front. Do not look at each other or make a noise.

I am going to read a number of statements. When I call out each statement, think silently about whether the statement is a Myth or a Fact (False or True).
When I count to three, you have to decide if the statement is a fact or a myth. If you believe the statement is a fact, you must jump up in the air and shout "Fact!" at the top of your voice. If you believe the statement is a myth, you will bob down and touch the floor, and shout "Myth!" If you cannot make up your mind, you can stay still.

It is ok to guess incorrectly, the point is for everyone to learn the facts while having fun!

Everyone must take part in this activity, so that on the count of three the silence will be broken by a disorderly, but fun, burst of shouts and jumps. Read a statement from the Activity Sheet 5: HIV and AIDS Statements (at the end of this session) to the group, and count out loud to three. After participants have responded with "Myth" or "Fact", reveal whether the statement is indeed a myth or fact, and explain the correct information.

\section{Tips}

- You might choose to ask one of the girls who got it right to explain why the statement is true or false, or you might choose to explain it yourself.

- Open the floor to questions and have a quick discussion where appropriate.
- Attention should not be brought to who is right and who is wrong, what is important is that everyone gets involved and the truth is shared in the end.

Repeat with other statements you have selected from Activity Sheet 5: HIV and AIDS Statements. Be sure to mix up the fun statements with the serious ones. Be aware that "\#4. Serious Statement Sheet - Other" from Activity Sheet 5 may only be appropriate for girls ages 15-19. 


\section{activity 2}

\section{HIV RUMORS ROLE-PLAY}

(25 MINUTES)

Seek out 5 volunteers to conduct a role-play. Away from the other participants, present the scenario

below to the volunteers:

\section{HIV Rumors Role-play}

A group of people is sitting around discussing the following rumors about HIV and AIDS. In the course of the discussion, present the correct information

(i.e., explain why each rumor is not true).

The rumors are:

- You can't get HIV if you only have sex one time.

- You can get HIV from kissing someone.

- You can tell if someone is HIV-positive by looking at them.

- Once you have become HIV-positive you can feel it in your body.

After they have had time to practice, have the volunteers conduct the role-play to the group. Allow the group to make suggestions to explain why each rumor is not true. Make sure the correct information is presented.

\section{Wrap-enp}

Instruct participants to write (or draw illustrations representing) the most important facts and myths on the chalkboard, or on flipchart, to help remember them.

Ask participants to summarize what they have learned. Fill in any key points they miss.

Key Message: To make the best choices about protecting yourself from HIV and AIDS, know the facts and dispel the myths.

Ask for any final questions or comments. When questions arise, have patience and try to encourage your group to come up with the answers themselves by starting a quick discussion about the topic.

Remind participants where and when the next meeting will take place, and what topics will be discussed.

Thank them for their participation.

\section{PRACTICE ACTIVITY}

Instruct participants to talk to a friend about myths surrounding HIV in their communities. Participants should dispel these myths with their friends with the knowledge they gained during this session. If they hear a new myth, they should be prepared to discuss and dispel it with the group at the beginning of the next session. 


\section{ACTIVITY SHEET 5}

\section{HIV AND AIDS STATEMENTS}

(NOTE: THERE ARE FOUR SHEETS IN THIS SET)

\section{1) FUN STATEMENT SHEET}

\begin{tabular}{|c|c|}
\hline Cows eat grass. & FACT \\
\hline The sky is green. & MYTH \\
\hline Chickens are taller than giraffes. & MYTH \\
\hline $\begin{array}{l}\text { Milk is bad for your health. } \\
\text { On the contrary, milk is very good for your health, especially as a child. }\end{array}$ & MYTH \\
\hline Paper is made from trees. & FACT \\
\hline $\begin{array}{l}\text { Children deserve an education. } \\
\quad \text { All children have the right to an education. }\end{array}$ & FACT \\
\hline $\begin{array}{l}\text { There are more chickens in the world than human beings. } \\
\text { Chickens are the most populous birds on earth and their predicted population is } 8 \text { billion! There are only } 7 \text { billion human beings. }\end{array}$ & FACT \\
\hline $\begin{array}{l}\text { The first tree was invented almost } 1000 \text { years ago in the year 1042AD. } \\
\text { Of course, trees have been on the earth for much longer than that. }\end{array}$ & MYTH \\
\hline $\begin{array}{l}\text { Camels are able to fly when they are born, but lose their wings when they are between } \\
\mathbf{3} \text { and } \mathbf{4} \text { months old. } \\
\text { Camels cannot fly. That's just silly! }\end{array}$ & MYTH \\
\hline $\begin{array}{l}\text { English is the most popular language in the world. } \\
\text { It is Chinese Mandarin. Remember the population of China is approximately } 1.3 \text { billion; that is more than all the English speaking } \\
\text { countries combined, plus those who speak English as a second language. }\end{array}$ & MYTH \\
\hline There are over 1800 languages spoken in Africa. & FACT \\
\hline $\begin{array}{c}\text { Football (soccer) is the best sport in the world. } \\
\text { Obviously, this one is open to interpretation }\end{array}$ & FACT/MYTH \\
\hline The strongest muscle in the human body is the tongue. & FACT \\
\hline $\begin{array}{l}\text { Children have different rights than adults. } \\
\text { Children's rights take into consideration that boys and girls have special needs that must be catered for, extra to their "human rights." }\end{array}$ & FACT \\
\hline $\begin{array}{l}\text { More than } \mathbf{9 0 \%} \text { of the world's population has access to a telephone. } \\
\text { In fact, more than } 50 \% \text { of the world's population has never even made or received a phone call. }\end{array}$ & MYTH \\
\hline $\begin{array}{l}\text { There are more children than adults living in Sub-Saharan Africa. } \\
\quad \text { A recent UNICEF statistic stated that } 51 \% \text { of the population of Sub-Saharan Africa is under } 18 \text { years of age. }\end{array}$ & FACT \\
\hline
\end{tabular}




\section{2) SERIOUS STATEMENT SHEET - TRANSMISSION RELATED}

\section{The only way to get rid of HIV is to give it somebody else.}

Firstly, there is no known way of getting rid of HIV from the body; it stays with you for life. Secondly, giving it to somebody else has no impact on the level of HIV in your own body.

Mosquitoes can spread HIV from one person to another.

This is a common misconception. Mosquitoes do not transfer any blood into people when they bite - they only withdraw the blood. In the process of withdrawing the blood, the mosquito injects its saliva into its victim. However, HIV cannot be transmitted through saliva, only blood, so there is no chance of HIV being transmitted through mosquito bites. (On the other hand, the malaria infection IS carried in mosquito saliva, so this illness can be passed on by mosquitoes)

Furthermore, HIV lasts for only a very short time in insects, so if the blood in the mosquito's belly WAS to pass on to another human being, the virus would have already been neutralized and there would be no chance of infection.

\section{Contraceptive pills help protect the body from HIV infection during sex.}

Contraceptive/birth control pills do nothing to guard against HIV infection, they just work against pregnancy.

Nits/head-lice can pass HIV from one person to another.

HIV can be passed on ONLY through blood, sex and mother to child transmission.

Kissing cannot pass on HIV.

The only way that the virus can be passed on is through sexual fluids, blood and mother to child transmission. HIV cannot be passed on through saliva, and therefore kissing. Having said that, if two people have open sores in their mouths when they kiss, this opens up a slight risk of infection.

Sharing toilets with somebody puts you at risk of infection.

You cannot pass on the virus by using the same toilet.

Girls are more likely to get HIV than boys.

Females are thought to be three times more likely to contract HIV than males in the 10-24 age group. This is due to both physical and social factors.

Boys are by no means immune to infection; they too can contract HIV through blood, unprotected sex and mother to child transmission.

Playing sports with someone who is HIV positive puts you at risk of infection.

The virus can only be transmitted through bodily fluids. 


\section{SERIOUS STATEMENT SHEET - AIDS TREATMENT RELATED}

\begin{tabular}{|c|c|}
\hline AIDS kills. & FACT \\
\hline $\begin{array}{l}\text { Being HIV positive means having a miserable life. } \\
\text { Having HIV does not stop a person living happily. If an HIV patient follows his or her doctor's advice and lives } \\
\text { healthily, s/he can lead a normal, enjoyable, meaningful life with a job, a partner, friends and children, for } \\
\text { many years to come. }\end{array}$ & MYTH \\
\hline $\begin{array}{l}\text { Anti-Retroviral Therapy (ART) treatment only keeps a patient alive for two years maximum. } \\
\text { There is no time limit on how long a person can live with HIV, a lot depends on how strong the person's im- } \\
\text { mune system is, how exposed they are to other infections (such as tuberculosis) and if they lead a healthy } \\
\text { lifestyle with a healthy diet. } \\
\text { Even without treatment, people have been known to live fifteen years and more. With treatment, no one } \\
\text { knows how long a person can live happily with HIV. }\end{array}$ & MYTH \\
\hline $\begin{array}{l}\text { If ART drugs are not taken on time, it can stop them working. } \\
\text { An ART treatment program changes people's lives in that they must be very punctual in taking their tablets. If } \\
\text { the drugs are not taken precisely according to the regime, the body begins to build up resistance to them and } \\
\text { in the future the drugs will not work as well against the HIV. }\end{array}$ & FACT \\
\hline $\begin{array}{l}\text { Anti-Retroviral Drugs eventually eliminate HIV from the body. } \\
\text { Anti-retroviral drugs do not eliminate HIV from the body, nor do they remove the risk of transmitting it to oth- } \\
\text { ers. ART contains the virus and does not allow it to get stronger. ART allows you to live a normal life and be } \\
\text { healthy WITH the virus in your body. }\end{array}$ & MYTH \\
\hline
\end{tabular}




\section{5-19-year-olds}

\section{SERIOUS STATEMENT SHEET - OTHER}

\section{The earliest symptom of AIDS is a rash that covers the person's body.}

There are no specific symptoms of AIDS. AIDS is a syndrome caused by HIV when the body's immune sys-

tem has been weakened so much that it is vulnerable to catch all sorts of different illnesses and diseases.

\section{There is a cure for AIDS in European Countries, but it is not available in Africa.}

No cure for HIV or AIDS has yet been discovered anywhere in the world, but the HIV treatment therapy is only

improving all the time.

Teaching young people about condoms and safe sex encourages them to have sex at an earlier age.

UNAIDS studies have shown that this is not the case. When young people are informed about sex they tend

to delay sexual activity and use a condom when they finally do have sex.

A relative or friend, not a stranger, usually carries out rape.

You should always try to avoid finding yourself in vulnerable situations. No matter what relationship the rapist has with the victim, it is ALWAYS sexual abuse and it is ALWAYS illegal, so do not be afraid to report it to the police.

Rape can happen to both men and women.

Men and boys are also victims of rape and sexual violence, it is not only women and girls who can be victims. These men are at high risk of contracting HIV.

There are no men in my country that have sex with other men.

There are homosexual and bisexual men and women all over the world who have active love lives in same

sex relationships.

\section{Street kids are the children of prostitutes.}

Children who live and work on the street come from all sorts of backgrounds. Some have been forced to leave their home due to abuse, poverty or stigma and have had no choice but to find themselves on the 


\section{3) HIV Testing and Counseling*}

SESSION
DESCRIPTION:
(HIV, AIDS, AND STIs)
Participants learn about
Voluntary Counseling
and Testing, and the
importance of getting
tested and talking to
partners about testing.

OBJECTIVES
By the end of this session,
participants will be able to:
- Define Voluntary
Counseling and Testing
(VCT)
- Explain why people
should be tested for HIV
- Explain the VCT process
- Explain what it means to
test positive and to test
negative
- Define the window period

TIME
55 MINUTES
(10-14-year-olds)
OR
1 HOUR, 25 MINUTES
(15-19-year-olds)
- Icebreaker (5 minutes)
- Review (5 minutes)
- Define Voluntary Counseling
and Testing (10 minutes)
- Why Should People Be Tested
for HIV? (25 minutes)
- Talking to Your Partner about
VCT (30 minutes)
- Wrap-up (5 minutes)
- Practice Activity (5 minutes)

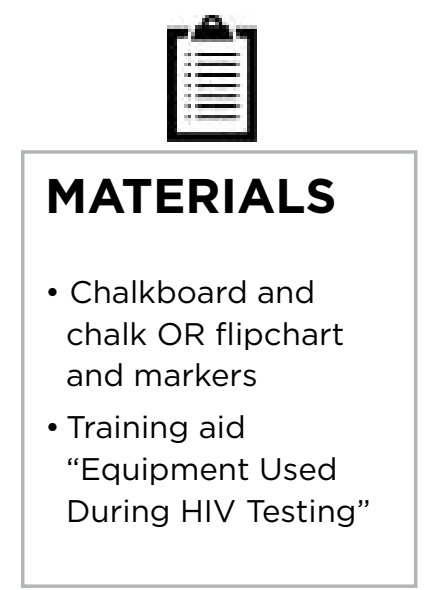

PRE-SESSION PREPARATION

- Read through the entire session and, if necessary, practice presenting the activities

- Prepare all materials needed for the session

- Identify the nearest VCT center, its location, opening times and other relevant information before facilitating this session 


\section{FACILITATOR NOTES}

A person cannot tell by looking at their body if they have HIV. A person cannot judge whether other people are infected by looking at them. Even when people have AIDS - they have been infected with HIV for a very long time and have become ill - you may not be able to know by looking at them unless you are a trained health worker. This is because most of the illnesses that come with AIDS can also come by themselves to people who do not have HIV. For example, someone can get TB whether or not they have HIV.

There is only one way for a person to know if they have HIV, and that is to have a test for HIV. In Zambia, HIV testing is accompanied by counseling, which usually refers to in-depth discussions with a trained and empathetic person who can help individuals cope with their HIV status and learn how to take care of themselves. If they are not infected, the counselor can help them take steps to keep themselves HIV-free.

The test is reliable, accurate, safe and painless. The health worker takes a small amount of blood from an individual's arm. The person tested cannot get weak from blood loss because so little blood is taken. Depending on the type of test used, the result may be available in just 30 minutes or after a week or two. In order for an individual to know whether they are truly free from HIV, they will also be asked to come back in another 3 to 6 months for another test when the 'window period' is over.

The window period is the time between the moment when HIV enters your body and the moment when the test can detect HIV antibodies. Usually the test can detect antibodies within 6 to 18 weeks of infection and in rare occasions, up to three years. This means that for up to several months after infection, the test may not be able to tell you whether or not you are infected. These months are the window period. During this window period, you are infected with HIV and can infect others.

There are many reasons to get tested for HIV. If a person has had unprotected sex and is worrying constantly about HIV infection and is anxious about every spot or cough that they get, the only way to put his or her mind at ease might be to have an HIV test. If a person has had sex with someone who has fallen sick and has heard that he or she has AIDS, then that person will also worry. Perhaps the only way for that person to put his or her mind at ease is to test. Never assume that you are infected or that you are not infected. Always go for a test.

Physicians currently recommend voluntary counseling and testing (VCT) to people who engage in high risk behavior including:

- Frequent sexual activity with multiple partners

- Encounters with sex workers

- Previous treatment for STIs

- Blood transfusions

- Anal sexual activity (male or female)

- Injection use

- Sexual activity with partners having any of the above

- Infants born to women with any of the above

\section{TERMS}

Voluntary Counseling and Testing (VCT)

The process by which a person can learn whether or not he or she is infected with $\mathrm{HIV}$, during which the person always counseled before and after the test regardless of the results; the decision to go for testing and to receive the results is voluntary

\section{Window Period}

The period between $\mathrm{HIV}$ infection and when the body produces antibodies for the HIV

\section{ICEBREAKER}

Open the session with an icebreaker of your choice, or allow participants to suggest one. See Appendix B: Participatory Facilitation Resources - Icebreaker Activities for ideas.

\section{REVIEW}

C) Ask participants what key points were covered in the last session (optional: throw a ball of paper around to encourage participation). Fill in any key points that are missed.

Go over any practice activities that were given, and ask if there are any questions. 


\section{activity 1}

\section{DEFINE VOLUNTARY COUNSELING AND TESTING}

\section{(10 MINUTES)}

\section{Ask:}

5 Does anyone know what "VCT" is?

[Voluntary Counseling and Testing, testing for HIV, which involves pre- and post-test counseling, done on one's own free will]

\section{Explain}

VCT stands for Voluntary Counseling and Testing. It is the process by which a person can learn whether or not he or she is infected with HIV, the virus that causes AIDS. A person is always counseled before and after the test regardless of the results. The decision to go for testing and to receive the results is voluntary.

If someone is tested for HIV, they have to be careful that they are being tested within the 'window period.' If the person is tested before the window period is over, they may have HIV because the body has not yet produced the antibodies that show up on an HIV test, but test negative for HIV, which is called a false negative. That is why it is important to know about the window period.

If the test is negative, the counselor will discuss the importance of prevention of HIV and other STIs in detail with the person in order to reduce his or her risks of infection in the future. The discussion will cover not only the methods available, but the person's individual situation, concerns and attitudes that may influence whether or not these methods are feasible and or acceptable and will be used. Remember: Testing does not prevent you from contracting HIV, but what you do between tests does.

If the result is positive, the counselor will discuss with the person all of the behaviors to avoid in order that he or she avoids infecting his or her partner (or children). In addition to this, the major task for the counselor will be to offer compassion, support, and practical advice, including referral to appropriate medical services, to enable him or her to cope with stress and anxiety and to make personal decisions. Follow-up sessions to ensure meaningful and long-term support will be necessary.

Show the Training Aid: Equipment Used During HIV Testing to explain the process, and answer any questions participants have about the HIV testing and counseling process. 


\title{
activity 2
}

\section{WHY SHOULD PEOPLE BE TESTED FOR HIV?}

\author{
(25 MINUTES)
}

\section{Ask:}

5 What are the advantages of being tested for HIV?

[possible answers include:

- if your result is negative, you can be reassured that you were not infected three months before the test,

- some of us think we would feel better if we knew our HIV status even if the result is positive,

- if we have a family we may want to know our status so we can plan for our children's future,

- some of us want to know whether or not we have HIV because we believe that if we know that we have the virus we can make changes to our way of living which will help us preserve our health and ensure that we live longer or better lives,

- it offers opportunities for early treatment of HIV and of HIV associated infections like TB or pneumonia, and

- it assists infected persons to protect others from being infected and to live positively]
Ask:

5 What are the disadvantages of being tested? [possible answers include:

- learning that a person is infected with HIV can be very distressing. The degree of distress depends on how well the person is prepared for the news, how well the person is supported by family and friends, and the person's cultural and religious attitudes towards illness and death,

- a person who learns he or she is infected with HIV is likely to suffer from feelings of doubt, fear, grief, depression, denial and anxiety; the person must make a variety of changes,

- partners and family members are likely to suffer from the consequences of an HIVpositive test result as well as the infected person; regardless of their status, they are affected, and

- a person who has tested positive for HIV may be discriminated against if the information is found out.]

\section{Ask:}

$S$ What are the benefits of VCT to the community?

[possible answers include:

- it generates feelings that things will turn out as large numbers of people test negative (about $80 \%$ of people visiting VCT centers test negative),

- it impacts community norms as regard to testing, risk reduction, discussion of HIV status,

- it reduces stigma as more people go public about being HIV positive,

- it serves as a catalyst for the development of care and support services like aid to orphans, and

- it generally reduces the rate of transmission of HIV.] 


\section{activity 3}

\section{TALKING TO YOUR PARTNER ABOUT VCT}

\section{(30 MINUTES)}

\section{Explain}

5 Talking with your partner, family, and others about HIV and AIDS prevention can bring up strong emotions and issues. Although it is difficult, it is important to have open and honest conversations about HIV and AIDS with people who are important to you. If you, or someone important to you, have practiced high-risk behaviors, it is important to be tested. Often it is best to get tested together with your partner. There are 4 steps to agreement that may help you make a decision together with your partner:

- Step 1: Say what you feel and want.

- Step 2: Listen to what the other person feels and wants.

- Step 3: Restate your point. Do not get sidetracked on other points of conflict.

- Step 4: Agree to what each of you will do.

Highlight the steps above while reading the following story to the group.

Review the four steps to agreement once more. Then divide participants into pairs (see Appendix B: Participatory Facilitation Resources - Group Formation Activities for ideas), and ask them to role-play the same scenario using the four steps.

After the pairs finish role-playing, ask the larger group:

5 What suggestions do you have to make the chances of reaching an agreement more likely?

In what other situations could you use these steps to resolve conflicts and problems? 15-19-year-olds only

\section{Mary's Story}

My name is Mary. I know my boyfriend, Thomas, has other partners, so I decided to talk to him about HIV and AIDS in order to protect myself. One day, when Thomas was relaxed and in a good mood, I said to him: 'Thomas, I have been hearing about HIV and AIDS, and I feel afraid. I want us to protect ourselves from getting it. What do you feel we should do?'

I listened respectfully to Thomas. 'What do I feel?' he said, 'I think you are trying to cover up the fact that you have other boyfriends!'

His words were painful to me, but I did not get angry. Instead, I restated what I felt and what I wanted. 'Thomas,

I can see you are upset, but we must talk about this. I am afraid and do not want you or me to die. What can we do to protect ourselves?

I continued to listen respectfully to Thomas' response. 'You are just changing the subject!' he said to me in a loud voice. 'You have other boyfriends! Next you will be wanting me to use a condom!'

I restated what I felt and wanted and said to Thomas, 'Because I am so worried about getting AIDS - believe me, I will be faithful! I really want to protect both of our lives.'

While Thomas was listening to me, I suggested what we could do. I said to him: 'Would you use a condom until we both get tested and make sure we do not have HIV? Then we can talk about what we need to do after that. How do you feel about that?'

Thomas and I finally agreed. 'I do not like it,' Thomas said, 'but I will wear a condom until we know we do not have the virus.'

\section{wrap-enp}

Ask participants to summarize what they have learned. Fill in any key points they miss.

$\sum_{3}$ Key Message: It is important for a person and their partner to get tested for HIV so that the necessary steps can be made to plan for the future.

Ask for any final questions or comments. Remind participants where and when the next meeting will take place, and what topics will be discussed.

Thank them for their participation.

\section{PRACTICE ACTIVITY}

Participants should explain in their own words why it is important to be tested for HIV to a friend. 
4) Risky Behavior*

\begin{tabular}{|l|l|}
\hline $\begin{array}{l}\text { SESSION } \\
\text { (HIV, AIDS, AND STIs) }\end{array}$ & $\begin{array}{l}\text { By the end of this session, } \\
\text { participants will be able to: } \\
\text { Participants categorize } \\
\text { activities based on how } \\
\text { risky they are in terms of } \\
\text { contracting HIV. }\end{array}$ \\
\hline
\end{tabular}

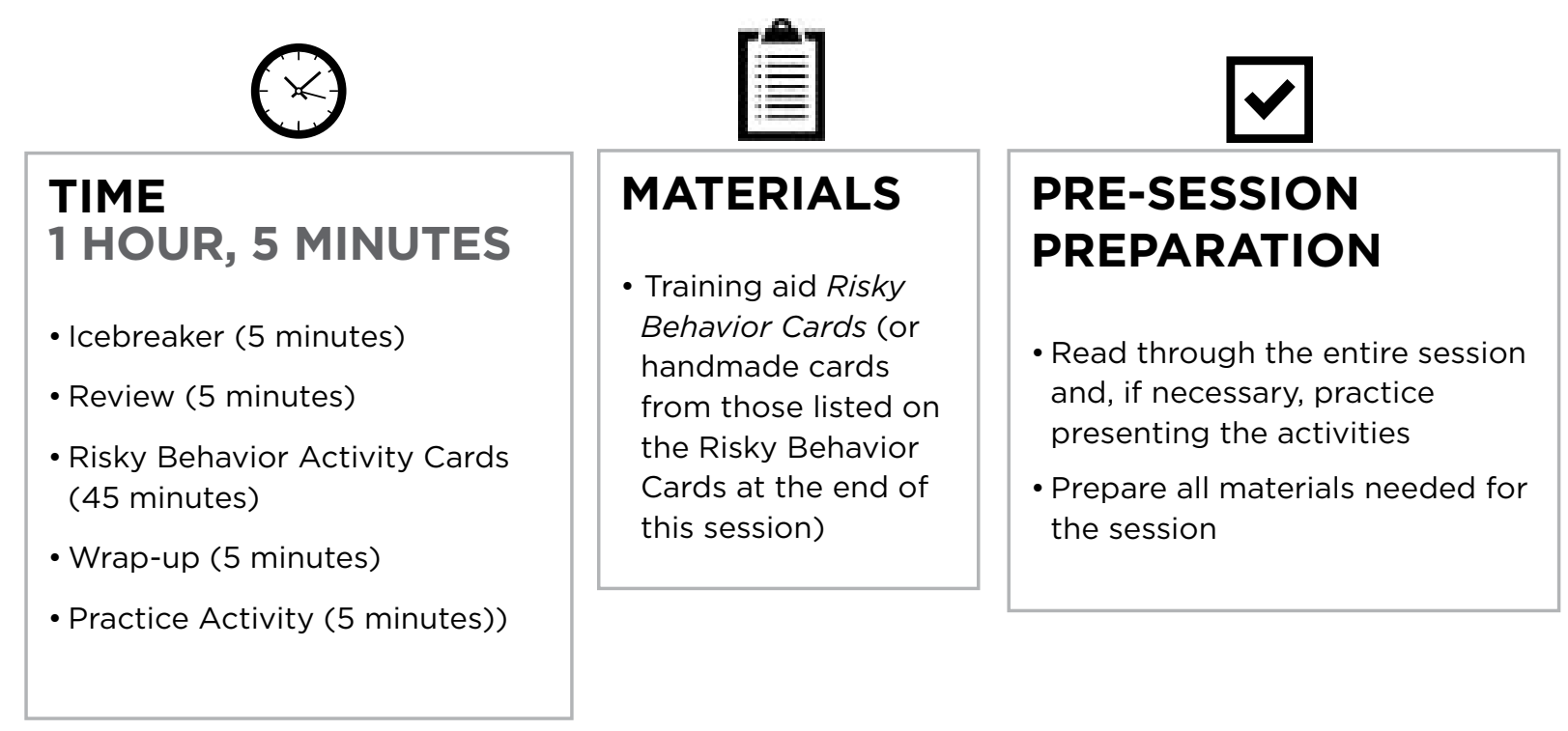




\section{FACILITATOR NOTES}

None

\begin{tabular}{|l|}
\hline TERMS \\
None \\
\end{tabular}

\section{ICEBREAKER}

Open the session with an icebreaker of your choice, or allow participants to suggest one. See Appendix B: Participatory Facilitation Resources - Icebreaker Activities for ideas.

\section{REVIEW}

(7) Ask participants what key points were covered in the last session (optional: throw a ball of paper around to encourage participation). Fill in any key points that are missed.

Go over any practice activities that were given, and ask if there are any questions. 


\section{RISKY BEHAVIOR ACTIVITY CARDS}

(45 MINUTES)

\section{Ask:}

$\int$ What risky behaviors can you think of related to HIV infection?

\section{Explain:}

$\bigcirc$ In attempting to change our behavior, it's very important to be aware of our own risky behavior and the reasons for these risk activities. We will now do an exercise to help us determine our levels of risk for HIV infection.

Pass out the cards from the Training Aid: Risky Behavior Cards (see also copies of the cards from at the end of the session, which can be used to handmake cards if training aids are not available), one to each participant, and give them time to read their individual cards.

Go over the levels of risk as explained in

Box 12: Levels of Risk for HIV before proceeding.

\section{Instruct:}

$\bigcirc$ Now line up according to the level of risk on your card from left to right. On the left side should be cards with "No Risk," in the middle should be cards with "Low Risk," and on the right should be cards with "High Risk."

\section{BOX 12: LEVELS OF RISK FOR HIV}

\section{No Risk}

No risk of getting HIV and AIDS - There is no exchange of blood, semen, vaginal fluids or maternal fluids.

\section{Low Risk}

Low risk of getting HIV and AIDS - There is a slight possibility of exchange of blood, semen, vaginal fluid, or maternal fluids.

\section{High Risk}

High risk of getting HIV and AIDS - There is a strong possibility of exchange of blood, semen, vaginal fluids or maternal fluids.

\section{After everyone has lined up, explain:}

Now place your card on the wall in the same order, from no risk to high risk, so that you are able to refer to them as the session continues. Then return to your seats so we can review the statements.
Go through each statement with the group. Reach an agreement on the levels of risk, changing any answers that are incorrect. There may be a great deal of debate on some cards. Answers can be found in the Risk Taking Activities Answer Key at the end of this session. Use this exercise to launch a full discussion of risky activities and the different levels of risk.

(NOTE TO FACILITATOR: There may be a lot of questions and debate during this session. Make sure you take time to clarify and make sure all the participants understand.) 


\section{Wrap-enp}

Ask participants to summarize what they have learned. Fill in any key points they miss.

Key Message: It is important to be aware of the risks of certain activities so that risks for HIV and AIDS can be avoided!

Ask for any final questions or comments. Remind participants where and when the next meeting will take place, and what topics will be discussed.

Thank them for their participation.

\section{PRACTICE ACTIVITY}

Instruct participants to think about three ways they will minimize their risk for HIV and AIDS now and/or in the future.

\section{RISK TAKING ACTIVITIES ANSWER KEY}

The following is an answer key for the Risk Taking Activities - the activities are listed as 'no risk', 'low risk' and 'high risk'. Use this list to guide you as you explain the session to the participants.

\section{No Risk}

- Abstaining from sexual intercourse

- Being bitten by a mosquito (no risk of HIV transmission, but risk of malaria!)

- Back rub or massage

- Body to body rubbing with clothes on

- Swimming with an HIV-infected person

- Eating food prepared by an HIV-positive person

- Going to school with an HIV-infected person

- Using toilets in a public washroom

- Dry kissing

- Sharing clothes with an HIV-infected person

- Donating blood

\section{Low Risk}

- Wet (deep) kissing

- Having vaginal sex with proper condom use

- Oral sex without a condom

- Receiving a blood transfusion

\section{High Risk}

- Being faithful sexually to one person whose HIV status you do not know

- Sharing needles for drugs, ear piercing or tattoos

- Having sex with a condom but the condom breaks

- Cutting your skin with a knife used by others

- Having sex using the same condom more than once

- Cleaning up spilled HIV-infected blood without wearing gloves

- Having anal sex without a condom 


\section{RISKY BEHAVIOR CARDS}

\begin{tabular}{|c|c|c|c|c|c|}
\hline $\begin{array}{l}\text { Using toilets in a } \\
\text { public washroom }\end{array}$ & $\begin{array}{l}\text { Touching or } \\
\text { comforting someone } \\
\text { living with HIV and } \\
\text { AIDS }\end{array}$ & $\begin{array}{l}\text { Having vaginal sex } \\
\text { with proper condom } \\
\text { use }\end{array}$ & Dry kissing & $\begin{array}{l}\text { Having sex using the } \\
\text { same condom more } \\
\text { than once }\end{array}$ & $\begin{array}{l}\text { Swimming with an } \\
\text { HIV-infected person }\end{array}$ \\
\hline $\begin{array}{l}\text { Sharing needles for } \\
\text { drugs, ear piercing or } \\
\text { tattoos }\end{array}$ & $\begin{array}{l}\text { Being sexually } \\
\text { faithful to one person } \\
\text { whose HIV status you } \\
\text { do not know }\end{array}$ & $\begin{array}{l}\text { Going to school } \\
\text { with an HIV-infected } \\
\text { person }\end{array}$ & $\begin{array}{l}\text { Cutting your skin } \\
\text { with a knife used by } \\
\text { others }\end{array}$ & $\begin{array}{l}\text { Being bitten by a } \\
\text { mosquito }\end{array}$ & Donating blood \\
\hline $\begin{array}{l}\text { Having anal sex } \\
\text { without a condom }\end{array}$ & $\begin{array}{l}\text { Eating food prepared } \\
\text { by an HIV-positive } \\
\text { person }\end{array}$ & Back rub or massage & $\begin{array}{l}\text { Cleaning up spilled } \\
\text { HIV-infected blood } \\
\text { without wearing } \\
\text { gloves }\end{array}$ & Wet (deep) kissing & $\begin{array}{l}\text { Receiving a blood } \\
\text { transfusion }\end{array}$ \\
\hline $\begin{array}{l}\text { Abstaining from } \\
\text { sexual intercourse }\end{array}$ & $\begin{array}{l}\text { Going to school } \\
\text { with an HIV-infected } \\
\text { person }\end{array}$ & $\begin{array}{l}\text { Having sex with a } \\
\text { condom, but the } \\
\text { condom breaks }\end{array}$ & $\begin{array}{l}\text { Body to body } \\
\text { rubbing with clothes } \\
\text { on }\end{array}$ & $\begin{array}{l}\text { Oral sex without a } \\
\text { condom }\end{array}$ & $\begin{array}{l}\text { Sharing clothes with } \\
\text { an HIV-infected } \\
\text { person }\end{array}$ \\
\hline
\end{tabular}




\section{5) The Relationship of STIs and HIV and AIDS*}

\begin{tabular}{|c|}
\hline $\begin{array}{l}\text { SESSION } \\
\text { DESCRIPTION: } \\
\text { (HIV, AIDS, AND STIS) }\end{array}$ \\
\hline $\begin{array}{l}\text { Participants match STI } \\
\text { names to lists of their } \\
\text { symptoms, learn how } \\
\text { STIs are related to HIV } \\
\text { transmission, and about } \\
\text { STI treatment. }\end{array}$ \\
\hline
\end{tabular}

\begin{tabular}{|l|}
\hline OBJECTIVES \\
By the end of this \\
session, participants will \\
be able to: \\
- Identify HIV and AIDS \\
risk factors \\
- Describe ways to \\
prevent HIV infection \\
- Identify symptoms of \\
four STIs \\
- Describe how an STI \\
infection increases the \\
risk of HIV transmission \\
- State why it is \\
important to get early \\
treatment for an STI \\
\end{tabular}

- Icebreaker (5 minutes)
- Review (5 minutes)
- The Role of Sexually
Transmitted
Infections (STIs) in
HIV Transmission (10
minutes)
- The STI Game (15
minutes)
- Discussion Questions (10
minutes)
- Wrap-up (10 minutes)
- Practice Activity (5
minutes)

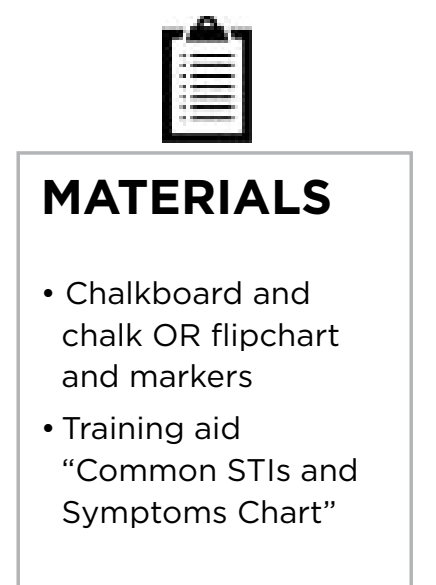

\section{$\checkmark$ \\ PRE-SESSION PREPARATION}

- Read through the entire session and if necessary, practice presenting the activities

- Prepare all materials needed for the session

- Write down the name of each STI from the Common STIs and Symptoms Chart (at the end of this session) on small pieces of paper

- Hide the names of the STIs on the Training Aid: Common STIs and Symptoms Chart with paper (if training aids are not available, write the names and symptoms of STIs on a chalkboard or flipchart paper and cover the names) - Know the local methods for treating STIs, and where participants can go for appropriate STI treatment

- If possible, invite a nurse, peer outreach person or staff from an NGO working on STIs and HIV to come to talk about HIV 


\section{FACILITATOR NOTES}

This session describes common sexually transmitted infections and their symptoms. Participants learn the concept that early treatment of sexually transmitted infections can dramatically reduce the risk of infection with HIV. They have an opportunity to role-play telling a partner about STIs and why they should get treated.

\section{TERMS}

\section{None}

\section{ICEBREAKER}

Open the session with an icebreaker of your choice, or allow participants to suggest one. See Appendix B: Participatory Facilitation Resources Icebreaker Activities for ideas.

\section{REVIEW}

Ask participants what key points were covered in the last session (optional: throw a ball of paper around to encourage participation). Fill in any key points that are missed.

Go over any practice activities that were given, and ask if there are any questions. 
activity 1

\section{THE ROLE OF SEXUALLY TRANSMITTED INFECTIONS (STIS) IN HIV TRANSMISSION}

(10 MINUTES)

Overview the relationship of HIV and STIs:

\section{Explain}

5 Having an STI is one of the most important factors in HIV transmission. It can increase the risk of HIV transmission substantially. Recent research showed that the presence of STIs in eastern and southern Africa was one of the two major reasons why there was a higher incidence of AIDS in these regions of the continent.

A genital sore or ulcer as in syphilis, cancroid, or herpes expands the portal of entry. Having a discharge, as in gonorrhea or chlamydia, means that more white blood cells are present. Since white blood cells are hosts for HIV, it means that more virus can be transmitted or received when the discharge is present.

Quick and proper treatment of STIs and immediate referral of partners can be important strategies for HIV prevention. Often women do not have apparent symptoms of sexually transmitted infections, so check-ups and partner referrals are very important. But men, too, may occasionally not have symptoms, even of gonorrhea; so, it is important that the man seek treatment also if his partner is infected and avoid blaming partners for infection.

\section{activity 2}

\section{THE STI GAME}

(15 MINUTES)

ADVANCE PREPARATION: Cover the names of the STIs with paper on the Training Aid: Common ST/S and Symptoms Chart (also provided at the end of this session). If the training aid is not available, write the names and symptoms (from the version provided at the end of this session) on chalkboard or flipchart paper and cover the names with pieces of paper. Write the names of STIs that appear on the Common STIs and Symptoms Chart (at the end of this session) on pieces of paper. (Write local or popular names of the diseases in parentheses next to the scientific names.)

Show participants the Training Aid: Common ST/S and Symptoms Chart with the names of the STIs covered up with paper (or the handwritten chart - with names still covered - on the chalkboard or flipchart, which you prepared before the session if training aids were not available). Put participants in groups, and give each group 2-3 pieces of with the names of STIs written on them.

Instruct the groups to match the names of the STIS with their descriptions on the chart. After participants have agreed on the placement, reveal the correct names and discuss anything they got wrong. 


\section{activity 3}

\section{DISCUSSION QUESTIONS}

\section{(10 MINUTES)}

Lead the participants in discussing the following questions:

-Where do people in our community go to get treated for STIs?

-Which of these places is the best place to get treated? Why?

-What other remedies do people in our community use to treat STIs?

-What are the risks associated with not seeking professional help?

[increased risk of HIV infection, transmit STI to partner(s), develop serious irreversible symptoms of the STI, etc.]

-Why is it important to get treated early for an STI? [HIV prevention, avoid spreading the STI to others, avoid experiencing more serious symptoms, relieve discomfort, etc.]

-Why is it important that your partners get treated? [so they do not spread STIs to you, so they are not at an increased risk for HIV, because they may be infected with an STI and not have symptoms]

- How can we tell someone that they have been exposed to an STI without blaming them or getting hurt ourselves?

[e.g., use good communication skills that have been discussed in previous sessions (calmly express the issue, allow the other person to express his/her feelings, listen while the other person speaks, work with the other person to find a solution, etc.)]

\section{optional activity}

15-19-year-olds only

\section{ROLE-PLAY}

\section{(2O MINUTES)}

Have volunteers from the group role-play two situations (right).

Evaluate how the situations went by asking the following questions:

-Were they realistic?

- Did they achieve the desired outcomewillingness of the partner to get tested?

- Did partners feel blamed?

- Are there other ways to reveal this news that would have been more effective at getting the desired outcome?

\section{Role-play Scenarios}

\section{Scenario 1:}

A male partner informs his female partner that she needs to get treated for gonorrhea because he is having symptoms of that disease.

\section{Scenario 2:}

A female partner tells her male partner that he needs to get treated for syphilis, because she just learned in her prenatal exam that she has that disease. 


\section{Wrap-enp}

\section{Explain:}

5 The only way to prevent and/or lower the risk of HIV transmission is abstinence. If a girl and her partner do not practice abstinence, together they can lower their risk of HIV transmission by being faithful to each other (being each other's only partner), and using a condom consistently and correctly each time they have sexual intercourse.

Offer resources to participants, if applicable, about how they can learn more about HIV/STIs and testing.

\section{Explain:}

5 It is normal to feel uneasy or embarrassed when discussing these topics, but it's important to get correct information about sexuality regardless of how embarrassing it may be to get it.

Ask participants to summarize what they have learned. Fill in any key points they miss.

$\sum_{4 m}^{3}$ Key Message: Practicing certain behaviors can put a person at risk for STIs, and also increase their risk for HIV.
Ask for any final questions or comments. Remind participants where and when the next meeting will take place, and what topics will be discussed.

Thank them for their participation.

\section{PRACTICE ACTIVITY}

Participants should ask people in their community about HIV. If they can find any information that contradicts what they learned today, they should bring that item or idea to the next session for discussion. 


\section{COMMON STIS AND SYMPTOMS CHART}

\begin{tabular}{|c|c|c|c|}
\hline $\begin{array}{l}\text { SEXUALLY TRANSMITTED } \\
\text { INFECTION (STI) NAME }\end{array}$ & SIGNS AND SYMPTOMS & EFFECTS & TREATMENT \\
\hline Gonorrhea & $\begin{array}{l}\text { - Most women who are infected show no symp- } \\
\text { toms } \\
\text { - Some women experience pain during urination, } \\
\text { vaginal discharge (milky white or yellow/green) } \\
\text { - In men, this infection can cause a burning pain } \\
\text { during urination, painful or swollen testicles or a } \\
\text { white, yellow or green discharge } \\
\text { - Symptoms usually occur } 2 \text { to } 14 \text { days after expo- } \\
\text { sure } \\
\text { - Possibly no symptoms }\end{array}$ & $\begin{array}{l}\text { - Untreated, it can lead to serious permanent } \\
\text { health problems in both men and women } \\
\text { including sterility and pelvic inflammatory dis- } \\
\text { ease in women } \\
\text { - Women with this infection can pass it to new- } \\
\text { born babies causing blindness (if not treated } \\
\text { with drops in eyes), joint infection, or blood } \\
\text { infection }\end{array}$ & $\begin{array}{l}\text { - This infection can be cured } \\
\text { with antibiotics }\end{array}$ \\
\hline Chlamydia & $\begin{array}{l}\text { - Most women who are infected have no symp- } \\
\text { toms } \\
\text { - If symptoms do exist they are most likely vaginal } \\
\text { discharge } \\
\text { - Symptoms in men include discharge from the } \\
\text { penis, a burning pain during urination as well as } \\
\text { itching around the opening of the penis }\end{array}$ & $\begin{array}{l}\text { - If left untreated, this infection can spread to the } \\
\text { uterus or fallopian tubes and cause constant } \\
\text { pelvic pain, infertility and miscarriage } \\
\text { - This infection can cause eye and respiratory } \\
\text { infections in newborns and bring on premature } \\
\text { delivery } \\
\text { - Women are up to five times more likely to } \\
\text { contract HIV if exposed to it while infected with } \\
\text { this virus }\end{array}$ & $\begin{array}{l}\text { - This infection can be cured } \\
\text { with antibiotics }\end{array}$ \\
\hline Cancroid & $\begin{array}{l}\text { - Most women do not show symptoms } \\
\text { - Symptoms may appear three to seven days after } \\
\text { infection and include small painful sores on the } \\
\text { genitals or one larger sore } \\
\text { - Inflammation of lymph gland on one side }\end{array}$ & $\begin{array}{l}\text { - The presence of sores, the common symptom } \\
\text { of this infection, increases a person's likelihood } \\
\text { of becoming infected with HIV if exposed to } \\
\text { the virus }\end{array}$ & $\begin{array}{l}\text { - This infection is curable with } \\
\text { antibiotics }\end{array}$ \\
\hline Genital Herpes & $\begin{array}{l}\text { - Most people are not aware they are infected } \\
\text { - Some people will develop painful blisters on the } \\
\text { genitals or mouth } \\
\text { - Other symptoms include headache, fever, } \\
\text { muscle aches and chills }\end{array}$ & $\begin{array}{l}\text { - Sores may reappear periodically throughout } \\
\text { one's life } \\
\text { - This infection can be passed to a newborn and } \\
\text { cause blindness, brain damage, and death } \\
\text { - People with sores from this infection are more } \\
\text { likely to contract HIV if exposed to the virus }\end{array}$ & $\begin{array}{l}\text { - There is no cure for this } \\
\text { infection; however the virus } \\
\text { can be treated with a medi- } \\
\text { cation called Acyclovir }\end{array}$ \\
\hline
\end{tabular}




\begin{tabular}{|c|c|c|c|}
\hline Syphilis & $\begin{array}{l}\text { - Many people have no symptoms } \\
\text { - Primary stage symptoms include a painless sore } \\
\text { on the penis or vagina } \\
\text { - If not treated, the sore will go away and sec- } \\
\text { ondary symptoms will appear including: rashes } \\
\text { on the palms of the hands or soles of the feet, } \\
\text { fever, headache, hair loss and sore throat } \\
\text { - Late stages of the disease are marked by paraly- } \\
\text { sis, numbness, gradual blindness and dementia }\end{array}$ & $\begin{array}{l}\text { - If untreated, this infection damages the internal } \\
\text { organs } \\
\text { - This infection can lead to blindness, stroke, and } \\
\text { death } \\
\text { - It can be passed from the mother to child caus- } \\
\text { ing deformities and mental illness, possibly } \\
\text { death } \\
\text { - A sore from this infection can increase the } \\
\text { chances of HIV transmission if exposed }\end{array}$ & $\begin{array}{l}\text { - This infection is easily } \\
\text { treated with the antibiotic } \\
\text { penicillin }\end{array}$ \\
\hline Trichomoniasis & $\begin{array}{l}\text { - This infection is caused by a parasite commonly } \\
\text { found in the vagina or urethra opening of the } \\
\text { penis } \\
\text { - Most men do not have symptoms but some may } \\
\text { experience mild discharge or a burning pain } \\
\text { after urination or ejaculation } \\
\text { - Symptoms in women may include yellow green } \\
\text { discharge, strong odor, itching or pain during } \\
\text { urination or intercourse }\end{array}$ & $\begin{array}{l}\text { - In women, genital inflammation can increase } \\
\text { the chance of transmission of HIV if exposed }\end{array}$ & $\begin{array}{l}\text { - This infection is easily cured } \\
\text { with medication }\end{array}$ \\
\hline $\begin{array}{l}\text { HPV (Human } \\
\text { papilloma virus) / } \\
\text { Genital Warts }\end{array}$ & $\begin{array}{l}\text { - Most people do not show symptoms. } \\
\text { - Some strains of this infection cause warts in the } \\
\text { infection }\end{array}$ & $\begin{array}{l}\text { - Certain strains of this infection can cause cervi- } \\
\text { cal cancer in some women }\end{array}$ & $\begin{array}{l}\text { - This infection is treatable } \\
\text { with medication } \\
\text { - Other strains may clear with } \\
\text { time }\end{array}$ \\
\hline Hepatitis B & $\begin{array}{l}\text { - Spread by sex, exposure to infected blood, and } \\
\text { to child during pregnancy or delivery } \\
\text { - Mild initial symptoms: headache and fatigue } \\
\text { - Later symptoms: dark urine, abdominal pain, } \\
\text { jaundice } \\
\text { - Often no visible symptoms }\end{array}$ & $\begin{array}{l}\text { - Can develop chronic liver disease. } \\
\text { - Causes inflammation of the liver and some- } \\
\text { times leads to liver failure and death }\end{array}$ & - There is no cure \\
\hline Pubic Lice & $\begin{array}{l}\text { - Transmitted by close physical contact, including } \\
\text { sexual contact } \\
\text { - These are small bugs that are visible to the } \\
\text { naked eye without the aid of a magnifying glass } \\
\text { or microscope living on pubic hair (or any other } \\
\text { hair) and are associated with itching }\end{array}$ & $\begin{array}{l}\text { - This infection affects the skin or hair and } \\
\text { causes itching but has no long-term effects }\end{array}$ & $\begin{array}{l}\text { - This is often cured with } \\
\text { shampoos, or easily obtain- } \\
\text { able medications }\end{array}$ \\
\hline
\end{tabular}


6) Stigma and Discrimination in HIV-Positive People*

\begin{tabular}{|l|l|}
\hline \multicolumn{1}{|l|}{} \\
\begin{tabular}{|l|l|}
\hline SESSION \\
DESCRIPTION: \\
(HIV, AIDS, AND STIs)
\end{tabular} & $\begin{array}{l}\text { OBJECTIVES } \\
\text { Barticipants will be able to: } \\
\text { participants learn } \\
\text { about stigma and } \\
\text { discrimination through } \\
\text { stories and pictures. }\end{array}$ \\
\hline & $\begin{array}{l}\text { - Define the terms stigma } \\
\text { and discrimination } \\
\text { - Describe the types of } \\
\text { stigma and discrimination } \\
\text { • Explain the effects of } \\
\text { stigma and discrimination } \\
\text { • Explain different ways } \\
\text { of reducing stigma and } \\
\text { discrimination }\end{array}$ \\
\hline
\end{tabular}

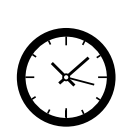

\section{TIME}

1 HOUR, 20 MINUTES

- Icebreaker (5 minutes)

- Review (5 minutes)

- Stigma (30 minutes)

- Discrimination (15 minutes)

- Reducing Stigma and

Discrimination (15 minutes)

-Wrap-up (5 minutes)

- Practice Activity (5 minutes)

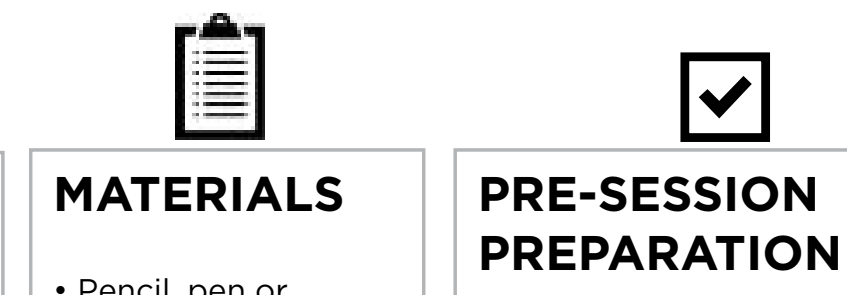

- Pencil, pen or

marker, and paper

for each participant

- Chalkboard and

chalk OR flipchart

and markers

- Training aid "Stigma

Illustration"

\section{PRE-SESSION}

- Read through the entire session and, if necessary, practice presenting the activities

- Prepare all materials needed for the session

- Write the True/False statements from Activity 3 on the board or flipchart 


\section{FACILITATOR NOTES}

People who are HIV-positive may be discriminated against or shunned in their communities because of misunderstandings or misconceptions about HIV and AIDS in the community. Adolescents may be particularly susceptible to negative attitudes and may be forced out of their school or home. They are typically less aware of their legal rights, more vulnerable to financial hardships, and less able to find and purchase care.

\section{TERMS}

\section{Discrimination}

Treating someone differently because

of perceptions or prejudices about

them

\section{Stigma}

Severe disapproval of, or discrimina-

tion against, a person on the grounds of characteristics that distinguish them from other members of a society

\section{External Stigma}

Enacted or expressed stigma

\section{Internal Stigma}

Self-hatred, shame, or blame; feeling of being judged by others; also called self-stigma

\section{ICEBREAKER}

Open the session with an icebreaker of your choice, or allow participants to suggest one. See Appendix B: Participatory Facilitation Resources - Icebreaker Activities for ideas.

\section{REVIEW}

(7) Ask participants what key points were covered in the last session (optional: throw a ball of paper around to encourage participation). Fill in any key points that are missed.

Go over any practice activities that were given, and ask if there are any questions. 


\section{activity 1}

\section{STIGMA}

(3O MINUTES)

Ask:

5 What is "stigma"?

[unfavorable attitudes and beliefs directed towards someone (e.g., pointing fingers, gossiping, making a person feel uncomfortable, other more direct types of discrimination]

\section{Explain}

$\int$ An example of stigma is when people who are HIV-positive are discriminated against or shunned in their communities because of misunderstandings or misconceptions about HIV and AIDS in the community.

Ask:

Can you think of other examples of stigma?

Distribute paper and pencils if the participants do not have their own.

\section{Instruct:}

5 Now draw pictures showing examples of stigma in your community and at school.

When the participants have finished their drawings, ask volunteers to show their illustrations and discuss how stigma is represented in them.

Show the picture in the Training Aid: Stigma Illustration of children playing and one child in the corner (similar to the one on the right), very miserable and denied to play with others. Have the participants discuss what they think the picture shows in relation to discrimination.
Explain:

stigma" is when someone has his or her own negative feelings/beliefs about having HIV and AIDS. It is also called self-stigma.

Facilitate a discussion with the following questions:

-Why is it that relatives of those who die of AIDS do not wish to talk about it? [stigma]

- Are people generally reluctant to talk about HIV and AIDS? Why do you think so? [fear]

Find a participant to volunteer to read aloud the story about Mary to understand internal stigma, or self-stigma:

Discuss how the story demonstrates internal stigma.

\section{Explain:}

$\int$ “External stigma" refers to stigma expressed by the external community. Adolescents may be particularly susceptible to negative attitudes and may be forced out of their school or home. They are typically less aware of their legal rights, more vulnerable to financial hardships, and less able to find and purchase care.

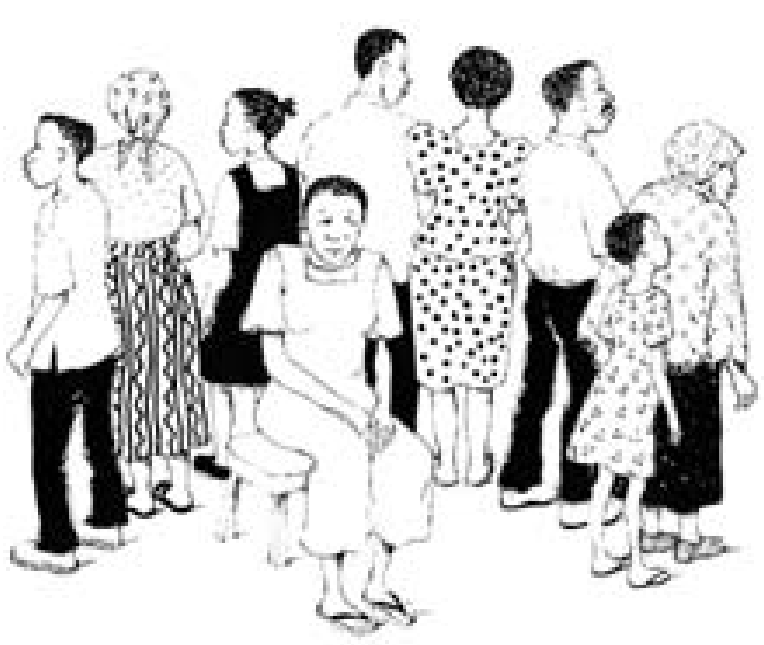

\section{Mary's Story}

Mary has HIV and AIDS, but no one knows about it except her. She goes to school and tries to play with some friends, but they are feeling tired and are not willing to play. Mary gets angry at herself and at them, thinking that they do not want to play with her because she is HIV-positive. Mary refused to go to school again and stays at home locked up in her bedroom.

\section{Florence's Story}

Florence is in grade 7 at Lusaka Girls Primary

School. She is HIV-positive. Almost everyone in her class and school know about it. When she arrives in the morning, nobody wants to sit with her, and they leave her to sit alone. They talk badly about her and call her names like "walking dead body" and "kaslim." They even have composed songs about her. No one wants to share their snacks with her during break-time. And whenever the teacher is teaching, he uses her as an example of all the bad things. One day he was talking about the woman in the Bible who had leprosy and said that woman was like Florence. She feels very bad, she cries when she goes home, and she is sad most of the time.

Read the story about Florence. Then,

\section{Ask:}

What are the different forms of external stigma in the story about Florence?

[gossiping, using Florence as a bad example, calling her names (nicknaming), composing songs about her, refusal to share food/utensils] 


\section{activity 2}

\section{DISCRIMINATION}

\section{(15 MINUTES)}

Read the story about Sarah (below):

\section{Ask:}

5 What is "discrimination"?

[when someone is treated unfairly as a result of stigma, treating someone differently because of perceptions or prejudices about them]

How is discrimination shown in Sarah's story?

Would anyone like to share different stories you have heard or gone through that demonstrate discrimination? (it is all right if no one feels comfortable sharing)

\section{Sarah's Story}

Sarah is an orphan who stays with her grandmother and uncle. Whenever her grandmother keeps food for her so that she can eat after school, her uncle throws it away and even breaks the plate if she has eaten from it. He says it's a waste of food and if they eat from that plate they will get AIDS.
What are the possible effects of stigma and discrimination?

[possible answers include:

- leads to absenteeism from school,

- leads to low self-esteem,

- fear to discuss and share with friends be-

cause of discrimination, and

- fear to associate in different groups.] 


\section{activity 3}

\section{REDUCING STIGMA AND DISCRIMINATION}

(15 MINUTES)

Read the story about Sarah (previous page)

\section{Ask:}

5 What are the different ways of reducing stigma and discrimination?

[see true statements from Table 4: True and

False for Stigma and Discrimination (below) for possible responses]

Write the content from Table 4:True and False for Stigma and Discrimination (below) on the chalkboard or flipchart. Go through the table with participants to discuss ways of reducing stigma and discrimination.

\section{TABLE 4: TRUE AND FALSE FOR STIGMA AND DISCRIMINATION}

\begin{tabular}{|c|c|c|c|}
\hline WAYS OF REDUCING STIGMA AND DISCRIMINATION & TRUE & FALSE & $\begin{array}{l}\text { CORRECT } \\
\text { ANSWER }\end{array}$ \\
\hline Learning to live and cope with the situation & & & TRUE \\
\hline Do not sensitize religious leaders & & & FALSE \\
\hline $\begin{array}{l}\text { Educating community through testimonies, especially key people } \\
\text { in the community such as teachers an religious leaders }\end{array}$ & & & TRUE \\
\hline $\begin{array}{l}\text { Involving infected people in local and national initiatives to help } \\
\text { reduce stigma }\end{array}$ & & & TRUE \\
\hline Continuing to laugh at people with HIV in the community & & & FALSE \\
\hline Building a school for only HIV-positive children & & & FALSE \\
\hline $\begin{array}{l}\text { Talking about how he or she feels and what he or she needs help } \\
\text { with among family, friends, and caregivers }\end{array}$ & & & TRUE \\
\hline
\end{tabular}<smiles>CCCCCCCCCCCCCCCCCCCC</smiles>

Ask participants to summarize what they have learned. Fill in any key points they miss.

$\sum_{m}^{m}$ Key Message: People who are HIVpositive may be discriminated against or stigmatized in your communities, but sharing your knowledge about HIV and AIDS can help reduce this!

Ask for any final questions or comments. Remind participants where and when the next meeting will take place, and what topics will be discussed.

Thank them for their participation.

\section{PRACTICE ACTIVITY}

Ask an older sibling or friend if they have ever seen anyone be stigmatized. Discuss with the older sibling or friend what the person was stigmatized for and then ask for advice on what someone can do to avoid stigma for that reason. 


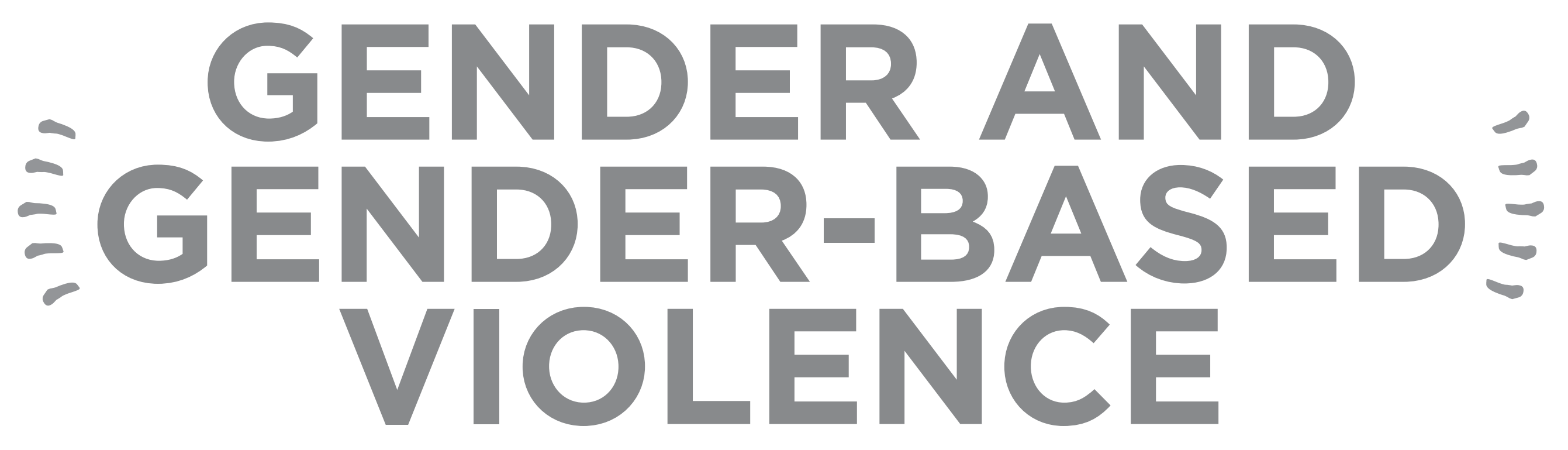


1) Sexual Exploitation*

\begin{tabular}{|l|l|}
\hline \multicolumn{2}{|l|}{} \\
\begin{tabular}{|l|l|}
\hline \multicolumn{1}{l|}{ SESSION } \\
DESCRIPTION: \\
CGENDER AND \\
GENDER-BASED \\
VIOLENCE)
\end{tabular} \\
$\begin{array}{l}\text { Participants learn about } \\
\text { Gender and Gender- } \\
\text { Based Violence, different } \\
\text { types of physical } \\
\text { contact, and think } \\
\text { about what they would } \\
\text { do in uncomfortable } \\
\text { situations. }\end{array}$ & $\begin{array}{l}\text { By the end of this session, } \\
\text { participants will be able to: } \\
\text { • Define sexual exploitation } \\
\text { - Differentiate between } \\
\text { a "good touch," "bad } \\
\text { touch," and "confusing } \\
\text { touch" } \\
\text { • Describe at least three } \\
\text { ways to get out of an } \\
\text { uncomfortable sexual } \\
\text { situation }\end{array}$ \\
\hline
\end{tabular}

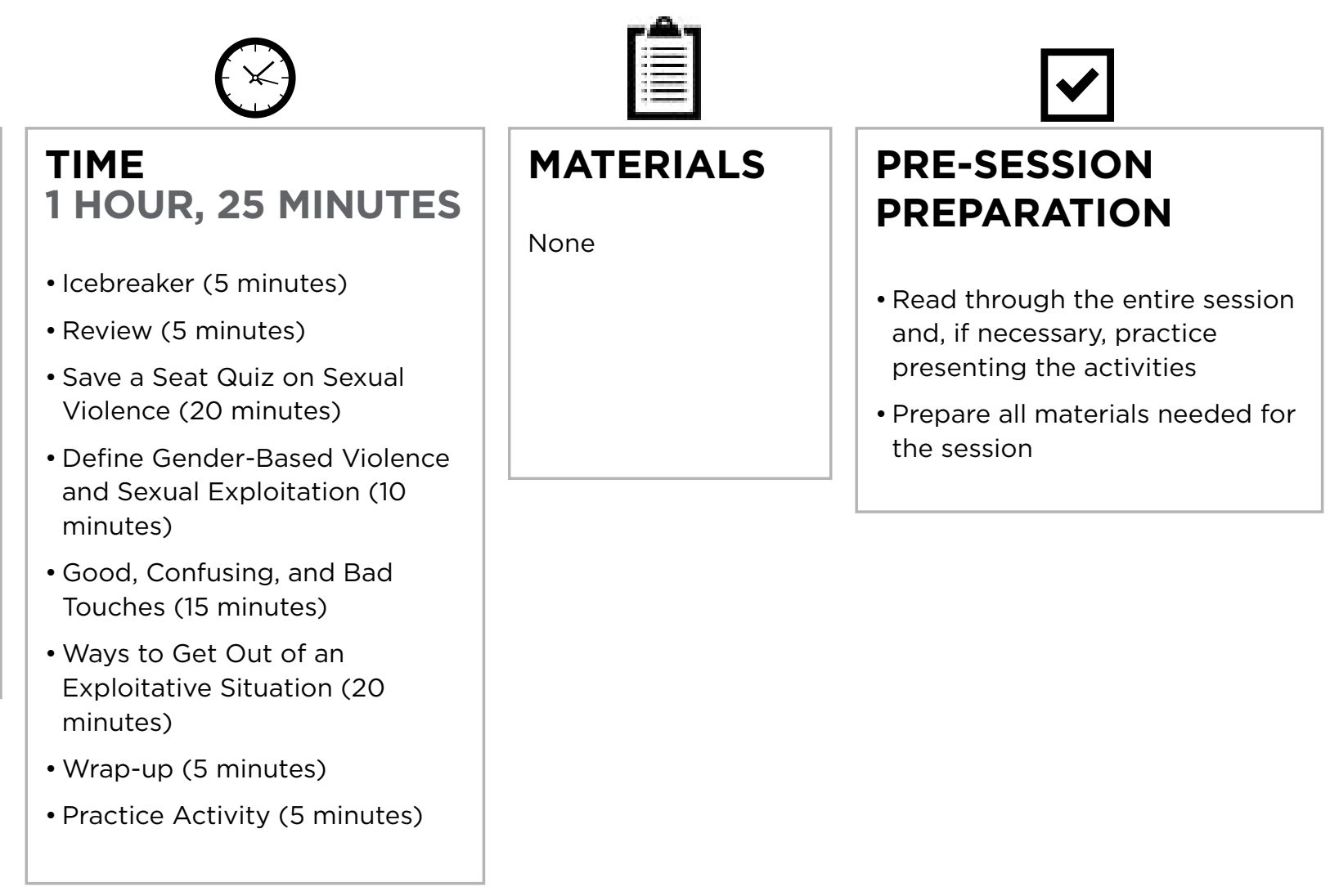




\section{FACILITATOR NOTES}

For many young people, sex is not a choice. Rape happens when a person is forced to have sex without giving permission. Statutory rape happens when sex occurs with a person (who may or may not give permission) that the law defines as too young to legally consent (girls and boys below 16). Date (or acquaintance) rape refers to rape that occurs between individuals who are dating or who know each other. Some adolescents are forced to have sexual relations; feel pressured to have sex in exchange for good grades or pocket money; are assaulted if they refuse to have sex; or sell sex in order to survive.

Every adolescent should know that his or her sexual organs are private and personal property. Nobody should touch them without permission. Some victims of sexual abuse are assaulted by family members or acquaintances. Often young children are the victims of incest (a young person may be forced to touch, kiss, or feel the sex organs, or have actual sexual intercourse with a relative). Because of the older person's position in the family, he or she may be able to pressure the child into doing sexual things without actually having to use force. These crimes, including rape, are the fault of the perpetrator or older person and not the fault of the victim or child.

For girls and women, the short-and long-term consequences of sexual violence can be physically and emotionally damaging. Because of the sexual nature of rape crimes, victims often suffer from serious mental issues. This is especially true in societies with strong sexual customs and taboos. If someone is raped and reports it to you encourage them to go to a hospital or health center. At the hospital they will have a medical evaluation and attention to any injuries, counseling support for the survivor and her family, treatment to prevent infection with HIV, pregnancy, and other sexually transmitted infections. Referrals to other services may be required.

(NOTE TO FACILITATOR: Be aware that one or more of your participants may have been raped or molested. If a participant becomes upset during this discussion, you may want to speak quietly to that person and make plans to talk privately at a later time. You may want to find local resources (police, spiritual leaders etc.) for rape victims (address and phone numbers) prior to presenting this topic. If a girl has been recently raped they can use emergency contraceptives to prevent pregnancy within 120 hours (5 days). See Appendix A: Additional Topical Information - Emergency Contraception for more information.

\section{TERMS}

\section{Date Rape}

Rape between individuals who are dating or know each other; also called acquaintance rape

\section{Consent}

Give permission or agreement for something to happen

\section{Gender}

What a society or culture expects from you based on whether you are male or female (roles, behaviors, etc.)

\section{Gender-based violence (GBV)}

Any act that results in, or is likely to result in, physical, sexual or psychological harm or suffering to someone (boy or girl) based on gender-role expectations and assumptions

\section{Exploitation}

Using a situation to your own advantage without concern about how the other person feels; sometimes achieved by using force, pressure or tricks

\section{Incest}

An act of two members of the same family having sexual intercourse, for example a father and daughter, or a brother and sister

\section{Rape}

A type of sexual assault usually involving sexual intercourse, which is initiated by one or more people without the other person's consent

\section{Sexual Exploitation}

When someone uses another person of the opposite sex to make him/herself feel good or to get something from the other person without concern about how that person feels

\section{Statutory Rape}

Sex with a person who the law defines as too young to legally consent, regardless of whether or not they consented (girls below 16 and boys below 14)

\section{ICEBREAKER}

Open the session with an icebreaker of your choice, or allow participants to suggest one. See Appendix B: Participatory Facilitation Resources - Icebreaker Activities for ideas.

\section{REVIEW}

O

Ask participants what key points were covered in the last session (optional: throw a ball of paper around to encourage participation). Fill in any key points that are missed.

Go over any practice activities that were given, and ask if there are any questions.

(NOTE TO FACILITATOR: Before beginning this session, brief participants on the sensitive nature of the issues discussed in this section. Remind them that you are available to discuss any questions, comments, or issues that may arise in private if they prefer. Also remind them of the local contacts you collected relevant to gender-based violence in $A c$ tivity 2: Brainstorming Community Resources and Contacts in the "Introductory Sessions, Session 2: What to Expect - Part 2".) 


\section{SAVE A SEAT QUIZ ON SEXUAL VIOLENCE}

\section{(2O MINUTES)}

Prepare by putting chairs in a circle. Make sure the amount of seats is equal to the number of participants (i.e., if there are 10 participants, there should be 10 seats). Instruct the participants to each sit in a chair. Then call out something that is common among participants and ask them to find a new seat (e.g., everyone wearing black shoes exchange seats now!).

After the participants get the hang of the activity, take a seat for yourself when the participants are exchanging seats. Now each time the participants try to find a new seat, one participant will not find a seat.

\section{Explain:}

$\int$ The person without a seat must now answer one true or false question about sexual and gender-based violence.

Choose a true or false question (see questions in Box 13: Questions \& Answers-Sexual and GenderBased Violence) after the 'seat-less' participant answers the question discuss the answer (see answers below). Then, the 'seat-less' participant should call out something common amongst the participants and continue the game.

\section{BOX 13: QUESTIONS \& ANSWERS - SEXUAL AND GENDER-BASED VIOLENCE}

1. If a victim of rape gives in and allows sexual intercourse out of fear, this is considered "consent."

False- Consent is based on choice, when two people have equal power. If a powerless person gives in out of fear, that is not consent.

\section{Being drunk and "out of control" is not an} excuse for rape.

True- Being drunk and "out of control" makes it harder for people to communicate effectively. However, it is not an excuse to force a person to into sexual intercourse.

\section{Men are not ever really raped.}

False- Some rapes are committed against boys and men but few ever acknowledge it.

4. Physical force is used in most rapes. True- There is often some form of physical force. Also, however, a victim often endures non-physical force, for example when they are pressured in to the sexual act through verbal force and psychological abuse.
5. Most victims of rape are teenagers and young adult women.

True- Young women between the ages of 16 and 24 are three times as likely to be raped as other women. However, children as young as a few months or adults as old as 98 years have been raped.

6. Women are most likely to be raped when they are out alone in a dangerous place, especially at night.

False- Rape can occur anywhere. Over half of all rapes occur inside a residence, most often the victim's home or compound.

7. Having sexual intercourse with a girl/woman after pressuring her to get high or drunk is not rape.

False- As long as a woman has not given consent, it is rape. 


\section{activity 2}

\section{DEFINE GENDER-BASED VIOLENCE AND SEXUAL EXPLOITATION}

(10 MINUTES)

\section{Ask:}

$\Omega$ What is meant by the term "gender-based violence" (GBV)?

[Any act that results in, or is likely to result in, physical, sexual or psychological harm or suffering to someone (boy or girl) based on gender-role expectations and assumptions.

What are some examples of gender-based violence (GBV)?

[examples include: female genital cutting, battering, intimidation at the workplace, deprivation of food or water, deprivation of education, trafficking of women, sexual assault, rape, etc.]

Brief participants on the official definition of gender-based violence using the information provided in Box 14: UN Declaration on the Elimination of Violence Against Women.
Ask:

5 What is "sexual exploitation"?

[when someone uses another person of the opposite sex to make him/herself feel good or to get something from the other person with-

out concern about how that person feels]

Explain:

Sometimes, people trick or pressure others into "bad touches," which we will discuss more in a moment. This is another type of sexual exploitation. People also force others into sex, which they did not want to be engaged in. That is called "sexual abuse" or "rape." Sexual exploitation is a form of gender-based violence.

\section{BOX 14: UN DECLARATION ON THE ELIMINATION OF VIOLENCE AGAINST WOMEN}

In 1993, the UN Declaration on the Elimination of Violence against Women offered the first official definition of gender-based violence. It defines gender-based violence as any physical, sexual or psychological harm or suffering to women, including threats of such acts, coercion or arbitrary deprivations of liberty, whether occurring in public or in private life.

According to the declaration, these acts include:

- spousal battery

- sexual abuse

- dowry-related violence

- rape

- female genital mutilation/cutting

- non-spousal violence

- sexual violence related to exploitation

- sexual harassment and intimidation at work, in

school and elsewhere

- trafficking in women

- forced prostitution

- systematic rape

- sexual slavery and forced pregnancy

- forced sterilization

- forced abortion

- coerced or forced use of contraceptives

- prenatal sex selection

*UNFPA. 2005. State of World Population. 


\title{
activity 3
}

\section{GOOD, CONFUSING, AND BAD TOUCHES}

\author{
(15 MINUTES)
}

\section{Ask:}

5 What different kinds of touches are there? [answers should fall into the categories of good touches, confusing touches, and bad touches as in Table 5: Kinds of Touches]

Draw three columns on a chalkboard or flipchart.

\section{Ask:}

5 What are some examples of good touches, confusing touches, and bad touches?

Write the participants' examples of the kinds of touches into their corresponding category on the table as illustrated in Table 5: Kinds of Touches.
Explain:

5 Some of these touches could be good touches or bad touches depending on the intent of the touch. If an older man starts a kiss with a child, it could be a bad touch, but if a mother kisses her child, it is a good touch. If a back rub is

intended to lead to sexual activities it could be a bad touch, but if a sister pats the back of a baby, it is a good touch

Sexual exploitation usually happens gradually. It starts with a good touch, goes to a confusing touch and into a bad touch. It also usually involves tricks, threats, or treats. Most often, involves a person known to the exploited, even though it also happens with strangers. Many times it can involve a pact of secrecy and it can affect both boys and girls.

\section{TABLE 5: KINDS OF TOUCHES}

\begin{tabular}{|l|l|l|}
\hline Good touches & Confusing touches & Bad touches \\
\hline Hugging & Kissing & Kicking \\
Holding hands & Tickling & Biting \\
Hair brushing & Touching private parts & Punching \\
A pat of the back & Handshake with a pinch & Slapping \\
A doctor's examination & Back rubs & Pinching \\
& & Forced sex \\
\hline
\end{tabular}




\section{activity 4}

\section{WAYS TO GET OUT OF AN EXPLOITATIVE SITUATION}

(2O MINUTES)

Read the following scenario (part 1) on prevention and reporting sexual exploitation.

\section{Sexual Exploitation Scenario Part 1}

Jomo and Emily were sent by their mother to get a packet of sugar from their neighbor. They have been sent there many times before. Upon arrival, the neighbor (an elderly man) invites them for some fruit in the house. While they are eating the fruit, he starts rubbing Emily's leg.

\section{Ask:}

How do you think Emily and Jomo felt?

Continue reading the scenario (part 2):

\section{Sexual Exploitation Scenario Part 2}

Just before Emily and Jomo left, the neighbor offered to give them some money if Emily would remove her clothes.

\section{Ask:}

What would you have done if you were Emily? If you were Jomo?

[discuss the following options:

- it may be sufficient to say no,

- leave, or

- be rude - after all the neighbor was being rude and therefore no need to consider his feelings, even though he is older.]
Continue reading the scenario (part 3):

\section{Sexual Exploitation Scenario Part 3}

After Emily refused, the neighbor left them alone but then gave them the money he had offered so that they would not tell anyone about the incident.

\section{Ask:}

5 What would you do now if you were Emily and Jomo?

[make sure the group decides the incident should be reported, for two reasons:

1) to protect themselves from a repeat incident with the neighbor, and

2) to protect other children from the neighbor]

Facilitate a discussion with the following questions:

-Who does one report to?

[community members (especially community leaders), teachers, parents, healthcare providers, friends, older siblings, etc.]

-Where do they report?

[refer to the list of local contacts you collected relevant to gender-based violence for this session in Activity 2: Brainstorming Community Resources and Contacts in the Introductory Sessions, Session 2: What to Expect - Part 2]
- What difficulties might an adolescent experience in deciding who to report to?

[fear of punishment, fear that they will not be believed, fear of stigma and discrimination, fear of attitude of those reporting to, feelings of shame, blame, or powerlessness, lack of support, fear of revenge, unreliability of public services to respond to the reporting]

\section{- How can the difficulties be resolved?}

[e.g., making safe and accessible spaces for reporting, improving policing of perpetrator support groups for other victims, etc.] 


\section{Wrap-epp}

Ask participants to summarize what they have learned. Fill in any key points they miss.

$\sum_{\text {In }}^{3}$ Key Message: Not all touches are good - if you experience a bad touch, tell someone about it and address the problem before it develops into something more serious.

\section{Explain}

$\bigcirc$ It is important to report the bad touches to a parent, guardian, teacher, or trusted relative as soon as possible because these touches do not normally end there - they can develop into actions such as forced sex. Reporting helps to protect yourselves and others.

Ask for any final questions or comments. Remind participants where and when the next meeting will take place, and what topics will be discussed.

Thank them for their participation.

\section{PRACTICE ACTIVITY}

Participants should write a short journal entry on (or spend 10 minutes thinking about) how gender-based violence affects their lives and communities. 
2)

SESSION
DESCRIPTION:
(GENDER AND
GENDER-BASED
VIOLENCE)
Participants will identify
trusted adults with
whom they can easily
open up and share
problems and learn
about avoiding and
reporting cases of
sexual violence or abuse.

\section{OBJECTIVES}

By the end of this session, participants will be able to:

- Identify trusted adults with whom they can easily open up and share problems

- Identify resources in their school and community that help young people who face sexual violence and where they can report cases of sexual violence

- Understand the roles that the different resources identified in their school and community can play to ensure access to justice for young people who face sexual violence

- Have confidence to open up and report cases of sexual violence (by practicing how to report incidences of sexual violence and sexual abuse)

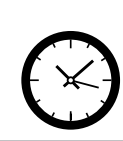

\section{TIME}

1 HOUR, 35 MINUTES

- Icebreaker (5 minutes)

- Review (5 minutes)

- What is a Trusted Adult? (20 minutes)

-What Should Ana Do? (25 minutes)

- Practice Reporting Violence (25 minutes)

-Wrap-up (10 minutes)

- Practice Activity (5 minutes)

\begin{tabular}{|l|}
\hline MATERIALS \\
- Chalkboard and \\
chalk OR flipchart \\
and markers \\
- List of organization \\
contacts \\
- Papers and \\
pencils (for each \\
participant) \\
- A list of sexual \\
violence or \\
abuse focused \\
organizations in the \\
community
\end{tabular}

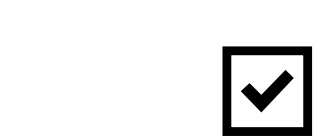

PRE-SESSION PREPARATION

- Read through the entire session and, if necessary, practice presenting the activities

- Prepare all materials needed for the session

- Prepare a list of telephone numbers and organizations for participants to use if they experience sexual violence or abuse - the list should include teachers, social workers at nearby schools, police, clinics, churches, and/ or community elders

- If possible, ask someone from the victim support unit (VSU) to visit to speak about gender-based violence, particularly Activities 2 and 3 


\section{FACILITATOR NOTES}

Be prepared to discuss what a trusted adult is, and how to identify adults to whom participants can go for help. It is important for participants to identify more than one trusted adult, so that in case one is not responsive, they have other options of people they can go to for help. Participants should also identify at least one trusted adult outside of their family or household that they can talk to about any problems at home.

If a guest speaker from VSU is able to attend, ask them to speak in particular about steps to take when reporting sexual violence (to emphasize the importance of not bathing until after a medical examination, not washing the clothes that were involved in the incident, etc.)

Bring along a list of telephone numbers and organizations for participants to use if they experience sexual violence or abuse the list should include teachers, social workers at nearby schools, police, clinics, churches, and/or community elders. Make sure the list is up-to-date!

\section{TERMS}

See Gender and Gender-Based Violence - Session 1: Sexual Exploitation

\section{ICEBREAKER}

Open the session with an icebreaker of your choice, or allow participants to suggest one. See Appendix B: Participatory Facilitation Resources Icebreaker Activities for ideas.

\section{REVIEW}

(7 Ask participants what key points were covered in the last session (optional: throw a ball of paper around to encourage participation). Fill in any key points that are missed.

Go over any practice activities that were given, and ask if there are any questions. 


\section{activity 1}

\section{WHAT IS A TRUSTED ADULT?}

(20 MINUTES)

Read "Molly's Story" (below) out loud or have a few volunteer participants do it as a role-play.

\section{Ask:}

5 Who is the trusted adult was in this story? [the elderly person who was her neighbor and mother's friend]

What makes someone a trusted adult? [possible responses include:

- someone you know who will help them if they need help

- someone you can talk to about anything, especially your problems, or if you are feeling scared, confused or uncomfortable

- someone you feel happy being around

- someone who listens to you and cares about

your problems

- someone who has helped you before, or

- someone who would help you solve a problem, be understanding, get help and work to keep you safe]

What steps did Molly take to get help? [she identified an adult in her community whom she could trust and one who could help her]

How did the elderly person help Molly? [she advised her not to get gifts from strangers and offered her a solution to her problem]

How did Molly feel when the elderly person helped her? [she was glad because the elderly person offered her help and advice.]

\section{Explain}

If anyone approaches you and tries to hurt you, touches you in a way that makes you feel scared, uncomfortable, or confused, or if you feel that you are in danger, you should tell a trusted adult immediately.

\section{Instruct:}

$\bigcirc$ Make a list of possible trusted adults in your notebooks.

Go around the room and ask:

$\int$ Who are some of the trusted adults in your lives? [potential responses include: mother, uncle, police officer, father, neighbor, coach, grandmother big brother/sister, church person, grandfather, principal/headmaster, friend's parent, aunt, teacher]

\section{Molly's Story}

My name is Molly and I am 13 years old. I walk the same way to school every day. It is the only way I can walk to school. The route passes by the bus depot and bar, and each day an older man offering to buy me a drink approaches me. He said he would buy me whatever I wanted and that a schoolgirl needs a special treat from time to time. One day he gave me a pretty perfume bottle, and I took it. Last week, he asked me to go on a walk with him after school. I said no, but he still asked me the same thing, and he got more and more persistent. Sometimes he gets close to me, and it's hard for me to get away from him without stepping into the traffic. Walking to school became a nightmare, because I was also scared of the man who harassed me.

The man continued harassing me until I decided one day that I had to tell someone elderly in my community who I trusted. It was difficult for me to speak to this
What role could these people play if they were faced with a report of sexual abuse or violence? potential responses include: consoling the victim, helping the victim find medical care, ensuring the case is followed up, seeking justice, etc.]

\section{Explain}

5 Remember that not all adults are trustworthy. While there are adults who may try to harm you, there are also many adults who will help you. You should go to someone you feel comfortable and secure around. If anyone does anything to you that is not appropriate, you should go to a trusted adult for help immediately. If the first person you tell does not believe you, you should keep on trying until someone does.

elderly person about my problem although she was my neighbor and my friend's mother, but I told her that a man had approached me while I was walking through the bus depot. I told her I was scared and wanted to avoid the man, but did not know what to do because the man was persistent. She asked me if I had taken any gifts from the man. I admitted that I had. She told me that I should not take gifts from strangers, because sometimes people use gifts to get favors or to trick young girls. She then advised me to walk to and from school in the company of other pupils or teachers and she offered to help me identify pupils or teachers who used the same way I used to school. Although I was scared, I was glad that I had told one of the elders about my problem because she listened to me and offered me help. I feel so relieved now that the situation has been resolved and I can walk to school safely. 


\section{activity 2}

\section{WHAT SHOULD ANA DO?}

\section{(25 MINUTES)}

\section{Explain}

5 You are going to hear a letter from a young girl named Ana and then discuss what she should do.

Read the letter (below)

Distribute a paper and pencil to each participant and instruct them to write (or brainstorm what they would include in) a letter to Ana telling her what she should do.

After participants have had a chance to write (or brainstorm) their letters, ask for volunteers to share their letters to answer the following question:

\section{A $2 k$ :}

$\int$ What should Ana do?

\section{Ana's Letter}

Dear Friend

My name is Ana and I have a very serious problem. Last week, my teacher asked me to come to his house so he could help me with my schoolwork. When I got to his house, he started touching me. I got a very bad feeling in my stomach, and I knew it was wrong. He then pulled me in his bedroom and forced me to have sex with him. I cried and screamed, but he did not stop. He told me that if I told anyone he would hurt me and fail me in school. I ran all the way home and felt sick. I am afraid to tell anyone because they will say it is my fault. I do not feel like eating or sleeping. I do not want to go to school and see that teacher. Please help me. What should I do? Sincerely, [make sure the following points are mentioned: - Ana should not be afraid to tell a trusted adult. It was not her fault. No matter what, no one should blame Ana. If the trusted adult is someone other than Ana's parents, someone should contact her parents.

- The trusted adult will help her by going to the police. Her teacher raped Ana. Rape is a crime. The trusted adult should look for someone in the police unit (Victim Support Unit-VSU) who has been trained to deal with sexual violence and abuse. The police will file a report against the teacher and offer a medical report, which enable medical examinations at the clinic or hospital to be conducted.

- The trusted adult should also take Ana to a hospital or clinic for medical treatment and to collect any evidence needed by the police. At the clinic/hospital medical personnel will check for pregnancy and offer emergency contraceptives and tablets are given to help reduce the risk of HIV infection. (For more information, see Appendix A: Additional Topical Information - Emergency Contraception)

- Advise Ana that the best thing to do is not to take a bath until she has been examined by a medical person to avoid washing away the evidence. This is why Ana should tell a trusted person as soon as she is defiled/raped. The trusted person will escort her to the police station and later go to the medical center to be examined. - The trusted adult should also tell the head teacher. The teacher should not be able to teach in the school anymore. Teachers are in school to help young people, not to hurt them
- If possible, Ana should also go to see a counselor. The counselor can help her process her feelings and understand it was not her fault. Talking to a counselor will also increase her courage and help her be more resilient.]

\section{Explain:}

It is very important to report cases of sexual abuse within 72 hours of the incident. Tablets to prevent pregnancy if rape took place during the abuse work more effectively within 72 hours. Also a delay in reporting may result in loss of some evidence.

\section{Ask:}

How can children and adolescents avoid being sexually abused?

[avoid moving or playing outside the house at night, avoid using lonely roads when you are not accompanied, ask a friend to accompany you when visiting male relatives in homes where there are no female adults, be assertive in telling boys and men that you do not want to have sex with them, etc.]

\section{Conclude by explaining:}

$\bigcirc$ Teachers and adults should always protect young people. If adults ever ask a girl to do anything that makes her uncomfortable, she has the right to refuse. She should not be in isolated places at school or walking to and from school. She should always walk with a group or another student. If a teacher or anyone asks to look under her clothes, she should not let that person do it. If someone touches her or gets too close, she must tell a trusted adult immediately. Adults need to ensure children's safety. It is not the student's entire responsibility. 


\section{activity 3}

\section{PRACTICE REPORTING VIOLENCE}

(25 MINUTES)

\section{Explain}

5 It is not always easy to speak up and report violence. In this activity you are going to practice telling someone you have experienced violence.

Divide participants into five groups (see Appendix B: Participatory Facilitation Resources - Group Formation Activities for ideas).

\section{Instruct:}

5 Now your group will create a role-play in which a young person experiences violence or abuse and reports it. Be sure to identify a trusted adult to whom the character in the role-play reports the incident.

After participants have had a chance to prepare the role-play, let each group present their role-play.
After each group has presented their role-play, review the following discussion questions:

-What happened to the girl in the role-play?

- What action did the girl take after the incidence?

- How did the steps taken by the girl help her?

-What were some of the things the girl used as evidence to report the incidence?

-Who was the trusted adult in the role-play?

- What did the adult do?

- Do you have any suggestions for the girl? For example, was there anyone else she could have told?

\section{Wrap-up}

Distribute the list of telephone numbers and organizations for participants to use if they experience sexual violence or abuse. The list should include teachers, social workers at nearby schools, police, clinics, churches, and/or community elders.

\section{Instruct:}

5 Choose three people who you consider to be trusted adults and write their names in your notebooks. For example: My three trusted adults are:

and (Demonstrate on a chalkboard or flipchart paper.)

\section{Explain:}

$\int$ No matter what happens, violence and abuse is not your fault. You should never feel ashamed or guilty. If someone tells you not to tell or threatens you or anyone you know, you should tell a trusted adult immediately.

Ask participants to summarize what they have learned. Fill in any key points they miss.

Key Message: If anyone ever asks you to do anything or does anything to you that makes you feel uncomfortable, you have the right to refuse and should report them.

Ask for any final questions or comments. Remind participants where and when the next meeting will take place, and what topics will be discussed.

Thank them for their participation.

\section{PRACTICE ACTIVITY}

Instruct participants to brainstorm where they would go and who they would talk to for support in situations where they were affected by gender-based violence. 
3)

Rape and Gender Violence*

\begin{tabular}{|l|}
\hline SESSION \\
DESCRIPTION: \\
(GENDER AND \\
GENDER-BASED \\
VIOLENCE) \\
Participants learn the \\
meaning of rape and \\
gender-based violence, \\
and what to do when \\
confronted with them. \\
\hline
\end{tabular}

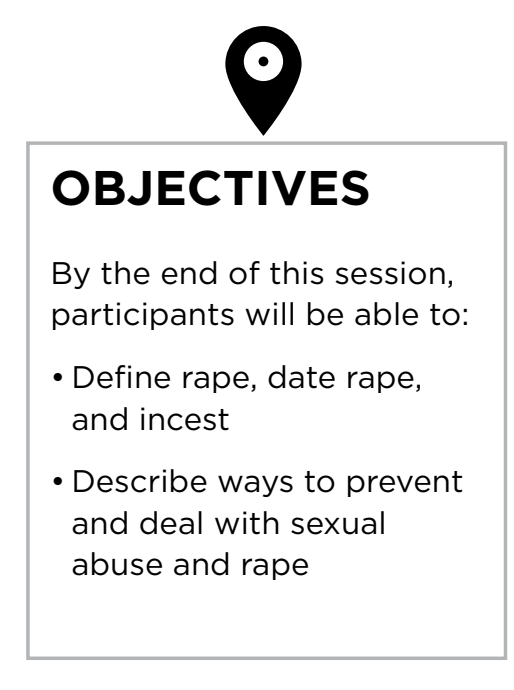

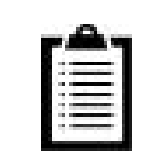

\section{TIME}

1 HOUR, 20 MINUTES

- Icebreaker (5 minutes)

- Review (5 minutes)

- Rape and Gender Violence (30 minutes)

-Ways to Prevent and Deal with Sexual Abuse (30 minutes)

-Wrap-up (5 minutes)

- Practice Activity (5 minutes)

\section{MATERIALS}

- Copies (for each

participant) of Activity

Sheet 6: Preventing

Acquaintance/Date

Rape provided at the

end of this session - or

write content on the

chalkboard or flipchart

ahead of time if copies

are not available

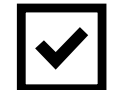

PRE-SESSION PREPARATION

- Read through the entire session and, if necessary, practice presenting the activities

- Prepare all materials needed for the session 


\section{FACILITATOR NOTES}

See Gender and Gender-Based Violence - Session 1: Sexual Exploitation

\section{TERMS}

See Gender and Gender-Based Violence - Session 1: Sexual Exploitation

\section{ICEBREAKER}

Open the session with an icebreaker of your choice, or allow participants

to suggest one. See Appendix B:

Participatory Facilitation Resources Icebreaker Activities for ideas.

\section{REVIEW}

A Ask participants what key points were covered in the last session (optional: throw a ball of paper around to encourage participation). Fill in any key points that are missed.

Go over any practice activities that were given, and ask if there are any questions. 


\section{activity 1}

\section{RAPE AND GENDER VIOLENCE}

(30 MINUTES)

\section{Explain}

5 Rape is sexual intercourse on an unwilling male or female by the use of force, coercion, intimidation, or any kind of threat. Rape happens to a person when they do not give consent to have sex.

Ask:

Can men or boys be raped?

[Yes, but few ever acknowledge it]

Can a husband rape his wife?

[Yes, if she does not give consent]

\section{Explain}

$\int$ Rape can be a form of gender-based violence Gender-based violence is any act done on a woman with the aim of hurting her because she is a woman. This may be physical, or psychological harm including threats and intimidation in public or private.

In Zambia sexual intercourse with boys or girls below 16 years are criminal offences, whether there was force used or not.

As long as one person is unwilling to have sexual intercourse, it is rape regardless if it is a husband, boy, girl, wife, acquaintance, relative, neighbor, or stranger committing the act.

\section{Ask:}

5 What is the name of the crime that occurs when a romantic partner forces another to have sex?

[date rape, or acquaintance rape]

\section{Explain}

$\bigcirc$ Acquaintance rape, also known as date rape, is forced oral, anal or vaginal sexual intercourse by someone the person knows and may even have a romantic relationship with.

Further explain rape by emphasizing the following points:

- Rape is an act of aggression that uses sex to show the victim that the rapist has power.

- Rape is a crime punishable by law.

- Many girls in Zambia are forced or tricked into their first sexual experience.

- Books and movies often suggest that women are turned on by the power and force of rape and may even fall in love with the rapist, but a victim of rape never experiences the act in a positive way, even in a date situation in which the beginning of the sexual encounter was pleasant.

- Alcohol and drugs are often involved when date rape occurs. Being drunk or high makes women less able to set clear boundaries and men less inclined to listen to those boundaries.
Divide participants into groups of four (see Appendix B: Participatory Facilitation Resources - Group Formation Activities for ideas)

\section{Instruct:}

5 In your group, plan and act out a two-minute role-play showing how alcohol and drugs can make a girl or woman more vulnerable to rape. Some participants should play the role of females and others will have to play the role of males.

When participants have finished planning and practicing their role-plays, invite a few groups to present to the larger group. Wrap-up the activity by explaining:

Nothing a woman does, including using drugs or alcohol, going to "risky" places, wearing certain clothes, kissing and sexually touching or even having previously had sex with a man, gives a man the right to force her to have intercourse against her will. 


\section{activity 2}

\section{WAYS TO PREVENT AND DEAL WITH SEXUAL ABUSE}

\section{(30 MINUTES)}

Distribute and go over the Activity Sheet 6: Preventing Acquaintance/Date Rape provided at the end of this session (or write the content on the chalkboard or flipchart if copies are not available). Inform participants that they should take it home to read if copies are available. If no copies are available, read over the fact sheet with the participants.

\section{Ask:}

5 Why do you think most rape cases are not reported?

[possible responses include: fear of being blamed, fear of consequence, a false sense of obligation to protect a relative or acquaintance, fear that no one will believe them, fear that everyone will know about it, fear that no one will care or listen]

Divide the participants into four small groups (see Appendix B: Participatory Facilitation Resources Group Formation Activities for ideas), and assign one scenario to each group from Activity Sheet 7: Sexual Abuse and Family Violence Scenarios (provided at the end of this session). If the group has low/no literacy, read the assigned scenario to each group of participants.

\section{Instruct}

5 After familiarizing yourselves with each scenario, with your group, discuss the options for the character in the scenario and decide what you would do, considering the positive and negative consequences. Then you will present your scenario and your decision to the larger group.

Suggestions for responses to each scenario are in Activity Sheet 7: Sexual Abuse and Family Violence Scenarios on the page following the scenarios themselves. While they are presenting, if necessary, help participants consider of different responses to each scenario by referring to these suggestions.

Facilitate a discussion with the following questions:

-What if you do all the right things and are unable to stop your date from raping or assaulting you? Does that mean you did not try hard enough? What should you do?

[Whenever rape occurs, regardless of what was or was not said or done to prevent it, it is never the victim's fault. If you are raped, get help immediately and do not feel guilty.]

-What are some of the things that we have discussed that have changed the way you think about rapists? How has your opinion of rape victims changed?

- What are some of the things you have heard people say about girls or women who have been raped and how do you feel about the things these people say?
-What precautions can girls and women take against stranger rape?

[be alert to the surroundings, avoid dark, lonely places at night, keep doors and windows locked, keep a loud whistle on a key ring, learn to defend yourself, walk in groups, or scream for help if cornered]

-What are some things that girls and women can do to help prevent date rape?

[communicate with your date, state expectations clearly, listen carefully, ask questions if things get confusing, avoid using alcohol and other drugs that cloud your judgment, and let the man know your intentions - "I like dancing with you, but I don't want to have sex with you"]

\section{Remind participants that:}

5 No matter what the circumstances, you have the right to choose when, with whom, and how you want to be sexual.

When first getting to know someone, go out with other people or groups rather than alone.

Trust your feelings - if you begin to feel nervous or uncomfortable about the way things are going, do something about it right away. Let your date know how you feel and get away from the situation to a place where you feel more comfortable.

(activity 2 continued on next page) 


\section{activity 2 (continued)}

\section{WAYS TO PREVENT AND DEAL WITH SEXUAL ABUSE}

Ask:

$\int$ What do you think someone should do if he or she is assaulted or harmed?

[responses should include:

- talk to a parent or trusted adult,

- report the incident to the nearest police station

and obtain a police report,

- go to the nearest hospital for treatment,

- get the medical report from the doctor and

take it to the police station where the case was

reported,

- identify the accused for arrest, and

- attend court when the accused is charged.]

What do you think someone should do if he or she has been raped?

[responses should include:

- talk to a parent or trusted adult,

- do not shower,

- do not wash any clothes, including underwear,

- go to the nearest police station and report the incident,

- go to the nearest hospital for a medical check-

up and a medical report,

- identify the accused for arrest, and

- attend court when the accused is charged.]

\section{Wrap-up}

Ask participants to summarize what they have learned. Fill in any key points they miss.

Key Message: Report anyone who makes advances that may be suspicious or who touches parts of the body in inappropriate ways. Rape can even occur in marriages or by close relatives.

Ask for any final questions or comments. Remind participants where and when the next meeting will take place, and what topics will be discussed.

Thank them for their participation.

\section{PRACTICE ACTIVITY}

Talk to a friend about steps to take to minimize the likelihood of rape, and what one should do in the case of rape. 


\section{ACTIVITY SHEET 6}

\section{PREVENTING ACQUAINTANCE/DATE RAPE}

Date rape is one of the most common types of sexual assault. It occurs when someone you know forces you into unwanted sexual activity of any kind. This includes unwanted sexual touch or oral, vaginal, or anal penetration, or forcing you to touch him/her in a sexual way. The rapist could be a teacher, a friend, boyfriend or girlfriend, a neighbor, a spouse, a co-worker, or a relative. Rape happens because of a need for power and control over someone else. It is never the fault of the victim.

\section{How Can I Protect Myself?}

5 The best thing you can do to protect yourself is trust your instincts. If you feel uncomfortable with a situation or threatened by someone, get to a safe place as soon as possible. Some other things you can do are:

1. Avoid being alone with a new boyfriend or girlfriend before you are ready. It is a good idea to go out in groups with friends, especially when dating someone new. Avoid secluded places including someone's home when parents or adults are not at home, your friend's home, empty buildings, etc.

2. Always make sure that someone (parents, siblings, friends, guardian) knows where you are going, who you will be with, and when you expect to be back. Carry a friend's phone number with you to call if you need help.

3. Think about your sexual limits. Before going out on a date, think about what you want to do and do not want to do. A decision to be sexual in any way should be made together and never forced.

4. Be clear with your date about your sexual limits. Give the message that "no" means "no," not try harder for a yes.

5. Trust your instincts. If you feel pressured or threatened in any way, do not hesitate to say what you feel or to leave if necessary.
6. Do not worry about being polite. Use strong nonverbal techniques to reinforce what you are saying such as pushing away, not smiling, using a firm voice, and so on.

\section{Danger Signs}

$\int$ The following are some actions and attitudes to watch out for. If your partner or acquaintance engages in any of these behaviors, it may be a warning sign that the partner is potentially abusive.

1. Threats. Verbal or physical threats to force you into sexual activity you do not want. Threats such as "If you don't have sex with me l'll break up with you."

2. Jealousy. Constant demands to know where you are and who you will be with. Watch out for someone who gets very jealous easily.

3. Criticism. Disapproval about your actions, your clothing, your friends, and so on.

4. Controlling. Failure to acknowledge your needs and wants, and/or not letting go when you try to pull away.

5. Anger or violence. Frequent and noticeable anger or violent acts, including small disagreements possibly with threats to hurt you or people you know. She or he may later apologize for the behavior, but that does not change the fact of the abuse.

6. Verbal abuse. Jokes about your physical appearance or your gender or constant criticism.

7. Manipulation. There are many ways in which people can be manipulative in an abusive way. For example, she or he could intentionally try to upset you by flirting with other people. 


\section{ACTIVITY SHEET 7}

\section{SEXUAL ABUSE AND FAMILY VIOLENCE SCENARIOS}

1. All night Nekesa had been listening to her stepfather yelling and slapping her younger brother, Andahi. He picks on Andahi all the time, but this is different, she thought. She noticed last weekend that Andahi had several bruises on his face and she wondered what happened, but her mother said "nothing" when she asked. Tonight there has been so much yelling, and poor Andahi was screaming and crying. Nekesa was scared because she didn't want Andahi hurt. She didn't know what to do. She decided to get help.

2. Ayesha started crying softly after her father left her room. She felt like she always did when he came into her room and touched her; she wanted to die. He would always do the same things that he had been doing since she was nine. She hated it and always felt so dirty and disgusted with herself when he left. He told her that it was her fault and that she made him do these things. He also told her that if she told anyone, she would be made to leave the family. Ayesha had thought about telling her mother, running away, or killing herself. But she was always too scared to do anything but lie in her bed and pretend she was asleep. She was so miserable. She wanted help. What should she do?

3. Charity wondered all the way home what she should do. Boniface had forced her to have oral sex with him and she had told him over and over again that she didn't want to. He said it was her fault for kissing and touching and letting him get so turned on. He said she wanted it, too, and besides, it was her place to please him. Afterward, she had felt numb and only stopped crying when he finally told her he loved her, but she felt no love, not anymore. She felt hurt, used, and betrayed. Would anyone care that he had made her do this? Would anyone believe she had told him no? He said it was her fault. Was it? She wanted to talk to someone so badly, but she couldn't bear to tell any of her friends. What would they think of her? What should she do?
4. Mulamba heard the sounds again. He knew what was going on. His mother's friend, Bwire, had come in around 9:00 and he had already been drinking. Mulamba's mother had given Bwire food and another beer. Mulamba always got angry when he watched his mother try to please this crazy man. Now it was almost midnight and he knew what was happening. He knew where his mother's last split lip and swollen eye came from. But he didn't know what made the most sense, whether to go in there and break it up, or to plead with his mother in the morning to leave this guy. Only tonight, things sounded worse than usual. Mulamba was really worried about his mother. He thought about talking to his aunt and uncle to see if they have any ideas.

\section{Suggested actions and responses for each Sexual} Abuse and Family Violence Scenario:

1. Nekesa and her stepfather- Nekesa needs to get help immediately. She should go to a neighbor's house. Her stepfather will be angry, but someone might be able to help her brother. Once the immediate danger is past, the family may need counseling and Nekesa's mother may have to separate from the stepfather to keep her children safe. Intervening in an abusive situation like this is always difficult. However, many children are in danger of abusive parents and other adults. Get help immediately. Calling a neighbor or the police to stop a parent from abusing a child may save a life.

2. Ayesha and her father- Ayesha is in a very difficult family situation. Since her father has been abusing her for so long, Ayesha may feel like she has given permission for the sexual contact, and she may be too embarrassed to tell anyone. Her father may even argue that Ayesha likes what he does to her. As her father, it is illegal for him to have sexual contact of any kind with her. He has been forcing her to have sex against her will, even though he hasn't used a weapon or physical force. Giving in to unwanted sex out of fear is not giving consent. Ayesha should talk to a trusted relative, counselor or teacher who can suggest a safe place for her to go to report the abuse. Several things may happen: Ayesha's father might stop the abuse as soon as it is reported and he is confronted with his abnormal sexual behavior; he might go to jail; or Ayesha might have to go live with a relative for a while. She may receive counseling to help her deal with some of the anger, shame, and sadness she feels; she will eventually recover and feel much better about herself.

3. Charity and Boniface- She may not think so, but Charity has just been raped and she can do something about it. Forced sex of any kind is called rape. Even though Boniface was Charity's boyfriend, he had no right to force her into any kind of sexual act and she can have him arrested. It is up to her to decide whether she wants to prosecute Boniface. Only about one in 100 rapes is reported - but it is an option. Not reporting rape or sexual assault may encourage the perpetrator to do it again. Women always have the right to refuse any kind of sexual contact, regardless of the nature of the relationship or the situation they are in.

4. Mulamba and his mother- Like Mulamba, some children witness family violence. According to research, these children often grow up with deep psychological scars, even when they have not been abused themselves. Mulamba should take immediate action by getting help for his mother, who is in danger from her boyfriend and appears to be powerless to stop the battering. If Mulamba fears that his mother's life is at risk at this moment, he should get out of the house and ask relatives or neighbors to go back to his house with him, even if it may be embarrassing to have the neighbors or relatives see what is happening. Mulamba should not try to interrupt the fight himself. He might get hurt or hurt Bwire more than he wants to. 


\section{4) Preventing Unwanted Advances*}

SESSION
DESCRIPTION:
(GENDER AND
GENDER-BASED
VIOLENCE)
Participants will discuss
unwanted advances and
what they can do to
protect themselves.

OBJECTIVES
By the end of this session,
participants will be able to:
- Understand that people
can be forced into sex
through both emotional
and physical means
- Identify how to avoid
unsafe places and
situations that might put
one at risk for unwanted
sex
- Identify who to go to for
help

\begin{tabular}{|l|l|}
\hline 1 TIME & \\
\hline \\
- Icebreaker (5 minutes) \\
- Review (5 minutes) \\
- Maiwase's Story (20 minutes) \\
- Lucy's Story (30 minutes) \\
- Getting Help (15 minutes) \\
- Wrap-up (5 minutes) \\
- Practice Activity (5 minutes)
\end{tabular}

\begin{tabular}{|l|}
\hline PRE-SESSION \\
PREPARATION \\
- Read through the entire \\
session and, if necessary, \\
practice presenting the \\
activities \\
- Prepare all materials needed \\
for the session \\
- Identify and list places where \\
girls who are the victims of \\
unwanted or coerced sex may \\
go for help
\end{tabular}




\section{FACILITATOR NOTES}

See Gender and Gender-Based Violence - Session 1: Sexual EXploitation

\section{TERMS}

See Gender and Gender-Based Violence - Session 1: Sexual Exploitation

\section{ICEBREAKER}

Open the session with an icebreake of your choice, or allow participants

to suggest one. See Appendix B:

Participatory Facilitation Resources Icebreaker Activities for ideas.

\section{REVIEW}

Ask participants what key points were covered in the last session (optional: throw a ball of paper around to encourage participation). Fill in any key points that are missed.

Go over any practice activities that were given, and ask if there are any questions. 


\section{activity 1}

\section{MAIWASE'S STORY}

(2O MINUTES)

Read Maiwase's story (below) to the group.

\section{Ask:}

5 What do you think might happen next?

What are some possible endings for Maiwase's story?

What could Maiwase do to improve her situation?

In discussing the answers to the above questions, emphasize the possibility of an ending in which Maiwase is able to escape the threat from Dabwiso.

\section{Maiwase’s Story}

Maiwase is 14 years old. She lives with her parents and her cousin, Dabwiso. Dabwiso often touches her breasts or bottom and laughs. Maiwase is afraid of him, but as he is her cousin she doesn't say anything. One day Maiwase came home from the market and went to the bathroom to wash and change her clothes. Dabwiso came into the house alone and Maiwase heard him coming towards the bathroom. He said, "Is that you Maiwase?" and opened the door.

\section{activity 2}

\section{LUCY'S STORY}

(30 MINUTES)

Read Lucy's story (below) to the group.

\section{Ask:}

5 What could happen to Lucy?

What are some possible endings for Lucy's story?

What could Lucy do to improve her situation?

\section{Lucy's Story}

Lucy is 15 and has four younger brothers and sisters. The family is experiencing financial difficulties and Lucy's mother is again pregnant. Lucy helps her mother by walking to the market each day to sell/buy goods. Every day on the way to the market she is approached by the owner of a local bar, who proposes his love for her. He is older and often ill. Her mother and aunt tell her it is an honor to receive the attention of this man and urge her to talk to him. She refuses because he is old and she doesn't like him, but they keep pushing her...
Then, lead a general discussion on the topic, by asking:

What do the stories of Maiwase and Lucy have in common?

[although physical force was not used in Lucy's situation, people were using emotional force to push her in a direction she didn't want to go]

What are other situations or places where girls are in danger of coercive/unwanted sex in our community?

How can girls in our own community avoid these situations or dangerous places? [be alert to the surroundings, avoid dark, lonely places at night, keep doors and windows locked, keep a loud whistle on a key ring, learn to defend yourself, walk in groups, or scream for help if cornered]

What do you think boys, girls, parents, leaders, the police, and the community can do to help stop unwanted sex from happening? [ideas may include: learn to respect others, have stronger law enforcement systems, become educated on the topics of rape and gender-based violence, etc.] 


\section{activity 3}

\section{GETTING HELP}

(15 MINUTES)

\section{Ask:}

5 What are some of the problems that might happen to girls who have unwanted sex?

[answers should include:

- unplanned pregnancy,

- contracting STIS/HIV,

- low self-esteem,

- feeling sad/down/helpless,

- unpleasant sexual experiences, or

- abuse.]

Who could Maiwase or Lucy from the stories go to for help?

[see list of local contacts you collected relevant to gender-based violence in Activity

2: Brainstorming Community Resources and Contacts from Introductory Sessions, Session 2: What to Expect - Part 2 and in Sexual and Gender-based Violence, Session 2: How to Report and Avoid Cases of Sexual Violence]

What can they do if the people they go to for help don't at first believe them or don't take any action?

[If the first person you tell does not believe you, you should keep on trying until someone does.]
Offer resources (from previous sessions) and remind participants to find and identify helping adults in and outside the family who they can talk to.

Read the poem "Stand Tall" (below).

\section{Explain}

$S$ Now we will have volunteers recite the poem and then say what they think the poem means.

After volunteers have recited the poem, remind participants of the assets and strengths they possess which can help protect them and see them through a bad experience.

\section{Stand Tall}

by Eunique Jones

Our self-esteem has been knocked down before But we're survivors and we won't allow it to happen anymore

We've struggled to make it this far And in our struggle sometimes we did fall But in the end we've always stood tall

\section{Wrap-wp}

Ask participants to summarize what they have learned. Fill in any key points they miss.

Key Message: Strategies can be used to prevent unwanted sex. When unwanted sex does occur, know where to go for help.

In addition to being risky, sex between an adult and a child is also against the law in most countries around the world.

Review what girls who have experienced unwanted sex can do to get help. Review the steps to be taken when reporting sexual violence.

Ask for any final questions or comments. Remind participants where and when the next meeting will take place, and what topics will be discussed.

Thank them for their participation.

\section{PRACTICE ACTIVITY}

Instruct participants to describe to an adult the risks young girls face in their community. Then they should ask the adult to help keep them safe. 
芒LEADERSHIP $三$ 
1) Leadership*

SESSION
DESCRIPTION
(LEADERSHIP)
Participants explore the
emotional implications
of leading and blindly
following, think
about what makes an
effective leader, and
consider how to avoid
negative leadership.

OBJECTIVES
By the end of this
session, participants will
be able to:
- Understand the
importance of
leadership
- Identify the qualities
of good and bad
leadership

1 HOUR, 15 MINUTES
- Icebreaker (5 minutes)
- Review (5 minutes)
- Car and Driver (30 minutes)
- Good Leader, Bad Leader (25
minutes)
- Wrap-up (5 minutes)
- Practice Activity (5 minutes)

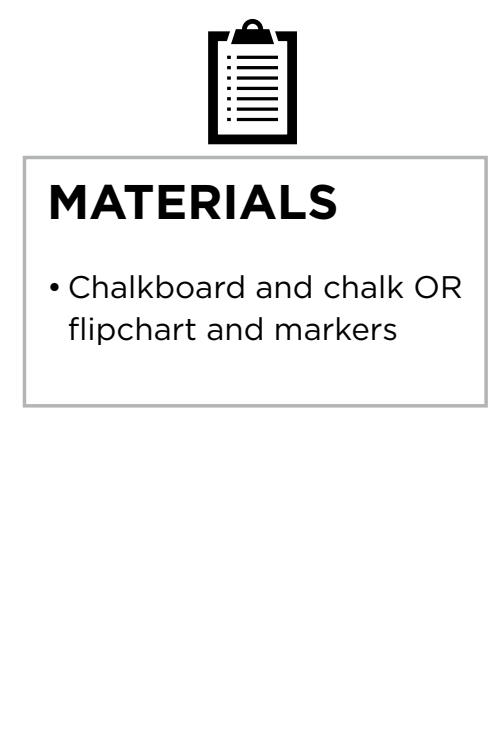

\begin{tabular}{|l|}
\hline PRE-SESSION \\
PREPARATION \\
- Read through the entire \\
session and, if necessary, \\
practice presenting the \\
activities \\
- Prepare all materials needed \\
for the session \\
- For Activity 1: Arrange seats \\
in a circle. To make the \\
exercise more challenging \\
you can scatter obstacles \\
like chairs and tables \\
throughout the space \\
\hline
\end{tabular}




\section{FACILITATOR NOTES}

Young women are change agents and their leadership can bring vitality, creativity and courage for social change. Young women have the power to inspire and mobilize others for positive action. They can encourage the questioning of systems and beliefs that limit lives and choices. With courage they can confront even the injustices that have been in place long before our lives began. With their leadership young women ensure that social change will not stop when the generation before us is no more, but only when peace, justice, health, human dignity and care for the environment has been achieved everywhere, and for everyone. By supporting one another, young women ensure that their leadership remains strong in the face of unfair gender and age biases, and maximize our power to change.

As they continue to develop and define leadership, the advice and example of older, more experienced women are invaluable. By working together, women of all ages can help each other grow, maximize their strengths and fulfill our potential as change makers.

\section{TERMS}

\section{Leadership}

The art of motivating a group of people to act towards achieving a common goal or a state of being in control of a group of people.

\section{ICEBREAKER}

Open the session with an icebreaker of your choice, or allow participants to suggest one. See Appendix B: Participatory Facilitation Resources - Icebreaker Activities for ideas.

\section{REVIEW}

A Ask participants what key points were covered in the last session (optional: throw a ball of paper around to encourage participation). Fill in any key points that are missed.

Go over any practice activities that were given, and ask if there are any questions. 


\section{activity 1}

\section{CAR AND DRIVER}

(3O MINUTES)

Randomly divide the group into pairs (see Appendix B: Participatory Facilitation Resources - Group Formation Activities for ideas). Assign one participant from each pair to be the car. The other participant will be the driver.

(NOTE TO FACILITATOR: To make the exercise more challenging you can scatter obstacles like chairs and tables throughout the space and pair girls together who do not know each other well.)

\section{Explain:}

1 The role of the participant who is the car is to keep her eyes closed and follow the driver's instructions. The role of the participant who is the driver is to keep her eyes opened and protect the car from collisions. Talking is not allowed in this activity so the drivers must communicate to the cars with the following touch signals.

(Demonstrate as you describe):

- A touch on the middle of the back means walk

- Subsequent touches on the middle of the back mean walk faster

- A touch on right shoulder means turn right

- A touch on left shoulder means turn left

- A touch on head means stop
Cars should be touched gently and all cars and drivers should be very careful!

Make sure everyone understands their roles and the signals, and then start the exercise. Ensure that there is no talking during the exercise - or that talking is at least kept at a minimum. After one or two minutes stop the exercise and have each pair switch roles. Cars become drivers and vice versa. Stop the second round after one or two minutes and have the group return to their seats.

Discuss the following with the group:

$\bigcirc$ How did it feel being a car?

How did it feel being a driver?

Which did you prefer? Why?

What were some of the challenges of being the car?

What were some of the challenges of being the driver?

What did you enjoy most about each role?

What did this exercise teach you about leadership?

What does it mean to be an effective leader?

Is there any value in following?

Does following have a role in leadership? If yes, what is it? 


\section{activity 2}

\section{GOOD LEADER, BAD LEADER}

\section{(25 MINUTES)}

Arrange seats in a circle and place flipchart paper where everyone in the circle will see it or use a chalkboard visible to the circle of participants. Draw two columns on a sheet of flipchart paper. Write 'Good Leader' at the top of one column and 'Bad Leader' at the top of the other.

Ask:

$S$ What do you think leadership means?

[The action of leading a group of people or an organization.]

Why is it important for everyone to have some good leadership skills?

[advancement of your own goals, use your resources to reach your vision, they strengthen communication and decision-making, increase productivity, etc.]

Hand out paper and pencils or pens to each participant (not necessary for low/illiterate groups).

\section{Instruct:}

5 Think of a leader you admire (e.g., mother, community leader, celebrity, politician) and write (or think of) three qualities you believe makes that person an effective leader.

Next think of a leader you dislike (e.g., Adolf Hitler, a celebrity or politician, or a character from a well-known story) and write (or think of) three qualities that make that person a bad leader.
Allow sufficient time for participants to write (or think of) these responses. Request each participant to share what they have written. Record the qualities listed on the chalkboard or flipchart paper under the column 'Good Leader' or 'Bad Leader'.

Discuss the similarities and differences in the qualities that were suggested:

\section{$\int$ Was anything surprising?}

Are there any similarities with the qualities for a good leader and for a bad leader?

Do the leaders we do not admire have similar qualities to ones we do admire?

How can we avoid becoming bad leaders?

What can we do to be effective leaders?

\section{Explain:}

5 Now I will go around the room and ask each participant to list:

- A positive quality that you believe you already have

- A positive quality that you would like to develop

- A negative quality that you would like to manage or eliminate

\section{Wrap-wp}

Ask participants to summarize what they have learned. Fill in any key points they miss.

Key Message: Leaders in our communities, families, and countries possess qualities causing different types of leadership. You can be a leader too!

Ask for any final questions or comments. Remind participants where and when the next meeting will take place, and what topics will be discussed.

Thank them for their participation.

\section{PRACTICE ACTIVITY}

Ask participants to identify community leaders near their homes. Explain that in the next session they will share who they identified. 
2)

Community Service-Putting Leadership into Action*

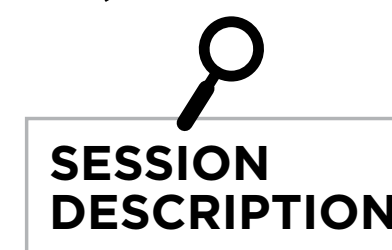

(LEADERSHIP)

Participants use

drawings to represent

their community,

design a community

service action plan, and

learn about democracy.

\begin{tabular}{|l|}
\hline OBJECTIVES \\
By the end of this session, \\
participants will be able to: \\
• Practice leadership skills \\
by designing and carrying \\
out a local community \\
service project \\
- Improve skills/knowledge \\
in public speaking, \\
democratic processes, \\
and teamwork \\
\hline
\end{tabular}

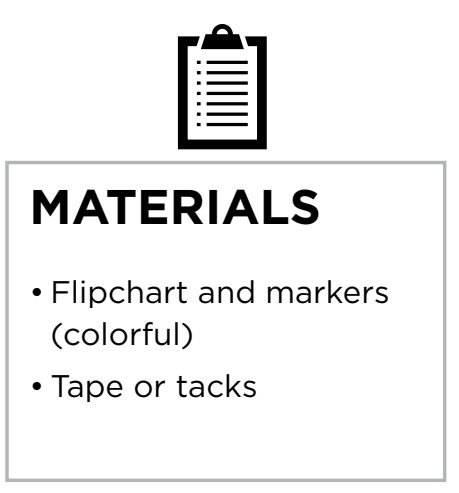

- Brainstorming (20 minutes)

- Discussion (10 minutes)

- Develop a Plan of Action (25 minutes)

-Wrap-up (5 minutes)

- Practice Activity (5 minutes)

\begin{tabular}{|l|}
\hline PRE-SESSION \\
PREPARATION \\
- Read through the entire \\
session and, if necessary, \\
practice presenting the \\
activities \\
- Prepare all materials \\
needed for the session \\
- Draw a map of the \\
community in a creative \\
way (see Activity 1) \\
\end{tabular}




\section{FACILITATOR NOTES}

Community leaders take responsibility for the well-being and improvement of their communities. Community leaders want to improve their communities and feel they have something to contribute to doing so. They do not wait around for someone else to get the job done. You don't have to run for office or be given a title to be a leader. All you need to do is decide to take responsibility for some corner (or bigger chunk) of your community. Community leaders are often selfappointed. Even people who run for office first make a decision that they want to be a leader. You can probably take as much responsibility for your community as you are willing to.

\section{TERMS}

\section{Anarchy}

A state of disorder due to absence or non-recognition of authority

\section{Community Assets}

Positive characteristics that benefit communities

\section{Community Service}

An activity that is performed by one or more people for the benefit of the public or its institutions

\section{Democracy}

A system of government in which the whole population, or all eligible members of a population (e.g., elected representatives), vote

\section{Dictatorship}

A ruler with total power over a country, typically one who has obtained power by force

\section{Ripple Effect}

The continuing and spreading results of an event or action

\section{ICEBREAKER}

Open the session with an icebreaker of your choice, or allow participants to suggest one. See Appendix B: Participatory Facilitation Resources - Icebreaker Activities for ideas.

\section{REVIEW}

A Ask participants what key points were covered in the last session (optional: throw a ball of paper around to encourage participation). Fill in any key points that are missed.

Go over any practice activities that were given, and ask if there are any questions. 


\section{activity 1}

\section{BRAINSTORMING}

(20 MINUTES)

ADVANCE PREPARATION: Draw a map of the community. Try to do it in a creative way. It does not have to be a literal map of the community but can be a representation through symbols, such as a town represented as a flower with different petals.

\section{Ask:}

5 What are some examples of communities? [e.g., family, church, school, town, Europe, world]

What are some characteristics of a community? What makes a community a community?

[e.g., common needs and interests, respect, a population, set of governing rules]

Do you think that we have formed a community in this group with our regular meetings? Why?

Show participants the map of the community that you have drawn. Explain your map if necessary.

\section{Then tell participants:}

5 Community assets are positive characteristics, aspects that benefit our communities.

Divide participants into groups of five or so (there should be an even number of groups) (see Appendix B: Participatory Facilitation Resources - Group Formation Activities for ideas). Pass out magic marker (every color but black) and big paper.

\section{Explain:}

5 Now you and your group should draw a map of the community. Be creative!

When the groups have finished drawing their maps, have the small groups move around their room and partner with another small group to present their map.

Show the facilitator-drawn community map again.
Explain:

$\int$ We will now add community problems, issues, and challenges to the community map in black (demonstrate on the facilitator-drawn community map). No community is perfect. Draw the problems, issues, and challenges you and your group can think of to your maps.

As participants draw on their maps, you can also add to yours. In the end, participants should hang their maps on the wall using tape or tacks to display. 


\section{activity 2}

\section{DISCUSSION}

\section{(10 MINUTES)}

Lead a discussion on the mapping activity.

\section{Ask:}

5 What did the maps have in common?

How does your community affect your selfesteem?

How does it affect our values?

What was the point in making these maps? [to remind ourselves of the many assets in our community and to learn about our problems]

What is community service?

[voluntary work to help people in a particular area]

\section{Explain:}

The "ripple effect" is like when you throw a stone into the water and the rings spread across a pond. If we do something positive for our community, it can have a positive impact on our world just as doing something negative has an impact on our world. An example is if you throw a piece of trash in a river, it will make the river look ugly, kill the fish, people won't have anything to eat, pollute the drinking water, etc.
Give an example of some volunteer work that you (the facilitator) have done. Tell the participants who you worked with, when you did it, what the work was, where the work took place, why you did it, and how it made an impact on the lives of others. List the positive and negative outcomes of your experience (e.g. maybe you felt stressed or worked in the hot sun, but you were able to provide hungry citizens with food). Stress the fact that the positives outweigh the negatives.

\section{Ask:}

$\int$ Why do community service?

What can you learn from community service? 


\section{activity 3}

\section{DEVELOP A PLAN OF ACTION}

\section{(25 MINUTES)}

Make sure participants are still in their small groups from Activity 1.

\section{Explain:}

In your groups, choose one issue, problem, or challenge to work on in your community over the next year.

Regroup the girls into one large group.

\section{Explain:}

Now as a group, we will agree on one issue out of all those that you brainstormed - that we want to address. To address the issue, we will use the skills that we learned in the goal setting sessions, including a) identifying a mission statement, b) answering the questions who, what, when where, why, and how, c) listing the positive and negative outcomes, and d) drawing a timeline.

First have the group share the issues they brainstormed. Then have the group agree on one issue make sure it is realistic! Follow the steps to address the issue, as in the following example:
- Mission Statement? Over the next year we will teach students in $12^{\text {th }}$ grade about the dangers of smoking.

-Who? $12^{\text {th }}$ grade students

- What? Education on the dangers of smoking

-When? After school

- Where? On school grounds

-Why? To prevent these students from taking up smoking and avoid health problems, which result from smoking

- How? Interactive learning sessions and activities

- Positives? Educate the students on a new subject, get to know students well, serve as a mentor or role model for the students, practice leadership skills

- Negatives? Teaching sessions inconvenient, not paid, takes lots of time to prepare lessons

- Timeline? Over a year long period

Determine when the community service activity will begin or take place, and make necessary plans for the execution of the plan. If there is extra time, have the group repeat this process with more topics.

\section{wrap-up}

Ask participants to summarize what they have learned. Fill in any key points they miss.

$\sum_{1}$ Key Message: Leadership starts on a small scale- with you! You can be a leader in your own community by working with a team on small initiatives.

Ask for any final questions or comments. Remind participants where and when the next meeting will take place, and what topics will be discussed.

Thank them for their participation.

\section{PRACTICE ACTIVITY}

Instruct participants to think of an issue or challenge they face in their daily lives, and then a simple plan for how they can address this issue, e.g., household chores take too much time. Explain to them that they will share their ideas at the beginning of the next session. Carrying out the steps to address the challenge between now and the next session is even better! 
音UUMAN RIGHTS 
1)

SESSION
DESCRIPTION
(HUMAN RIGHTS)
Participants learn
about human rights,
draw posters to
illustrate various rights,
and learn what to do if
their rights are violated.

\section{Human Rights and Children's Rights*}

\begin{tabular}{|l|}
\hline OBJECTIVES \\
By the end of this \\
session, participants will \\
be able to: \\
- Recognize that \\
everyone has human \\
rights regardless of age, \\
sex or ethnicity \\
- State that rights are \\
inalienable and cannot \\
be taken away \\
- Explain responsibilities \\
in relation to upholding \\
human rights \\
\hline
\end{tabular}

1 HOUR, 30 MINUTES
- Icebreaker (5 minutes)
- Review (5 minutes)
- What Are Human Rights?
(20 minutes)
- Illustrate Rights (30 minutes)
- What to Do If Your Rights Are
Violated (15 minutes)
- Wrap-up (10 minutes)
- Practice Activity (5 minutes)

\begin{tabular}{|l|}
\hline MATERIALS \\
- Chalkboard and chalk OR \\
flipchart and markers \\
- Container \\
-1 copy of Activity Sheet \\
8: Children's Rights \\
(provided at the end \\
of this session) cut into \\
strips \\
- Copies of Activity Sheet \\
8: Children's Rights for \\
each participant \\
- Poster paper (flipchart \\
paper) and markers \\
\hline
\end{tabular}

PRE-SESSION
PREPARATION
- Read through the entire
session and, if necessary,
practice presenting the
activities
- Prepare all materials needed
for the session




\section{FACILITATOR NOTES}

Rights are something every person should have or be able to do. All children have the same rights. To uphold rights means to stand up for, maintain or help other to maintain their rights. These rights are listed in the UN Convention on the Rights of the Child ( $C R C$ ). Almost every country has agreed to these rights. All the rights are connected to each other, and all are equally important. In this session, it is not necessary to ensure that participants know the numbers of the articles in the CRC, as it can be overwhelming. It is important, however, that they know that everyone has rights. Participants should be familiar with the rights that pertain to them as young people.

In some countries, there has been a backlash against children's rights because the topic had been misunderstood. Some adults worry that if children have rights, then children will be free to do whatever they wish, including disobeying their parents or other authority figures. This is not true. Children's rights help teach young people respect and are not a threat to adult authority. They encourage children to be respectful, not only of themselves, but of their teachers and other children as well. Think about rights in terms of what is the best for children in a situation and what is critical to life and protection from harm. As children grow, they have more responsibility to make choices and exercise their rights.

Children's rights are a special case because many of the rights laid down in the Convention on the Rights of the Child have to be provided by adults or the state. However, the Convention also refers to the responsibilities of children, in particular to respect the rights of others, especially their parents (Article 29). Children are expected to listen to what adults tell them to do. Given that, adults should always act in the best interest of the child. Unfortunately, this is not always the case. Adults, including teachers, have sometimes used their power to take advantage of young people. This session is meant to equip young people with the skills they need to exercise their rights and to grow in an environment free from violence and abuse.

\section{TERMS}

\section{Children's Rights}

Legal, social, or ethical principles stating that all children should be free from or entitled to certain things

\section{Convention on the Rights of the Child (CRC)}

A UN document in which the rights of children are listed

\section{Human Rights}

Legal, social, or ethical principles stating that all humans should be free from or entitled to certain things

\section{Rights}

A moral or legal entitlement to have or obtain something or to act in a certain way

\section{ICEBREAKER}

Open the session with an icebreaker of your choice, or allow participants to suggest one. See Appendix B: Participatory Facilitation Resources Icebreaker Activities for ideas.

\section{REVIEW}

( Ask participants what key points were covered in the last session (optional: throw a ball of paper around to encourage participation). Fill in any key points that are missed.

Go over any practice activities that were given, and ask if there are any questions. 


\section{activity 1}

\section{WHAT ARE HUMAN RIGHTS?}

(2O MINUTES)

On a flipchart or chalkboard, write "What Are Human Rights?" Ask participants if they have ever heard of human rights. Let them share their answers, and record them on flipchart paper.

Explain human rights in your own words.

\section{For example:}

5 Everyone has rights. Human rights are about respect for everyone. It does not matter if the person is old or young, a man or woman, a girl or boy or where he or she lives. Everyone has a right to have his or her needs met, to be safe and to have a say in what happens in his or her life.

\section{Ask:}

What are some examples of human rights? [e.g., everyone has the right to:

- education (go to school),

- employment (have a job),

- movement (travel from one place to another),

- ownership of property (own land, a house, a shirt, etc.),

- government services (use roads, parks, hospitals, schools, etc.),

- clean water (drink water that will cause disease),
- access to information (research and learn any information, not including private information),

- practice religion (go to any church, believe in any god (or not)),

- live free from violence (not have to worry about being hurt),

- health care (access medial services),

- vote (in country or local elections), and

- be protected from economic or sexual

exploitation (protected from being scammed, robbed, raped, and abused).]

Record answers on the flipchart or chalkboard.

\section{Explain:}

5 There are many rights and they fall into three basic categories:

- Rights to things they need, such as a home, food, health care and places to stay and learn.

- Rights to keep them safe from harm.

- Rights to take part in decisions that affect their lives.

Write the rights from Activity Sheet 8: Children's Rights on the chalkboard or flipchart. Discuss the rights using the other information provided on Activity Sheet 8: Children's Rights as a guide, and relate them to those that were covered in previous sessions, such as avoiding violence and being able to access health services.
The following are examples of responsibilities that are associated with rights.

\section{Explain:}

5 Rights come with responsibilities. For example:

- With the right to be treated equally comes the responsibility to treat others equally.

- Children have the right to be protected from abuse, cruelty, exploitation and neglect, but they also have the responsibility not to bully or harm others.

- Children also have responsibility for their own learning, which includes respecting their teacher and the rules in the classroom.

- Children have a right to a clean environment. They also have a responsibility to do what they can to look after their environment.

Rights and responsibilities are inseparable!

Put the slips of paper cut from the Activity Sheet 8: Children's Rights in a container. Let participants take turns picking one of the rights out of the container. Ask them to read the right and its explanation. 


\section{activity 2}

\section{ILLUSTRATE RIGHTS}

\section{(3O MINUTES)}

Divide the participants into groups of three or four (see Appendix B: Participatory Facilitation Resources Group Formation Activities for ideas). Give each group one of the eight rights from the slips of paper cut from Activity Sheet 8: Children's Rights. Also distribute flipchart paper and markers. Some groups may have the same right if there are more than eight groups.

\section{Explain:}

5 You are going to create informational posters about the right on your slip of paper. The posters will be displayed around the community to inform your peers about human rights. On your posters, don't forget to include information about the responsibilities that come with the rights too.

When participants have finished, let the groups share their posters. Put the posters up around the community.

\section{activity 3}

\section{WHAT TO DO IF YOUR RIGHTS ARE VIOLATED (15 MINUTES)}

Read the Bwalya's Story (below):

Ask:

5 Which human rights violations happened in this scenario?

[possible responses include: the right to education, the right to live free from violence, the right to employment, the right to health care, the right be protected

from economic or sexual exploitation]

Who was the victim of the violations? [Bwalya and her baby daughter]
Who is responsible to ensure that children's rights are not violated?

[responses should include: Everyone has a responsibility to work together to uphold rights, and that includes:

- students,

- family,

- community,

- school, and

- government]

\section{Bwalya's Story}

Bwalya is a grade 12 pupil and very dedicated to achieving her academic goals. She is an orphan and lives a homeless life, mainly surviving on the streets. Bwalya washes clothes in people's homes and sells fritters and tap water on the streets to raise money for her education. Her boyfriend John impregnated her before she sat for her final exams. John is very abusive and often beats her up whenever she performs well at school. When he learnt she was pregnant, he beat her up until she began to bleed, and he threatened to kill her if she did not get rid of the pregnancy. When Bwalya was 12 months pregnant (I don't think you can be 12 months pregnant!!), she secretly gave birth to a baby girl and dumped her at a nearby church. 


\section{wrap-epp}

Ask participants to summarize what they have learned. Fill in any key points they miss.

$\sum_{m m}^{n n}$

Key Message: Everyone has human rights, which cannot be taken away. Everyone also has certain responsibilities to meet so that these human rights are upheld for themselves and others.

\section{Explain:}

5 We're going to go over the definition of human rights in simple terms:

- Human rights are about respect for everyone.

- Everyone has the right to have his or her needs met, to be safe and to take part in decisions that affect him or her.

- Everyone has rights, as well as responsibilities.

- Adults (both men and women) and children (both boys and girls) have rights and responsibilities.

With rights come responsibilities. Participants have rights, but they also have responsibilities to themselves, their peers, their parents and other adults.

Ask for any final questions or comments. Remind participants where and when the next meeting will take place, and what topics will be discussed.

Thank them for their participation.

\section{PRACTICE ACTIVITY}

Participants should write down (or think of) three rights that they have, and the responsibilities they must uphold in order to maintain those rights. 


\section{ACTIVITY SHEET 8 \\ CHILDREN'S RIGHTS}

\section{YOU HAVE THE RIGHT TO AN EDUCATION.}

You have the right to go to school and get an education. You should be encouraged to go to school to the highest level possible.

\section{YOU HAVE THE RIGHT TO BE PROTECTED FROM HARMFUL PRACTICES.}

Some traditional practices are bad for your health and against your rights, such as early and forced marriage or someone forcing you to have sex against your will. You have a right to know about the danger of such practices and to be protected from them.

\section{YOU HAVE THE RIGHT TO BE AS HEALTHY AS POSSIBLE AND TO BE ABLE TO} ACCESS THE BEST POSSIBLE HEALTH CARE SERVICES.

You have the right to the best health care possible, safe water to drink, nutritious food, a clean and safe environment and information to help you stay well.

\section{YOU HAVE THE RIGHT TO PRIVACY AND CONFIDENTIALITY.}

If you tell a medical person or teacher something that you don't want anyone else to know, they should respect your privacy. However, if you have been abused, adults may have a duty to inform others who can protect you.
YOU HAVE THE RIGHT TO FREEDOM FROM ABUSE AND EXPLOITATION.

No one, including your parents, relatives or teachers, should physically, sexually or mentally abuse you. The government should make sure that you are protected from abuse and must take action if you experience violence or abuse.

\section{YOU HAVE THE RIGHT TO TAKE PART IN IMPORTANT LIFE DECISIONS.}

When decisions are made about your life, you have a right to take part in making those decisions. Your feelings and opinions should be listened to and taken into consideration.

\section{YOU HAVE THE RIGHT TO FREEDOM OF ASSOCIATION.}

You have the right to meet friends and form groups to express ideas, as long as no laws are broken. You have a right to ask publicly for your rights to be met. Some ways of doing this include meeting with friends and discussing issues or forming groups.

\section{YOU HAVE THE RIGHT TO FREEDOM OF EXPRESSION.}

Young people have the right to think and believe what they like, as long as it does not harm anyone else. You have a right to form your own views. 
2)

\section{Sexual and Reproductive Health Rights*}

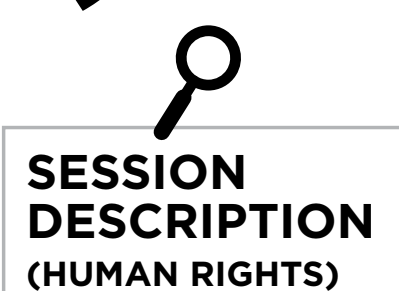

Participants review

the concept of human rights, are introduced

more specifically

to sexual and

reproductive health

rights by analyzing a

story of sexual rights

violations, and explore

the idea of advocacy

for rights in their own

lives.

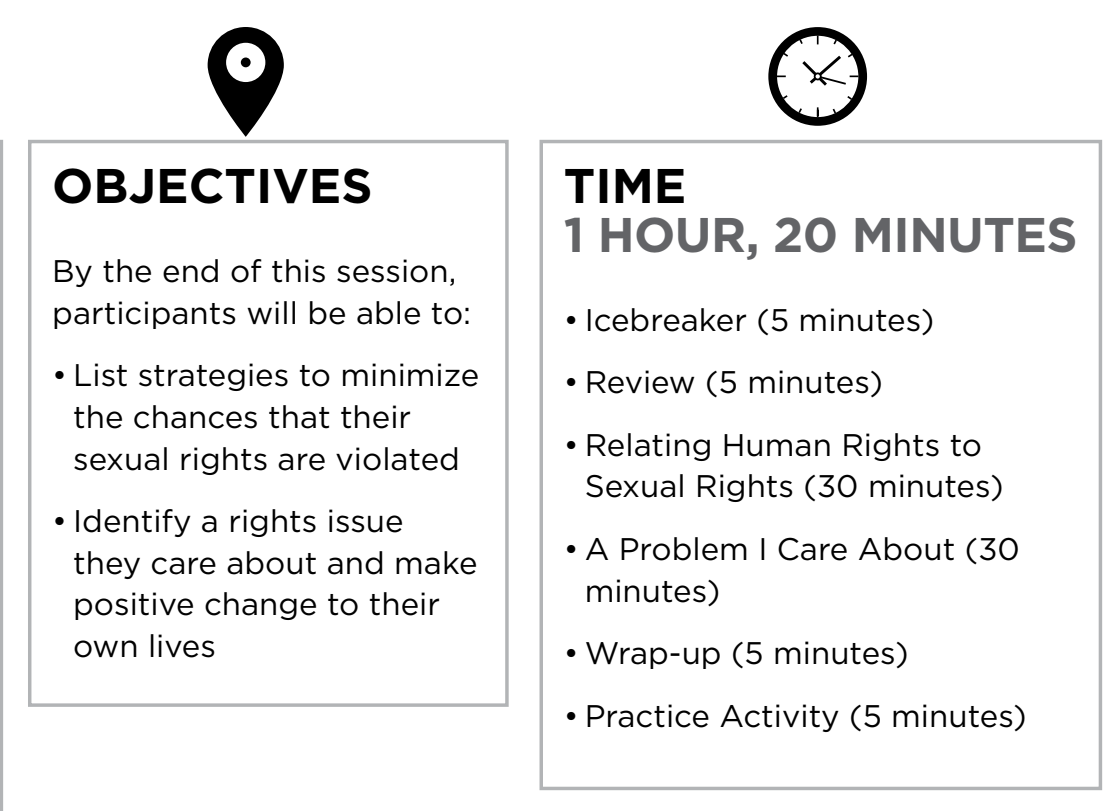

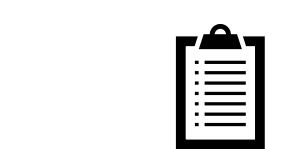

\section{MATERIALS}

- Chalkboard and chalk OR flipchart and

markers

- Copies of Activity

Sheet 9: A Problem I

Care About provided at

the end of this session

(for each participant)

or write the content

on the chalkboard

or flipchart ahead of

time if copies are not

available 


\section{FACILITATOR NOTES}

When human rights relate to people's sexuality or reproduction, we call them "sexual rights" or "reproductive rights." Sexual rights and reproductive rights sometimes overlap. However, sexual rights generally include individuals' control over their sexual activity and sexual health. Reproductive rights usually concern controlling the decisions related to fertility and reproduction.

People's romantic and sexual experiences can become human rights issues. Only when our basic rights are honored (both by governments and by other individuals) can we make optimal decisions about intimate relationships, sex, and childbearing. For example: Individuals can make decisions about if, when, and with whom they will form a romance, a long-term relationship, or a marriage. They can decide if, when, with whom, and under what circumstances to have sex (free from sexual abuse and coercion). They can negotiate condom use to prevent infection. They can decide whether or when to become pregnant or have children. They can obtain contraceptive information and services. They can have a safe abortion.

Sexual and reproductive rights also apply to young people. Children have the right to develop a positive sense of their own bodies and sexuality. Children have the right to be free of abuse and inappropriate touching. Younger children need help in making decisions. The direction and guidance provided by caring adults must take into account the best interests of children. It must also consider the capacity of children to exercise rights on their own behalf. As children grow and develop their capacities, their rights and responsibilities continue to evolve. Young people have the right to obtain information to protect their health, including their sexual and reproductive health.

Girls living in poverty are more likely than other girls to suffer early or forced marriage, unwanted pregnancy, unsafe abortion, and sex trafficking (coercive relocation of people for purposes of sexual exploitation). Some people's sex partners (including some who pay for sex with cash or gifts) refuse to wear a condom. Many people face discrimination when they try to seek necessary sexual health information and services. This problem is particularly severe among young people and among people living with HIV and AIDS. Unfortunately, economic and social barriers and violations are so common that they are typically excused, overlooked, or seen as culturally "normal." These barriers and violations take different forms around the world.

\section{TERMS}

\section{Advocacy}

Public support for or work to promote a specific cause

\section{Sexual Rights}

The right of an individual to control their sexual activity and sexual health

\section{ICEBREAKER}

Open the session with an icebreaker of your choice, or allow participants to suggest one. See Appendix B: Participatory Facilitation Resources - Icebreaker Activities for ideas.

\section{REVIEW}

O

Ask participants what key points were covered in the last session (optional: throw a ball of paper around to encourage participation). Fill in any key points that are missed.

Go over any practice activities that were given, and ask if there are any questions. 


\section{activity 1}

\section{RELATING HUMAN RIGHTS TO SEXUAL RIGHTS}

\section{(30 MINUTES)}

Ask:

What does the term "human rights" mean to you?

[Legal, social, or ethical principles stating that all humans should be free from or entitled to certain things]

What human rights do you have?

[e.g., the right to: education, employment, movement, ownership, etc.]

What they consider to be basic human rights for all people, including those with HIV and AIDS?

[possible answers include: the right to medical care, employment, housing, education, reproductive rights, etc.]

Read Gloria's Story (below).

\section{Gloria's Story}

Gloria is 12 years old and really enjoys school. Lately, she has been having trouble in math and her teacher has offered to give her extra help. One day she stayed after school and the teacher grabbed her breast and told her she was turning into a beautiful young woman. Gloria felt very uncomfortable but was afraid to speak up to the teacher. She decided she would fail math instead of asking this teacher or any other teacher for help again.
Ask:

5 Which rights were violated for Gloria?

[the right to protection from abuse and sexual exploitation]

How can the student, family, community, school, and government help make sure that Gloria's rights are upheld?

[possible responses are:

- a student should speak up and tell someone that the teacher has abused her,

- her family should protect her from abuse by the teacher,

- the community should make sure the school is a safe space and that teachers are not abusing students,

- the school should ensure that teachers are not abusing the students, and

- the government should ensure that teachers are not abusing students. If a teacher is found guilty of abusing a student, he or she should be fired or prosecuted.]

Explain:

"Sexual rights" generally include individuals' control over sexual activity and sexual health. These sexual and reproductive rights also apply to young people; that is, children have the rights to develop a positive sense of their bodies and sexuality. Children have the right to be free of abuse and inappropriate touching. Thus young people have the right to obtain information to protect their health, including their sexual and reproductive health.

Ask:

What can you do to make sure your sexual rights are not violated?

[responses should include those listed below] - Say "no." You have a right to say "no" to anyone who touches you in a way that makes you feel uncomfortable or afraid.

- Some secrets should never be kept. There are some secrets that you should never keep even if you are asked not to tell or you promised not to tell. Often people who do bad things to children tell them not to tell and threaten to hurt them or someone they love. They know they are doing something wrong, and they are afraid of what will happen. Do not be afraid to tell.

- Hugs and kisses are great, especially from people you like! No one should ever ask you to keep a kiss, hug or touch a secret. If someone says, "It is our little secret," you should tell a trusted adult.

(activity 1 continued on next page) 


\section{activity 1 (continued)}

\section{RELATING HUMAN RIGHTS TO SEXUAL RIGHTS}

- Your body belongs to you. Learn the names of your body parts and remember the difference between "good touch" and "bad touch." No one should touch you in a place that makes you feel bad. Remember, if you get a feeling that makes you uncomfortable, use one of the phrases you learned. Always tell a trusted adult if someone touches you, even if you are not sure if it is a "good touch" or "bad touch."

- Run or get away. If a stranger or someone you know tries to harm you, run and get away. Get help. Make sure to run to a place where there are people.

- Yell! It is all right to yell and shout if someone is trying to hurt you. You should not feel embarrassed. Yell and call for help.

- Do not take gifts. Do not take any candy, money or gifts from anyone without telling your mother, father or guardian. It is usually OK to take gifts from family and friends. But some adults, maybe even ones that you know, might try and give you gifts or money to trick you into doing something wrong.
- Tell a trusted adult. If you are being physically, psychologically or sexually abused or bullied, tell a friend, teacher, your parents or a trusted adult. It can be hard sometimes,

but remember your courage and that you are resilient

Ask:

From these ways to ensure your sexual rights are protected, what could be hard to do in real life?

[e.g., tell a trusted adult, say "no," run or get away, etc.]

Acknowledge that it is not always easy to do the things listed above. Discuss challenges and strategies that participants can use to stand up for their rights. 


\title{
activity 2
}

\section{A PROBLEM I CARE ABOUT}

\author{
(3O MINUTES)
}

\section{Explain:}

5 We have learned about various sexual and reproductive health issues that have an impact on our lives.

\section{Ask:}

What are some of the sexual and reproductive health issues we studied?

[e.g., gender-based violence, unwanted pregnancy, abortion, negotiating condom use, gender roles, etc.]

\section{Instruct:}

5 Each of you should identify a sexual or reproductive health issue that you care about. It should relate to an issue we have discussed.

Distribute a copy of Activity Sheet 9: A Problem I Care About to each participant (or write the content on the chalkboard or flipchart if copies are not available).

\section{Explain:}

Review the list of issues, asking yourself: "Which issues do I care about?" You will see that the list is divided into two categories (sexual health, and sexual rights). Check off two topics that interest you. They can all be in one category or they can come from different categories. You may also add an issue that you care about that is not on the list.
Put participants into groups of four.

Explain:

$\bigcirc$ In your groups, discuss one or more of the issues that matter to you. Share what you find compelling about your choices, or why you want to learn more about them. You may have a story to share.

Bring the group back together.

Ask:

5 Would anyone like to share which problem or problems they selected, and why?

Introduce students to the concept of working for social change (advocacy):

\section{Explain:}

5 Some people get involved in big campaigns to change the world. "Advocacy" often refers to big changes. But even a small effort can make a meaningful change for the better - in your own life or the life of someone around you. Imagine and consider a small step you can take to make a difference, specifically to improve gender equality or to protect the sexual or reproductive rights of yourself or of another person.
Ask:

Have any of you heard of actions people have taken to fix one of the problems on the worksheet that you or your classmates care about?

What is an example of a change that such actions have brought about in the world?

[e.g., ending the practice of female genital mutilation, increasing numbers of girls in school, men joining campaigns against gender-based violence, legalization of abortion, and allowing pregnant girls to stay in school, etc.]

Can you think of a situation you have seen in your own life where someone made a positive change, whether large or small?

What benefits or growth can a person have by engaging in advocacy?

[e.g., feeling empowered to know you can have an impact on others, building new relationships, strengthening leadership skills, being assertive, admiration from others, etc.]

What are some risks that a person can face by engaging in advocacy? [e.g., disapproval, distraction from schoolwork or other important parts of life, disappointed if you do not achieve the changes you aim for, being arrested or facing other dangers, etc.]

Remind students that it is important to be safe when engaging in advocacy activities for human rights issues. 
wrap-up

Ask participants to summarize what they have learned. Fill in any key points they miss.

Key Message: Girls are particularly vulnerable to sexual rights violations, but advocating for our sexual rights (and other human rights) can bring positive change.

Ask for any final questions or comments. Remind participants where and when the next meeting will take place, and what topics will be discussed.

Thank them for their participation.

\section{PRACTICE ACTIVITY}

Instruct participants to talk to a friend about sexual rights. Participants and their friends should brainstorm three sexual rights they have. 


\section{ACTIVITY SHEET 9}

\section{A PROBLEM I CARE ABOUT}

\section{SEXUAL HEALTH ISSUES}

- Adolescents do not have access to sexual and reproductive health services that are youth-friendly.

- It is difficult to get condoms.

- Many of my peers do not know about HIV.

- Many schools in our area do not teach about HIV.

- Many people don't know their HIV status.

- Young people do not have basic information about their own bodies.

- The rate of sexually transmitted infections among young people is far too high.

- People don't know or care enough about maternal mortality.

- Abortion is legally restricted - and as a result, dangerous - in many places.

- Other:

\section{SEXUAL RIGHTS ISSUES}

- Many girls are being sexually exploited by "sugar daddies."

- Rape is too common, and even tolerated.

- Girls sometimes have to drop out of school to raise children if they have early pregnancies.

- Girls who get abortions are stigmatized by their families and communities.

- People do not realize that boys are also at risk of sexual abuse.

- Sometimes trusted adults may not believe reports of sexual or genderbased violence.

- Many young people, especially girls, do not feel that they really have a right to insist on condom use.

- People living with HIV and AIDS don't get enough support and respect.

- Other: 


\section{3) \\ ○ \\ SESSION DESCRIPTION (HUMAN RIGHTS) \\ Participants explore \\ the concept that \\ protecting the human \\ rights of people living \\ with HIV and AIDS \\ not only helps them \\ to live positive and \\ productive lives, but \\ also helps to prevent \\ HIV transmission.

\begin{tabular}{|l|}
\hline OBJECTIVES \\
By the end of this session, \\
participants will be able to: \\
- List at least five human \\
rights of people living \\
with HIV \\
- Identify a link between \\
the protection of \\
human rights for people \\
living with HIV and the \\
prevention of infection \\
- Define what it means to \\
live positively with HIV \\
and AIDS
\end{tabular}

TIME
1 HOUR, 25 MINUTES
(10-14-year-olds)
OR
1 HOUR, 55 MINUTES
(15-19-year-olds)
- Icebreaker (5 minutes)
- Review (5 minutes)
- Losing Our Rights (20
minutes)
- Interacting with a Person
Living with HIV and AIDS (30
minutes)
- The Loss Exercise (45
minutes)
- Wrap-up (5 minutes)
- Practice Activity (5 minutes)

MATERIALS
- Five small pieces
of paper for each
participant
- Pencils
- Water for the guest
speaker
- Tissues
- List of local
associations of People
Living with HIV and
AIDS in your country

\begin{tabular}{|l|}
\hline PRE-SESSION \\
PREPARATION \\
- Read through the entire \\
session and, if necessary, \\
practice presenting the \\
activities \\
- Prepare all materials needed \\
for the session \\
- A few weeks before \\
this session, visit local \\
organizations of People \\
Living with HIV and AIDS \\
and find out if they have a \\
speakers' component; get \\
to know their philosophy \\
and experience related to \\
public speaking on personal \\
experiences of living with HIV \\
and AIDS; talk to speakers, \\
explain your purpose, and \\
invite a speaker for your \\
presentation on human rights \\
\end{tabular}




\section{FACILITATOR NOTES}

Many HIV support groups now have people living with HIV who are willing to educate groups about HIV and AIDS by sharing their personal experience with the disease. Participants should be prepared ahead of time for this visit, and the facilitator should check with the speaker what types of questions they are comfortable answering. Sample questions could relate to the human rights theme:

-What made the speaker decide to speak publicly about his or her HIV infection?

- Has he or she experienced any discrimination?

-What have been the advantages to speaking out?

The group should make a pact of confidentiality related to the speaker's comments. It is important to select a speaker who is honest, prepared, and eager to speak with groups, and who can model what it means to live positively with HIV. This can be a transformational moment in changing stereotypes about the disease and breaking through denial about personal risk factors.

(See Appendix A: Additional Topical Information - HIV and AIDS and Human Rights as a background for the discussion in Activity 1.)

\section{TERMS}

None

\section{Open the session with an ice-}

CEBREAKER breaker of your choice, or allow participants to suggest one. See Appendix B: Participatory Facilitation Resources - Icebreaker Activities for ideas.

\section{REVIEW}

(7) Ask participants what key points were covered in the last session (optional: throw a ball of paper around to encourage participation).

Fill in any key points that are missed.

Go over any practice activities that were given, and ask if there are any questions. 


\section{activity 1}

\section{LOSING OUR RIGHTS}

\section{(2O MINUTES)}

Give each participant five small pieces of paper.

\section{Instruct:}

On each of your five papers, write down (or draw a picture of) a right that is important to you. Then hold your papers up in your hands.

While participants are holding their papers up, walk around the room with a basket and randomly takes slips of paper from the participants. You may skip some participants altogether and take all five from another.

\section{Explain:}

Check to see which papers or rights I have taken from you. You have just lost those rights.

\section{Ask:}

Which rights did you lose?

How did that make you feel?

How did you feel about the injustice of the selection process?

If you thought you might be infected with HIV and you knew that you would probably suffer discrimination and the loss of human rights, would you want to get tested?

\section{Explain:}

Often people living with HIV or AIDS experience a loss of their rights-usually because they are discriminated against. For example, a business owner may not want to hire someone living with HIV or AIDS and that person loses their right to employment. Or their right to be free from violence may be violated if they are targeted with violence because of their HIV status. Losing your rights in this activity was not fair. It is not fair for people living with HIV or AIDS to lose their rights either.

\section{activity 2}

15-19-year-olds only

\section{INTERACTING WITH A PERSON LIVING WITH HIV AND AIDS} (3O MINUTES)

\section{Ark:}

$\int$ If you knew you were HIV-positive, would you tell your partner or potential partner?

If not, could this affect transmission of HIV in our community?

Introduce and welcome the guest speaker and initiate a pact of confidentiality between the group and the guest to start a dialogue between the older group members and a person living with HIV or AIDS (a guest speaker) regarding how the disease has affected his or her life. 


\section{activity 3}

\section{THE LOSS EXERCISE}

\section{(45 MINUTES)}

(NOTE TO FACILITATOR: This activity could be done with or after another session (particularly for 15-19 year-olds for whom this activity would make cause the session to be particularly lengthy), to explore grief and loss. The Loss Exercise provides a powerful framework for discussing empathy for those experiencing grief or loss, especially those infected or affected by HIV and AIDS.)

Review some of the issues that you have covered up to this point.

\section{Explain:}

$\int$ We are about to do an exercise to help us to look at HIV and AIDS from a very personal perspective. Clear off your desks of everything except a sheet of paper and a pen or pencil not necessary for low/no literacy groups, who can simply brainstorm responses in this exercise in their heads). Number your papers with 1 to 5 . I am going to read five statements, and you will respond to those statements on your papers. It is very important that no one else in the room should see your papers-and the papers will not be collected. They will not be used at any later time-the papers are your own personal property.

Do this exercise slowly and seriously. Participants should feel the full impact of this discussion. One by one, read off the statements (below "Statements Part
I") and tell the participants to write (or draw) their responses on their papers. Reinforce that it will not be shared with others.

\section{STATEMENTS PART I:}

1. Write (or draw) the name of the personal possession that you love the most. Maybe it is your house, or a special item your grandmother gave you, or a book, or anything else. What one thing that you own means the most to you? Write that thing on \#1.

2. Write (or draw) the part of your body that you are most proud of. Perhaps you really love your eyes, or you are very proud of your hair, or you enjoy your ears the most because they help you listen to music, or you love your voice because it helps you to sing. Write down the one part of your body that you are most proud of on \#2.

3. Write (or draw) the name of the activity you most enjoy doing. Maybe it is going to a religious event, or playing football, or dancing, or any other activity. What do you most enjoy doing in the whole world? Write that activity on \#3.

4. Think about one secret or very confidential thing about yourself that no one else in the world or only one other person knows about. Every one of us has some secret or very private thing that he or she does not want others to know about. Write (or draw) that personal, private piece of information down on \#4. (Or if they prefer, participants can just keep the secret in their minds and write the word "secret.")
5. Lastly, write (or draw) the name (a picture) of the person whose love and support means the most to you in the world.

\section{Alter everyone has finished, explain:}

$\int$ Now I will now go through the list again. As I go through each statement, imagine that you are living through what I am saying.

Read the following statements (below "Statements Part II" slowly so that participants are able to fully envision that they are living through what you are reading.

\section{STATEMENTS PART II:}

1. Imagine that something terrible happens that causes you to lose the material possession that you love most. Either a theft occurs or a loss of some kind that takes this thing away from you completely. You will never again see the thing listed on \#1. Take your pen or pencil and cross out \#1 now.

2. Imagine that an accident or other unfortunate occurrence causes you to lose the part of your body that you are proudest of. This part of your body is gone, and you will never have it again as long as you live. Cross out \#2 now with your pen or pencil.

(activity 3 continued on next page) 


\section{activity 3 (continued)}

\section{THE LOSS EXERCISE}

3. Imagine that this same accident or unfortunate occurrence makes it impossible for you to do your favorite activity ever again. You will never again, in your entire life, be able to do the activity you wrote on \#3. Cross out \#3 with your pen or pencil now.

4. Imagine that because of all of the above situations, your secret has been exposed. Everyone now knows what you wrote on \#4. It has become public knowledge-everyone in the school, town, church, mosque, and community knows about what you wrote on \#4. Circle \#4 with your pen or pencil now.

5. Lastly, because of all of these changes (losing your possession, losing your body part, not being able to do your favorite activity, and everyone knowing your secret), the person that you love most in the world leaves you forever. You will never again see this person that you love and who is your most important source of support. Cross out \#5 with your pen or pencil now.

When you finish reading, allow a few silent moments for the participants to truly feel what you have just said. People are usually a bit upset and uncomfortable at this point. Give them some time to think about this.

\section{Ask:}

In one word or phrase, how would you describe the emotions you feel after crossing off the items? [e.g., sadness, grief, feeling like killing myself, hopeless, alone, miserable, depressed, angry, blaming others, no reason to continue, etc.]
Write the words on a chalkboard or flipchart. Keep brainstorming until all of the possible ideas are exhausted.

\section{Explain:}

5 Now let's take a look at the list that you have created (or remember the responses you thought of for low/no literacy groups). Imagine how these feelings might relate to testing positive for HIV and AIDS. You have placed yourselves in the position of a person living with HIV and AIDS and allowed yourselves to experience the very powerful emotions that such a person might be living with every day. These negative feelings are even worse if they experience stigma, discrimination, or violation of their human rights.

\section{Ark:}

Now thinking of this exercise, what kind of support might you be able to give someone living with AIDS?

How can you help someone in the situations we imagined?

How would you feel if you or someone you love were involved in this situation?

\section{wrap-up}

Ask participants to summarize what they have learned. Fill in any key points they miss.

$\sum_{3}$ Key Message: People living with HIV have the same human rights as anyone else.

Thank the guest speaker for volunteering to share his or her stories and knowledge with the group.

Ask for any final questions or comments. Remind participants where and when the next meeting will take place, and what topics will be discussed.

Thank them for their participation.

\section{PRACTICE ACTIVITY}

Participants should draw a picture or write a story about what they learned from this session, or write a letter to the visitor thanking him or her and saying how the speaker's talk influenced their views towards people living with HIV and/or affected their behavior. 


$$
\text { 立APPENDIXES }
$$




\section{Abortion}

Abortion Stigma

Abstinence

Addiction

Adolescence

\section{Advocacy}

Aggressive

\section{AIDS}

\section{Alcoholic}

Alcoholism

Anarchy

Antenatal Care

Assertive

\section{Attack}

Attributes
The early termination of a pregnancy, resulting in the death of the embryo or fetus

The discrediting of individuals as a result of their association with abortions

Refraining from sexual activity, the only 100 percent effective method for avoiding unwanted pregnancy and sexually transmitted infections, including HIV

The condition of being dependent on a substance, thing, or activity

The period of time when people transition from childhood to adulthood, usually between ages 10 and 19

Public support for or work to promote a specific cause

Delivering a message forcefully without thinking of the other person's feelings; expressing oneself in a confrontational manner

Acquired Immune Deficiency Syndrome; the final stage of HIV disease, which causes severe damage to the immune system

An individual who consumes alcohol in access and has difficulty functioning without alcohol

The addiction to alcohol

A state of disorder due to absence or non-recognition of authority

The care of women and their children before birth

Delivering a message by honestly expressing one's thoughts and feelings; being direct and clear without putting down the rights of others; showing mutual respect

Take aggressive action against

A quality or feature that is characteristic of someone

Keep away from
Bladder

Body Language

Cervix

Children's Rights

Clitoris

Communication

Communication

Blockers

Community Assets Positive characteristics that benefit communities

Community Resource An organization, institution, group, or person in the community that provides assistance and support to those at risk

Community Service An activity that is performed by one or more people for the benefit of the public or its institutions

\section{Conception}

Condom

Conflict

Conflict Resolution

Consequences

Consent

The sac where urine is collected before excretion

See non-verbal communication

The neck-like passage from the uterus to the vagina

fromical principles stating that all children

A sensitive area near the top of the opening of the vagina that helps a woman have sexual pleasure

Process of sending and receiving information or thoughts through words, actions, or signs

Barriers or things that interfere with good

When a sperm cell meets an egg and fertilizes it, so that it begins to develop into an embryo

A barrier device commonly used during sexual intercourse to protect against pregnancy, sexually transmitted diseases, and HIV transmission, infection, or (re)infection

A serious disagreement or argument, typically one that lasts a while

Methods, strategies and/or processes involved in facilitating the peaceful ending of social disagreement or problem Good or bad things that can result from a decision or action

Give permission or agreement for something to happen 
Contraceptives

Convention on the

Rights of the Child

(CRC)

Danger Signs

Date Rape

Decision

Decision-Making

Democracy

Depressants

Dictatorship

Discrimination

Drugs

Drug Abuse

Drug Use

Effective

Communication

Ejaculation
Methods for preventing pregnancy; also known as family planning

A UN document in which the rights of children are listed

Warnings of an impending hazard or negative outcome

Rape between individuals who are dating or know each other; also called acquaintance rape

A choice between two or more options

The process of reaching a decision

A system of government in which the whole population, or all eligible members of a population (e.g., elected representatives), vote

Drugs which reduce the functioning of nervous activity to make the body react slowly

A ruler with total power over a country, typically one who has obtained power by force

Treating someone differently because of perceptions or prejudices about them

Substances other than food which affect the chemistry and function of the body causing changes in behavior, e.g. dagga, mandrax, glue, marijuana, kachasu and other forms of alcohol. Substances intended for use in the treatment or prevention of disease, e.g. Panadol, chloroquine, and fancida

The habitual taking of illegal or addictive drugs; considers the frequency, attitude toward, effects of, and physiological responses caused by the of use of drugs, and the age and level of dependency of the user

The consumption of drugs

Communication that avoids misunderstandings and improves relationships

Release of semen from the penis during orgasm

\section{Embryo}

Empowerment

Energizer

Erection

Exploitation

External Stigma

Fact

Fallopian Tubes

Fertilization

Fetus

Friendship

Gende

Gender Role

Gender Stereotype

Gender-Based

Violence
A developing human that has not yet reached the fetus stage, usually from the time of conception until around two months after conception

Making someone stronger and more confident, especially in controlling their life and claiming their rights

An activity used to establish or reestablish energy and enthusiasm among participants, especially if concentration is broken

The stiffened and swollen state of erectile tissue, especially that of the penis, usually as a result of sexual arousal

Using a situation to your own advantage without concern about how the other person feels; sometimes achieved by using force, pressure or tricks

Enacted or expressed stigma

A truth, which can be backed up by evidence

Tubes which connect a woman's ovaries to her uterus

The fusion of a male sperm cell and a female egg; necessary before an egg can begin to grow into an embryo

A developing human that is past the embryo stage but not yet born (usually from two months after conception until birth)

A particularly fulfilling relationship involving intimacy, trust and honesty

What a society or culture expects from you based on whether you are male or female (roles, behaviors, etc.)

Expectations of how men and women should act and what their roles are in society

An oversimplified or biased description of the abilities of men and women

Any act that results in, or is likely to result in, physical, sexual or psychological harm or suffering to someone (boy or girl) based on gender-role expectations and assumptions 
Something that you hope to achieve, especially when much time and effort will be needed

Group Norms

Group Rules

Hallucinogens

HIV

Hormones

Human Rights

Immune System

Internal Stigma

Icebreaker

Implantation

Incest

Induced Abortion

Labia

Leadership

Life Cycle

The standard behaviors and characteristics of a group

Basic rules set to help you feel safe and respected, and maintain productivity

Drugs which cause hallucinations changing the way a person sees, hears, or feels

Human Immune Deficiency Virus; the virus that causes AIDS and is transmitted through blood, semen, vaginal fluid and breast milk

A chemical substance produced in the body that controls and regulates the activity of certain cells or organs

Legal, social, or ethical principles stating that all humans should be free from or entitled to certain things

The body's natural defense system for fighting off disease

Self-hatred, shame, or blame; feeling of being judged by others; also called self-stigma

An activity used to 'warm' participants up in preparation for core activities

An event that occurs early in human pregnancy when a fertilized egg adheres to the uterus wall

An act of two members of the same family having sexual inter course for example a father and daughter, or a brother and sister

The termination of pregnancy by removal or expulsion of the fetus before it is able to survive independently

The two folds of skin, or lips, at the opening of the vagina

The art of motivating a group of people to act towards achieving a common goal or a state of being in control of a group of people

The process of changes through which a human goes during their life, including infancy, childhood, adolescence, adulthood, and old age

A strong feeling of affection towards something or someone

Maternal Emergency When a woman who is pregnant, delivering her baby or in the first 42 days after giving birth experiences a problem or complication and must be rushed to the health center immediately

Maternal Mortality

Maternal mortality is the death of a woman from a cause related to pregnancy or childbirth

Medicine

Menstrual Cycle

A drug used for the prevention or treatment of a disease

The period of time beginning on the first day of a woman's period until the day before she begins her next period

Menstrual Hygiene Taking care of oneself in a clean, safe, and healthy way during menstruation

Menstruation

When blood leaves a woman's body through the vagina, because the egg that was released into her uterus was not fertilized; signifies that a woman or girl can become pregnant if she has sexual intercourse; occurs around once a month for most women, and is commonly called the "monthly period"; usually lasts between three and seven days

Mind-Altering

Substance

Miscarriage

ugs that affect brain function resulting in alterations in perception, mood, consciousness, cognition, and behavior

The spontaneous end of a pregnancy at a stage where the fetus is incapable of surviving independently, also known as a 'Spontaneous abortion'

Myth

Negative Conflict

Non-Verbal

Communication

Ovaries

Ovulation
A belief that is told by a group of people, which may be based on truth, but is untrue

A conflict which is dysfunctional

Facial expressions, eye contact, body position, touch and actions that give meaning to what is said

A pair of organs that contain a female's eggs or ova

The periodic release of a mature egg from the ovary, which usually happens around the middle of a woman's menstrua cycle 
Ovum

Passive

Peer Pressure

Penis

Placenta

Positive Conflict

Process

Puberty

Rape

\section{Recreational Drugs Drugs used for enjoyment}

Rights

Ripple Effect

Scrotum

Secondary Abstinence The choice to stop having sex after one is no longer a virgin

Self-Esteem

Sex

The mature female reproductive cell, which can produce an embryo after fertilization by sperm

Accepting or allowing what happens, or what others do, without active response or resistance

Influence on another person's decisions or the exertion of influence on someone to manipulate them into following certain behaviors or beliefs of people in their social group

The male sex organ. It provides passage for both urine and semen; places sperm in the woman's vagina during sexual intercourse

The organ that transfers nutrients from the mother to the fetus, which is dispelled after giving birth, also known as afterbirth

A conflict which is functional or constructive

A series of actions or steps taken to achieve something

The physical and emotional changes that people go through during adolescence; results in sexual maturity and capability for reproduction

A type of sexual assault usually involving sexual intercourse, which is initiated by one or more people without the other person's consent

A moral or legal entitlement to have or obtain something or to act in a certain way

The continuing and spreading results of an event or action

The pouch of skin containing the testicles

How people feel about themselves

Whether a person is male or female; also a term used for sexual intercourse
Sexual Activity

Sexual Desire

Sexual Exploitation

Sexual Intercourse

Sexual Rights

Sexually Transmitted Infections that are transmitted through sexual contact:

Infections (STIs)

Skilled Provider

Sperm

Spontaneous Abortion See Miscarriage

Statutory Rape

Stigma

Stimulants

Stress

Teamwork

Testes
Activities associated with sexual intercourse

A longing for sexual intimacy or expression, or feeling of sexual attraction

someone uses another person of the opposite sex to make him/herself feel good or to get something from the other person without concern about how that person feels

When a male inserts his penis into a female's vagina

The right of an individual to control their sexual activity and sexual health anal, vaginal or oral

A person qualified in the practice of medicine

Male reproductive cells, which fuse with eggs during fertilization

Sex with a person who the law defines as too young to legally consent, regardless of whether or not they consented (girls below 16 and boys below 14)

Severe disapproval of, or discrimination against, a person on the grounds of characteristics that distinguish them from other members of a society

Drugs which the level of nervous activity to make the body speed up

A state of mental or emotional strain or tension resulting from adverse or demanding circumstances

The ability to positively relate with others, to identify and complement the strengths of one another, and to contribute towards a common goal

These are two egg-shaped organs in front of and between a man's thighs; each testicle produces and stores sperm, which can fertilize a woman's egg during sexual intercourse 
Unintended

Pregnancy

Unsafe Abortion

Urethra

Uterus

Vagina

Value
A pregnancy that is unwanted or mistimed

Abortions performed under unsafe conditions (without a skilled provider and/or with minimal medical standards) posing a high risk of complications for the mother

The duct which conveys urine (in males and females) and sperm (in males) outside the body

Where a fertilized egg grows and develops when a woman becomes pregnant; also called the womb

Female sex organs with the functions of sexual intercourse and childbirth

A personal measure of worth, such as how important certain beliefs, principles or ideas are to someone
Vas Deferens

Verbal

Communication

Voluntary Counseling The process by which a person can learn whether or not and Testing (VCT)

he or she is infected with HIV, during which the person

always counseled before and after the test regardless of

the results; the decision to go for testing and to receive the results is voluntary

Vulva

External female genital organs

Well-Being

Window Period

A state of being comfortable, healthy, or happy

The period between HIV infection and when the body produces antibodies for the HIV 


\section{THE MENSTRUAL CYCLE*}

\section{What is the menstrual or ovulatory cycle?}

At puberty, girls begin to experience cycles of fertility. Unlike males, who are fertile continuously from puberty onward, females can become pregnant only during certain days of the cycle. The length of the cycle varies from person to person but is generally about one month. During each cycle, the female body goes through many changes. The most obvious part of the cycle is menstrual bleeding, also called menstruation or the "period." We often think of menstruation as the climax of the cycle, but menstruation is just one part of an amazing array of changes that take place during the cycle. These changes are the body's way of preparing for a potential pregnancy. They include producing mucus at the cervix, growing and releasing an egg, and changes in the lining of the uterus. These changes are controlled by hormones (natural chemicals produced by glands in the body and carried in the bloodstream). These hormonal changes affect many parts of the female body, and also how women feel and function. Knowing about these changes can give a girl or woman a sense of greater comfort and control regarding her own body. A woman can learn simple techniques for identifying when she is ovulating and when her menstrual period is due.

\section{What changes does the body go through during the cycle?}

\section{Before ovulation}

Menstrual Bleeding: Menstruation, or menstrual bleeding, signals the beginning of a new cycle. During menstruation, blood and tissue are shed by the uterus and flow out of the vagina. The first day of bleeding is designated as "day one" of the cycle. Bleeding usually lasts between four and six days.

Dryness: After menstrual bleeding ends, the vagina may feel dry because hormone levels are low and the cervix is producing little or no mucus.
Thickening of the Uterine Lining: After a few days, as her body releases more hormones, the woman (or girl) may notice a vaginal discharge of mucus. At first, this mucus is cloudy-white or yellowish and may feel sticky. At the same time, although she cannot detect it, the lining of her uterus begins to thicken and an egg (also called the ovum) "ripens."
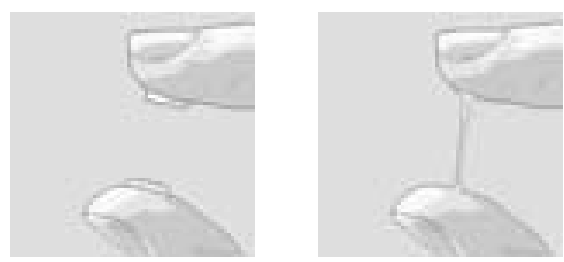

\section{Ovulation}

Clear Mucus/Ovulation: As the egg ripens, the mucus becomes clearer and slippery often similar to raw egg white. Often it can be stretched between the fingers. This clear mucus nourishes sperm and helps them to move toward the egg. At this time, a woman's sexual desire may also increase. The release of the egg from the ovary is called ovulation. The days just before and around the time of ovulation are the time when a girl or woman can become pregnant. These are sometimes called her "fertile days." The female body goes through other changes around this time as well. For example, some women experience an increase in sexual desire and in their sense of well-being for a few days. And some feel a twinge or slight discomfort on one side of their abdomen at about the time the egg pushes out of the ovary.

\section{After Ovulation}

Post Ovulation: After ovulation, the egg can live for one day. The mucus again becomes thicker and creamy or sticky. For the next 14 days (more or less), hormones keep the thickened lining of the uterus in place. The body temperature also rises slightly. 
Menstrual Bleeding: If no pregnancy has occurred at the end of the 14 days, the hormone levels fall. The lining of the uterus sheds, and the body temperature falls back down. This shedding is menstruation, and a new cycle begins. (If a pregnancy occurs, the body continues to produce hormones to keep the thickened lining of the uterus in place for nine months.)

\section{How long is the ovulation-menstrual cycle?}

During the first year or two after menarche (the first menstrual period), the length of time from one period to the next may vary. Several months may pass between periods. Even for adult women, the length of the cycle may vary from one woman to the next. It may also vary from cycle to cycle for any one woman. Things like travel, stress, depression, malnutrition, and illness can affect it. Most commonly, however, women begin a new cycle every 24-36 days. The part of the cycle from the beginning of menstrual bleeding until ovulation may vary a great deal. It can be as short as a couple of days or as long as several months or more. Most commonly, it lasts between one and three weeks. In contrast, the part of the cycle from ovulation to the next menstrual period does not vary; it is always close to 14 days. In other words, once ovulation occurs, a girl or woman knows that - unless she has become pregnant - her menstrual period is due in 14 days.

\section{Which are the fertile days of the cycle?}

The fertile period includes the day of ovulation and the five previous days. Sperm can survive in the female genital tract for as long as five or six days, and the egg (if it is not fertilized) survives for as long as 24 hours. Predicting the fertile days is difficult, however, because the first phase of the cycle (from menstruation to ovulation) is the part that may vary widely in duration. Some women learn how to observe the changes in their mucus (and in their body temperature) so that they can tell when they are likely to be ovulating. Some women also feel a slight pain when they ovulate. Many women and girls use such "fertility awareness" techniques to have a better sense of when their menstrual period is due. Knowing which days are the fertile ones can be useful for women who are trying to become pregnant and for those who want to avoid pregnancy. Using fertility awareness techniques correctly, however, requires thorough instruction, follow-up, and careful ongoing observation. (See the Training Aid: Types of Contraception Flipchart and "Reproductive Health - Session Preventing Unintended Pregnancy (Contraceptives) for more information about fertility awareness techniques.)

\section{For how long do women have menstrual or ovulatory cycles?}

As women enter mid-life, their hormone levels change. Eventually they stop releasing eggs and menstruation also ceases. This phase, called menopause, also signals the end of fertility. The age of menopause varies by woman and differs in different settings, but typically it begins in the mid-40s in developing countries and in the early 50 s in developed countries. 


\section{REPRODUCTION AND PREGNANCY*}

\section{How does pregnancy occur?}

Before a pregnancy can occur, an egg and a sperm must join. This event is called fertilization. Fertilization can occur only during the fertile phase of a woman's menstrual cycle. During the woman's fertile phase, one of her two ovaries releases an egg. This event is called ovulation. Within minutes, fingerlike projections (called fimbria) at the ends of the fallopian tube begin moving to surround the egg and draw it into the tube. Also during the fertile phase, the woman's cervix moves into a position that eases the sperm's entry from the vagina. The cervix secretes a large amount of clear cervical mucus. This mucus provides nourishment to enable sperm to survive for several days. The mucus also provides an environment that helps sperm swim upward toward the fallopian tube, to reach the egg. During sexual intercourse, the sperm are ejaculated near the cervix. They enter the cervix within seconds. If the woman is fertile, some sperm may reach the egg in the fallopian tube within five minutes, while other sperm can survive in the clear ("fertile-type") mucus in the cervix. Sperm continue to exit the cervix and are available to fertilize an egg for up to five days after ejaculation. Hence, a woman who ovulates several days after she has unprotected sex is likely to have sperm remaining in her cervix, and these sperm may still be able to reach the fallopian tube and fertilize the egg. Once ovulation occurs, however, fertilization must occur within 24 hours because the egg can survive for only that long. Fertilization takes place in the fallopian tube. Once a sperm has fused with the egg, it creates a barrier to other sperm. The fertilized egg continues down toward the uterus, propelled by tubal contractions and by the cilia (little hair like projections within the tube).

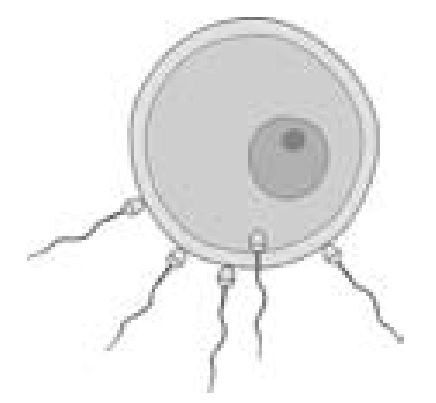

\section{What happens after fertilization?}

In the fallopian tube, the fertilized egg, or zygote, begins to divide and grow, as it moves toward the uterus. This journey takes about five days. After it has divided once, it is called an embryo. Within two days of reaching the uterus, the embryo attaches or implants itself in the lining of the uterus. Implantation is the beginning of pregnancy.

\section{How can a woman tell if she is pregnant?}

Early signs of pregnancy differ from woman to woman and between pregnancies. They include:

- a missed period

- tender or swollen breasts,

- sensitive nipples,

- frequent urination

- unusual fatigue,

- nausea and vomiting,

- cramps,

- feeling bloated,

- changes in appetite, and

- feeling unusually emotional.

Pregnancy can be confirmed with a pregnancy test, which may be performed by a health care provider or purchased from a pharmacy. Some women who have learned how to detect when their body is ovulating can predict fairly well which day menstruation is due; therefore, they may be aware of a pregnancy as soon as their period is late. 


\section{What happens during pregnancy?}

After implantation, the embryo (at this stage called a blastocyst) also gives rise to an amniotic sac and a placenta. The sac provides a protective fluid environment for the growing fetus. The placenta provides the fetus with nutrients and oxygen from the mother, and carries out waste products. An umbilical cord connects the placen ta to the fetus. Human pregnancy lasts 38 weeks after fertilization (about 40 weeks from the last menstrual period). Pregnancy is divided into three periods of about three months each, called trimesters. During the first trimester, until the twelfth week, all of the major organs and structures of the body are formed: the brain, heart, lungs, eyes, ears, arms and legs. After the eighth week, the embryo is called a fetus. Women commonly feel nauseous during the first trimester; the nausea is sometimes called "morning sickness." During the second trimester, from the 13th to approximately the 27th or 28th week, the fetus grows rapidly, and usually around the 19th week, the woman can feel fetal movement. Most women begin to put on weight during the second trimester. In the third trimester, the fetus continues to gain weight, and its movements become stronger and more frequent.

\section{What can women do to promote a healthy pregnancy?}

If a woman or girl chooses to keep her pregnancy, it is particularly important for her to avoid taking unnecessary medications, drugs, and alcohol. Taking the recommended vitamins and mineral supplements (especially iron and folic acid) is very important (including before pregnancy, if possible). She should also visit an antenatal-care provider, from whom she can get medical checkups and can learn about her pregnancy, potential danger signs, and childbirth. Women infected with HIV should take anti-HIV medication to prevent the fetus from becoming infected and to maintain their own health. Treatment with anti-HIV medicines during labor and delivery is critical for reducing the risk of transmitting HIV to the baby. 


\section{EMERGENCY CONTRACEPTION*}

\section{What is emergency contraception?}

Emergency contraception (EC) refers to methods of preventing pregnancy that can be used after unprotected intercourse has occurred. For example, it can be used after contraceptive failure (such as in cases where a condom breaks), when a method has been used incorrectly, after having sex without contraception, or after rape. EC can prevent pregnancy if taken within five days after unprotected sex, but works best when taken as early as possible within this time period. EC is not abortion.

\section{What methods are used for emergency contraception?}

Pills: Pills containing progestin (a hormone contained in many contraceptive pills) are the most common EC method. As of 2009, the recommendation is to take one pill containing $1.5 \mathrm{mg}$ of this hormone or two pills containing $.75 \mathrm{mg}$ each. The pill or pills may be taken in a single dose or in two doses, the first as soon as possible after unprotected sex and the second 12 hours later. In some places EC comes pre-packaged as two pills. The method is sometimes called the "morning after pill." Regular contraceptive pills taken for a short time at a much higher dosage than usual can also work, but the dosage depends on the type and brand of pill and must be determined by a knowledgeable health care provider

IUD: Another emergency contraceptive method is the copper-releasing intrauterine device (IUD), which can be inserted by a trained health care provider within 5-7 days after the woman has had unprotected sex. The IUD is not appropriate for women at risk of a sexually transmitted infection, however, and in some countries it has not been approved for emergency contraception.

\section{How do they work?}

EC pills work by preventing ovulation (see Appendix A: Additional Topical Information - The Menstrual Cycle), preventing an egg and sperm from joining, or preventing implantation, whereby a fertilized egg attaches to the uterus (see Appendix $A$ : Additional Topical Information - Reproduction and Pregnancy). EC does not cause an abortion, because it does not work if the woman is already pregnant. Copperreleasing IUDs are believed to work by interfering with implantation.

\section{How effective is emergency contraception?}

The effectiveness of emergency contraceptive pills depends on the type of pill that is used and how soon it is taken after having unprotected sex. The sooner the pills are taken after unprotected sex, the more effective they are. Estimates suggest that EC pills are about 90 percent effective in preventing pregnancy. Emergency IUD insertion is 99 percent effective.

\section{Does emergency contraception protect against sexually transmitted infections?}

EC provides no protection against sexually transmitted infections, including HIV. 


\section{ZAMBIA'S ABORTION ACT AND REGULATIONS*}

\section{Termination of Pregnancy Act, 13th October 1972}

\section{Section 1}

This Act may be cited as the Termination of Pregnancy Act.

\section{Section 2}

In this Act, unless the context otherwise requires:

- Hospital means any institution run as such by the Government or any other institution approved in writing for the purpose of this Act by the Permanent secretary, Ministry of Health;

- Other law relating to abortion means sections 151-153 of the Penal Code, and includes any written law or rule of law relating to the procurement of abortion; - Registered medical practitioner means a medical practitioner registered as such under the provisions of the Medical and Allied Professions Act.

\section{Section 3}

(1) Subject to the provisions of this section, a person shall not be guilty of an offence under the law relating to abortion when a pregnancy is terminated by a registered medical practitioner if he and two other registered medical practitioners, one of whom has specialized in the branch of medicine in which the patient is specifically required to be examined before a conclusion could be reached that the abortion should be recommended, are of the opinion, formed in good faith

(a) That the continuation of the pregnancy would involve

i. Risk to the life of the pregnant woman; or

ii. Risk of injury to the physical or mental health of the pregnant woman; or

iii. Risk of injury to the physical or mental health of any existing children of the pregnant woman; greater than if the pregnancy were terminated; or

(b) That there is a substantial risk that if the child were born it would suffer from such physical or mental abnormalities as to be seriously handicapped.

(2) In determining whether the continuation of a pregnancy would involve such risk as is mentioned in paragraph (a) of subsection (1), account may be taken of the pregnant woman's actual or reasonably foreseeable environment or of her age.
(3) Except as provided by subsection (4), any treatment for the termination of pregnancy must be carried out in a hospital.

(4) Subsection (3) and so much of subsection (1) as relates to the opinion of two registered medical practitioners, shall not apply to the termination of a pregnancy by a registered medical practitioner in a case where he is of the opinion, formed in good faith, that the termination of pregnancy is immediately necessary to save the life or to prevent grave permanent injury to the physical or mental health of the pregnant woman.

\section{Section 4}

(1) Subject to subsection (2), no person shall be under any duty, whether by contract or by any statutory or other legal requirement, to participate in any treatment authorized by this Act to which he has a conscientious objection:

Provided that in any legal proceedings the burden of proof of conscientious objection shall rest on the person claiming to rely on it

(2) Nothing in subsection (1) shall affect any duty to participate in any treatment, which is necessary to save the life or to prevent grave permanent injury to the physical or mental health of a pregnant woman.

(3) In any proceedings before a court, a statement on oath by any person to the effect that he has a conscientious objection to participating in any treatment authorized by this Act shall be sufficient evidence for the purpose of discharging the burden of proof imposed upon him by subsection (1).

\section{$\underline{\text { Section } 5}$}

(1) The Minister may, by statutory instrument, make regulations for the better carrying out of the provisions of this Act and, without prejudice to the generality of the foregoing; such regulation may make provision for:

(a) Anything which is to be or which may be prescribed under this Act;

(b) Requiring any such opinion as is referred to in section three to be certified by the registered medical practitioner concerned in such form and at such time as may be prescribed by the regulations; 
(c) The preservation and disposal of certificates made pursuant to the regulations;

(d) Requiring any registered medical practitioner who terminates a pregnancy to give notice of the termination of pregnancy and such other information relating to the termination of pregnancy as may be prescribed; (e) Prohibiting the disclosure, except to such persons or for such purposes as may be prescribed, of notices given or information furnished pursuant to the regulations. ( $f$ ) Any person who willfully contravenes or willfully fails to comply with the requirement of regulations made under subsection (1) shall be guilty of an offence and on conviction shall be liable to a fine not exceeding two hundred kwacha.

\section{Section 6}

For the purpose of the law relating to abortion, anything done with intent to procure the miscarriage of a woman is unlawfully done unless it is done in accordance with the provisions of the Act.

\section{Termination of Pregnancy Regulations (Statutory Instrument No. 219 of 1972)}

\section{Section 1}

These Regulations may be cited as the Termination of Pregnancy Regulations.

\section{Section 2}

(1) Any opinion to which section 3 of the Act refers shall be certified in the appropriate form set out in the First Schedule.

(2) Any certificate of an opinion referred to in subsection (1) of section three of the Act shall be given before the commencement of the treatment for the termination of pregnancy to which it relates.

(3) Any certificate of an opinion referred to in subsection (4) of section three shal be given before the commencement of the treatment for the termination of pregnancy to which it relates or, if that is not reasonably practicable, not later than twenty-four hours after such termination.
(4) Any such certificate as is referred to in sub-regulations (2) and (3) shall be preserved by the practitioner who terminated the pregnancy to which it relates for a period of three years beginning with the date of such termination and may then be destroyed.

\section{Section 3}

(1) Any registered medical practitioner who terminates a pregnancy anywhere in Zambia shall, within seven days of the termination, give to the Permanent Secretary, Ministry of Health, notice thereof and the other information relating to the termination in the form set out in the Second Schedule.

(2) Any such notice and information as is referred to in sub-regulation (1) shall be sent in a sealed envelope marked confidential to the Permanent Secretary, Ministry of Health, P.O. Box 205, Lusaka.

\section{Section 4}

A notice given or any information furnished to the Permanent Secretary, Ministry of Health, in pursuance of these Regulations shall not be disclosed except that disclosures may be made;

(a) for the purposes of carrying out his duties, to an officer of the Ministry of Health authorized by the Permanent Secretary, Ministry of Health; or

(b) for the purposes of carrying out his duties in relation to offences against the Act or the law relating to abortion, to the Director of Public Prosecutions or member of his staff authorized by him; or

(c) for the purposes of investigating whether an offence has been committed against the Act or the law relating to abortion, to a police officer not below the rank of Assistant Superintendent or a person authorized by him; or

(d) for the purposes of criminal proceedings which have begun;

(e) for the purposes of bona fide scientific research; or

(f) to the registered medical practitioner who terminated the pregnancy; or

(g) to a registered medical practitioner, with the consent in writing of the woman whose pregnancy was terminated. 


\section{CHILDBIRTH AND BREASTFEEDING*}

\section{What happens during childbirth?}

When a woman is about to give birth, her body enters a stage called "labor." Labor often begins with one or more of the following: clear or pink-colored mucus flowing from the vagina; amniotic fluid flowing from the vagina; and contractions of the uterus that are perceived as a hardening of the belly. The intensity of the contractions increases during labor. The cervix opens and the uterine contractions help push the baby through the opened cervix and vagina. Labor generally lasts between 5 and 18 hours, but varies among women. It usually becomes quite painful (although the perception of pain varies among women and may depend on the preparation the woman made during antenatal care), exhausting, and can be anxiety provoking. However, many women experience labor and childbirth as a wonderful and incredible experience.

\section{What is a cesarean section?}

Cesarean section, also known as C-section, is a surgical method of childbirth. During this procedure, an incision is made through the woman's abdomen and uterus and the baby is removed. It is usually performed when a vaginal delivery would put the mother's or baby's life or health at risk. Sometimes it is performed for the benefit of the doctor rather than for that of the woman or baby, for example to allow the doctor to schedule a convenient time for delivery. Unnecessary cesarean sections may increase risks to the health of the mother and the baby, including the risk of death.

\section{What help do women need when giving birth?}

Wherever a woman gives birth - whether at home, in a health post, or in a hospital - she needs assistance from a trained person such as a midwife or doctor. Proper conditions and access to emergency care are also necessary in case of complications. Conditions and practices related to childbirth vary around the world. In some countries, all women have access to skilled assistance, but in other places most women give birth at home without the help of a trained attendant and lacking prop- er conditions and emergency backup care. In some places, women in labor also rely on support from other women. In other places, the woman's husband or partner is present and can give her support. Some women give birth alone, without any help.

\section{Why is breastfeeding important?}

Breast milk is the only perfect food for a baby, especially for a newborn. The first yellow-colored milk, called colostrum, is rich in nutrients and antibodies that protect the baby from diseases and infections. Colostrum also helps to clean the baby's gut. Breastfeeding during the first hour after birth helps the uterus to stop bleeding and the milk to start flowing. In addition, breast milk is always clean, ready, and has the right temperature. It helps the mother and baby to feel close, and it costs nothing. (The World Health Organization recommends breastfeeding without other food for the first six months of a baby's life. If possible, extend breastfeeding beyond six months in combination with safe and nutritious foods.)

\section{What can a pregnant woman who is HIV-positive do to reduce the chance} of passing the virus to her baby?

A pregnant HIV-positive woman can transmit the virus to her baby during pregnancy, labor, and delivery, and through breastfeeding. If she takes no preventive drugs and breastfeeds, she runs about a 20 to 45 percent chance of transmitting her infection to her baby. Today, however, effective drugs can prevent the transmission of HIV from a mother to her baby during and after pregnancy. An HIV-positive woman who is or wants to become pregnant should seek the advice of a physician about which drugs to take and when. HIV-positive mothers should also speak with their health care providers about appropriate feeding options for their newborn that can reduce the chance of transmission through breast milk. In areas where a mother may not have regular access to safe water and infant formula, it is better to breastfeed exclusively for the first six months and then to wean abruptly. Combining breastfeeding with commercial formula or starter foods carries the greatest risk of passing HIV infection from mother to child. By taking preventive medicines and following the appropriate feeding guidelines, an HIV-positive mother can reduce the chance of passing HIV to her baby. 


\section{TIPS FOR TEACHING ABOUT HIV AND AIDS*}

The topic of HIV and AIDS can seem overwhelming. It seems like every day the newspaper reports a new fact about the disease. This curriculum provides basic background information about HIV and AIDS to help you teach about HIV prevention and transmission. If your discomfort with the subject of HIV and AIDS makes it difficult to help young people, find another person in your school or community who can conduct the HIV and AIDS education activities in this session. Remember that even if we try to tell all the youth in our community about the risk of HIV and AIDS or to abstain, many will still go ahead and have sex. It is more important to inform sexually active adolescents about how to prevent HIV and how to protect themselves than to avoid talking about the topic because it makes people uncomfortable. When teaching young people about HIV and AIDS, there will be many opportunities for reassessing your personal beliefs and values. Explore your own feelings and seek the support of another teacher if necessary.

It is important to acknowledge that there will be a wide range of sexual experiences in any group of young people. For example, some will be dating; others may not yet be interested in romantic relationships. Be realistic about the numbers of young people in your group who are having sexual intercourse. In a group of 16 year olds, half are likely to have not yet had sexual intercourse and half are likely to be engaging in sexual intercourse. You can help those who are not sexually active delay sexual activity and help those who are already sexually active practice safe sex.

You can help young people understand the risk of becoming infected and how to practice safer sex. Any type of sex between two uninfected partners is safe. The difficulty is that most people, teenagers and adults, do not know if they have been exposed to the virus. 'Knowing someone well' or 'asking your partner about AIDS' is an unrealistic way to assess potential risk, especially for young people. They need to understand that it is impossible to tell if someone is HIV-infected just by looking at her or him. Avoid emphasizing monogamous relationships as safe, since young people think each time they have a relationship with a person, they are being monogamous. Emphasize that abstaining from sexual intercourse is the only way to completely avoid the risk of infection.

\section{Dealing with Sensitive Questions}

Young people today receive a lot of information from many different sources. An audience can misunderstand even the best messages. It is important that we as adults remain open to the questions of young people so that we can help them understand accurately. However, it is not always easy to answer some questions, especially on topics that are socially restricted. Teachers or parents who have the experience of receiving sensitive questions, such as those about the condoms, may have some suggestions.

You may want to take some time to think through the answers to certain questions. However, do not wait more than a day to answer as young people may look for answers elsewhere. Sometimes it is better to answer the question with a colleague parent or health specialist. Even if a question is asked in front of the group, it might be best to answer it in a smaller group depending on what level of experience you believe the young people have.

Always, before you answer the question, find out what the young people already know or think is the answer. Then you can build on what they have told you and explain what they do not understand.

In your answer use the words the young people have used either in their question or when they have explained to you what they know. Be honest and ready to explain. 


\section{BACKGROUND INFORMATION ON HIV AND AIDS*}

HIV stands for Human Immunodeficiency Virus. HIV is a virus that is too small to see that is passed between people through blood and other body fluids. HIV weakens the immune system making it easier for people to become sick. When a person becomes sick with many illnesses that do not go away, then he or she is said to have AIDS. AIDS stands for Acquired Immunodeficiency Syndrome. Acquired refers to the fact that you get the disease from somewhere else; it does not develop on its own. Immunodeficiency means the immune system is weak and unable to fight off infections and illnesses. Syndrome means a specific collection of symptoms and diseases, such as weight loss combined with skin cancer and pneumonia. AIDS is a term used to indicate the most serious stage of a person's infection with HIV. It means that they have a particular collection of symptoms and diseases defined medically as AIDS.

After years of living normally with HIV, a person will start developing AIDS, as the immune system begins to weaken. At this state, the person will be vulnerable to various opportunistic infections, which can attack any part of the body. Opportunistic infections are infections that attack the body when the immune system is weak. These infections could range from simple medical conditions like fungal infections and colds to more serious diseases like tuberculosis or cancer. Though the person is HIV positive, these conditions can be treated and often cured. There is no cure for HIV or AIDS.

\section{From HIV to AIDS}

As with other infections, when HIV enters the body, the immune system produces a response to try to fight off the infection, by producing antibodies. However, these are insufficient to battle against the growth and multiplication of the virus, which slowly destroys key cells in the immune system. HIV slowly weakens the immune system and eventually the body cannot fight off even mild infections and people become very sick from a range of different illnesses, including the common cold, fungal infections, cancer, or tuberculosis.

Most people who have HIV do not become sick right away. In some cases, it can take as many as 10 years or more for a person to develop AIDS. People can stay healthy longer by eating well and getting prompt treatment of illnesses and infections.

The most obvious signs that someone has AIDS are diseases such as tuberculosis or pneumonia. However, the following can also be signs that someone has AIDS:

- Sudden, unexplained weight loss

- Fever for more than one month

- Diarrhea for more than one month

- Genital or anal ulcers for more than one month

- Cough for more than one month

- Nerve complaints

- Enlarged lymph nodes

- Skin infections that are severe or recurring

Although the above are all symptoms of AIDS, the only way to tell if a person is infected with HIV is by testing. 


\section{FREQUENTLY ASKED QUESTIONS ABOUT HIV AND AIDS*}

\section{Where did AIDS come from?}

No one really knows for sure where AIDS came from or how long it has been around. What is important to understand is that it affects people from nearly every corner of the world, regardless of their socio-economic status, educational background or religious affiliation. It is having a huge impact on all societies and is draining the resources of families, communities and countries. AIDS is an issue that demands the attention of each and every one of us.

\section{What is the immune system?}

All human beings are born with an immune system to protect the body from disease. Some people have stronger immune systems than others. During a lifetime, a person's immune system may be stronger or weaker at different times. The immune system is sometimes referred to as a defense system. In the way that a country's defense system protects it from enemies, the immune system protects the body from diseases. The immune system works like an army by first detecting the enemy, then by sounding the alarm, and lastly by attacking the enemy. A healthy body has its own way to attack invading germs and viruses that make the body sick. The HIV virus works to weaken the body's ability to attack other germs and viruses. Eventually the body becomes unable to fight off other diseases, which overwhelm the body and cause the HIV positive person to finally die.

\section{Can you pass the virus through kissing?}

There are no reported cases of people becoming infected with HIV just from deep kissing. HIV is rarely found in saliva. It might be risky, however, to kiss someone if there is a chance for blood contact if the person with HIV has an open cut or sore in the mouth or on the gums. It would be even more risky if both people had bleeding cuts or sores in their mouths. People should use common sense and should wait until any sores or cuts have healed before kissing.

\section{Can a person get HIV infection from a mosquito?}

When mosquitoes bite someone they do not inject the blood of the previously bitten person into the next person. They use their saliva as a lubricant. Diseases like malaria are spread through mosquito saliva. HIV gets digested in the mosquito's stomach before it can find its way to the saliva.

\section{What is the 'window period'?}

Most common HIV tests do not detect HIV but the HIV antibodies produced by the human immune system. It is assumed that if a person has the HIV antibody, then the virus itself must be present. It can take as little as 6 weeks and as many as 18 weeks before the body has enough HIV antibodies to be detected by an HIV test. Until this time, tests will give a false negative result. The period between infection by HIV and the presence of enough HIV antibodies to be detected by an HIV test is known as the 'Window Period'. Between 56 and $92 \%$ of HIV infections are believed to be transmitted during this period.

\section{Does a person with HIV have AIDS?}

One big difference between HIV and AIDS is that one is a virus and the other is a condition or syndrome. A person with HIV may or may not have AIDS. However a person with AIDS will always have HIV in the blood. An HIV positive person who does not yet have AIDS may feel and look perfectly healthy, have an active and effective immune system, can work and support his or her family. A person with AIDS may have the symptoms of various diseases which he or she has acquired such as TB, meningitis and cancer. A person with AIDS may be weak and thin and may feel sick. The immune system of a person with AIDS is rapidly growing less and less effective at protecting his or her body. 


\section{What does HIV-positive mean?}

When the body's defense system (immune system) comes into contact with a disease, it produces germ fighters, called antibodies, which fight off and destroy various viruses and germs that invade the body. An antibody is found in the blood and it tells us that the person has been infected with a particular germ or virus.

HIV tests look for HIV antibodies. If your body is making antibodies to fight HIV, then you are considered HIV positive. However, there is a 'window period' between when a person is infected with HIV and when a blood test will show that a person is HIV-positive because it takes the body a little while to start producing antibodies to fight the virus. It is possible for someone to test HIV-negative during this window period but be infected with HIV and be able to transmit the virus to someone else. Scientists are unsure about the length of the window period: it is generally between six and eighteen weeks but in rare cases may be longer.

People who are taking an HIV test who have had unprotected sex during the past three months are advised to have another test in three months if they have a negative result. While waiting through this time, known as the window period, they must avoid being exposed to HIV.

\section{When are people with HIV infectious to others?}

People with HIV can infect others as soon as they are infected with the virus. People with HIV may not know they are infected and may look, act and feel healthy for a long time, possibly longer than 10 years. It is impossible to tell from looking at someone if he or she is infected. Knowing a person well does not tell you anything about his or her HIV status.

\section{If a person tests negative for HIV does it mean they cannot catch it?}

No. It only means they have not got it now or possibly that they have the infection and it is still in the window period. They can still catch it when they have unprotected sex.

\section{What is 'safer sex'?}

People who have decided to be sexually active can make choices to practice 'safer sex'. Safer sex describes a range of ways that sexually active people can protect themselves from infection with all sexually transmitted infections, including HIV infection. Practicing safer sex also provides protection against pregnancy. There are lots of ways for loving and sexual feelings to be shared that are not risky. Some of them include:

- Hugging

- Holding hands

- Kissing

- Massaging

- Rubbing against each other with clothes on

- Sharing fantasies

- Touching your partner's genitals, as long as males do not ejaculate near any opening or broken skin

Using a latex condom correctly for every act of sexual intercourse is called protected sex because when used correctly for each sexual act, condoms can significantly reduce the risk of HIV infection. However, condoms are not 100 percent effective in preventing HIV infection. Unprotected sexual intercourse (without a condom) exposes people to the bodily fluids in which HIV lives.

\section{Is there a cure for HIV?}

There is still no cure for HIV. Many indigenous healers and unscrupulous people in many countries have claimed over the years to be able to cure AIDS. All their claims have proved false. We often hear of other people who have developed a cure for AIDS. People should be very cautious about claims that a "cure" for AIDS has been discovered unless they have been medically proven. 


\section{HIV AND AIDS AND HUMAN RIGHTS*}

\section{Excerpts from HIV and AIDS and Human Rights International Guidelines, United Nations, 1998}

\section{International human rights obligations and HIV and AIDS}

Introduction: HIV and AIDS, human rights and public health

72. Several years of experience in addressing the HIV and AIDS epidemic have confirmed that the promotion and protection of human rights constitute an essential component in preventing transmission of HIV and reducing the impact of HIV and AIDS. The protection and promotion of human rights are necessary both to the protection of the inherent dignity of persons affected by HIV and AIDS and to the achievement of the public health goals of reducing vulnerability to HIV infection, lessening the adverse impact of HIV and AIDS on those affected and empowering individuals and communities to respond to HIV and AIDS

73. In general, human rights and public health share the common objective to promote and to protect the rights and well-being of all individuals. From the human rights perspective, promoting and protecting the rights and dignity of everyone, with special emphasis on those who are discriminated against, can best accomplish this or whose rights are otherwise interfered with. Similarly, public health objectives can best be accomplished by promoting health for all, with special emphasis on those who are vulnerable to threats to their physical, mental or social well-being. Thus, health and human rights complement and mutually reinforce each other in any context. They also complement and mutually reinforce each other in the context of HIV and AIDS.

74. One aspect of the interdependence of human rights and public health is demonstrated by studies showing that HIV prevention and care programs with coercive or punitive features result in reduced participation and increased alienation of those at risk of infection. In particular, people will not seek HIV-related counseling, testing, treatment and support if this would mean facing discrimination, lack of confidentiality and other negative consequences. Therefore, it is evident that coercive public health measures drive away the people most in need of such services and fail to achieve their public health goals of prevention through behavioral change, care and health support.

75. Another aspect of the linkage between the protection of human rights and effective HIV and AIDS programs is apparent in the fact that the incidence or spread of HIV and AIDS is disproportionately high among some populations. Depending on the nature of the epidemic and the legal, social and economic conditions in each country, groups that may be disproportionately affected include women, children, those living in poverty, minorities, indigenous people, migrants, refugees and internally displaced persons, people with disabilities, prisoners, sex workers, men having sex with men and injecting drug users-that is to say groups who already suffer from a lack of human rights protection and from discrimination and/or are marginalized by their legal status. Lack of human rights protection disempowers these groups to avoid infection and to cope with HIV and AIDS, if affected by it. (For the purposes of these Guidelines, these groups will be referred to as "vulnerable" groups although it is recognized that the degree and source of vulnerability of these groups vary widely within countries and across regions.)

76. Furthermore, there is growing international consensus that a broadly based, inclusive response, involving people living with HIV and AIDS in all its aspects, is a main feature of successful HIV and AIDS programs. Another essential component of a comprehensive response is the facilitation and creation of a supportive legal and ethical environment, which is protective of human rights. This requires measures to ensure that Governments, communities and individuals respect human rights and human dignity and act in a spirit of tolerance, compassion and solidarity. 
77. One essential lesson learned from the HIV and AIDS epidemic is that universally recognized human rights standards should guide policy makers in formulating the direction and content of HIV-related policy and form an integral part of all aspects of national and local responses to HIV and AIDS.

\section{A. Human rights standards and the nature of State obligations}

78. The Vienna Declaration and Program of Action, adopted at the World Conference on Human Rights in June 1993, affirmed that all human rights are universal, indivisible, interdependent and interrelated. While the significance of national and regional particularities and various historical, cultural and religious backgrounds must be borne in mind, States have the duty, regardless of their political, economic and cultural systems, to promote and protect universal human rights standards and fundamental freedoms.

79. A human rights approach to HIV and AIDS is, therefore, based on these State obligations with regard to human rights protection. HIV and AIDS demonstrates the indivisibility of human rights since the realization of economic, social and cultural rights, as well as civil and political rights, is essential to an effective response. Furthermore, a rights-based approach to HIV and AIDS is grounded in concepts of human dignity and equality, which can be found in all cultures and traditions.
80. Among the human rights principles relevant to HIV and AIDS are, inter alia: - The right to non-discrimination, equal protection and equality before the law;

- The right to life:

- The right to the highest attainable standard of physical and mental health;

- The right to liberty and security of person

- The right to freedom of movement;

- The right to seek and enjoy asylum;

- The right to privacy;

- The right to freedom of opinion and expression and the right to freely receive and impart information

- The right to freedom of association;

- The right to work;

- The right to marry and found a family;

- The right to equal access to education

- The right to an adequate standard of living:

- The right to social security, assistance and welfare;

- The right to share in scientific advancement and its benefits;

- The right to participate in public and cultural life;

- The right to be free from torture and cruel, inhuman or degrading treatment or punishment.

- Particular attention should be paid to human rights of children and women. 


\section{TRUST-BUILDING ACTIVITIES}

\section{ACTIVITY 1: BALL TOSS NAME GAME}

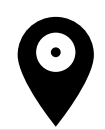

OBJECTIVES

Participants learn

each other's name

with this icebreaker,

while learning a

simple metaphor for

communication skills.

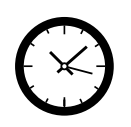

TIME

\section{MINUTES}

Have the balls ready for use at any time during the exercise. Make sure that the circles are positioned with a safety zone of one or two meters of space behind each group in case the participants move backwards to try to catch a ball. Have small groups of participants (about 8 to 12 people in a group) stand in a circle.

\section{Explain:}

In this game, we will try to learn each other's names in the small groups. First, everyone should get in a circle. Then go around the circle, and say your names. Remember to call out your names slowly and clearly so that the others have a chance to remember them!

Repeat this process once or twice. Then get one ball and explain:

5 At the beginning, the person holding the ball calls out the name of someone in the group and then throws the ball to her (demonstrate how this is done). The person who receives the ball then makes eye contact with another group member, calls out that person's name, and tosses the ball to them. If you forget someone's name and want to be reminded of it, you can ask her to repeat it to you. If you like, you can even throw the ball back to the person who threw it to you.

Repeat this process and after some time, when the participants start to remember several names, add in a second ball and instruct the group to continue playing with the two balls. After a minute or so, introduce a third ball to the game. The group should then aim at throwing and catching each ball, all the while calling out the receiver's name, ten or 15 times without dropping the balls; if a ball is dropped, they must start counting again. All three balls must be used in the exercise.

When the ball throwing has been done,

\section{Ask:}

5 How did you feel while playing the game?

\section{Explain:}

$\int$ Throwing the ball from one person to another can be considered a metaphor for how we communicate as peer educators, bouncing ideas off of one another.

Ask:

What actions were necessary to ensure that the game was successfully completed?

[e.g., making eye contact, calling someone by name, making sure the person was ready to receive the ball (or message), throwing it directly to the person, not throwing it when another ball was coming in, etc.]

Close by pointing out how one of the most fundamental skills in peer education is good communication. Suggest that the peer educators remember this game as a guide for asking themselves whether they are using the best possible communication skills in their teaching. 


\section{ACTIVITY 2: PASS THE MASK}

\section{P}

\section{OBJECTIVES}

Participants break the ice,

the group's energy is raised

and steps are made towards

team building. Participants

relax with each other by

being able to appear silly

with each other.

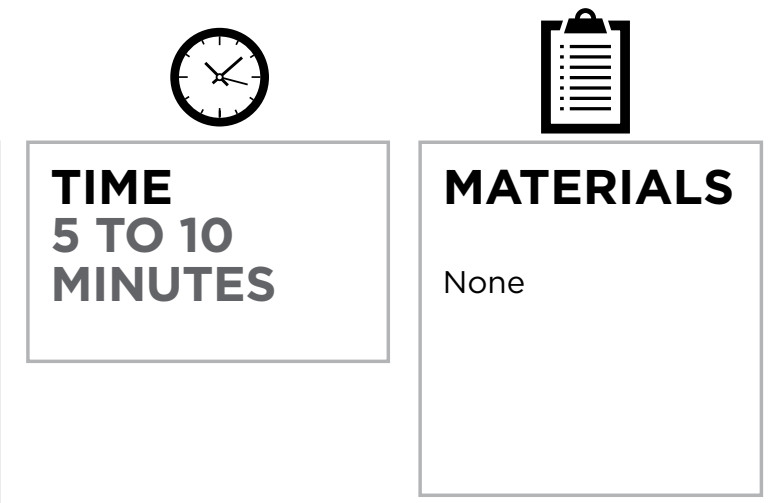

\section{Instruct:}

Everyone should stand in a circle, facing inwards. Each person is going to receive, and then make a facial 'mask,' which he or she will pass on to the next person in the group, who will make a new one to pass on, etc.

\section{Explain:}

I am going to make a face or a 'mask' and make eye contact with the person on my left. She or he must try to copy or make the exact same mask, with her face, as if she were looking in a mirror (demonstrate). Then, she will turn to the left and change the first mask into a new one to pass on to the next person. We will 'pass the mask' around the circle. Let's try it now, and remember to make eye contact and give the person enough time to make a really good copy of your mask with her face. Do not rush through it too quickly; give everyone time to copy your mask exactly!

\section{To close, ask:}

5 How did you feel while playing the game? 


\section{ACTIVITY 3: WILLOW IN THE WIND}

P

\section{OBJECTIVES}

Participants learn

how to build trust.

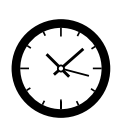

TIME

30 MINUTES
MATERIALS participants have enough room to move around comfortably and to make up circles of eight people. An area with a soft (carpeted) floor is preferable, but not essential.

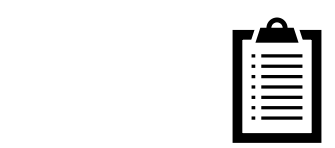

- An area in which

Arrange the participants in the area available, which should have enough room so that three circles, of approximately eight people in each, can fit in easily. There should be a little extra room around the outside of each circle. Banish chairs elsewhere or to the edges of the room.

\section{Explain:}

This activity is aimed at building trust and therefore requires careful attention to instructions. It is very important that every individual in the group carries out the instructions carefully; if not, someone could get hurt. Every participant will have a chance to be in the center that is to be the 'willow', but only if they want. The willow will be blown around, but will also be supported by the wind.

\section{Instruct:}

Everyone should stand in a circle, shoulder to shoulder, and to look towards the middle of the circle where one participant is standing. The person in the center is the 'willow'. Everyone standing in the circle should hold their hands up, with palms facing the person, just below chest height of the person in the middle. Their legs should be apart, with one slightly in front of the other, and their knees bent a little, so that they will not be thrown off balance if someone leans heavily on them (demonstrate how this is done).

As participants engage in the activity, carefully check and monitor the position of participants in the circle as much as possible.

\section{Explain:}

$\bigcirc$ The person in the center must remain standing as stiff as a board the whole time, with their arms crossed at chest level and hands under the armpits.

When she is ready to begin, she should make a series of statements about a particular topic and then say, "Ready to fall." The circle should reply, "Ready to catch." The person then says, "I'm falling," and the circle responds, "Fall away."

As the 'willow' falls out towards the circle, make sure she remains stiff and doesn't bend at the waist. The participants support the 'willow' and slowly move her around, back and forth. Invite people in the circle to make very soft blowing sounds, passing air between their lips to make it sound like a gentle wind (demonstrate).

After the 'willow' has been moved around in the 'wind' for a couple of minutes, ask the group to help the person stand upright, placing their hands on her shoulders to indicate it is time to stop.

Ask:

SHow did you feel playing the game?

(NOTE TO FACILITATOR: Some people may be afraid to play this game. They should never be forced or pressured to do so. The right-to-pass rule should always be respected.) 


\section{ACTIVITY 4: MOVING SCULPTURES}

\section{9}

\section{OBJECTIVES}

Participants are energized

encouraged to be

spontaneous and 'get

outside themselves' while

performing. Participants also

work towards building the

team and building trust.

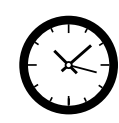

TIME

20 TO 45

MINUTES

(often repeatable

with variations)

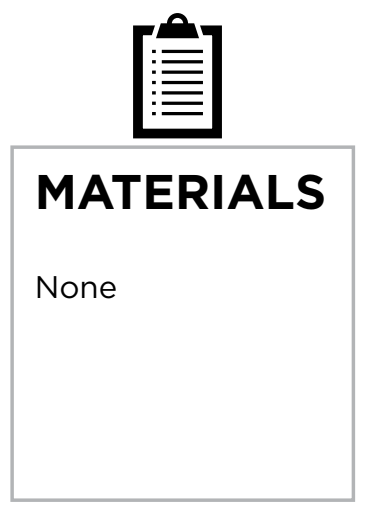

(NOTE TO FACILITATOR: Make sure that everyone is comfortable with the physical contact before beginning the game.)

Designate an open space at the front of the room as the 'stage' area.

\section{Explain:}

In this exercise we will make some human team sculptures and poems together. It's a team-building and group creativity exercise.

Ask for a group of about five to eight volunteers to come up and stand on either side of the stage (indicate where the stage area is).

\section{Instruct:}

$\int$ The first volunteers should come up and strike a pose of their choice (demonstrate examples). Once the first volunteer is in their pose, the rest of the volunteers should come up and strike their pose. Everyone else must touch at least one other 'poser'.
Continue instructing participants to come up voluntarily, strike a pose and freeze in that position.

\section{Explain:}

When I say the word 'change' (let the word last a few seconds: chaaaaange), you should change to a new pose. Remember, you should still be touching at least one other participant, even during the time you change poses. As soon as I finish saying chaaaaange, you should freeze in your new positions.

Watch the group carefully and advise them whenever you see that someone is not in contact with at least one other person in the group. You can also play with the group by changing the length of the word 'change', so that sometimes they have a long time to find their pose, while at other times they must rearrange themselves very quickly (in two to three seconds). This makes the game more challenging and entertaining. Allow more teams to come up after the first group has made a few poses.

To clase, ask:

5 How did you feel while playing this game? 


\section{ACTIVITY 5: THE HUMAN KNOT}

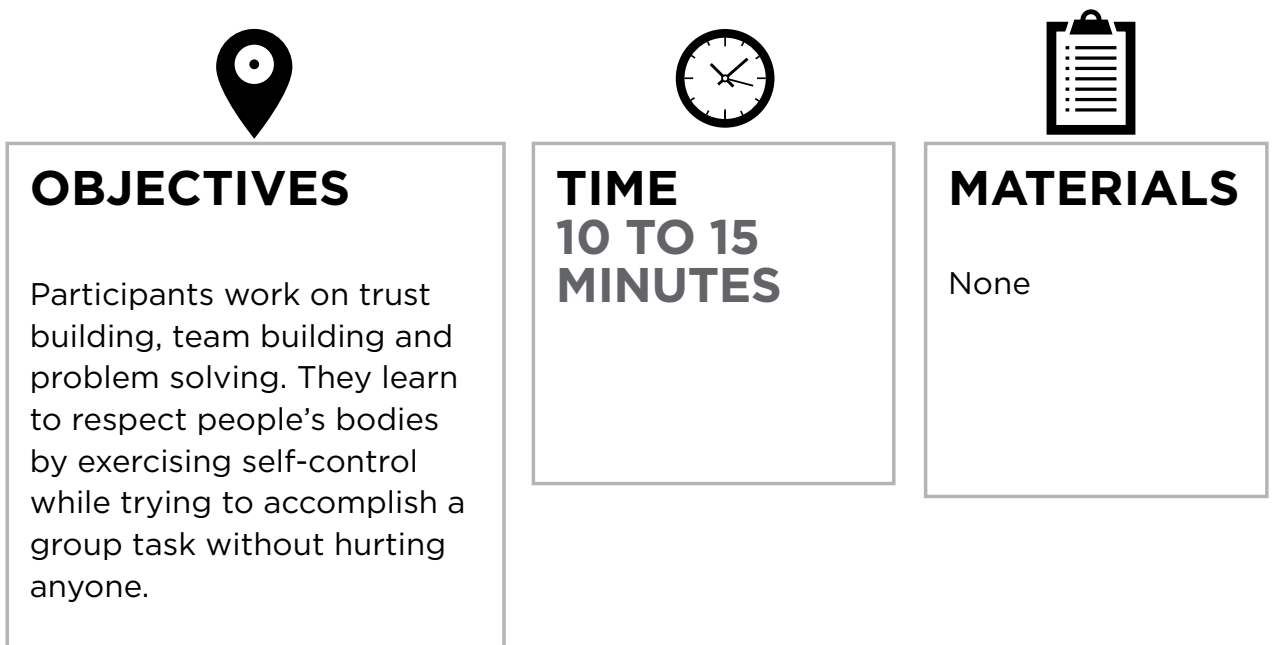

If the group gets very good at this, variations can be made such as, no talking, or only whispering, etc.

\section{To clase, ask:}

5 How did you feel while playing this game?

(NOTE TO FACILITATOR: Participants taking part in this game should be warned before beginning that they need to be very careful not to hurt anyone by twisting their wrist, stepping on them, etc.)

Clear a space in which to form one or more circles of about eight to ten people.

Explain:

For this game it is very important to follow instructions and listen to each other carefully, so that no one gets their wrist twisted or hurt in any way. Everyone should stand in a circle, reach into the middle of the circle with both hands to get hold of the hands of two other people. Try to grab the right hand of one person and the left hand of another person. Then, without letting go, your job is to untangle the 'rope' and back into a circle (demonstrate this with a few volunteer participants). Do this activity slowly and carefully. Make sure you never let go of the hands you are holding! 


\section{ACTIVITY 6: AHA, AND I WAS THERE!}

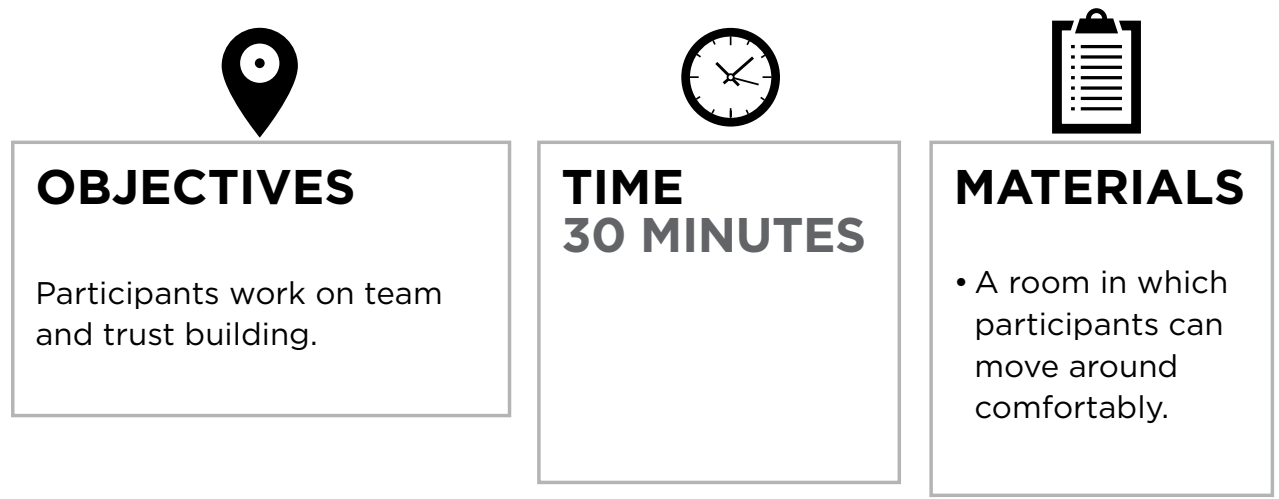

Prepare the room so that participants have enough space to run around a little. Chairs should be put out of the way.

\section{Instruct:}

One of you will begin narrating a story and acting out a role in the story. Then rest of you will respond to the narrator by engaging in the same actions, as if you also were the narrator's character in the story. For example, if I, as the first narrator, were to begin by saying "One day I was walking down the street..." while I walk, you all walk as well. I might then continue, "I saw a giant tree and began to climb it," all of you begin climbing the tree as well. At any time, anyone in the group can shout, "Aha, and I was there!" At this moment everyone in the group responds together, calling out, "And what did you see my friend?" The person who interrupted takes over the narration and the exercise continues like before.

\section{Explain:}

It is important that everyone tries to support each other as much as pos sible. For example, if the narrator is obviously stuck and can't think of anything else to say, someone can suggest what they would like to happen next if they were the narrator or someone else can jump in. In a team, everyone should be ready to jump in and 'save' someone who appears stuck or uncomfortable, just as others would like someone to help them if they were in an awkward situation. Even if there are other characters described in the story, no matter what the other characters might say, the group's job is only to say or do whatever the narrator's character says or does in the story.

If, as the facilitator, you realize that people are describing less active behaviors, such as thinking, waiting, watching, etc., you can point out that it is more fun if the choices involve a lot of action. You can bring the game to an end when most participants have had an opportunity to be the narrator.

Lead a discussion on the following questions:

- How did you feel while playing the game?

- Does anyone remember feeling 'saved' by the person who jumped in to take over the narration or if they helped a narrator who appeared stuck?

\section{Clase by painting out that:}

1 Working well as a team requires paying careful attention to how group members are doing and that it is important to learn how and when to help them, without dominating them or trying to take over too quickly or at the wrong time. Things work much better when you know people will be there for you if you need help, and your target audience will probably feel it. 


\section{ACTIVITY 7: TRUST FALL}

\begin{tabular}{|l|l|l|}
\hline OBJECTIVES & \begin{tabular}{|l|l|}
\hline \multicolumn{1}{|c|}{ TIME } \\
Participants work on team \\
and trust building.
\end{tabular} & $\begin{array}{l}\text { MATERIALS } \\
\text { Participants can } \\
\text { move around } \\
\text { comfortably. }\end{array}$ \\
\hline
\end{tabular}

Have girls pair up (try to have them be similarly sized).

\section{Explain:}

5 One girl in the pair should stand with her feet firmly planted and her arms in an " $X$ " across her chest (demonstrate). The partner should stand very close behind her with her hands up at shoulder level (demonstrate). Then the partners should exchange the following words:

- Girl in front: "Ready to fall"

- Girl in back: "Ready to catch"

- Girl in front: "Falling"

- Girl in back: "Fall away"

At this point, the girl in front should fall back slowly, with her feet still firmly on the ground, and her partner should catch her. Each time the "catcher" partner should take one small step back so the falling girl falls a little bit more each time, building trust with each step.

To clase, ask:

5 How did you feel while playing this game? 


\section{FORMING PAIRS}

1. Form pairs by dividing the total number of participants in half. Ask participants to count off up to the number that represents half of the total. For example, if you have 20 participants, they will count off up to 10 and then start again at 1. The two people who have the same number are partners (the $1 \mathrm{~s}, 2 \mathrm{~s}$, $3 \mathrm{~s}$, etc.)

2. Ask participants to turn to the person on their right (or left). This person is their partner.

3. Create sets of pairs constructed around opposite words or similar objects or first and last names of famous people. The number of pairs you create should equal half the number of participants. Each pair must have 2 parts. Write 1 word of each pair on a slip of paper. Ask participants to draw a slip of paper from a container and find the other half of their pair. This is their partner. Some examples for a group of 10 participants include:
4. Ask everyone to pick a number between 1 and (choose the upper number depending on the size of your group). Line them up according to which number they picked. The two people at the end of the line become partners, the next two become partners, etc. Those who have picked the same number become partners. If only one person chooses a particular number, ask them to choose another number.

5. Group lines up according to any variable you can think of to use. Examples are: oldest to youngest; tallest to shortest; alphabetically by first or last name; chronologically by month and date of birthday. If you want to add challenge to the process, do not allow people to talk. The two people at the ends of the line become partners, the next two become partners, etc.

\begin{tabular}{|ll|ll|ll|}
\hline Opposites & & \multicolumn{2}{|l|}{ Matching Objects } & Famous People \\
\hline black & white & bed & sheets & Nelson & Mandela \\
\hline sad & happy & table & chair & Bob & Marley \\
\hline dark & light & camera & photograph & Jua & Kali \\
\hline tall & short & car & driver & Michelle & Obama \\
\hline wide & narrow & shoes & socks & David & Beckham \\
\hline
\end{tabular}

The group's theme can provide the inspiration for your selection of paired words. Or, select famous people who are relevant to the age range of your participants. For example, music, sport and movie stars tend to work well with young people. 


\section{FORMING GROUPS OR TEAMS}

1. Count off. For example, ask participants to count off by 4 s. One by one, each participant will say a number (the first participant says "1", the second says " 2 ," and when it is the fifth participant's turn, he will start again at 1). When everyone has counted, instruct participants to form groups with people who have the same number. In the end, you will have 4 groups.

2. Make simple puzzles with 3-5 pieces each. Distribute the puzzle pieces to participants and ask them to find all of the others who have the pieces to complete their puzzle. Be sure to use simple puzzles and have the same number of puzzle pieces as participants.

3. Ask participants to stand in line in the order of their birthdays-month and day only-and then count off (such as 1 through 3 ) to form groups.

4. Assign colors, symbols or pictures at random. Instruct participants to find all others with the same assigned color, symbol or picture.

5. Place the names of four well-known pop culture stars in different places around the room and ask participants to stand next to their favorite. If everyone flocks to the same star, you will have to adjust the exercise so that you end up with than one group. For example you can ask participants to move to their second favorite star
6. Select four different animals (or whatever number of groups you want to create) and write the name of each animal on several slips of paper. The number of slips will depend on how many participants will be in each group. For example, if you have 16 participants, you can make 4 groups of 4 people. In that case, you will write the name of each animal on 4 slips of paper. Each participant will draw 1 slip of paper from a container. Tell participants that when you say "now", each person must make the noise of the animal written on her slip of paper. While making their noises, participants must look and listen for those making the same animal noise they are making. These people are their group members.

7. Have everyone cross their arms across their chest. Amazingly, it almost always works out to about $50 \%$ cross right over left, and the other $50 \%$ cross left over right. Have participants close their eyes and then put their hands together so their fingers are interlocking and their palms are touching each other. Have them open their eyes and look down at their hands. If their right thumb is on top then they are one team and if their left thumb is on top then they go to the other team. 
6. Match the cards The facilitator chooses a number of well-known phrases, and writes half of each phrase on a piece of paper or card. For example, they write "Happy" on one piece of paper and "Birthday" on another. (The number of pieces of paper should match the number of participants in the group.) The folded pieces of paper are put into a hat. Each participant takes a piece of paper from the hat and tries to find the member of the group with the matching half of the phrase. opposite way around the circle, until the two people meet. They greet each other three times by name, in their own language. The two people then race back, continuing in opposite directions around the circle, to take the empty place. Whoever loses walks around the outside of the circle again and the game continues until everyone has had a turn.

2. Juggling ball game Everyone stands in a close circle. (If the group is very large, it may be necessary to split the group into two circles.) The facilitator starts by throwing the ball to someone in the circle, saying their name as they throw it. Continue catching and throwing the ball establishing a pattern for the group. (Each person must remember who they receive the ball from and who they have thrown it to.) Once everyone has received the ball and a pattern is established, introduce one or two more balls, so that there are always several balls being thrown at the same time, following the set pattern.

3. Names and adjectives Participants think of an adjective to describe how they are feeling or how they are. The adjective must start with the same letter as their name, for instance, "I'm Henri and I'm happy." Or, "I'm Arun and I'm amazing." As they say this, they can also mime an action that describes the adjective.

4. Three truths and a lie Everyone writes their name, along with four pieces of information about themselves on a large sheet of paper. For example, "Emma likes singing, loves football, has five husbands and loves toast." Participants then circulate with their sheets of paper. They meet in pairs, show their paper to each other, and try to guess which of the "facts" is a lie.

5. Connecting eyes Participants stand in a circle. Each person makes eye contact with another person across the circle. The two walk across the circle and exchange positions, while maintaining eye contact. Many pairs can exchange at the same time, and the group should try to make sure that everyone in the circle is included in the exchange. Begin by trying this in silence and then exchange greetings in the middle of the circle.
7. Space on my right Participants are seated in a circle. The facilitator arranges for the space on their right to remain empty. They then ask a member of the group to come and sit in the empty space; for example, "I would like Lili to come and sit on my right." Lili moves and there is now a space on the right of another participant. The participant who is sitting next to the empty space calls the name of someone different to sit on his or her right. Continue until the entire group has moved once.

8. What we have in common The facilitator calls out a characteristic of people in the group, such as "having children." All those who have children should move to one corner of the room. As the facilitator calls out more characteristics, such as "likes football," people with the characteristic move to the indicated space.

9. Who is the leader? Participants sit in a circle. One person volunteers to leave the room. After they leave, the rest of the group chooses a "leader." The leader must perform a series of actions, such as clapping, tapping a foot, etc., that are copied by the whole group. The volunteer comes back into the room, stands in the middle and tries to guess who is leading the actions. The group protects the leader by not looking at him/her. The leader must change the actions at regular intervals, without getting caught. When the volunteer spots the leader, they join the circle, and the person who was the leader leaves the room to allow the group to choose a new leader.

10. Who are you? Ask for a volunteer to leave the room. While the volunteer is away, the rest of the participants decide on an occupation for him/her, such as a driver, or a fisherman. When the volunteer returns, the rest of the participants mime activities. The volunteer must guess the occupation that has been chosen for him/her from the activities that are mimed. 
11. What kind of animal? Ask participants to divide into pairs and to form a circle. Put enough chairs in the circle so that all but one pair has seats. Each pair secretly decides what type of animal they are. The two participants without chairs are the elephants. They walk around the circle calling the names of different animals. Whenever they guess correctly, the animals named have to stand up and walk behind the elephants, walking in mime. This continues until the elephants can guess no more. Then they call "Lions!" and all pairs run for seats. The pair left without chairs become the elephants for the next round.

12. Killer wink Before the game starts, ask someone to be "the killer" and ask them to keep their identity a secret. Explain that one person among the group is the killer and they can kill people by winking at them. Everyone then walks around the room in different directions, keeping eye contact with everyone they pass. If the killer winks at you, you have to play dead. Everyone has to try and guess who the killer is.

13. The sun shines on... Participants sit or stand in a tight circle with one person in the middle. The person in the middle shouts out "the sun shines on..." and names a color or articles of clothing that some in the group possess. For example, "the sun shines on all those wearing blue" or "the sun shines on all those wearing socks" or "the sun shines on all those with brown eyes." All the participants who have that attribute must change places with one another. The person in the middle tries to take one of their places as they move, so that there is another person left in the middle without a place. The new person in the middle shouts out "the sun shines on..." and names a different color or type of clothing.

14. COCONUT The facilitator shows the group how to spell out C-O-C-O-N-U-T by using full movements of the arms and the body. All participants then try this together.

15. Body writing Ask participants to write their name in the air with a part of their body. They may choose to use an elbow, for example, or a leg. Continue in this way, until everyone has written his or her name with several body parts.

16. Names in the air Ask participants to write their name in the air first with their right hand, then their left hand. Finally, ask them to write their name in the air with both hands at the same time.
17. Family members Prepare cards with family names. You can use different types of professions, such as Mother Farmer, Father Farmer, Sister Farmer and Brother Farmer. Or you could use names of different animals or fruits. Each family should have four or five in it. Give each person one of the cards and ask everyone to walk around the room. Explain that when you call out, "family reunion," everyone should try to form a "family group" as quickly as possible.

18. Who am I? Pin the name of a different famous person to each participant's back, so that they cannot see it. Then ask participants to walk around the room, asking each other questions about the identity of their famous person. The questions can only be answered by "yes" or "no." The game continues until everyone has figured out who they are.

19. A's and B's Ask everyone to choose silently someone in the room that is their "A" person and another person who is their "B" person. There are no particular criteria on which to base their choices - selections are entirely up to individuals. Once everyone has made their choices, tell them to get as close to their respective "A" person as possible, while getting as far away from their "B" person. People can move quickly but should not grab or hold anyone. After a few minutes, participants stop and reverse the process, getting close to their " $B$ " persons and avoiding their "A" persons.

20. Group statues Ask the group to move around the room, loosely swinging their arms and gently relaxing their heads and necks. After a short while, shout out a word. The group must form themselves into statues that describe the word. For example, the facilitator shouts "peace." All the participants have to instantly adopt, without talking, poses that show what "peace" means to them. Repeat the exercise several times.

21. Move to the spot Ask everyone to choose a particular spot in the room They start the game by standing on their "spot." Instruct people to walk around the room and carry out a particular action, for example, hopping, saying hello to everyone wearing blue or walking backwards, etc. When the facilitator says "Stop," everyone must run to his or her original spots. The person who reaches their place first is the next leader and can instruct the group to do what they wish. 
22. Banana game A banana or other object such as a bunch of keys is selected. The participants stand in a circle with their hands behind their backs. One person volunteers to stand in the middle. The facilitator walks around the outside of the circle and secretly slips the banana into someone's hand. The banana is then secretly passed round the circle behind the participant's backs. The job of the volunteer in the middle is to study people's faces and work out who has the banana. When successful, the volunteer takes that place in the circle and the game continues with a new person in the middle.

23. Taxi rides Ask participants to pretend that they are getting into taxis. The taxis can only hold a certain number of people, such as two, four, or eight. When the taxis stop, the participants have to run to get into the right sized groups. This is a useful game for randomly dividing participants into groups.

24. Fruit salad The facilitator divides the participants into an equal number of three to four fruits, such as oranges and bananas. Participants then sit on chairs in a circle. One person must stand in the center of the circle of chairs. The facilitator shouts out the name of one of the fruits, such as "oranges," and all of the oranges must change places with one another. The person who is standing in the middle tries to take one of their places as they move, leaving another person in the middle without a chair. The new person in the middle shouts another fruit and the game continues. A call of "fruit salad" means that everyone has to change seats.

25. "Prrr" and "Pukutu" Ask everyone to imagine two birds. One calls "prrr" and the other calls "pukutu." If you call out "prrr," all the participants need to stand on their toes and move their elbows out sideways, as if they were a bird ruffling its wings. If you call out "pukutu," everyone has to stay still and not move a feather.

26. Dancing on paper Facilitators prepare equal sized sheets of newspaper or cloth. Participants split into pairs. Each pair is given either a piece of newspaper or cloth. They dance while the facilitator plays music or claps. When the music or clapping stops, each pair must stand on their sheet of newspaper or cloth. The next time the music or clapping stops, the pair has to fold their paper or cloth in half before standing on it. After several rounds, the paper or cloth becomes very small by being folded again and again. It is increasingly difficult for two people to stand on. Pairs that have any part of their body on the floor are "out" of the game. The game continues until there is a winning pair.
27. Tide's in/tide's out Draw a line representing the seashore and ask participants to stand behind the line. When the facilitator shouts "Tide's out!," everyone jumps forwards over the line. When the leader shouts "Tide's in!," everyone jumps backwards over the line. If the facilitator shouts "Tide's out!" twice in a row, participants who move have to drop out of the game.

28. Lusaka Buses This game can be called after any type of local transport. Select a number of "drivers." Assign a certain number of passengers for each driver to pick up. (Make sure that you have counted correctly, so that no one is left without a ride!) Ask the drivers to go around the room making vehicle noises and touting for business. The passengers form up behind or alongside their driver to make it look like they are in a vehicle. Now all the "vehicles" drive around as if in traffic, sounding their horns and shouting at other drivers and vehicles.

29. Rabbits Someone starts by putting both hands up to their ears and waggling their fingers. The people on either side of this person put up one hand only, to the ear nearest the person with both hands up. The person with both hands up then points to another person across the circle. This person now puts both hands up to their ears and waggles their fingers. The people on either side have to put up the hand nearest the person with both hands up and waggle their fingers. The game continues in this way until everyone has been a "rabbit."

30. Port/Starboard Participants stand in the center of the room. If the leader shouts "Starboard," everyone runs to the right. If they shout "Port," everyone runs left and if they shout "Man the ship," everyone runs back to the center. Other statements can be introduced; for example, "Climb the rigging" when everyone pretends to climb, "Scrub the decks," and so on.

31. I'm going on a trip Everyone sits in a circle. Start by saying "I'm going on a trip and I'm taking a hug," and hug the person to your right. That person then has to say "I'm going on a trip and I'm taking a hug and a pat on the back," and then give the person on their right a hug and a pat on the back. Each person repeats what has been said and adds a new action to the list. Go round the circle until everyone has had a turn.

32. Find someone wearing... Ask participants to walk around loosely, shaking their limbs and generally relaxing. After a short while, the facilitator shouts out "Find someone..." and names an article of clothing. The participants have to rush to stand close to the person described. Repeat this exercise several times using different types of clothing. 
33. Touch something blue Ask participants to stand up. Explain that you will tell everyone to find something blue, and that they have to go and touch it. This could be a blue shirt, pen, shoe or whatever. Continue the game in this way, asking participants to call out their own suggestions for things to touch.

34. Simon says The facilitator tells the group that they should follow instructions when the facilitator starts the instruction by saying "Simon says..." If the facilitator does not begin the instructions with the words "Simon says," then the group should not follow the instructions! The facilitator begins by saying something like "Simon says clap your hands" while clapping their hands. The participants follow. The facilitator speeds up the actions, always saying "Simon says" first. After a short while, the "Simon says" is omitted. Those participants who do follow the instructions anyway are "out" of the game. The game can be continued for as long as it remains fun.

35. What has changed? Participants break into pairs. Partners observe one another and try to memorize the appearance of each other. Then one turns their back while the other makes three changes to his/her appearance; for example, putting their watch on the other wrist, removing their glasses, and rolling up their sleeves. The other player then turns around and has to try to spot the three changes. The players then switch roles.

36. Birthday graph Ask people to line up according to their birthday months or seasons. Discuss which month or season has the largest number and what reasons there might be for this.

37. Body "tig" Explain to participants that you will "tig" someone. They then use just the part of their body that you have "tigged" to "tig" someone else in turn. Continue the game until everyone has been "tigged."

38. Five islands Draw five circles with chalk on the floor, big enough to accommodate all of the participants. Give each island a name. Ask everyone to choose the island that they would like to live on. Then warn participants that one of the islands will sink into the sea very soon and participants on that island will be forced to move quickly to another island. Allow the suspense to build and then call out the name of the island that is sinking. Participants run to the other four islands. The game continues until everyone is squashed onto one island.

39. The animal game This game helps to divide a large group into smaller groups. Make slips of paper for each member of the large group. Write the name of an animal on each slip, using as many different animals as you need smaller groups.
Hand the papers out at random and ask people to make the noise of their animal to find the other members of their smaller group.

40. Mime a lie Everyone stands in a circle. The facilitator starts by miming an action. When the person on their right says their name and asks "What are you doing?," they reply that they are doing something completely different; for example, the facilitator mimes swimming and says "I am washing my hair." The person to the facilitator's right then has to mime what the facilitator said that they were doing (washing their hair), while saying that they are doing something completely different. Go around the circle in this way until everyone has had a turn.

41. Bring me Participants sort themselves into small teams, and the teams stand as far as possible from the facilitator. The facilitator then calls out "Bring me...," and names an object close by. For example, "Bring me a man's or woman's shoes." The teams race to bring what has been requested. You can repeat this several times, asking the teams to bring different things.

42. Locomotion Everyone sits in a circle and a leader stands in the middle. The leader then walks or runs around the outside of the circle, imitating some means of locomotion such as a car, a train or swimming. S/he stops in front of several people, gives them a signal and they follow the leader, imitating the form of locomotion. When the leader has six to ten people behind him/her, s/he shouts "Al change" and everyone, including the leader, races for a seat. The person who is left without a seat must start the game again, with a different form of locomotion.

43. Paper and straws Participants split into teams. Each team forms a line and places a piece of card at the beginning of their line. Each member of the team has a drinking straw or reed. When the game starts, the first person has to pick up the piece of card by sucking on the straw. The card then has to be passed to the next team member using the same method. If the card drops, it goes back to the first person and the whole sequence has to start again.

44. The king is dead The first player turns to their neighbor and says, "The king is dead!" The neighbor asks, "How did he die?" and the first player responds, "He died doing this," and starts a simple gesture or movement. All participants repeat this gesture continuously. The second player repeats the statement and the third player asks, "How did he die?" The second player adds another gesture or movement. The whole group then copies these two movements. The process continues around the circle until there are too many movements to remember. 
45. Don't answer Ask the group to stand in a circle. One person starts by going up to someone and asking them a question such as, "What is your most annoying habit?" However, they must not answer the question themselves - the person to their left must answer. People can make their answers as imaginative as possible!

46. Tug of war The participants split into two teams. Each team takes one end of the rope. The teams have to pull on the rope to bring the opposite team towards them.

47. Pass the parcel The facilitator has wrapped a small gift with many different layers of paper. On each layer they have written a task or a question. Examples of tasks are "sing a song" or "hug the person next to you." Examples of questions are "What is your favorite color?" or "What is your name?" The facilitator starts the music, or claps their hands if there is no music available. The participants pass the parcel around the circle, or throw it to each other. When the facilitator stops the music or the clapping, the person who is holding the parcel tears off one layer of paper and carries out the task or answers the question that is written on the paper. The game continues until all the layers have been unwrapped. The gift goes to the last person to take off the wrapping.

48. Fox and rabbit You need two scarves for this game. Participants stand in a circle. One scarf is called "Fox" and the other is called "Rabbit." "Fox" must be tied around the neck with one knot. "Rabbit" is tied around the neck with two knots. Start by choosing two participants who are opposite each other in the circle. Tie the "Fox" scarf around one person's neck and the "Rabbit" scarf around the other. Say "go." People need to untie their scarves and retie them around the neck of the person on their right or left. The scarves should travel in the same direction around the circle. The "Fox" scarf with only one knot will travel faster than the "Rabbit" scarf. The people tying the two knots for the "Rabbit" scarf will try to go faster and faster to get away from the "Fox" scarf.

49. The longest line This game requires a lot of space and may need to be done outdoors. Divide into teams of eight to ten people. Each team must have the same number of members. Explain that the task is to create the longest line using participants own bodies and any clothing or things in members pockets. Participants are not allowed to collect other things from the room/outside. Give a signal for the game to start and set a time limit, such as two minutes. The team with the longest line wins.
50. Robots Divide the participants into groups of three. One person in each group is the robot controller and the other two are the robots. Each controller must manage the movements of their two robots. The controller touches a robot on the right shoulder to move them to the right, and touches them on the left shoulder to move them to the left. The facilitator begins the game by telling the robots to walk in a specific direction. The controller must try to stop the robots from crashing into obstacles such as chairs and tables. Ask participants to swap roles so that everyone has a chance to be the controller and a robot.

51. King of the Jungle The group sits in a semi-circle. The "King of the Jungle" (usually an elephant) sits on one end of the semi-circle. This person makes a sign to show they are sitting in the elephant's position. At the other end of the semicircle sits the monkey, and the person in this seat makes an appropriate sign. All the seats in between belong to different animals, such as lions, fish, and snakes, which people define with different signs. Once everyone has defined the sign for their seat, the game begins. The elephant makes their sign, and then makes the sign of another animal. That animal makes his or her own sign, then the sign of another animal, and so it continues. If someone makes a mistake, or doesn't notice that their sign has been made, they have to swap places with the person next to them, moving down towards the monkey. They then take on the sign of the seat they now occupy, and the person who moves up a place takes their sign. The aim is to move all the way up to take the place of the King of the Jungle.

52. Pass the energy Participants stand or sit in a circle, hold hands and silently concentrate. The facilitator sends a series of "pulses" both ways round the group by discreetly squeezing the hands of those next to her/him. Participants pass these pulses round the circle, as in an electric current, by squeezing the hand of the person next to them and literally "energizing" the group.

53. Bottle game Participants stand in a circle. In the first round, a bottle (or some other object) is passed around the circle. Participants have to do something with the bottle, such as kiss it, rub it, or turn it upside down. In the second round, tell participants to remember what they did with the bottle, and do the same thing to the person standing on their right.

54. How do you like your neighbor? Ask participants to sit in a circle. Go around the circle and number each person one, two, three, four, etc. One person stands in the middle and one chair is removed. The person in the center points to someone and asks them, "How do you like your neighbor?" If the person replies 
"I like him," everyone gets up and moves to another chair. There will be one person left standing, who then takes their turn in the center of the circle and asks someone, "How do you like your neighbor?" If the person replies "I don't like him," the person in the middle asks him/her "Who do you want?" The person calls out two numbers. The two people whose numbers have been called have to get up and change chairs with the two people on either side of the answerer.

55. Dragon's tail Ask the group to divide into two. The two groups form dragons by holding on to one another's waists in a long line. The last person in the line has a brightly colored scarf tucked into his/her trousers or belt, to form the dragon's tail. The object is to catch the tail of the other dragon without losing your own tail in the process.

56. Group massage Ask the group to stand in a circle and turn sideways so that each person is facing the back of the person in front of them. People then massage the shoulders of the person in front of them.

57. Pass the person Participants stand in two lines facing each other. Each person tightly grasps the arms of the person opposite. A volunteer lies face up across the arms of the pairs at the beginning of the line. Pairs lift their arms up and down to move the volunteer gently on to the next pair. The game continues until the volunteer is "bumped" all the way to the end of the line.

58. Blindfold pairs An obstacle course is set out on the floor for everyone to look at. Participants split into pairs. One of the pair puts a scarf around their eyes, or closes their eyes tightly so they cannot see. The obstacles are quietly removed.

The other member of the pair now gives advice and direction to their partner to help them safely negotiate what are now imaginary obstacles.

59. Ball under chins Make some small balls out of any material that is available such as crumpled paper. Participants split into teams and each team forms a line. The line passes a ball under their chins. If the ball drops, it has to go back to the beginning of the line. The game continues until one team has finished passing the ball along their line.

60. Knees up Participants stand in a close circle with their shoulders touching and then turn, so that their right shoulders are facing into the center of the circle. Ask everyone to put their hand on the shoulder of the person in front and to carefully sit down so that everyone is sitting on the knees of the person behind them.
61. I like you because... Ask participants to sit in a circle and say what they like about the person on their right. Give them time to think about it first!

62. Heads to tummies People lie on the floor in a chain so that each person has their head on another person's stomach. Someone will laugh. Hearing someone laugh through their stomach makes the next person laugh and so on round the chain.

63. Get up, sit down! Give each participant a number (several participants could have the same number). Then tell a story that involves lots of numbers - when you say a number, the person(s) with this number has (have) to stand up.

64. Knots Participants stand in a circle and join hands. Keeping their hands joined, they move in any way that they want, twisting and turning and creating a "knot." They must then unravel this knot, without letting go of one another's hands.

65. Coin game Participants divide into two lines. The two people at the end of each line start the race by dropping a coin down their clothes. When it drops free on the floor, they hand the coin to the next person in the line who does the same. The race continues until the coin has reached the end of one of the lines.

66. Countdown Ask participants to form a circle. Explain that the group needs to count together from one to 50. There are a few rules: they are not to say "seven" or any number which is a multiple of seven. Instead, they have to clap their hands. Once someone claps their hands, the group must count the numbers in reverse. If someone says seven or a multiple of seven, start the counting again.

67. Fizz buzz Go round the group counting upwards. The group replaces any number divisible by three with "fizz," any number divisible by five with "buzz," and any number divisible by both three and five with "fizz buzz." Count up and see how high you can go!

68. Group balance Ask participants to get into pairs. Ask pairs to hold hands and sit down then stand up, without letting go of one another's hands. Repeat the same exercise in groups of four people. Then form into groups of eight people holding hands in a circle. Ask members in each group to number off in even and odd numbers. At a signal, ask the even numbers to fall backwards while the odd numbers fall forwards, achieving a group balance.

69. Leading and guiding Participants split into pairs. One participant puts on a blindfold. Their partner then leads them carefully around the area making sure they don't trip or bump into anything. After some time, the facilitator asks the pairs to swap roles. At the end, participants discuss how they felt when they had to trust someone else to keep them safe. 
70. Clap exchange Participants sit or stand in a circle. They send a clap around the circle by facing and clapping in unison with the person on their right, who repeats the clap with the person on their right, and so on. Do this as fast as possible. Send many claps, with different rhythms, around the circle at the same time.

71. An orchestra without instruments Explain to the group that they are going to create an "orchestra" without instruments. The orchestra will only use sounds that can be made by the human body. Players can use hands, feet, voice etc. but no words; for example, they could whistle, hum, sigh or stomp their feet. Each player should select a sound. Choose a well-known tune and ask everyone to play along, using the "instrument" that they have chosen. Alternatively, don't give a tune and let the group surprise itself by creating a unique sound.

72. Hands slapping Ask participants to kneel on the floor, link arms with the people on either side of them, and place their palms flat on the floor. Now ask people to slap their palms on the floor in turn so that it goes round the circle. Having linked arms makes it difficult to work out which hand is your own! If someone makes a mistake, they have to put a hand behind their back and the game continues.

73. Pass the action Participants sit in a circle. One person (A) stands in the center. A moves towards another person (B) using a specific action, such as jumping. When $\mathrm{s} /$ he reaches $\mathrm{B}, \mathrm{s} /$ he takes $\mathrm{B}$ 's place and $\mathrm{B}$ then moves to the center of the circle using A's action or movement. When B reaches the center, s/he walks towards $C$, using a new action or movement. The game continues in this way until everyone has taken part.

74. People to people Everyone finds a partner. A leader calls out actions such as "nose to nose," "back to back," "head to knee," etc. Participants have to follow these instructions in their pairs. When the leader calls "people to people" everyone must change partners.

75. Count to seven The group sits in a circle and someone starts the process of counting. Each person counts in sequence. When the counting reaches seven, the next person starts over with the number one. Every time someone says a number, they use their hands to point out the direction that the counting should go in.
76. Football cheering The group pretends that they are attending a football game. The facilitator allocates specific cheers to various sections of the circle, such as "Pass," "Kick," "Dribble" or "Header." When the facilitator points at a section, that section shouts their cheer. When the facilitator raises his/her hands in the air, everyone shouts "Goal!"

77. Clap and point Participants form a circle. The facilitator sends a clap all the way around the circle, first in one direction, then in the other direction. The facilitator then shows participants how they can change the direction of the clap, by pointing the clapping hands in the opposite direction. Repeat this until the clap is running smoothly around the group and changing direction without missing a beat. Finally, show how you can "throw" the clap by pointing the clapping hands at someone across the circle.

78. Rainstorm Everyone sits quietly in a circle, with their eyes closed, waiting for the facilitator's first movement. The facilitator rubs their palms together to create the sound of rain. The person to their right makes this sound, and then the next person until everyone in the group is making the same sound. Once everyone is rubbing palms, the facilitator makes the rain sound louder by snapping his/her fingers, and that sound in turn is passed around the circle. Then the facilitator claps both hands together, and that sound is passed around the circle to create a rainstorm. Then the facilitator slaps their thighs, and the group follows. When the facilitator and the group stomp their feet, the rain becomes a hurricane. To indicate the storm is stopping, the facilitator reverses the order, thigh slapping, then hand clapping, finger snapping, and palm rubbing, ending in silence.

79. Statue stop Ask participants to form two circles of people of equal numbers. The people in the inner circle should face outwards. The people in the outer circle should face inwards. Each person in the outer circle uses the person opposite them in the inner circle to create a "statue." They have only ten seconds to do this. The person in the inner circle allows the "sculptor" to bend and twist their body into any shape that they wish, provided they do not hurt them. The "statue" must remain in that position without speaking, until you call "time." The outer circle then moves round one person to the left and they begin sculpting again. The people in the inner circle are bent and twisted into new positions through this process. Continue in this way and then ask people in the inner circle to change with people in the outer circle so that everyone has a chance to be "sculptor" and "statue." 
80. Orchestra Divide the group into two and ask half to slap their knees and the other half to clap their hands. The facilitator acts as the conductor of the orchestra, controlling the volume by raising or lowering their arms. The game can continue with different members of the group taking the role of conductor

81. Stand, sit and sing Participants sit in a circle and sing a song they all know. Before beginning, have the girls divide into two groups (each half of the circle could be one group or alternate every other girl to be in a group). Choose two letters which occur frequently in the song, and ask the first group to stand up when they sing a word beginning with one letter and the second group to stand up when they sing a word beginning with the other letter. For example, the first group would stand up each time the girls sing a word that starts with the letter "m," while the second group would stand up every time they sing a word that starts with the letter "f."

82. Passing the rhythm Participants sit in a circle. The facilitator establishes a rhythm; for example, clapping your thighs, clapping your hands together, then clapping your neighbor's hands. This rhythm is then passed around the circle. Once the rhythm is moving steadily through the group, try to speed it up. Once the group can do this, try inserting more rhythms into the circle so that several rhythms are being passed around the circle at the same time.

83. Messenger Before the game starts, the facilitator builds something out of blocks and covers it with a cloth. Participants are divided into small groups and each group is given a set of blocks. Each group selects a "messenger" to look under the cloth. The messengers report back to their groups about what they have seen under the cloth. They must give their group instructions for how to build the same thing. The messengers are not allowed to touch the blocks or to demonstrate how it should be done - they can only describe how it should look. The group can send the messenger to have a second look at the structure. When all the groups are finished, the structures are compared to the original.

84. Drawing game Participants work in pairs, sitting back to back. One person in each pair has a simple drawing. The other person has a blank piece of paper and a pen. The person with the drawing describes it in detail so that the other person can reproduce the drawing on their sheet of paper.
85. Mirror image Participants sort themselves into pairs. Each pair decides which one of them will be the "mirror." This person then copies (mirrors) the actions of their partner. After some time, ask the pair to swap roles so that the other person can be the "mirror."

86. Hokey Pokey Participants stand in a circle to sing the song and do the actions. The first verse goes like this: You put your RIGHT FOOT in You put your RIGHT FOOT out In, out, in, out And you shake it all about You do the hokey-pokey (wiggling waist) And you turn around That's what it's all about! With each new verse substitute a different body part for "right foot" - left foot, right arm, left arm, head, and whole self.

87. Muddling messages Participants sit in a circle. Think of a long message, such as "I'm going to go to the market to buy some bananas and mangos tomorrow morning, and then I am going to meet my cousin for lunch." Whisper this message to the person sitting on your right. That person then whispers the same message to the person on their right and so on. Once the message has been passed around the circle, ask the last person to say the message aloud. Compare the final message with the original version.

88. Talking object Participants sit in a circle. An object is passed around the circle. The person who receives the object has to talk continuously until his/her neighbor decides to take the object.

89. Samson and Delilah The game revolves around the story of Samson and Delilah and the lion. Participants divide into two teams and stand in two lines, with their backs to the other team. Each team decides whether they will be Samson, Delilah or the lion, without telling the other team. They turn around to face the other team and mime an action representing who they are. For example, a sexy pose could represent Delilah, flexed muscles could be Samson, and a ferocious roar could represent the lion. Delilah defeats Samson, Samson defeats the lion, and the lion defeats Delilah. Sometimes, neither group will defeat the other because they will both choose to be the same thing!

90. Yes/No game Participants split into two lines, so that each person faces a partner. Line one has to say "Yes" in as many different ways as possible, and line two has to try to change their partner's minds by saying "No" as convinc ingly as possible. Give both lines a chance to say both "Yes" and "No." Then discuss how people felt. How did it feel to say "Yes" or "No"? Was it easier to say one than another? 
91. The "E" game Write a large, curvy letter E on a piece of flipchart paper and place it in the center of the circle. Ask participants to describe exactly what they see on the piece of paper, from where they are standing/sitting. Depending on where they are in the circle, they will either see an "m," a "w," a "3," or an "E." Participants can then move places so that they see the letter from a different perspective. This is a useful activity to highlight the fact that people see things differently, according to their own specific perspective. Alternatively, put a person in the center of the circle and ask those around to describe exactly what they see from their perspective.

92. What are we doing? Two teams line up at opposite ends of the room. Team A are the Mimes and Team B are the Tigers. Team A decides secretly on an activity to be mimed. They walk toward Team B, coming as close as they dare, and then act out their mime. Team B tries to guess what is being mimed. When they succeed they try to tag members of Team A before they can get back to their goal line. All who are tagged join the Tiger's side. After the first round, get the teams to swap roles.

93. What is the adverb? One participant leaves the room and the others choose an adverb; for example, "quickly" or "sleepily." When the leaver returns, s/he must find out what the adverb is by commanding people to do various actions "in that way." For example, if the leaver says "Talk that way," the group must talk "quickly" or "sleepily." After each command, the participant tries to guess the word.

94. Shopping list The group forms a circle. One person starts by saying "I am going to the market to buy fish." The next person says, "I am going to the market to buy fish and potatoes." Each person repeats the list, and then adds an item. The aim is to be able to remember all of the items that all of the people before you have listed.
95. Sagidi sagidi sapopo The group forms a circle or a line. The facilitator teaches everyone the simple chant "Sagidi sagidi sapopo." Every time the group chants "Sagidi sagidi sapopo," the facilitator makes a different action, such as clicking fingers or clapping, to the rhythm of the chant. With each new repetition of the chant, each person copies the actions of the person to their left so that everyone is always one move behind the person to their left.

96. What am / feeling? Participants sit in a circle. Each person takes a turn acting out an emotion. Other participants try to guess what feeling the person is acting out. The person who guesses correctly acts out the next emotion.

97. O Kabita! Everyone in turn has to say "O Kabita!" (or another name) in as many different ways as possible, for example with anger, with fear, with laughter, and so on.

98. Presenting gifts This can be used at the end of a workshop. Put participants names in a box or bag. Pass the box or bag around and ask each person to pick a name. If they get their own name they have to put it back and choose another. Give the group a few minutes to think of an imaginary gift they would present to the person whose name they have drawn. Ask them also to think how they would present it. Go round the group asking each person to present their imaginary gift.

99. Writing on backs At the end of a workshop, ask participants to stick a piece of paper on their backs. Each participant then writes something they like, admire or appreciate about that person on the paper on their backs. When they have all finished, participants can take their papers home with them as a reminder.

100. Reflecting on the day To help people to reflect on the activities of the day, make a ball out of paper and ask the group to throw the ball to each other in turn. When they have the ball, participants can say one thing they thought about the day. 
All sessions were adapted from the guides and curricula referred to below. Other publications referenced below were used to enhance content of the sessions.

Abstinence Focus Poster No. R045, Scotts Valley, CA: ETR Publishing, 2002.

Austrian, K. and Ghati, D. 2010. Girl Centered Program Design: A Toolkit to Develop, Strengthen and Expand Adolescent Girls Programs. Population Council. http://www.popcouncil.org/ publications/books/2010_AdolGirlsToolkit.asp

Central Statistical Office, Ministry of Health, Tropical Diseases Research Centre, University of Zambia, and Macro International Inc. (2009). Zambia Demographic and Health Survey 2007.

Dwyer, J. 1993. "Legislative AIDS Away: The Limited Role of Legal Persuasion in Minimizing the Spread of HIV", in 9 Journal of Contemporary Health Law and Policy 167.

Elizabeth Glaser Pediatric AIDS Foundation (EGPAF), Uganda. A Guide on How to Start and Implement Ariel Children's Clubs. www.pedaids.org

Exhale. 2005. Teaching support: A guide for training staff in after-abortion emotional support. Oakland, CA, Exhale.

Global Press Institute, "Unsafe Abortion on the Rise in Zambia Despite 'Liberal' Law," by Chanda Katongo, February 22, 2012. www.globalpressinstitute.org/africa/zambia/unsafe-abortionrise-zambia-despite-"liberal"-law

Grossman L, Kowal D. Kids, Drugs, and Sex. 1987. Preventing Trouble. Brandon, VT: Clinical Psychology Publishing.

Guttmacher Institute. In Brief: Unsafe Abortion in Zambia. 2009 Series, No. 3. www.guttmacher.org/pubs/IB-UnsafeAbortion-Zambia.pdf

Health Promotion Unit, 2007. Stages of behaviour change: Queensland Stay On Your Feet Community Good Practice Toolkit. Division of Chief Health Officer, Queensland Health.

International HIV/AIDS Alliance. 2002. 100 ways to energize groups: Games to use in workshops, meetings and the community. www.icaso.org/vaccines toolkit/subpages/files/English/energiser guide eng.pdf

International HIV/AIDS Alliance. 2008. Sexuality and Life-Skills: Participatory activities on sexual and reproductive health with young people wwwibe unesco.org/fileadmin/user upload/ HIV and AIDS/publications/Alliance Sexuality/lifeskills.peff

International HIV/AIDS Alliance, Academy for Educational Development, and the International Center for Research on Women. 2006. Understanding and challenging HIV stigma: a toolkit for Action. www.icrw.org/files/images/Understandingand-challenging-HIV-stigma-Picture-Booklet.pdf
International Labor Organization. 2007. "A Special Module On HIV and AIDS and Child Labor: Scream-Stop Child Labor." www.ilo.org/public/english/region/afpro/daressalaam/ download/specmod hiv rev.pdf

International Sexuality and HIV Curriculum Working Group. 2009. It's All One Curriculum: Guidelines and Activities for a Unified Approach to Sexuality, Gender, HIV and Human Rights Education. Edited by Nicole Haberland and Deborah Rogow. www.popcouncil.org/publications/books/2010 ItsAllOne.asp

Johns Hopkins Bloomberg School of Public Health/Center for Communication Programs. 2011. Go Girls! Community-based Life Skills for Girls: A Training Manual. Baltimore Maryland. Life Skills for Girs: A Traning Manu Girlsi Community-based Dev-00032-0O Project SEARCH, Task Corder O1. hH. GHH-1-OO07-00032-00, Project SEARCH, Task Ord k4health.org/toolkits/go-girls/go-girls

Kenya Adolescent Reproductive Health Project (KARHP), PATH, Population Council. 2005. Tuko Pamoja: Adolescent Reproductive Health and Life Skills Curriculum. www.popcouncil org/pdfs/frontiers/Manuals/KARHP_guide1.pdf

Marais, Thea. 1996. Abortion values clarification training manual. Melrose, South Africa, Planned Parenthood Association of South Africa. "Family Life Peer Education manual and Resource book: Margaret Sanger Centre International - South Africa."

Mobilizing Access to Maternal Health Services in Zambia-MAMaZ (2012). "Community Discussion Guide for Maternal and Newborn Health Care: A Training Manual for Safe Motherhood Action Groups."

National Institutes of Health, Eunice Kennedy Shriver National Institute of Child Health and Human Development, "Menstruation and the Menstrual Cycle." www.nichd.nih gov/health

One Love Southern Africa Campaign. www.onelovesouthern africa.org

Peace Corps. 2001. Camp GLOW (Girls Leading Our World): Handbook for Volunteers. www.peacecorps.gov/multimedia/ pdf/library/M0056_campglow.pdf

Peace Corps. 2001. Information Collection and Exchange Publication: Life Skills Manual. www.peacecorps.gov/multimedia/ pdf/library/M0063 lifeskillscomplete.pdf

Pick, S., M. Givaudan, V. Olicon and M. Beltrum. My Voice, My Life Curriculum. The Mexican Institute for the Research of Family and Population (IMIFAP). www.imifap.org.mx/imifap/portal/ cfpages/contentmgr.cfm?fuente $=$ nodo $\&$ docld $=40 \&$ doc Tipo $=1$

Population Council. 2010. Safe Space Curriculum. Lusaka, Zambia.

Project Concern International - Zambia, Africa KidSAFE. 2006. Street Life - The Story of Sufi and Site. A Life Skills Guide for Children 'on' and 'of' the Street.
Quigley, Maria, et al. 1997. "Sexual behavior patterns and other risk factors for HIV infection in rural Tanzania: a case-control study." AIDS 11(2): 237-248.

RAPIDS/Consortium in Zambia. RAPIDS Youth Life Skills Training Manual. Prepared by Motivational Centre for Africa's Transformation (MOCAT) for AFRICARE.

Republic of Zambia. 2000. First Draft, Reproductive Health Policy, Ministry of Health. www.k4health.org/sites/default/ files/Zambia\%2OReproductive\%2OHealth\%2OPolicy.pdf

Sport in Action, International Alliance for Youth Sports. 2010 Game On! Life Skills Manual. www.iays.org/programs-andservices/game-on-youth-sports/life-skills-activity-guide/

Sustainability Through Economic Strengthening Prevention an Support for Orphans and Vulnerable Children, Youth and Other Vulnerable Populations (STEPS OVC/Consortium) Zambia. STEPS OVC Youth Services Training Manual.

Turner, Katherine L. and Kimberly Chapman Page. 2008. "Abortion attitude transformation: A values clarification toolkit for global audiences." Chapel Hill, NC, Ipas.

UNFPA, World YWCA. 2006. Empowering Young Women to Lead Change: A Training Manual. www.unfpa.org/upload/lib pub_file/628_filename_empowering-young-women_eng.pdf

UNFPA. 2005. "State of World Population." www.unfpa.org/ swp/2005/english/ch7/

UNHCR and UNAIDS. 2002. HIV/AND Human Rights International Guidelines: Third International Consultation on HIV/AIDS and Human Rights. Geneva. http://data.unaids.org/publications/irc-pub02/jc905-guideline6_en.pdf

UNICEF Harare. 1995. Think About It! An AIDS Action Programme for Schoo/s. http://catalogue.safaids.net/publications/thinkabout-it-aids-action-programme-schools-form-4-studentsbook

UNICEF. Fact Sheet: A Summary of the Rights Under the Convention on the Rights of the Child. www.unicef.org/crc/files/ Rights overview.pdf

USAID. 2006. Doorways I: Student Training Manual on SchoolRelated Gender-Based Violence Prevention and Response. www.usaid.gov/our work/cross-cutting programs/wid/

USAID. 2009. Doorways III: Teacher Training Manual on SchoolRelated Gender-Based Violence Prevention and Response. www.usaid.gov/our work/cross-cutting programs/wid/

World Health Organization. 1994. School Health Education to prevent AIDS and STD: A Resource Package for Curriculum Planners. http://library.unesco-iicba.org/English/HIV AIDS/ cdrom\%20materials/navigation $\% 20$ pages/School\%20 Health\%20Education.htm 

For more information, contact

Population Council - Zambia

Plot 3670 No. 4 Mwaleshi Road

Olympia Park, Lusaka

P/Bag RW 319X, Lusaka 10101, Zambia

Lusaka, Zambia 10101

Tel: +260 211295925

www.popcouncil.org 